\title{
Surgical site infections in vascular surgery
}

Citation for published version (APA):

Langenberg, J. C. M. (2021). Surgical site infections in vascular surgery. [Doctoral Thesis, Maastricht University]. Maastricht University. https://doi.org/10.26481/dis.20210625jl

Document status and date:

Published: 01/01/2021

DOI:

10.26481/dis.20210625jl

Document Version:

Publisher's PDF, also known as Version of record

\section{Please check the document version of this publication:}

- A submitted manuscript is the version of the article upon submission and before peer-review. There can be important differences between the submitted version and the official published version of record.

People interested in the research are advised to contact the author for the final version of the publication, or visit the DOI to the publisher's website.

- The final author version and the galley proof are versions of the publication after peer review.

- The final published version features the final layout of the paper including the volume, issue and page numbers.

Link to publication

\footnotetext{
General rights rights.

- You may freely distribute the URL identifying the publication in the public portal. please follow below link for the End User Agreement:

www.umlib.nl/taverne-license

Take down policy

If you believe that this document breaches copyright please contact us at:

repository@maastrichtuniversity.nl

providing details and we will investigate your claim.
}

Copyright and moral rights for the publications made accessible in the public portal are retained by the authors and/or other copyright owners and it is a condition of accessing publications that users recognise and abide by the legal requirements associated with these

- Users may download and print one copy of any publication from the public portal for the purpose of private study or research.

- You may not further distribute the material or use it for any profit-making activity or commercial gain

If the publication is distributed under the terms of Article $25 \mathrm{fa}$ of the Dutch Copyright Act, indicated by the "Taverne" license above, 
$\square$

$\square$

$\square$

$\square$

$\square$

$\square$

$\square$

$\square$

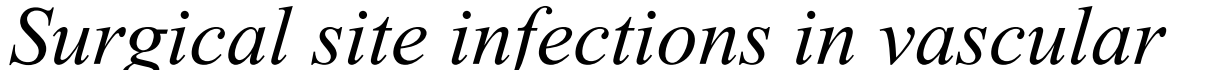

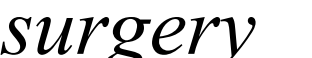

$\square$

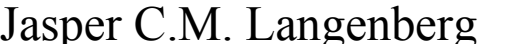




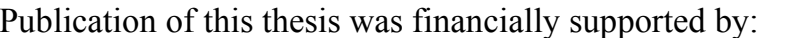

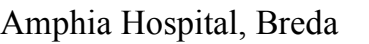

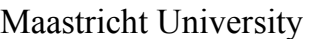

$\square$

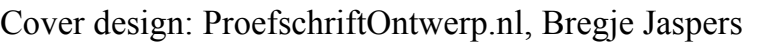

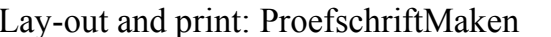

$\square$

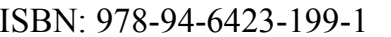

$\square$

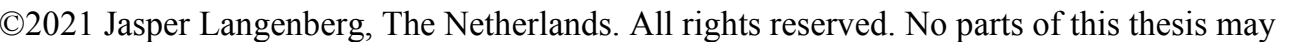

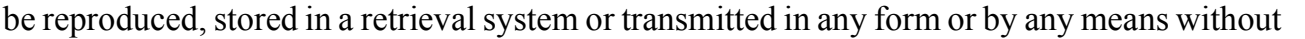

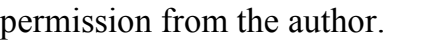


$\square$

$\square$

$\square$

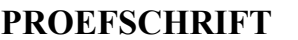

$\square$

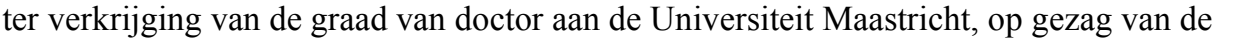

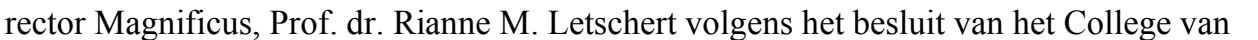

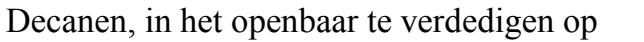

四

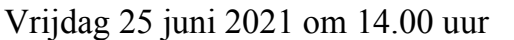

$\square$

$\square$

$\square \square \square$

$\square$

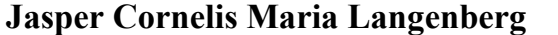

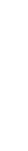




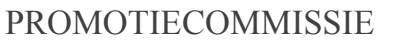

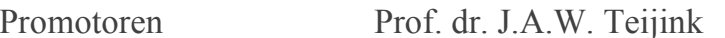

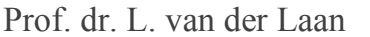

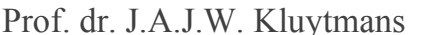

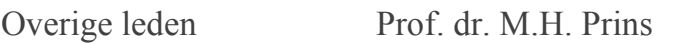

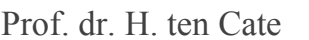

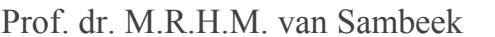

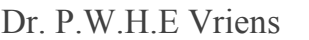

$\square$ 


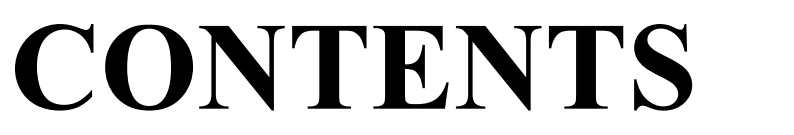

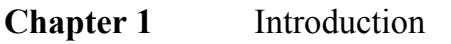

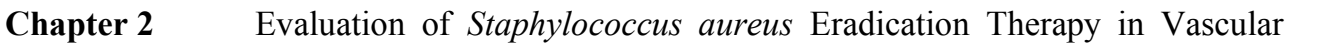

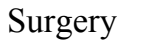

PLoS One. 2016;11(8):e0161058 $\square$

.

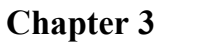

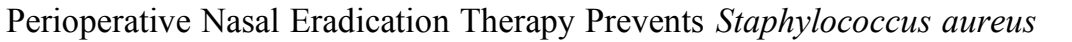

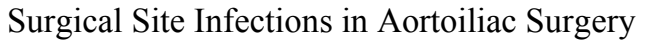

Surg Infect (Larchmt). 2018;19(5):510515

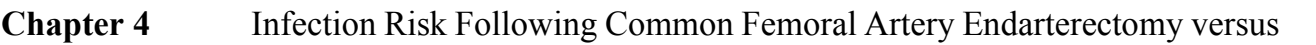

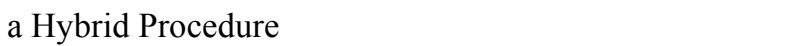

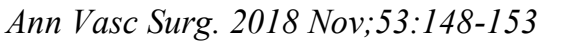

$\square$

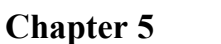

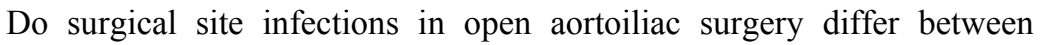

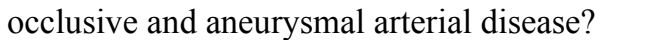

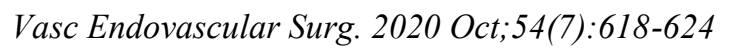

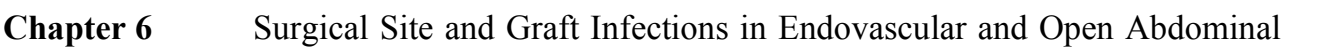

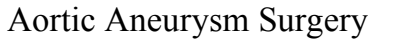

Surg Infect (Larchmt). 2018 May/Jun;19(4):424 429

$\square$

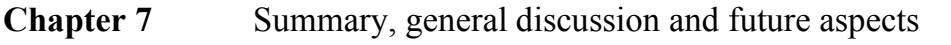

$\square$

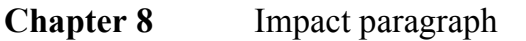

$\square$

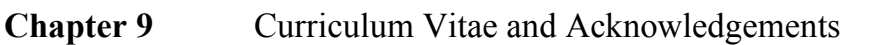




$$
1
$$




\section{Chapter 1}

INTRODUCTION 


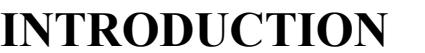

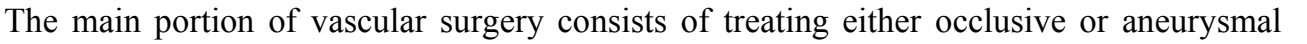

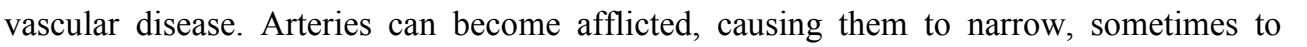

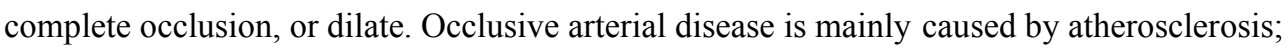

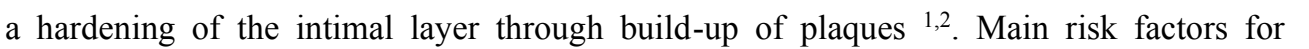

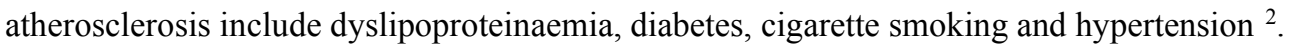

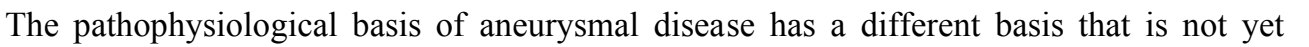

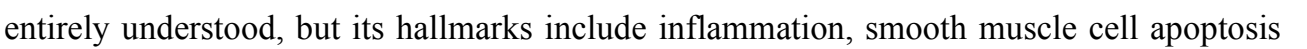

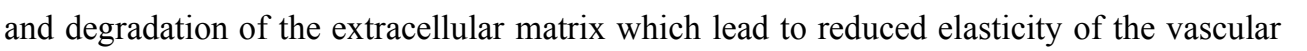

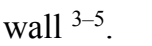

$\square$

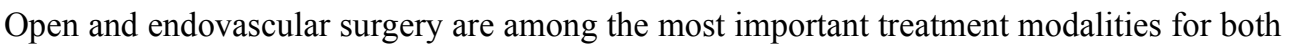

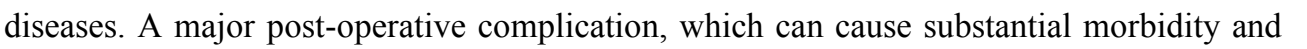

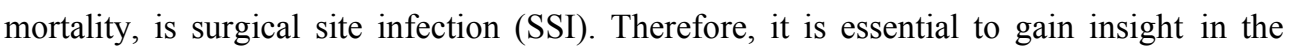

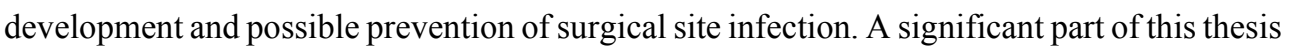

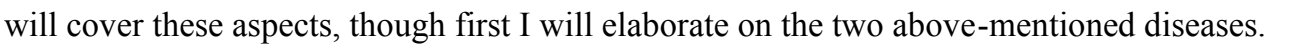

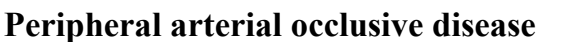

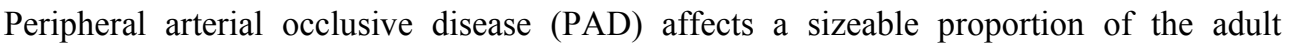
population; its prevalence rising with age. The total disease prevalence ranges between $3 \%$

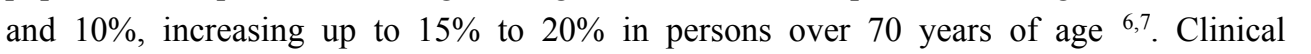

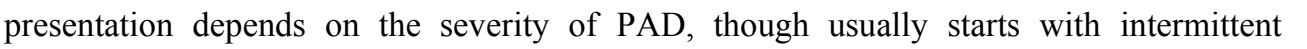

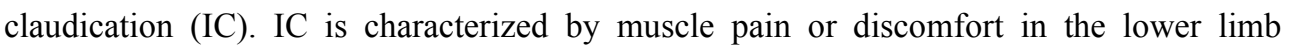

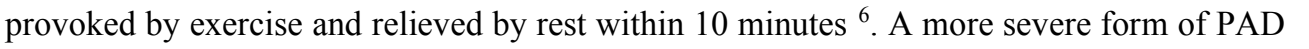

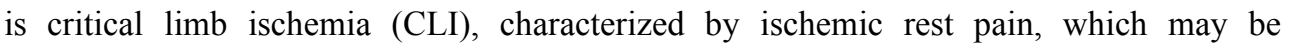

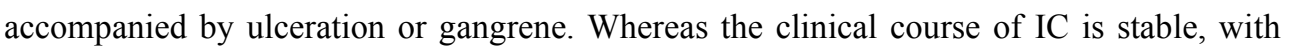
major amputation rates between $1 \%$ and $3 \%$ over a 5 year period, between $16 \%$ and $40 \%$ of

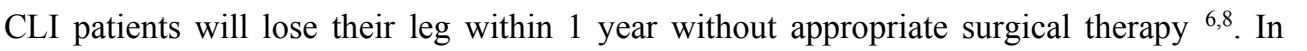

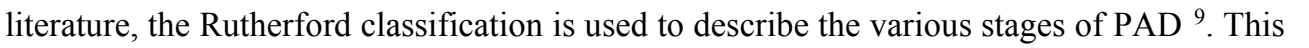

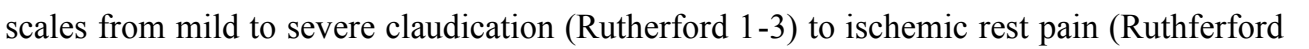

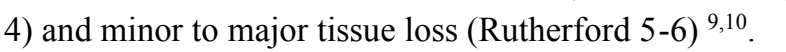

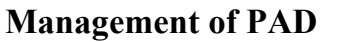

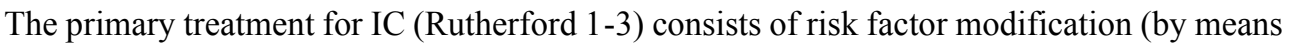

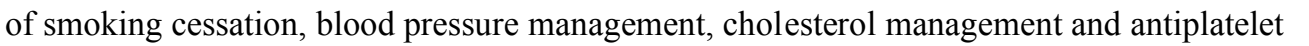
ए

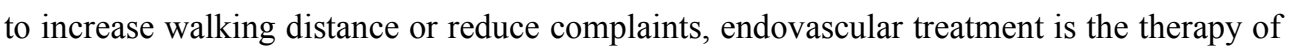

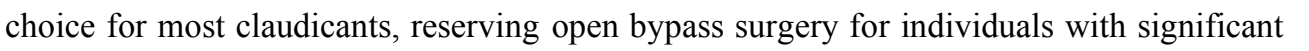

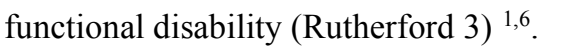




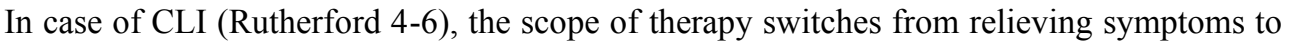

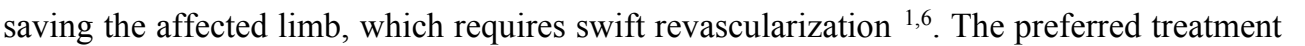

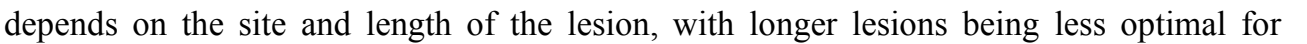

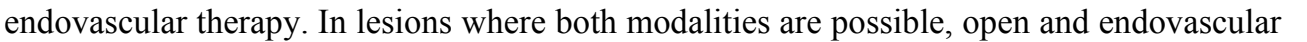

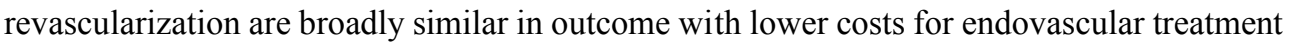

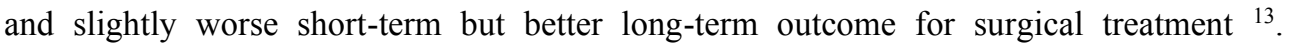

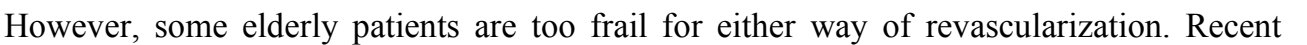

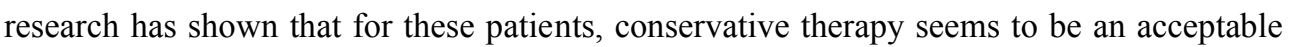

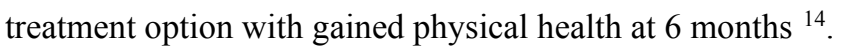

$\square$

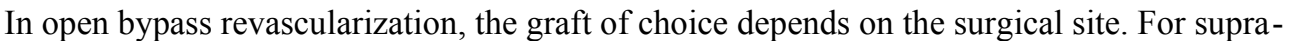

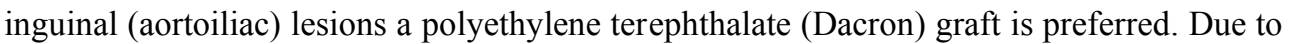

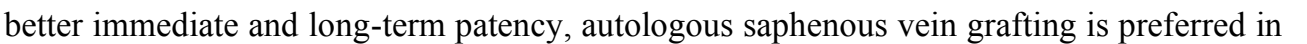

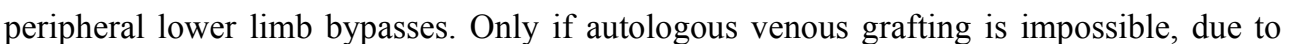

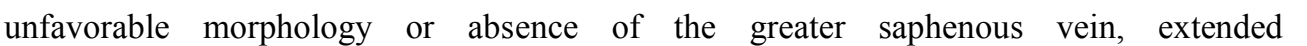

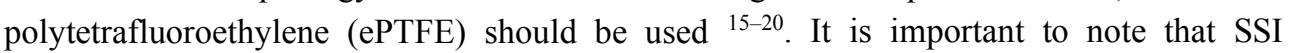

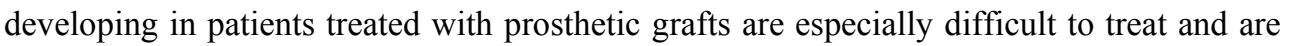

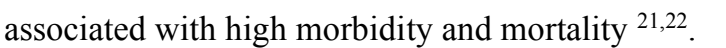

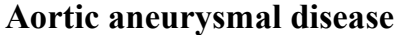

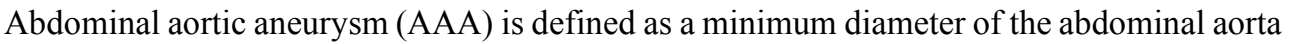

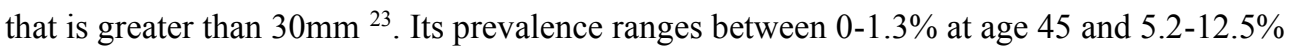

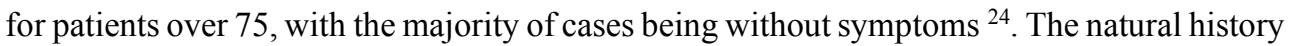

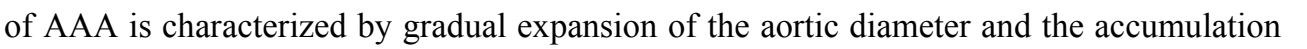
पणm

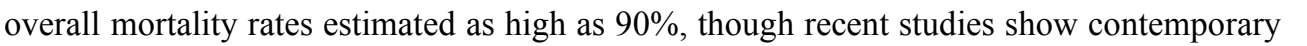

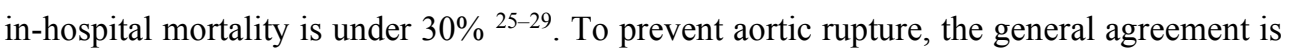
ए ए

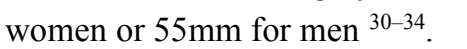

$\square$

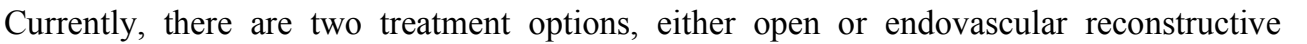

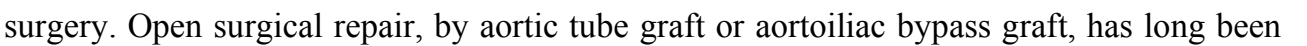

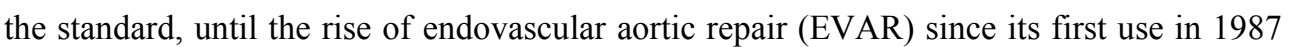
एயम

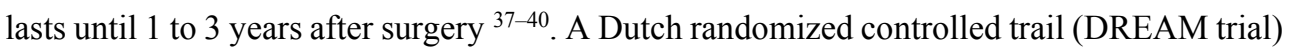

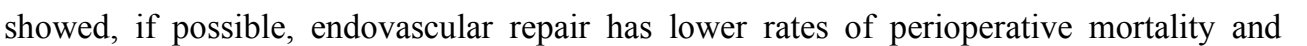

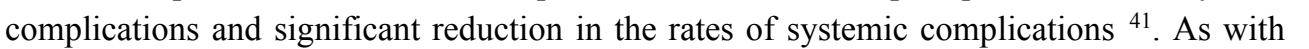

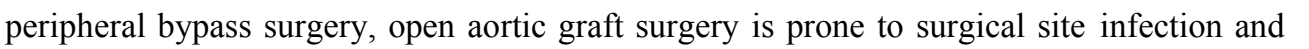

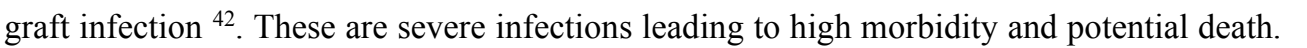




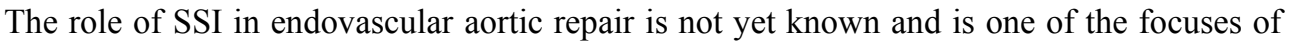

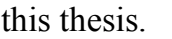

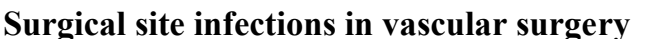

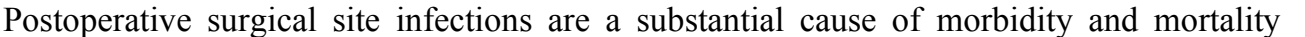

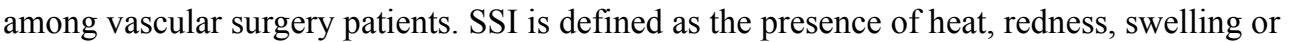

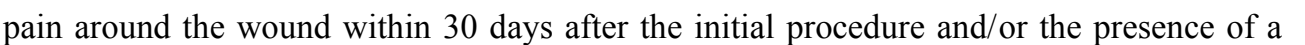

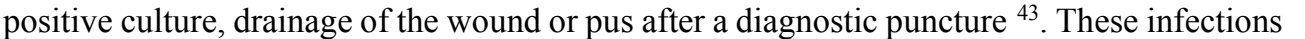

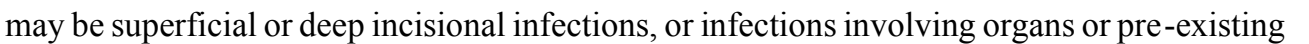

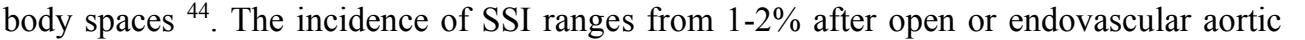

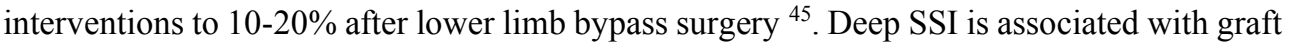

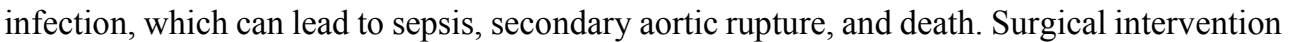

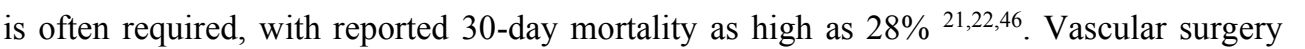

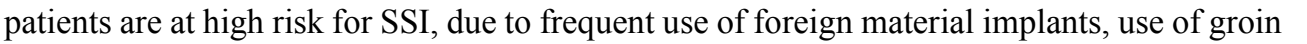
ए ए। $\square$

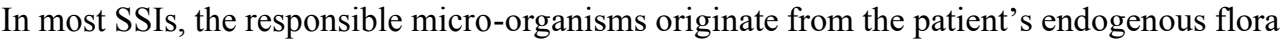

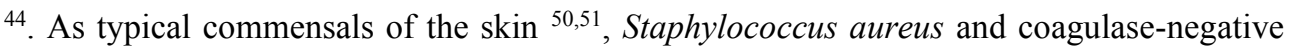

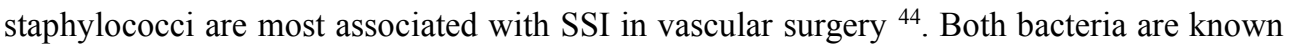

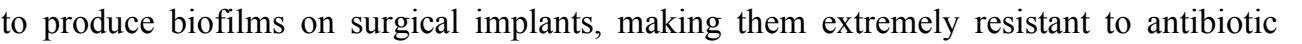

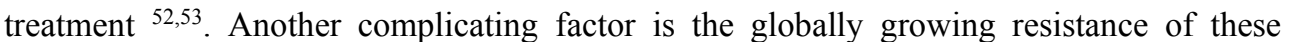

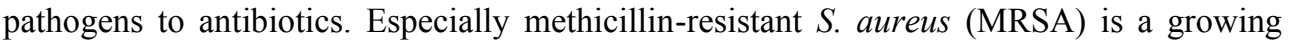

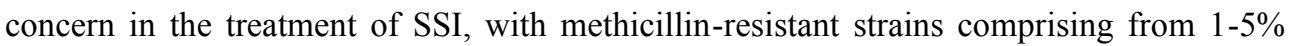

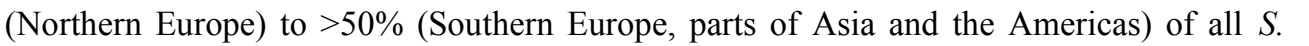

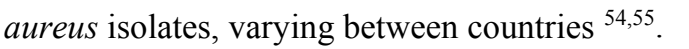

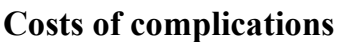

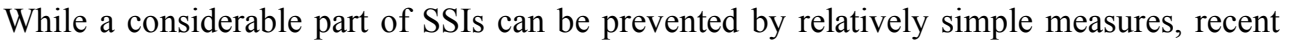

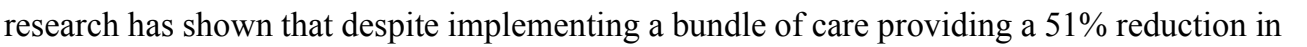

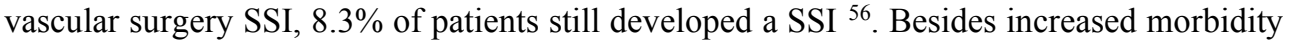

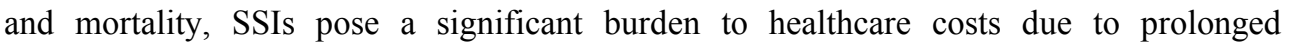

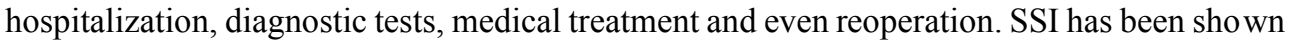

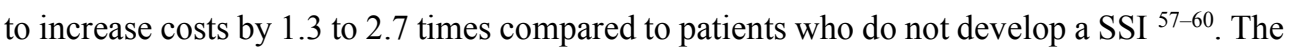

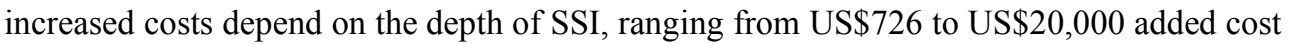

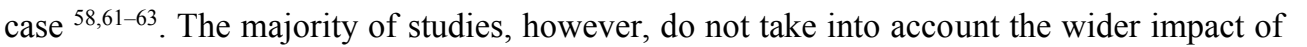

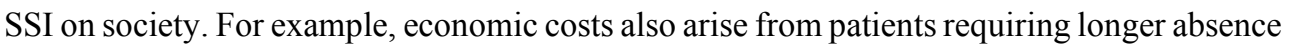

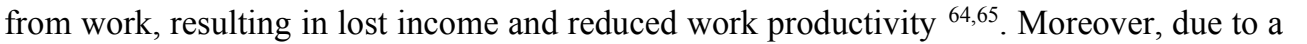

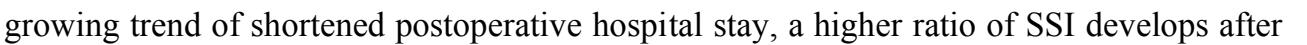

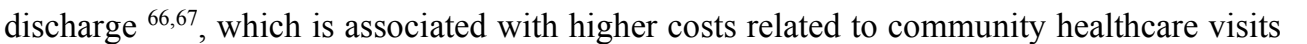




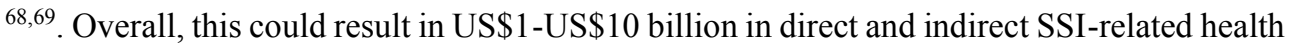

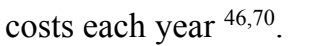

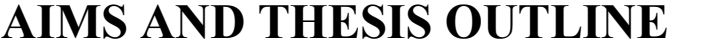

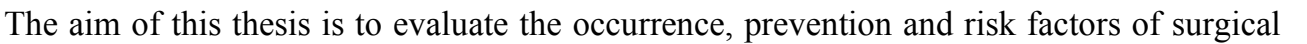

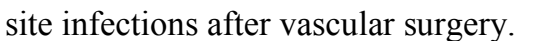

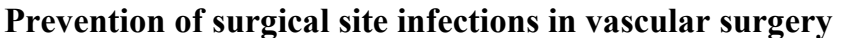

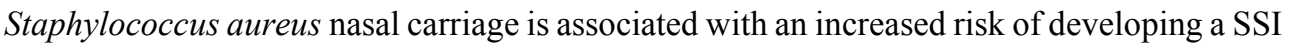

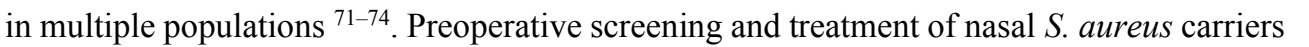

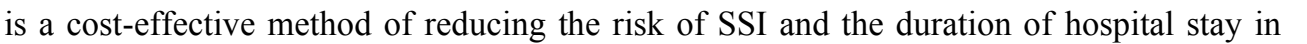

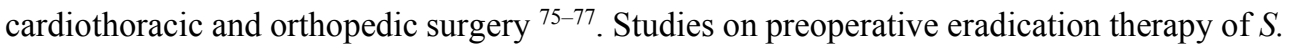

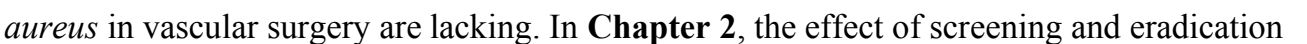

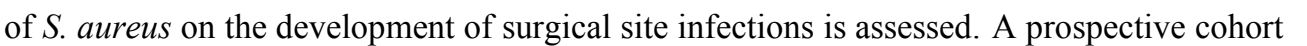

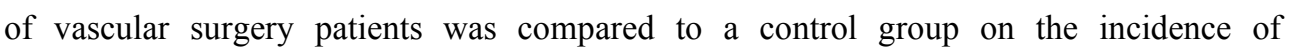

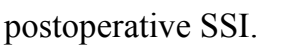

$\square$

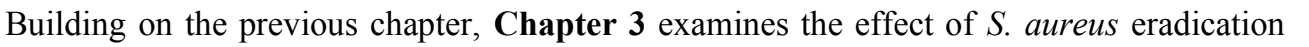

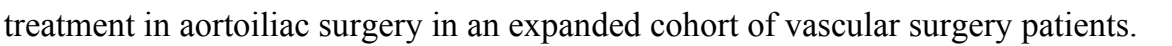

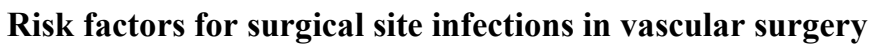

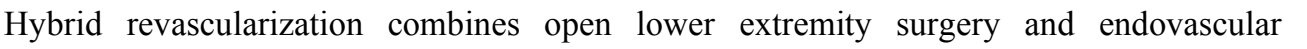

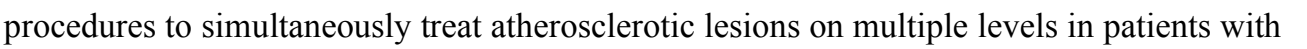

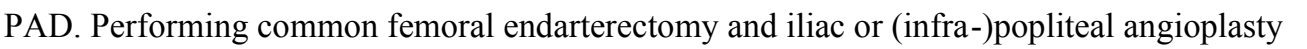

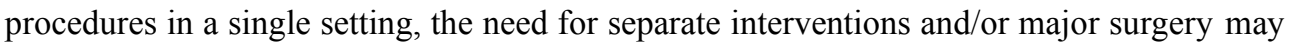

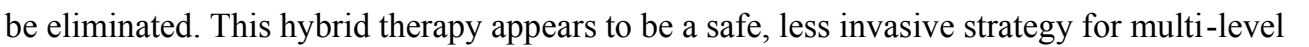

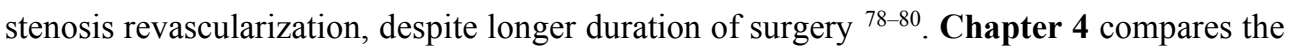

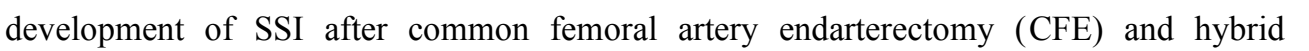

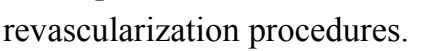

$\square$

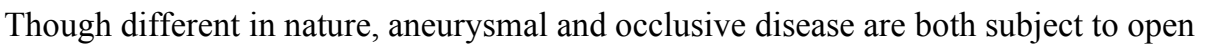

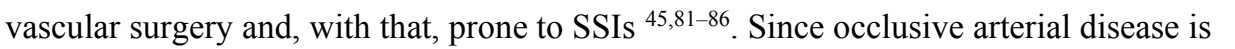

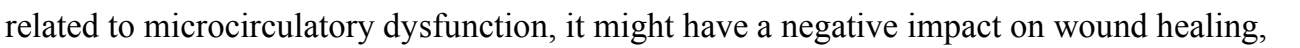

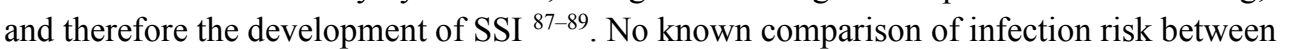

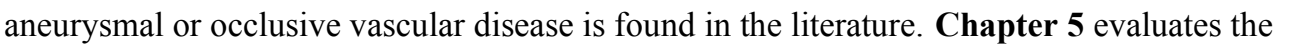

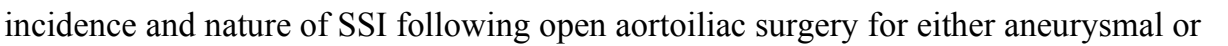

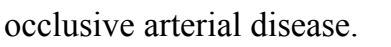

$\square$ 
Chapter 1

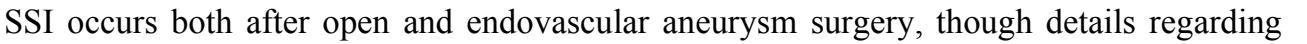

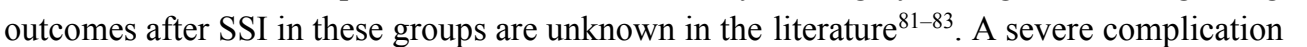

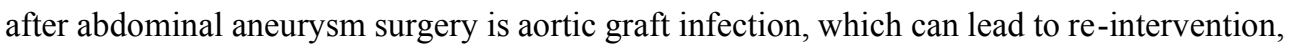

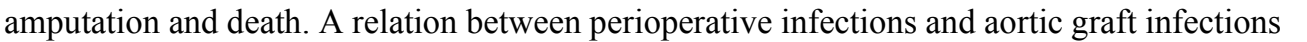

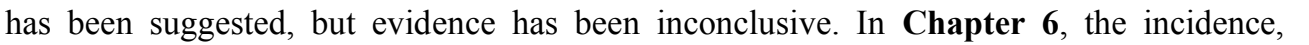

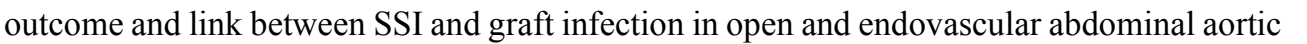

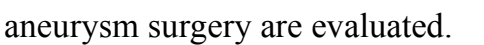

$\square$

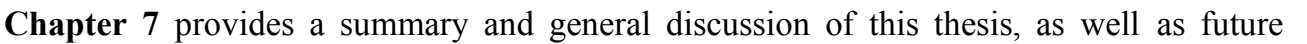

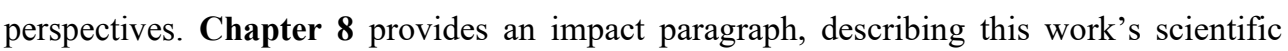

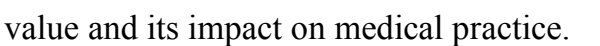




\section{प्रण $\square \square \square \square \square \square$}

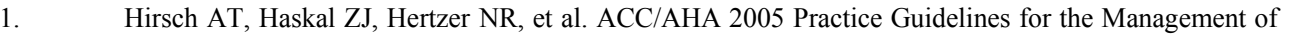

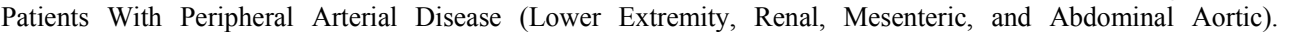

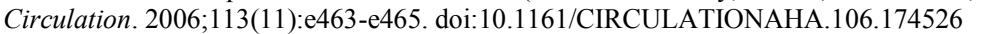

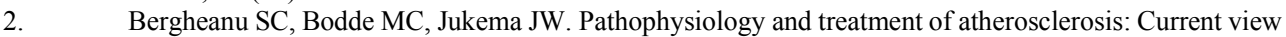

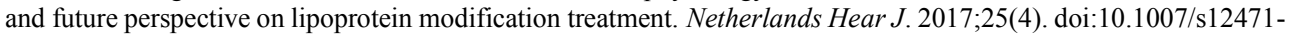
$017 \mathbb{1 1 | | ण | ण ~}$

3. $\square \quad$ Kuivaniemi H, Ryer EJ, Elmore JR, Tromp G. Understanding the pathogenesis of abdominal aortic

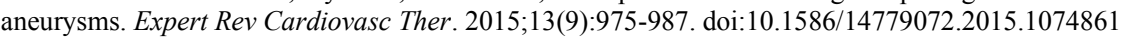

4. $\square \quad$ Boddy AM, Lenk GM, Lillvis JH, Nischan J, Kyo Y, Kuivaniemi H. Basic research studies to understand

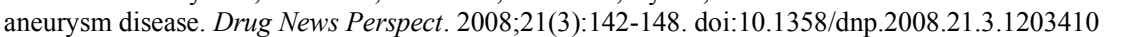

III Kuivaniemi H, Tromp G, Carey DJ, Elmore JR. The molecular biology and genetics of aneurysms. In:

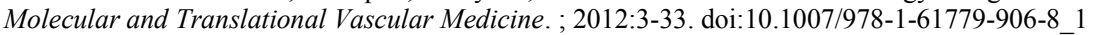

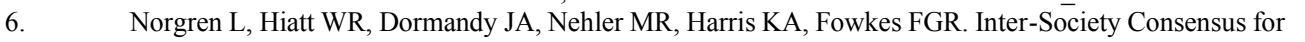
the Management of Peripheral Arterial Disease (TASC II). $\square \square \square \| \square \square \square \square .2007 ; 45(1 \quad$ SUPPL.). doi:10.1016/j.jvs.2006.12.037 $\square$

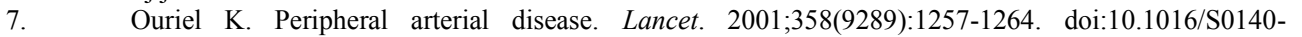
$6736(01) 06351 \square \square$

IIII Thomas AR, Raats JW, Lensvelt MMA, de Groot HGW, Veen EJ, van der Laan L. Conservative Treatment in Selected Patients with Severe Critical Limb Ischemia $\square \square \square \| \square \square \square \mid \square . ~ 2015 ; 39(8): 2090 \square \square 11 \square$ doi: $10.1007 / \mathrm{s} 00268 \square \square 3069 \square$

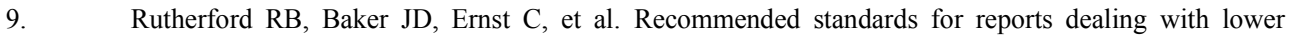

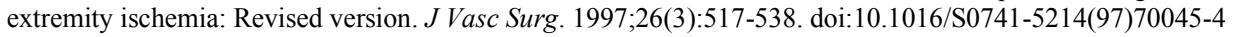

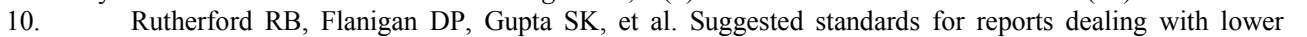

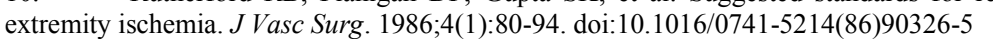

पIII Fakhry F, Fokkenrood HJP, Spronk S, Teijink JAW, Rouwet E V., Hunink MGM. Endovascular

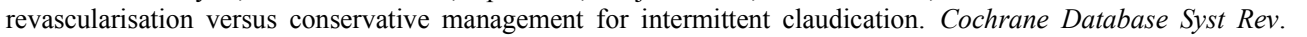
2018;2018(3). doi:10.1002/14651858.CD010512.pub2 $\square$

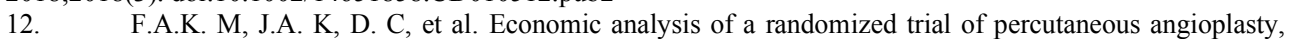
supervised exercise or combined treatment for intermittent claudication due to femoropopliteal arterial disease. $\square \square \square$

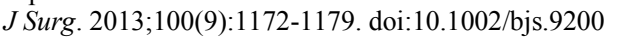

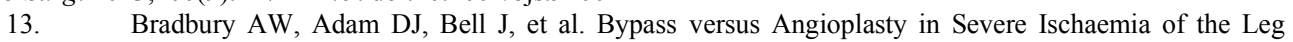

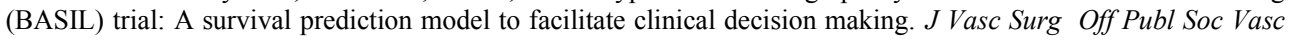

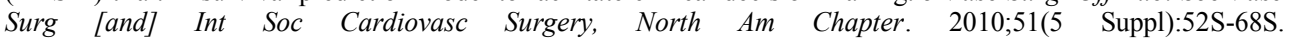
doi:10.1016/j.jvs.2010.01.077 $\square$

14. $\square \quad$ Steunenberg SL, de Vries J, Raats JW, et al. Quality of Life and Mortality after Endovascular, Surgical

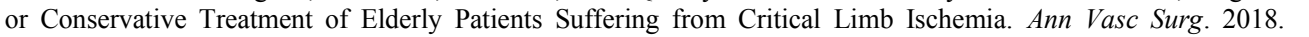
doi:10.1016/j.avsg.2018.02.044

GIII Green RM, Abbott WM, Matsumoto T, et al. Prosthetic above knee femoropopliteal bypass grafting:

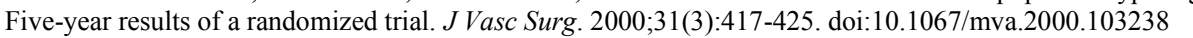

$\square \mathrm{\square} \square \square \square \square \square \square$ AF, Robinson PA, Holt SM. Prospective controlled study of polytetrafluoroethylene versus saphenous vein in claudicant patients with bilateral above knee femoropopliteal bypasses. $\quad \square[\|\square\| m$ 1999;126(4):594602. doi:10.1016/S0039 6060(99)70110匹

17. $\square \quad \square \square\|\|$ WC, Lee KK. A comparative evaluation of polytetrafluoroethylene, umbilical vein, and saphenous vein bypass grafts for femoral popliteal above knee revascularization: A prospective randomized

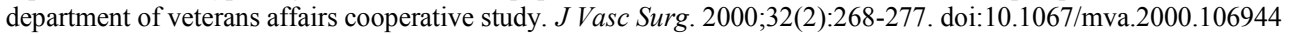
IIII Klinkert P, Schepers A, Burger DHC, van Bockel JH, Breslau PJ. Vein versus polytetrafluoroethylene in

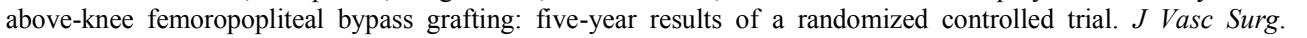
2003;37(1):149 155. doi:10.1067/mva.2002.86ロ

पाW Donker JMW, te Slaa A, de Vries J, Ho GH, Mulder PGH, van der Laan L. Midterm follow

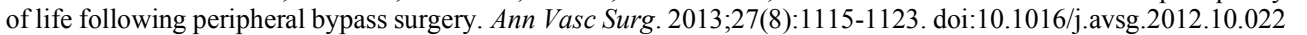

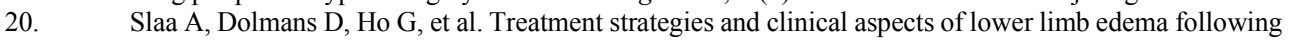

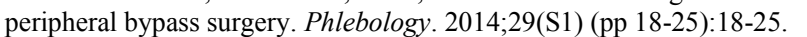

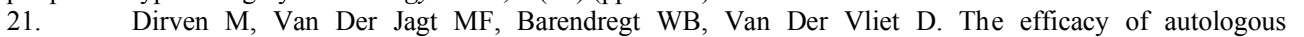
femoropopliteal vein reconstruction for primary aortic and aortic graft infection. $\square \square \square \square \square \square\|\| \square \backslash \square .2015 ; 29(6): 1188 \square$ 1195. doi:10.1016/j.avsg.2015.03.043 $\square$

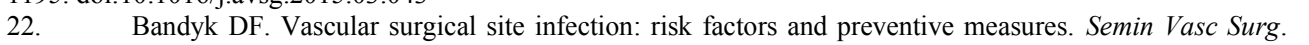
2008;21(3):119ロ23. doi:10.1053/j.semvascsurg.2008.05.008 $\square$ 


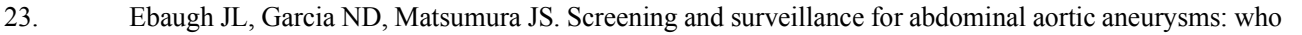

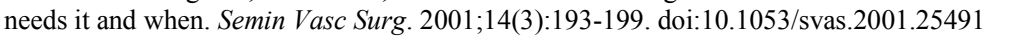

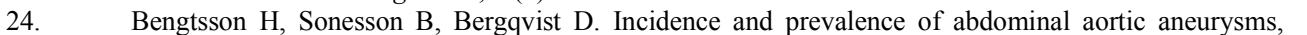

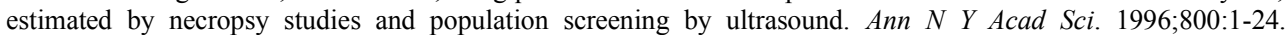
doi:10.1111/j.1749 6632.1996.tb33294.x $\square$

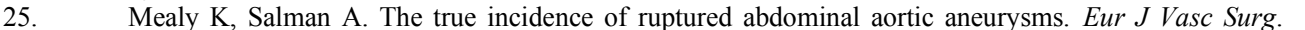
1988;2(6):405 408. doi:10.1016/S0950 821X(88)80020匹

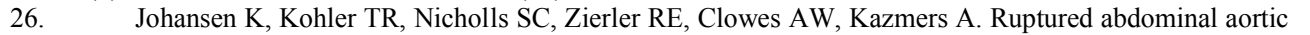
aneurysm: the Harborview experience. $\square \square \square \square \square \square \square .1991 ; 13(2): 240$ 247. doi:10.1067/mva.1991.25530

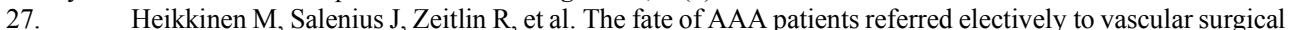

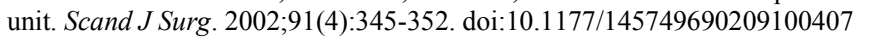

28. $\square \quad$ Soden PA, Schermerhorn ML. The Epidemiology of Ruptured Abdominal Aortic Aneurysm (rAAA). In:

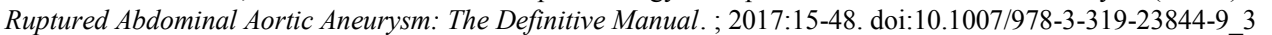

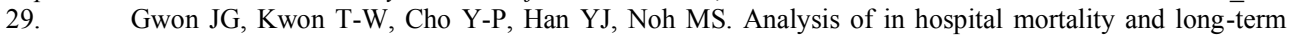
survival excluding in hospital mortality after open surgical repair of ruptured abdominal aortic aneurysm. $\square \square \square \square \square \square \square$ $\square \square \square \square \square .2016 ; 91(6): 303$ 308. doi:10.4174/astr.2016.91.6.303 $\square$

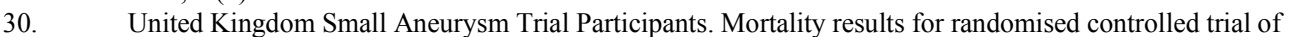

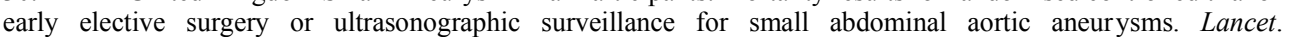
1998;352:1649 1655. doi:10.1016/S0140 6736(98)10137Х $\square$

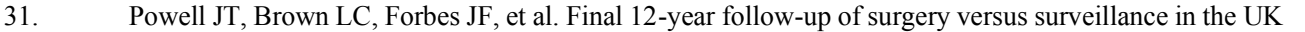

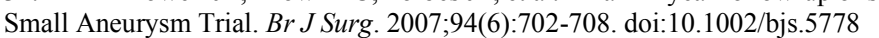

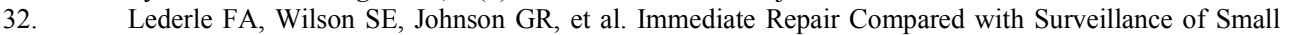

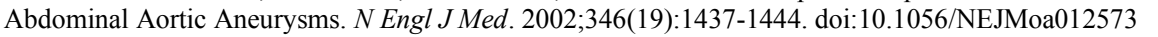

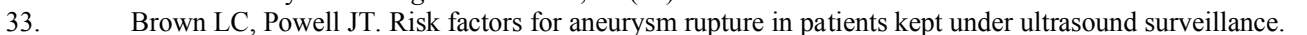

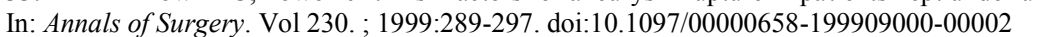

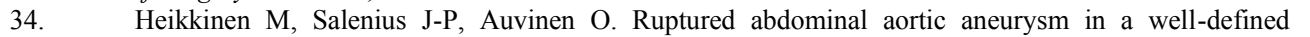

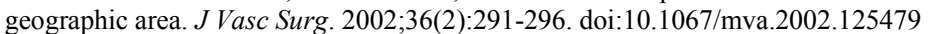

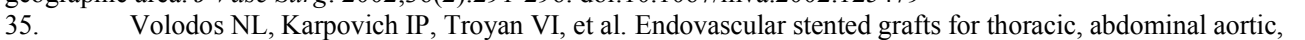

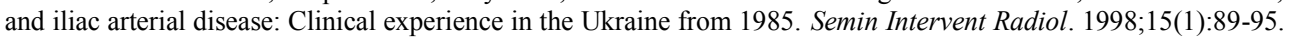
doi: $10.1055 / \mathrm{s} 2008 \square 057062$

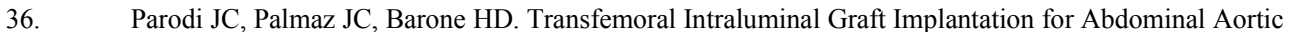

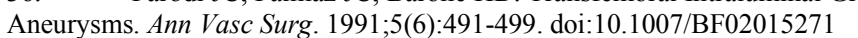

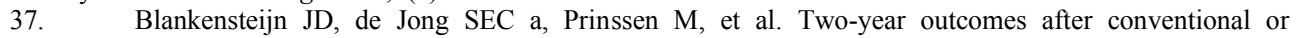

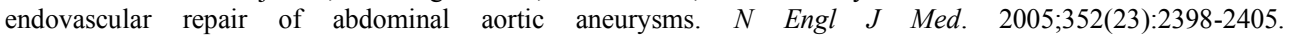
doi:10.1056/NEJMoa051255 $\square$

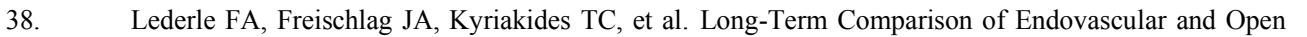

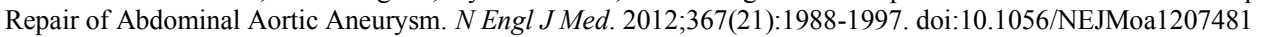

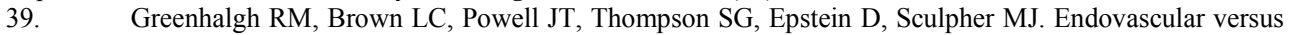

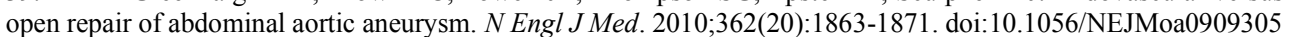
40. $\square \quad$ Paravastu SCV, Jayarajasingam R, Cottam R, Palfreyman SJ, Michaels JA, Thomas SM. Endovascular

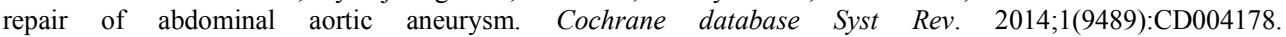
$\square \Pi 1$.1002/14651858.CD004178.pub2 $\square$

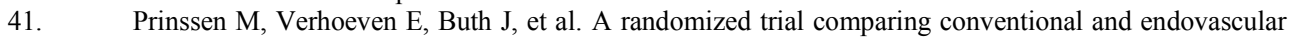

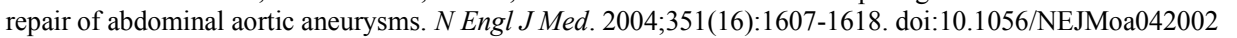

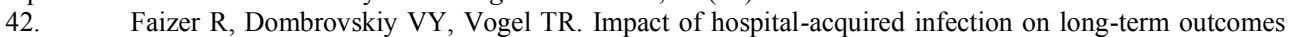

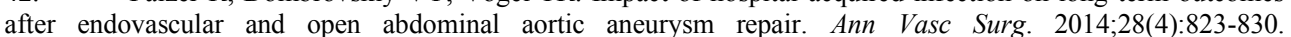
doi:10.1016/j.avsg.2013.06.028 $\square$

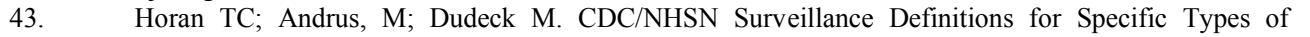

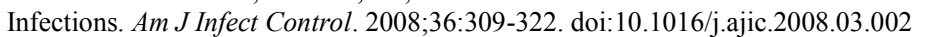

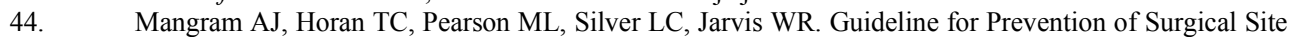

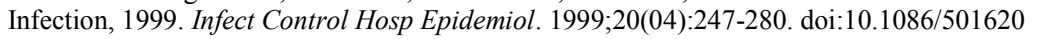

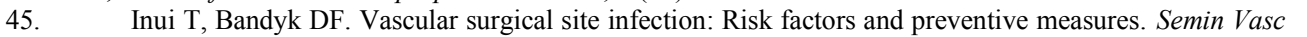
$\square 1 \amalg .2015 ; 28(34): 201$ 207. doi:10.1053/j.semvascsurg.2016.02.002 $\square$

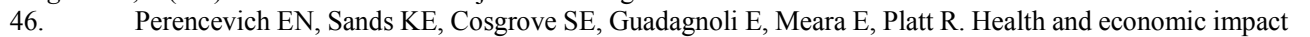

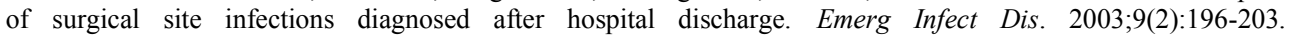
doi:10.3201/eid0902.020232 $\square$

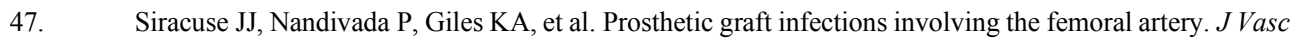
$\square \amalg \amalg .2013 ; 57(3): 700 \square 705$. doi:10.1016/j.jvs.2012.09.049 $\square$

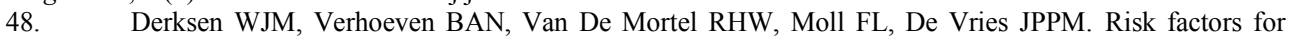

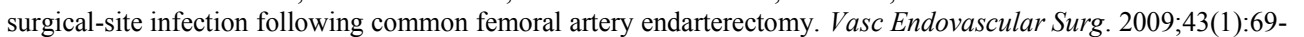
75. doi:10.1177/1538574408323502 $\square$ 


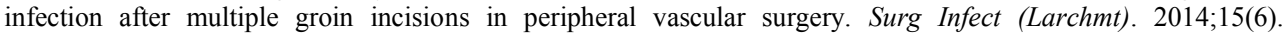
doi:10.1089/sur.2013.253

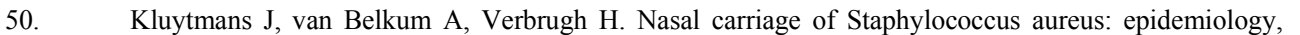

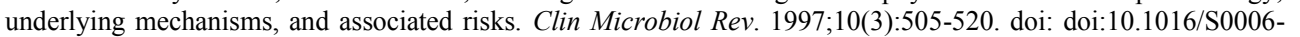
3207(03)00146ஐ

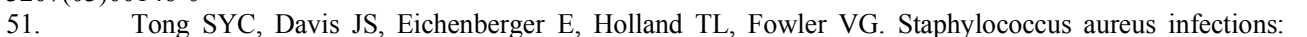

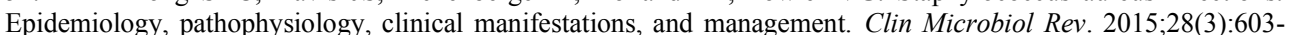
661. doi:10.1128/CMR.00134⿴囗十

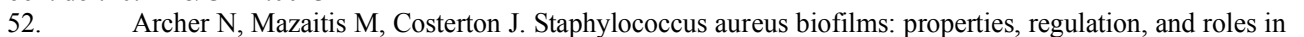
human disease. .... 2011;2(5):445 459. doi:10.4161/viru.2.5.17724

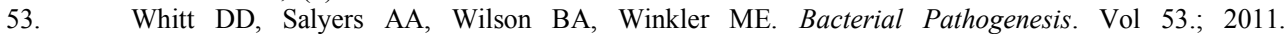
doi: $10.1128 / 9781555816162$

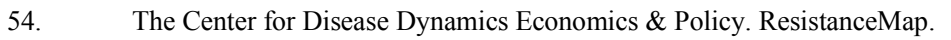

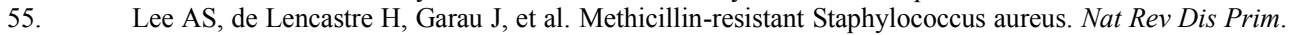
2018;4:18033. doi:10.1038/nrdp.2018.33 $\square$

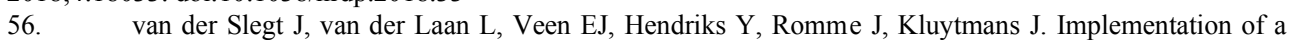
Bundle of Care to Reduce Surgical Site Infections in Patients Undergoing Vascular Surgery. $\square \square \square \square \square \square .2013 ; 8(8)$. doi:10.1371/journal.pone.0071566

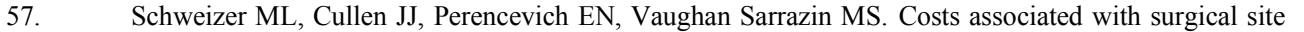

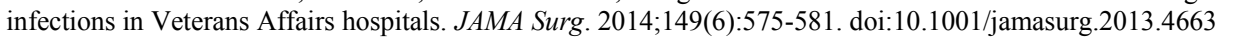

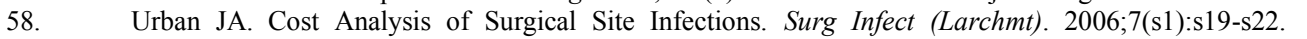

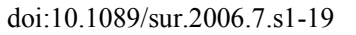

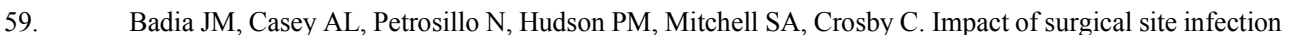

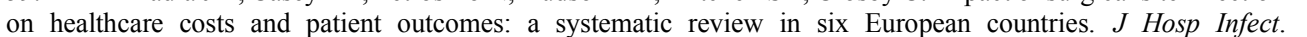

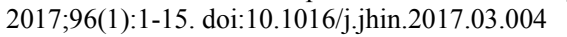

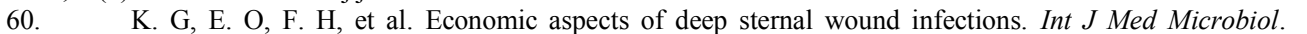
2009;299:24 25 .

http://ovidsp.ovid.com/ovidweb.cgi?T=JS\&PAGE=reference\&D=emed9\&NEWS=N\&AN=70139570.

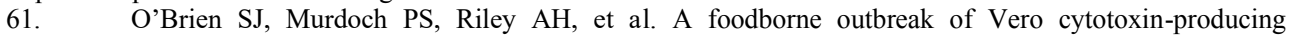

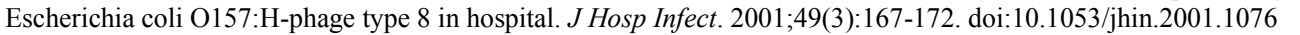

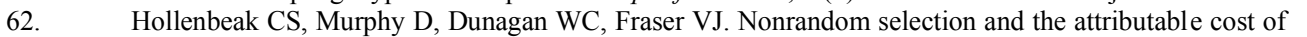

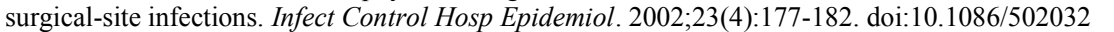

63. $\square$ Whitehouse JD, Friedman ND, Kirkland KB, Richardson WJ, Sexton DJ. The Impact of Surgical $\square \square \square$ Infections Following Orthopedic Surgery at a Community Hospital and a University Hospital Adverse Quality of

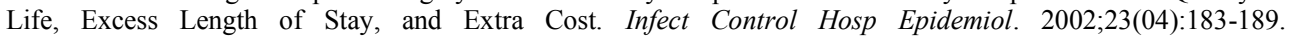
doi: $10.1086 / 502033 \square$

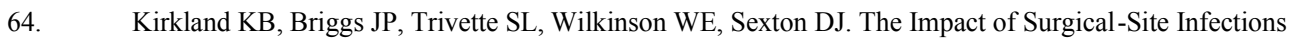

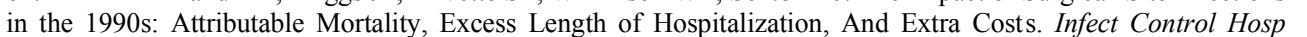

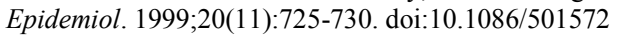

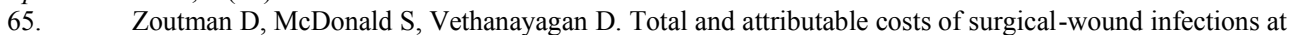

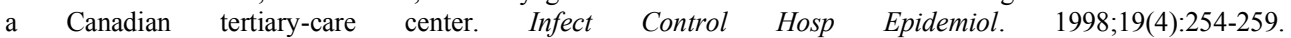
doi:https://doi.org/10.1017/S0195941700087348

66. $\square \quad$ Sands K, Vineyard G, Platt R. Surgical Site Infections Occurring after Hospital Discharge. J Infect Dis. http://jid.oxfordjournals.org/content/173/4/963.full.pdf. Published 1996.

67. $\square$ Brown RB, Bradley S, Opitz E, Cipriani D, Ploczarka R, Sands M. Surgical wound infections

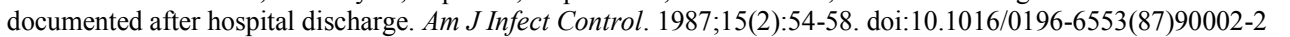

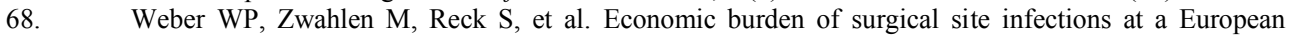

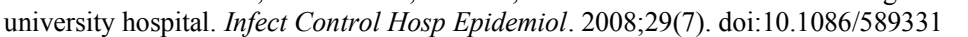

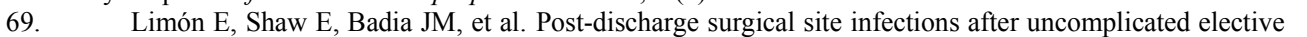

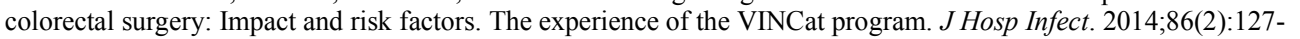
132. doi:10.1016/j.jhin.2013.11.004 $\square$

पIIII Holtz TH, Wenzel RP. Postdischarge surveillance for nosocomial wound infection: A brief review and

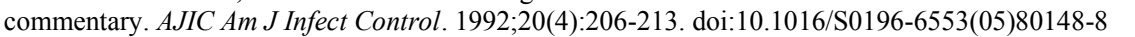

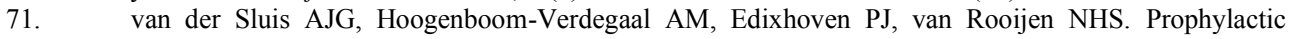
mupirocin could reduce orthopedic wound infections: 1,044 patients treated with mupirocin compared with 1,260

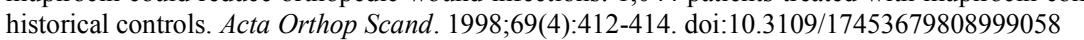

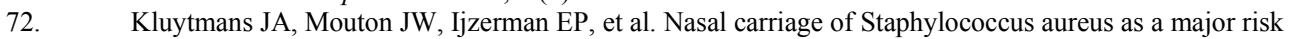

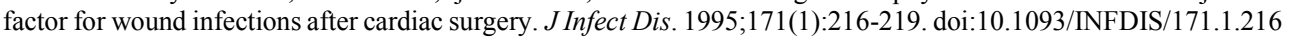




\section{पाएा

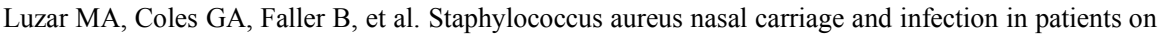

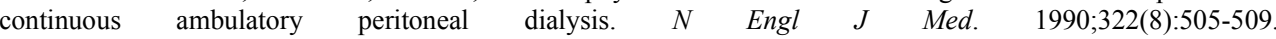
doi:10.1056/NEJM199002223220804

74. Donker JMW, van der Laan L, Hendriks YJAM, Kluytmans JAJW. Evaluation of Staphylococcus aureus

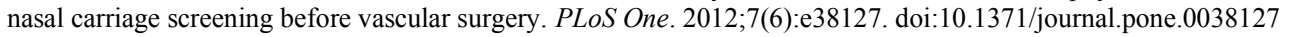
75. Wenzel RP, Perl TM. The significance of nasal carriage of Staphylococcus aureus and the incidence of

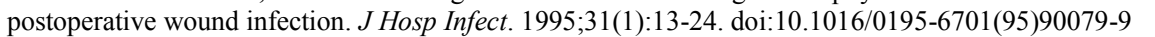

76. Bode LGM, Kluytmans JAJW, Wertheim HFL, et al. Preven $\square=0$

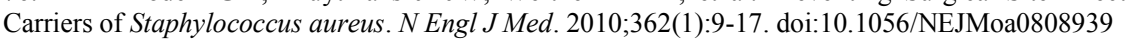

पIII Wassenberg MWM, de Wit GA, Bonten MJM. $\square \square \|$ effectiveness of preoperative screening and

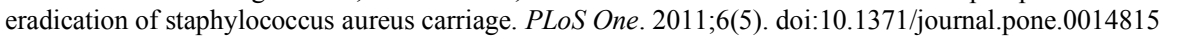

78. $\square \quad$ Cotroneo AR, Iezzi R, Marano G, Fonio P, Nessi F, Gandini G. Hybrid therapy in patients with complex

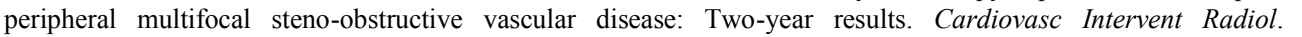
2007;30(3):355 361. doi:10.1007/s00270 005 02965 $\square$

पIII Dougherty MJ, Young LP, Calligaro KD, et al. One hundred twenty five concomitant endovascular and

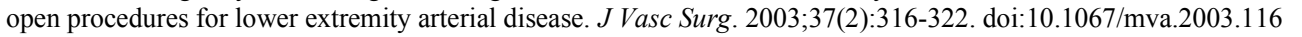
80. Nelson PR, Powell RJ, Schermerhorn ML, et al. Early results of external iliac artery stenting combined

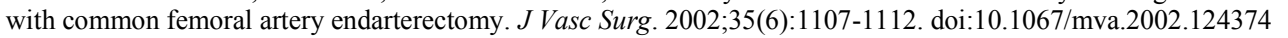
81. Giles KA, Wyers MC, Pomposelli FB, Hamdan AD, Avery Ching Y, Schermerhorn ML. The impact of body mass index on perioperative outcomes of open and endovascular abdominal aortic aneurysm repair from the

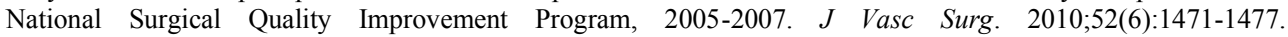
doi:10.1016/j.jvs.2010.07.013 $\square$

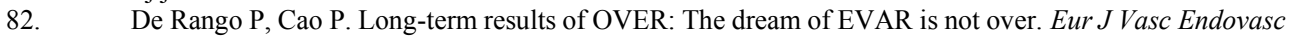
पIII. 2013;45(4):313 314. doi:10.1016/j.ejvs.2013.01.013

83. Prinssen M, Buskens E, Blankensteijn JD. The Dutch Randomised Endovascular Aneurysm Management (DREAM) trial. Background, design and methods.

84. Ghammad K, Dupuis A, Amond L, et al. Total laparoscopic bypass is safe and effective for aortoiliac

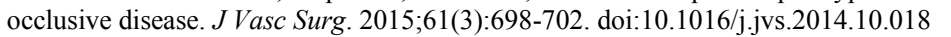

85. Pejkić S, Dragaš M, Ilić N, et al. Incidence and relevance of groin incisional complications after

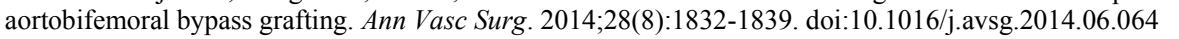

86. $\square \quad$ Sen I, Stephen E, Agarwal S. Clinical profile of aortoiliac occlusive disease and outcomes of

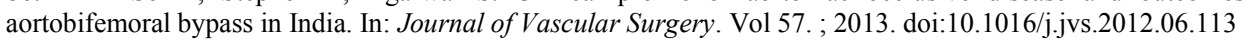

87. Rossi M, Carpi A. Skin microcirculation in peripheral arterial obliterative disease. $\square \square \square \square \square$ $\square \square \square \square \square \square ा .2004 ; 58(8$ SPEC. ISS.):427431. doi:10.1016/j.biopha.2004.08.004

88. Kabbani M, Rotter R, Busche M, et al. Impact of Diabetes and Peripheral Arterial Occlusive Disease on

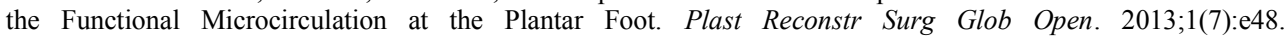
doi:10.1097/GOX.0b013e3182a4b9cb $\square$

89. Abularrage CJ, Sidawy AN, Aidinian G, Singh N, Weiswasser JM, Arora S. Evaluation of the

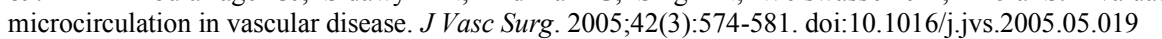


$\square$ 


$$
2
$$




\section{Chapter 2}

\section{Evaluation of Staphylococcus aureus Eradication Therapy in Vascular Surgery}

Langenberg JCM, Thomas AR, Donker JM, van Rijen MM, Kluytmans JAJW, van der Laan L. 


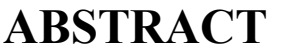

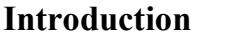

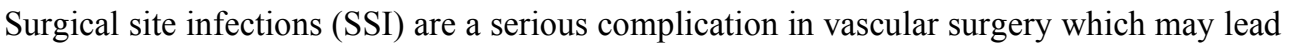

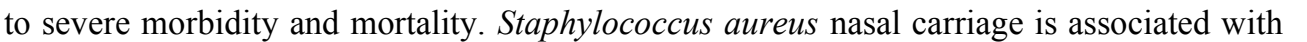

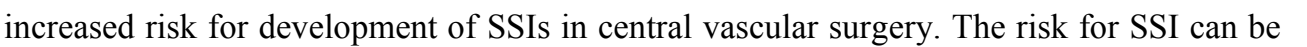

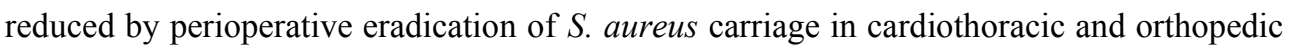

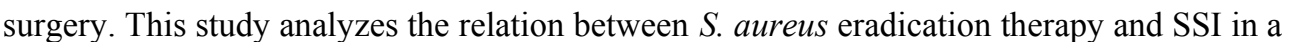

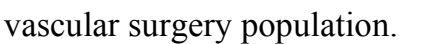

\section{$\square \square \square \square \square \square$}

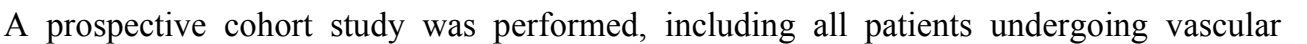

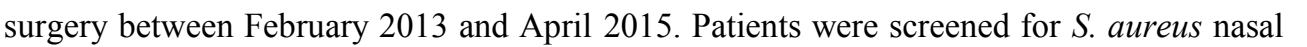

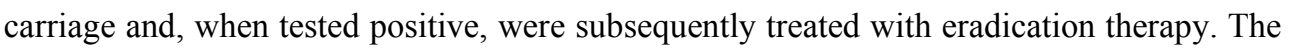

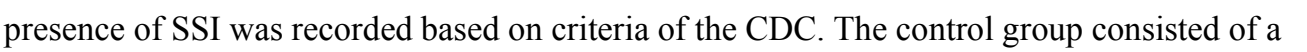

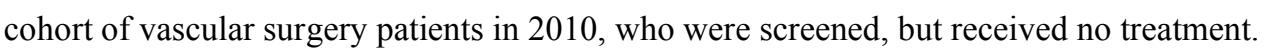

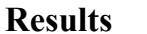

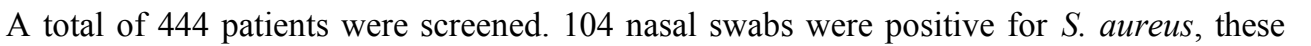

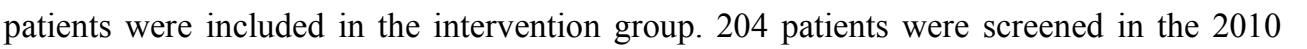

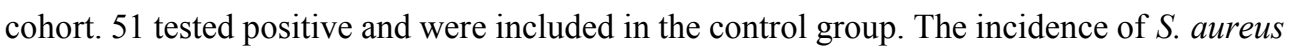

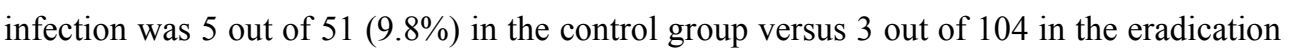

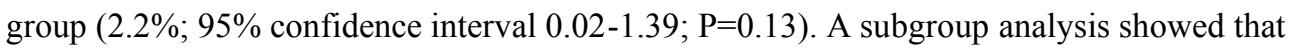

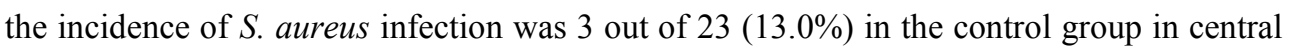
reconstructive surgery versus 0 out of 44 in the intervention group $(\mathrm{P}=0.074)$. The reduction

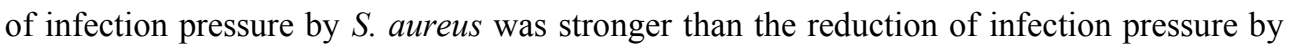
other pathogens (exact maximum likelihood estimation; $\mathrm{OR}=0.0724 ; 95 \% \mathrm{CI}: 0.001 \square .98$; $\mathrm{p}=0.0475)$. $\square$

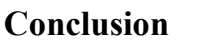

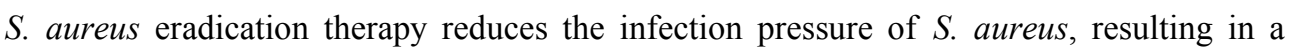

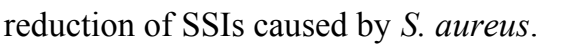

\section{$\square$}




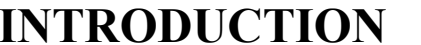

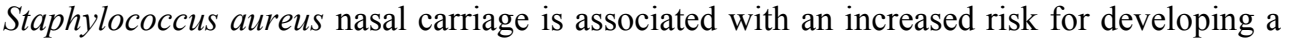

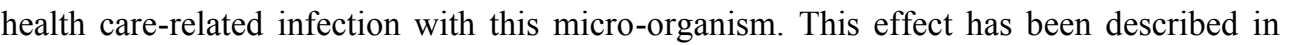

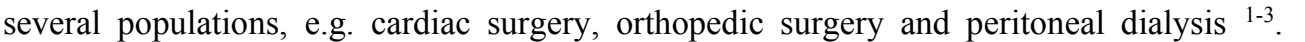

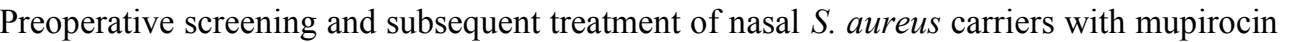

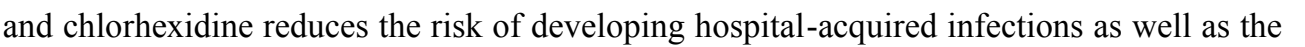

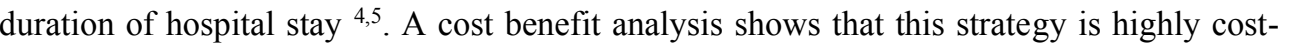
पामाणापा

$\square$

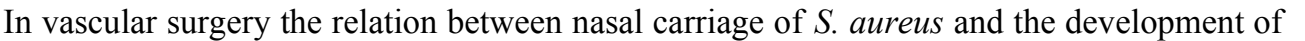

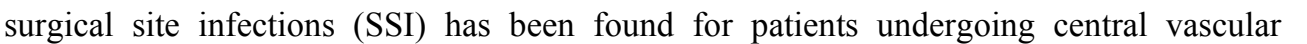

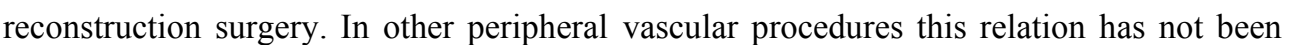

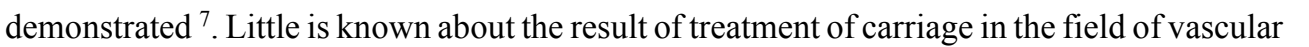

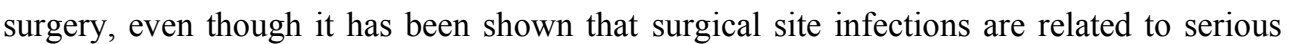

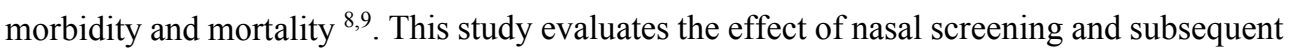

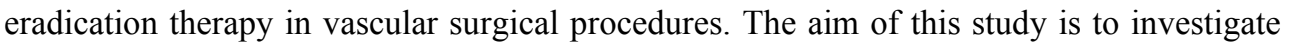

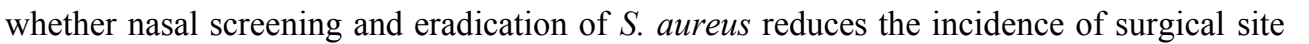

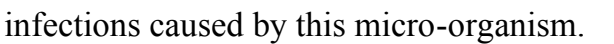

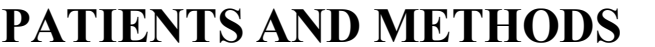

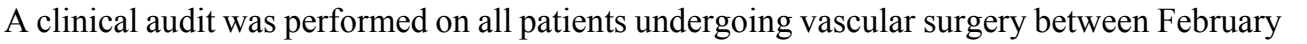

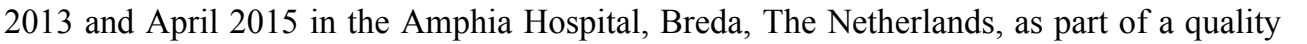

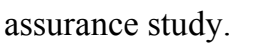

\section{$\square$}

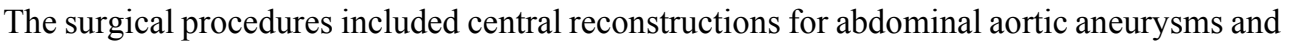

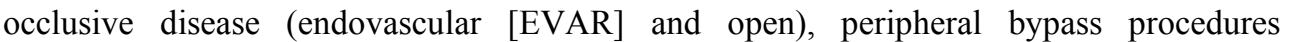

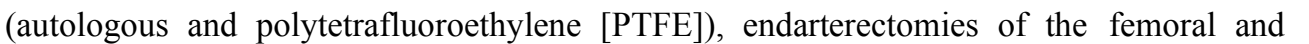

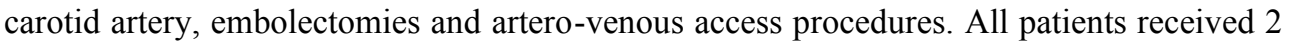

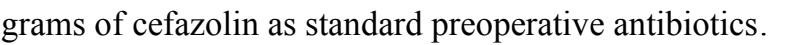

$\square$

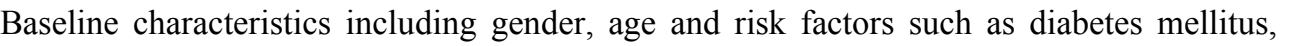

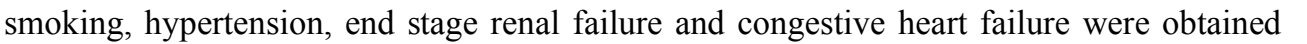

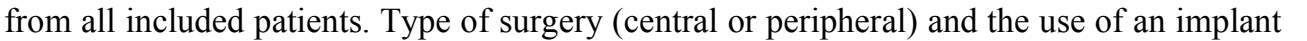

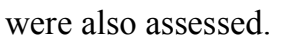

$\square$

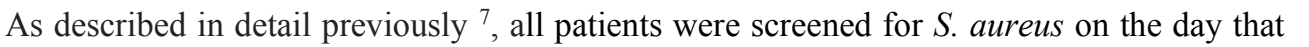

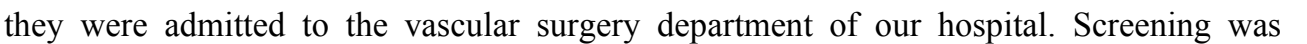

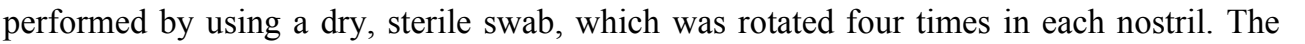




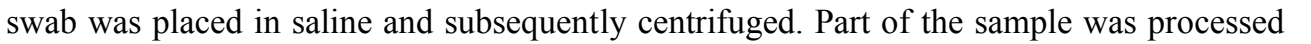

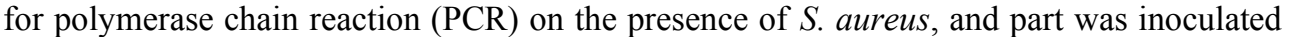

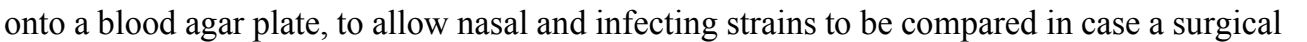

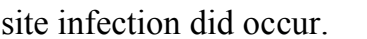

$\square$

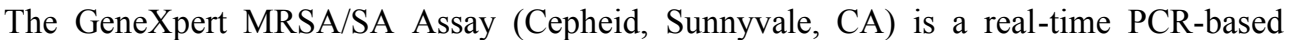

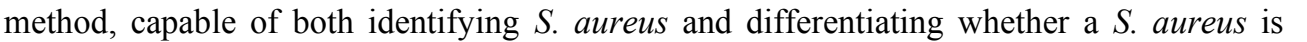

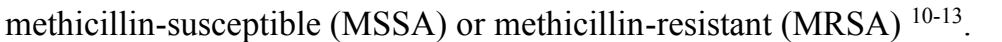
$\square$

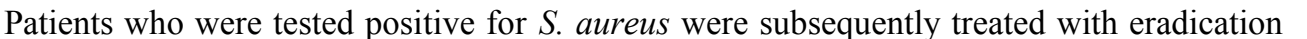
एाणा1ण

$\square$

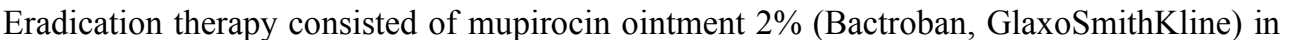

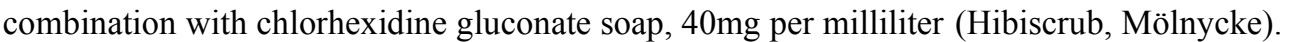

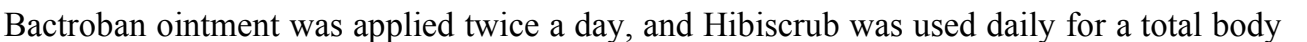

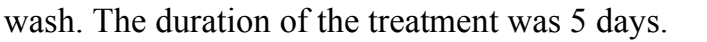

$\square$

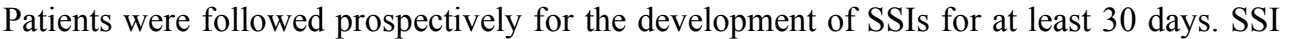
$\square \square$ defined in agreement with the Centers for Disease Control's criteria $\square \square$ $\square$

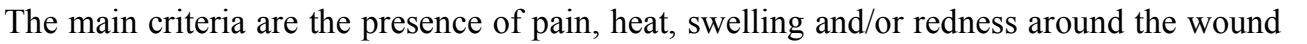

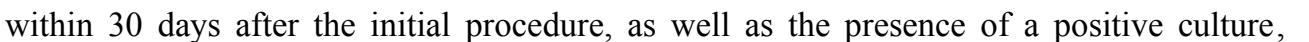

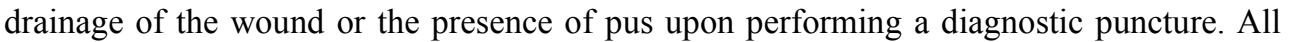

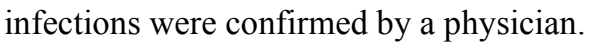

$\square$

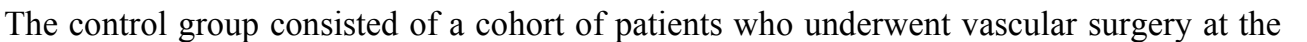

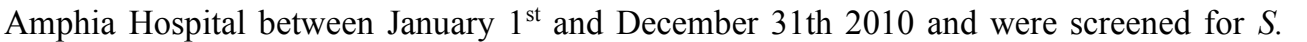

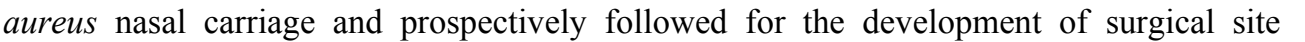

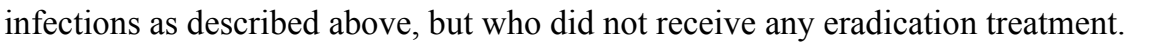

$\square$

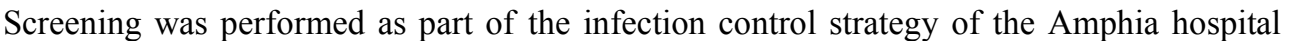

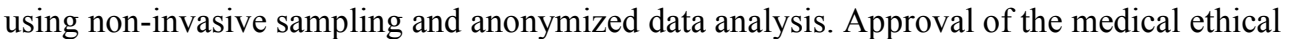

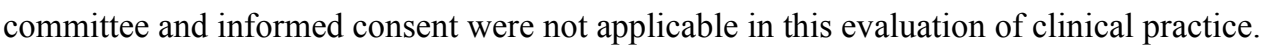
$\square$

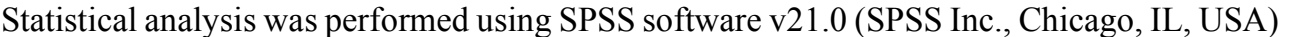
[nd LogXact (Cytel, Cambridge, MA, USA). A binary logistic regression with a fisher's

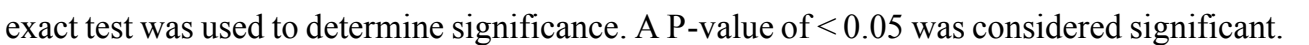




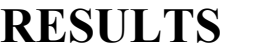

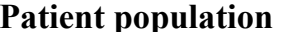

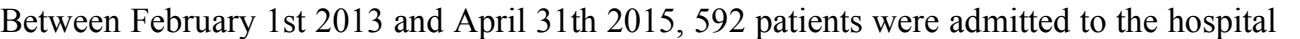

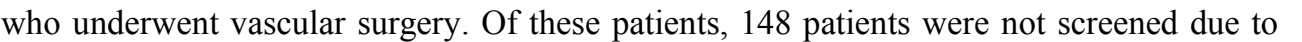

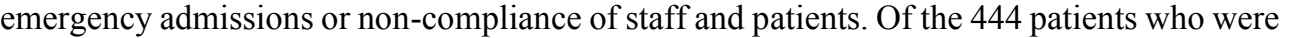

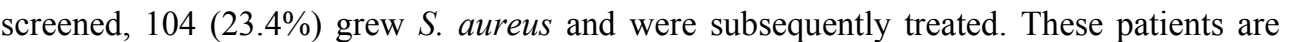

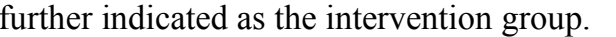

\section{$\square$}

ए

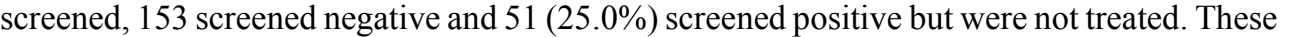

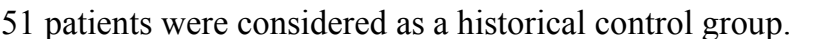

$\square$

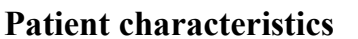

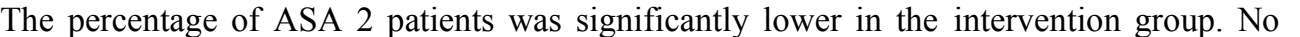

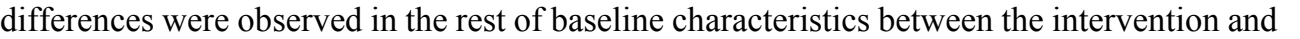

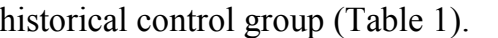

$\square$

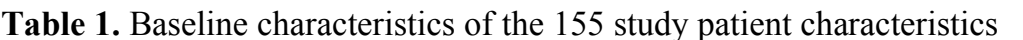

\begin{tabular}{|c|c|c|c|}
\hline 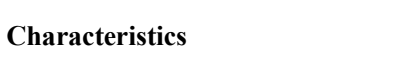 & 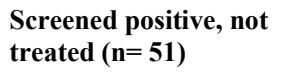 & 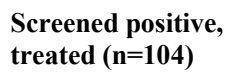 & 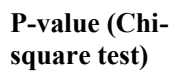 \\
\hline 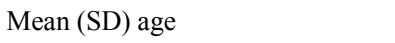 & पणाणाणाप & पापाणाप & पाणाए \\
\hline 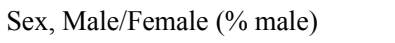 & पणाणाण & पणाणाण & $\square \square$ \\
\hline 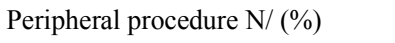 & $\square \square \square \square$ & 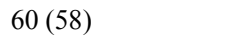 & पाणाए \\
\hline 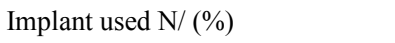 & 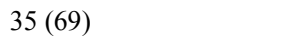 & पाणाण & पाए \\
\hline 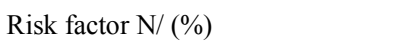 & $\square$ & $\square$ & $\square$ \\
\hline 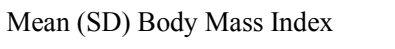 & पणाणापा & पणाणापा & $\square \square$ \\
\hline 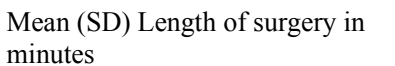 & $\square 101 \square$ & पाणाएव & पाएा \\
\hline 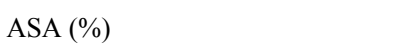 & $\square$ & $\square$ & $\square ण 1 \square$ \\
\hline$\square$ & $\square \square ण \square$ & पाणाप & \\
\hline$\square$ & पाणाण & पाणाण & $\square$ \\
\hline$\square$ & पाणाण & $\square \square$ & \\
\hline$\square \square ण \square$ & 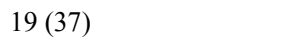 & 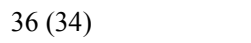 & $\square \square$ \\
\hline 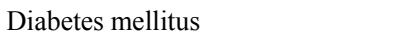 & 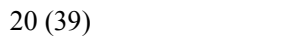 & 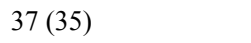 & पाणए \\
\hline 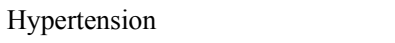 & 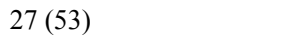 & पाणाए & पाणाए \\
\hline 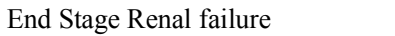 & 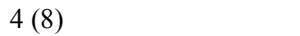 & 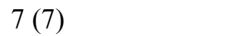 & पणाए \\
\hline 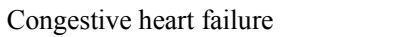 & पाणाणा & पाणाण & एणाए \\
\hline
\end{tabular}




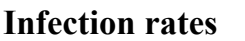

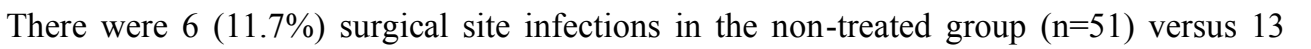

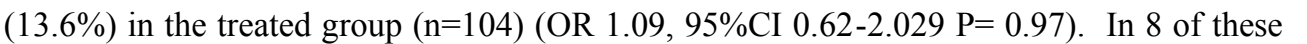

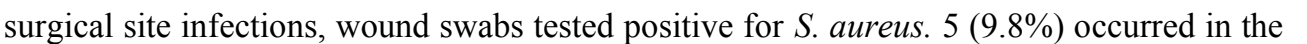
$\square \backslash$ treated group versus $3(2.2 \%)$ in the treated group (OR $0.37 ; 95 \% \mathrm{CI} 0.02 \square .39 ; \mathrm{P}=0.13$ )

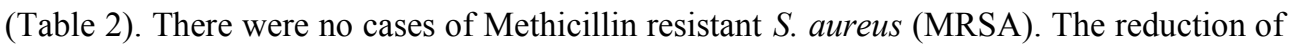

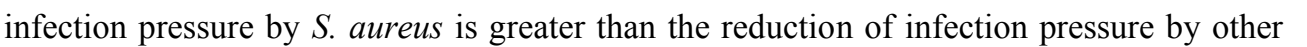
pathogens (exact maximum likelihood estimation; $\mathrm{OR}=0.0724 ; 95 \% \mathrm{CI}: 0.0010 .98 ; \mathrm{p}=$

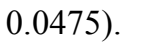

$\square$

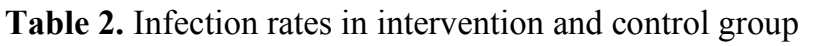

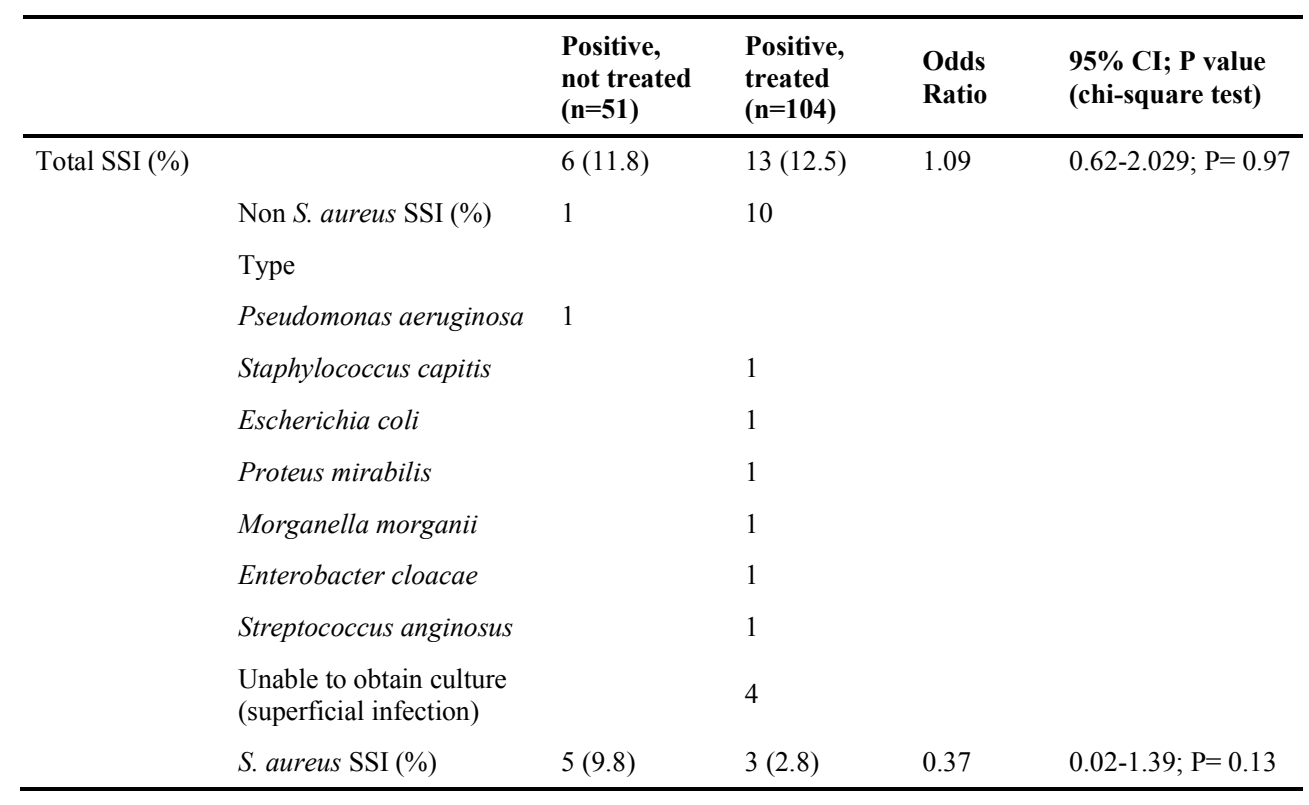




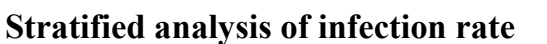

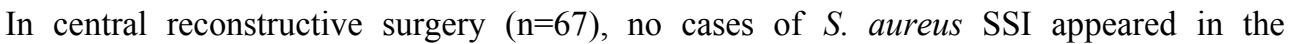

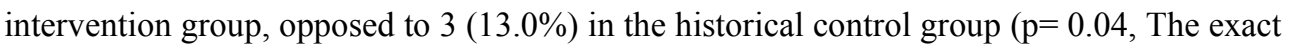

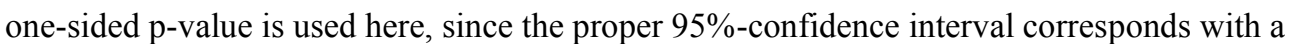

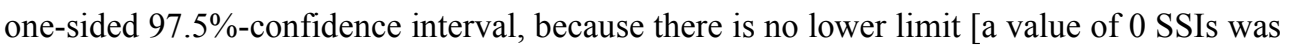

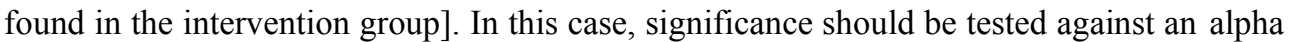

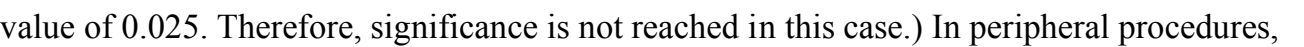

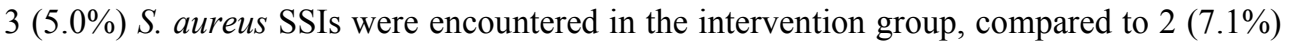

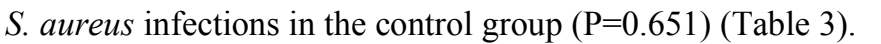

$\square$

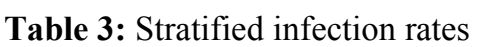

\begin{tabular}{|c|c|c|c|}
\hline पாயாயா & 四 & $\square$ & 四 \\
\hline \multirow{2}{*}{$\square$} & \multirow{2}{*}{$\square$} & \multirow{2}{*}{ 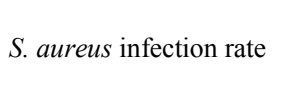 } & 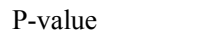 \\
\hline & & & 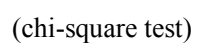 \\
\hline 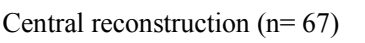 & 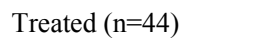 & 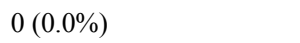 & पाणा \\
\hline$\sqcup$ & 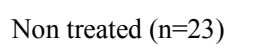 & पण口卄ा प & $\sqcup$ \\
\hline 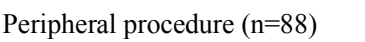 & पणाणाणाणा & 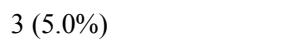 & पाणए \\
\hline$\sqcup$ & 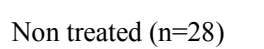 & पणाण प प & $\sqcup$ \\
\hline 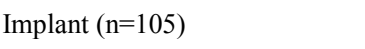 & 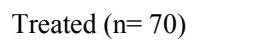 & 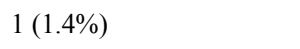 & एणाए \\
\hline$\sqcup$ & 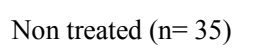 & 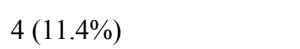 & $\sqcup$ \\
\hline 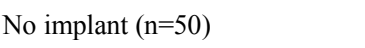 & 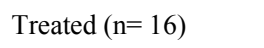 & पणाणा & पणाए \\
\hline 四 & 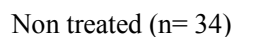 & एणाणा ए ए & 四 \\
\hline
\end{tabular}




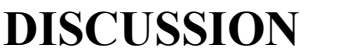

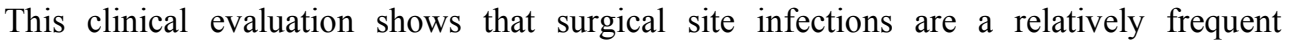

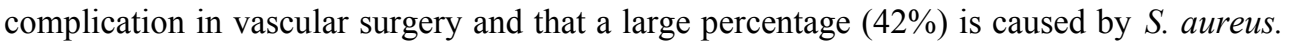

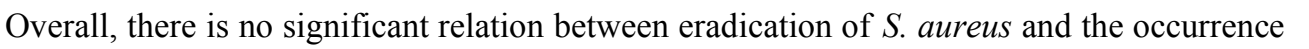

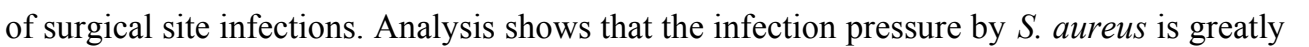

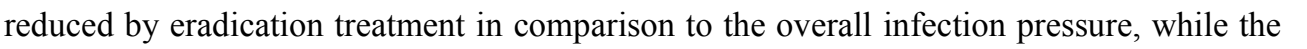

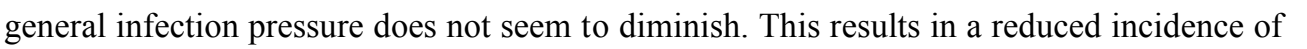

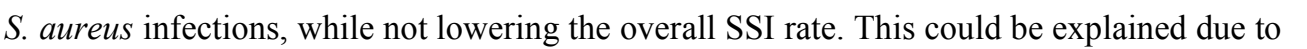

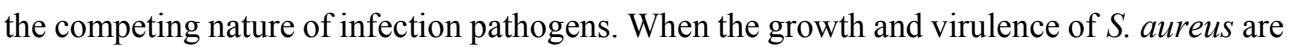

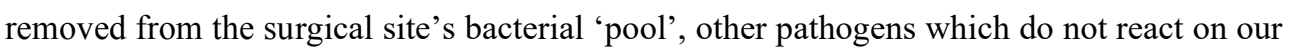

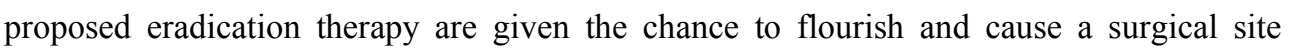
एणाणाणा

$\square$

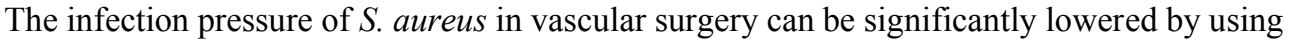

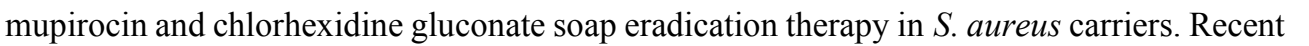

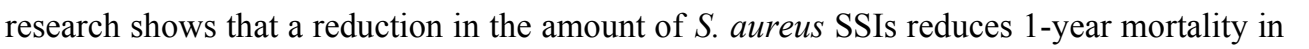

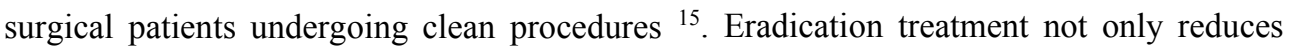

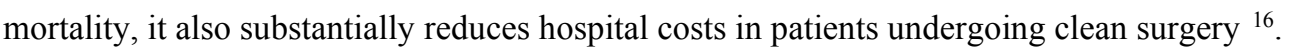

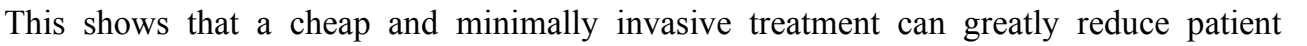

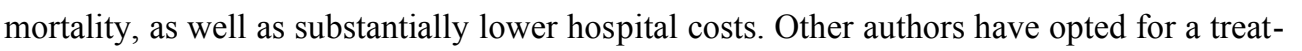

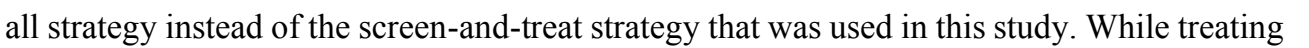

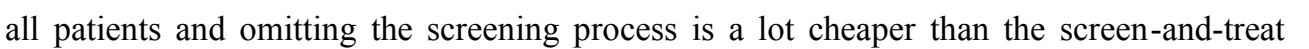

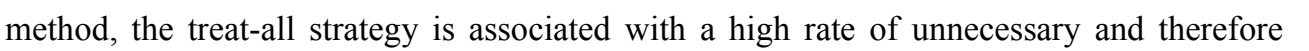

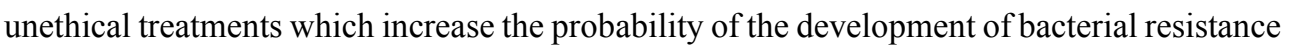
매맘

$\square$

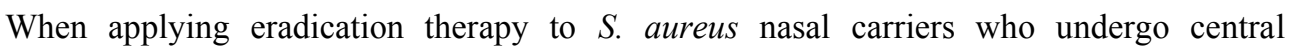

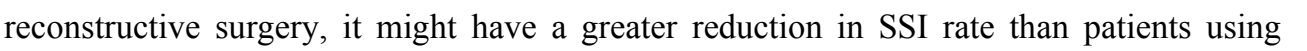

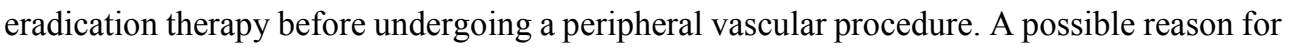

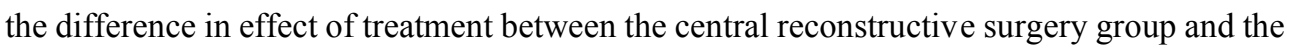

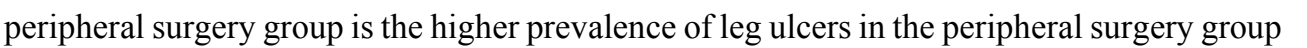

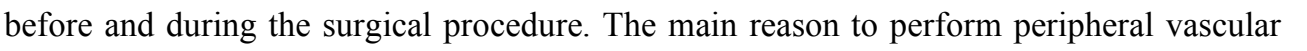

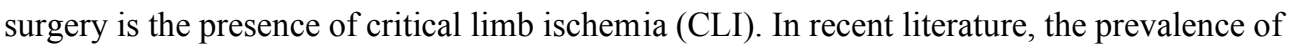

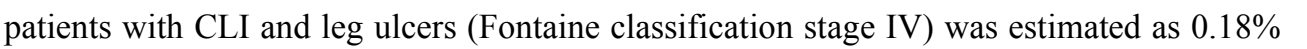

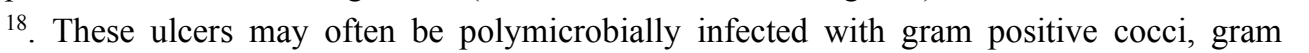

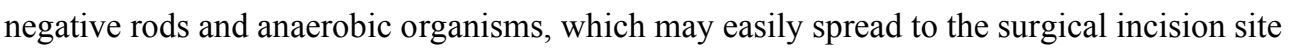

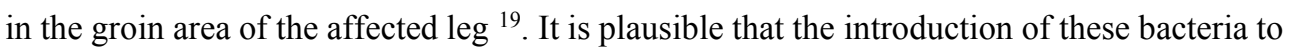

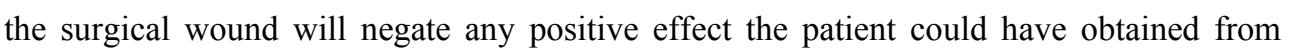

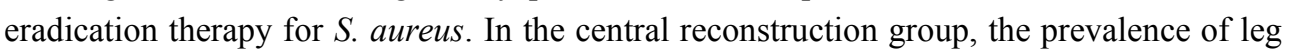




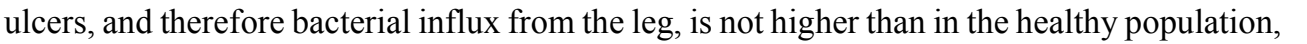

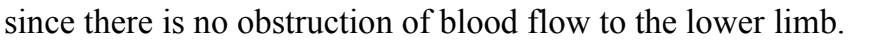

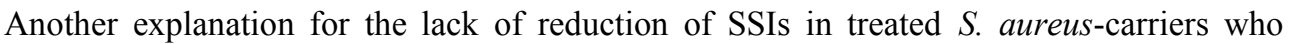
प

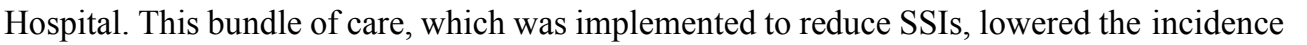
of SSIs in patients who underwent vascular surgery by $44 \%$ in two years' time (from $14.9 \%$

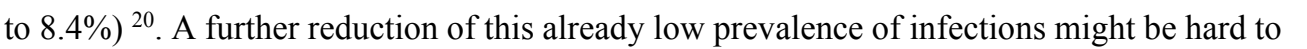
एाणाण

$\square$

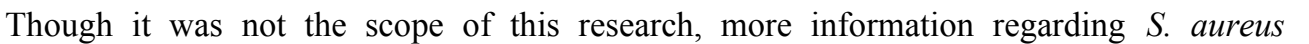

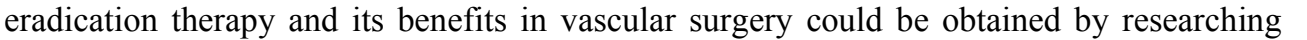

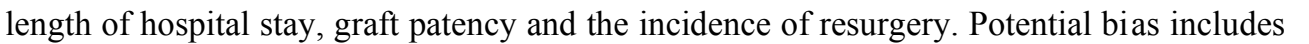

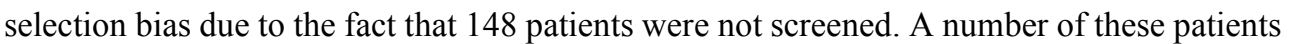

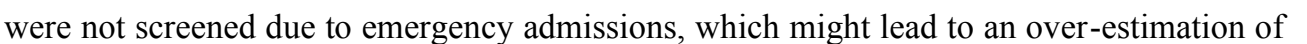
एणा

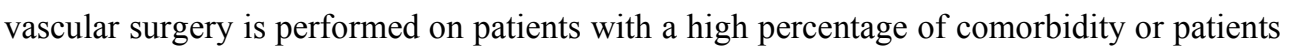

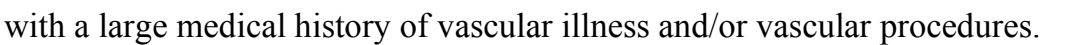
$\square$

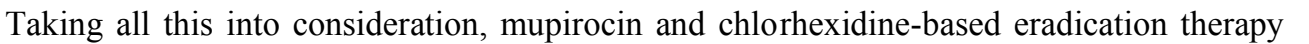

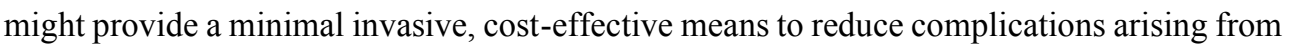

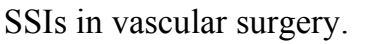




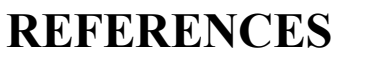

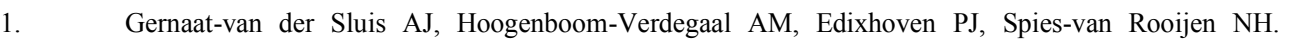

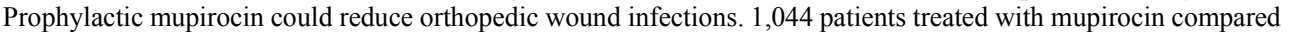

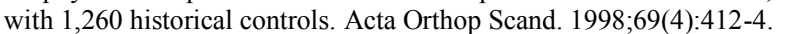

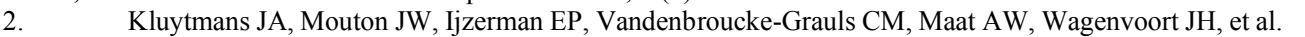

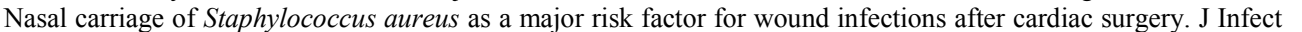
Dis. $1995 ; 171(1): 216 \square \square$

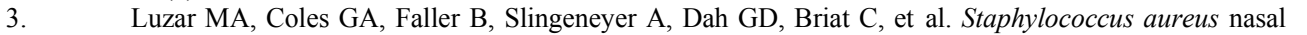
carriage and infection in patients on continuous ambulatory peritoneal dialysis. N Engl J Med. 1990;322(8):505 $\square$

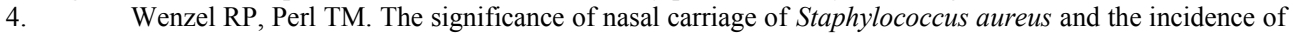

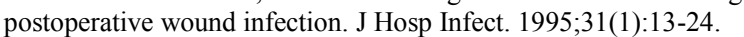

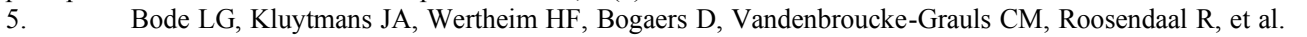

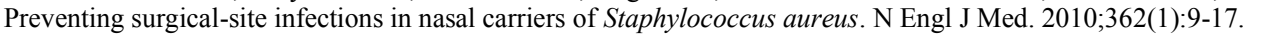

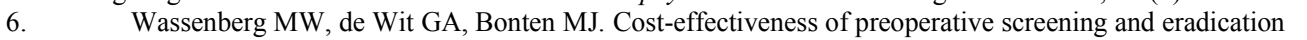

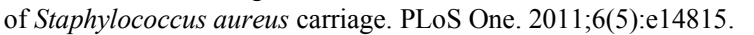

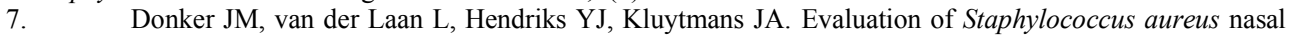
carriage screening before vascular surgery. PLoS One. 2012;7(6):e38127. $\square$

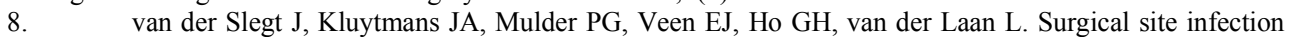

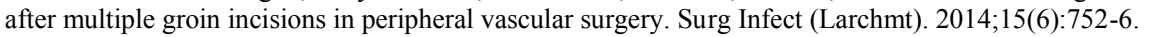

III van der Slegt J, Kluytmans JA, de Groot HG, van der Laan L. Treatment of surgical site infections (SSI)

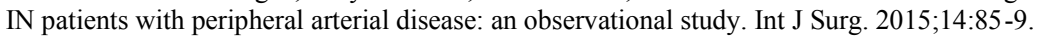

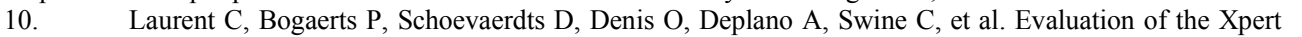

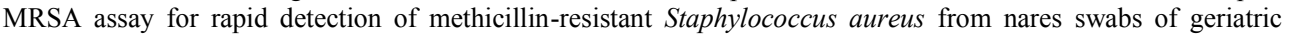

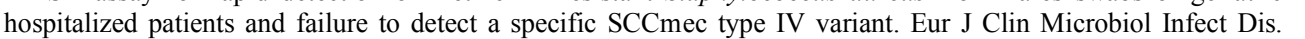

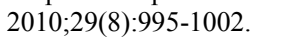

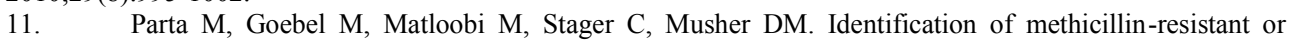

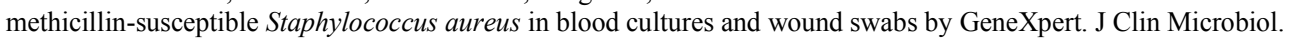
2009;47(5):1609 एाएा

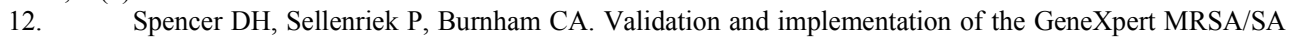
blood culture assay in a pediatric setting. Am J Clin Pathol. 2011;136(5):690

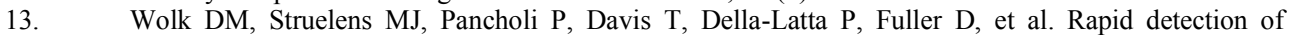

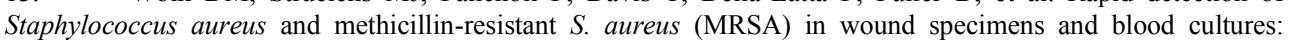

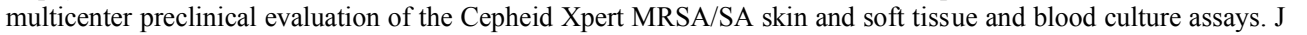
Clin Microbiol. 2009;47(3):823 $\square \square$

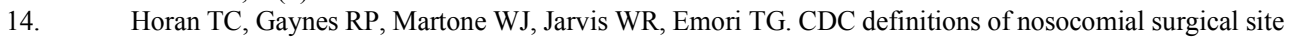

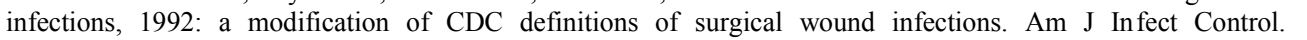
1992;20(5):271 एण

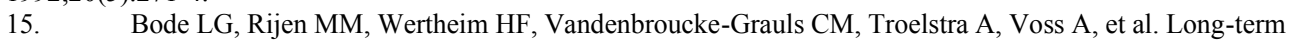
Mortality After Rapid Screening and Decolonization of Staphylococcus Aureus Carriers: Observational Follow $\amalg \longrightarrow$

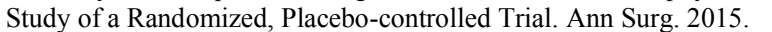

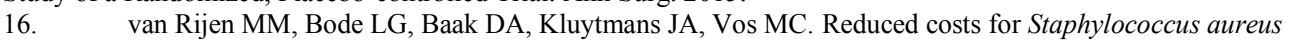

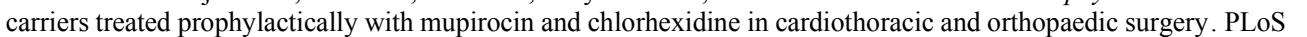
One. 2012;7(8):e43065. $\square$

17. Cookson BD. The emergence of mupirocin resistance: a challenge to infection control and antibiotic prescribing practice. J Antimicrob Chemother. 1998;41(1):11匹ा

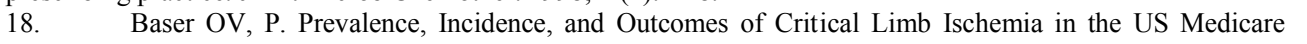
Population. Vascular Disease Management. 2013;10(2)(E26 E36). $\square$

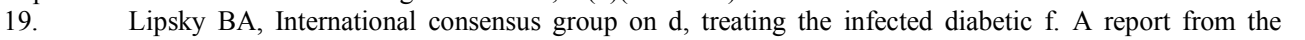

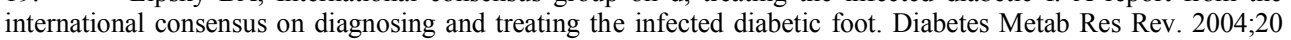
Suppl 1:S68 77. $\square$

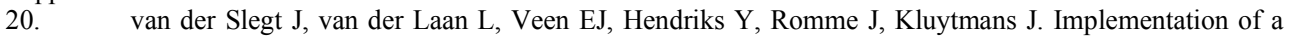

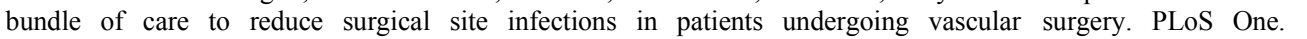
2013;8(8):e71566. $\square$

$\square$ 


$$
3
$$




\section{Chapter 3}

\section{Perioperative nasal eradication therapy prevents Staphylococcus aureus surgical site infections in aortoiliac surgery}

Langenberg JCM, Kluytmans JAJW, Mulder PGH, Romme J, Ho GH, van der Laan L. 


\section{Chapter 3}

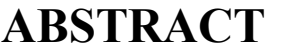

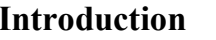

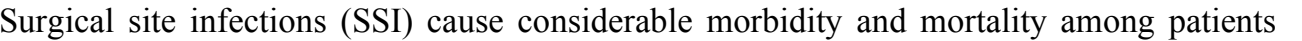

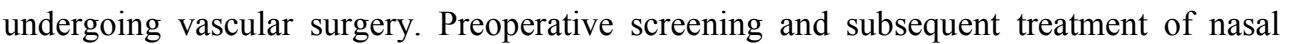

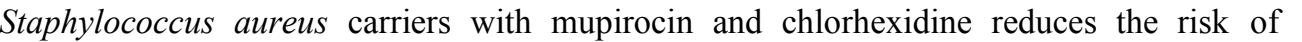

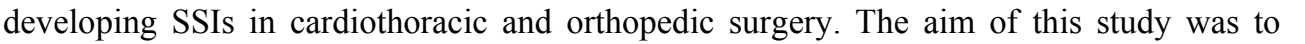

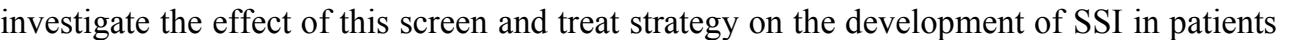

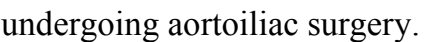

\section{$\square \square \square \square \square \square$}

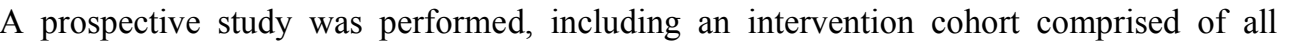

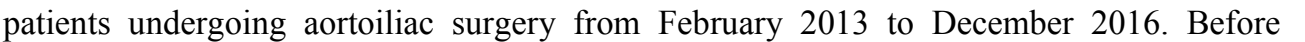

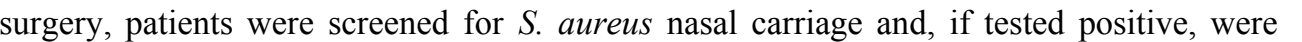

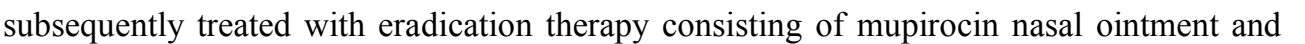

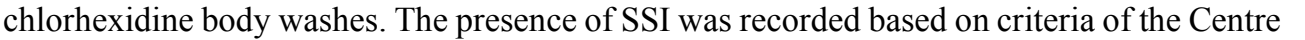

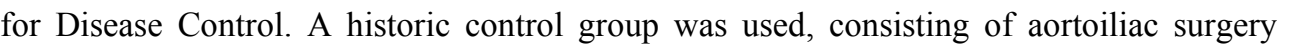

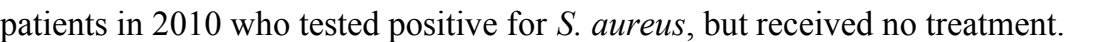

\section{$\square \square\|\square\| \square$}

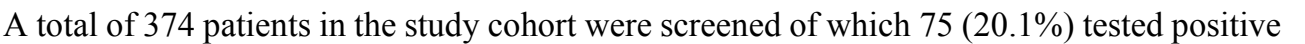

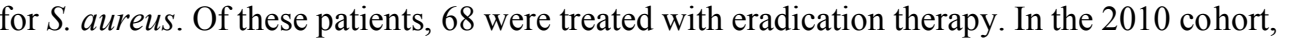

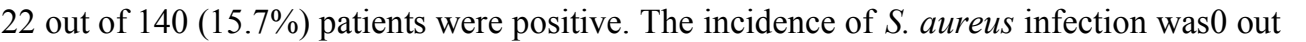

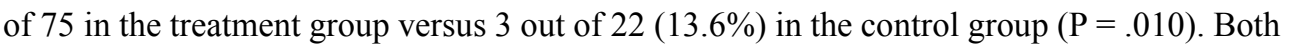

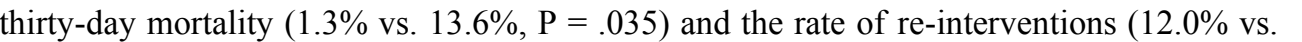

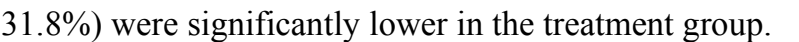

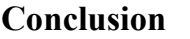

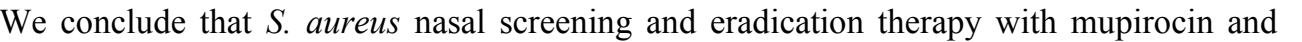

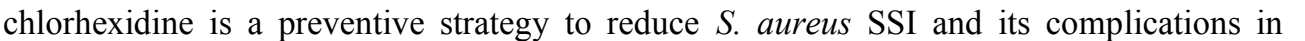

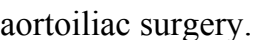

$\square$ 


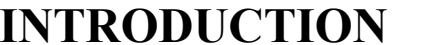

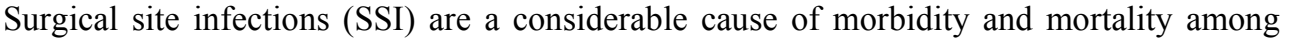

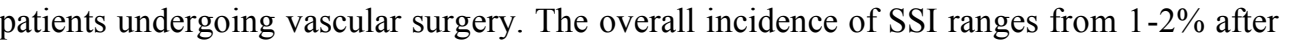

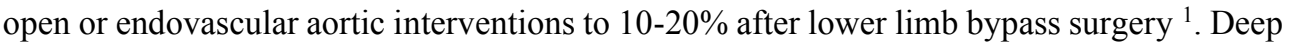

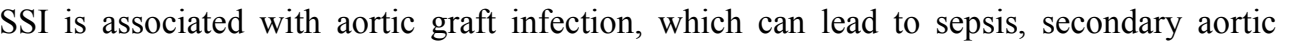

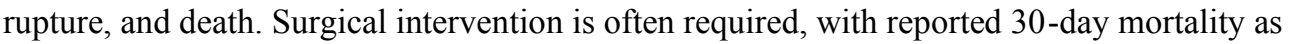
एणाएणमएण

$\square$

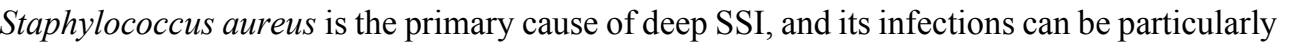

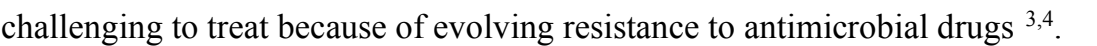

$\square$

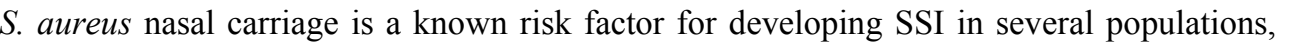

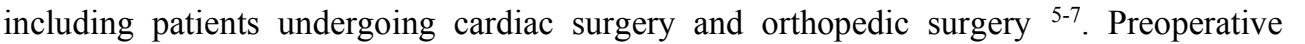

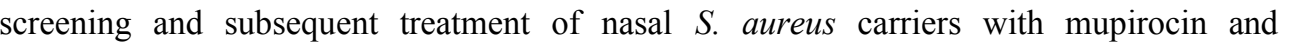

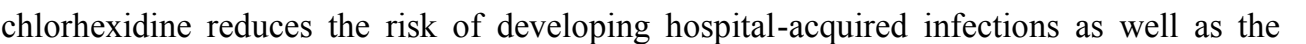

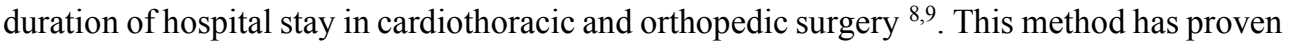

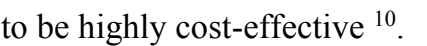

$\square$

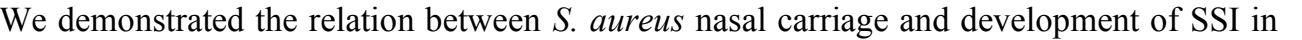

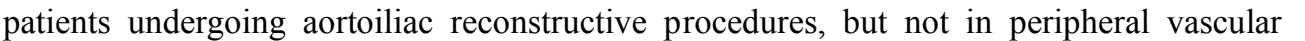

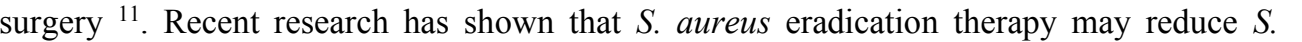

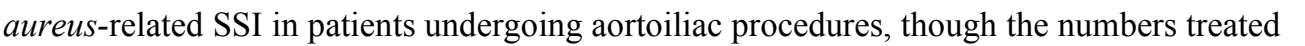

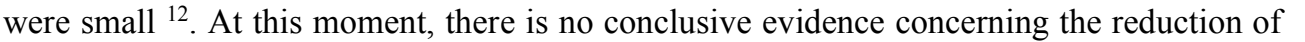

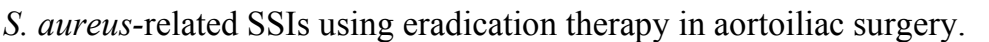

$\square$

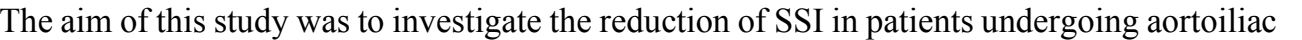

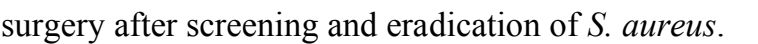

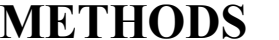

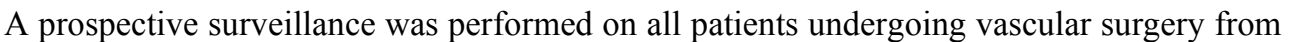

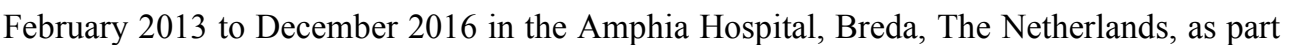

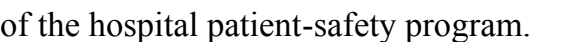

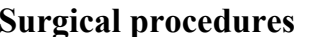

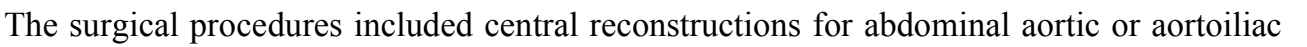

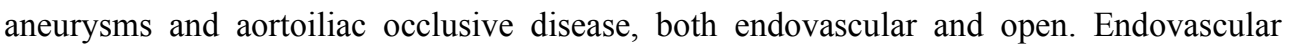

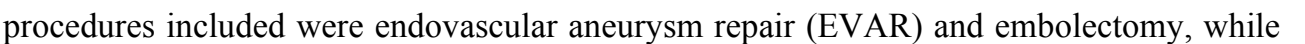

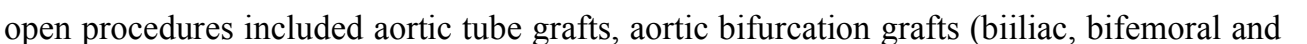




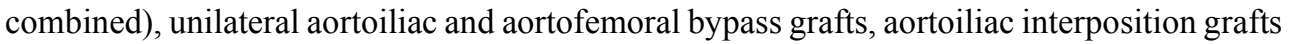

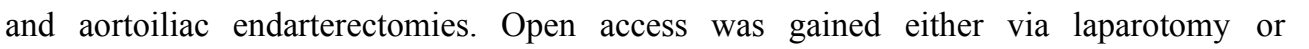

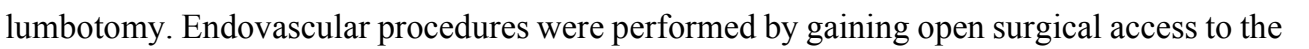

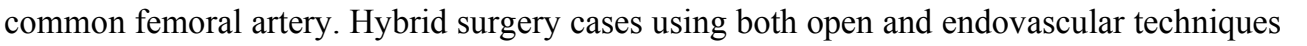

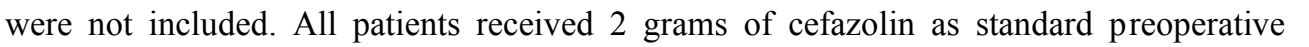

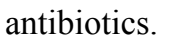

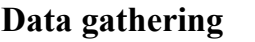

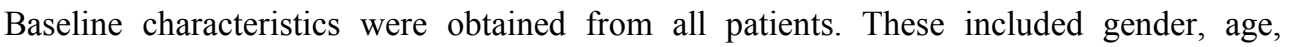

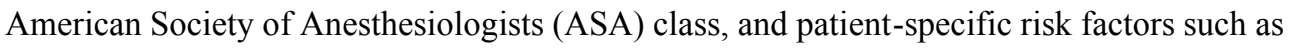

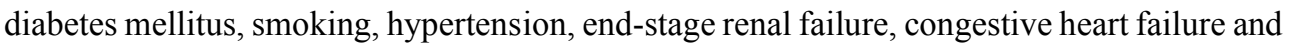

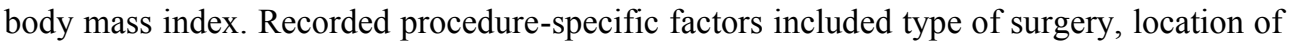

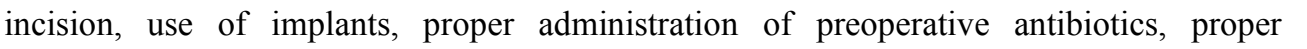

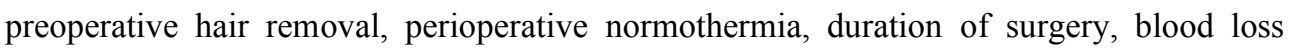

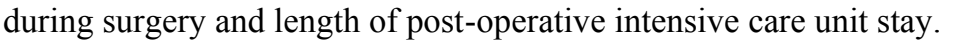

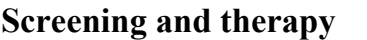

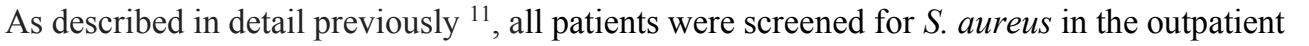

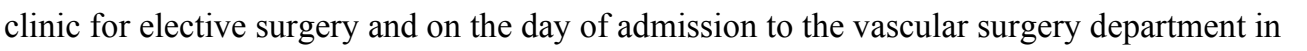

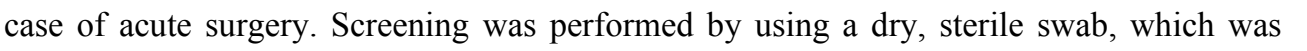

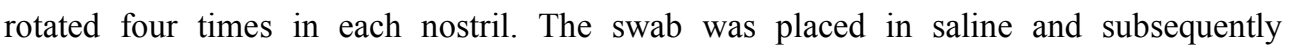

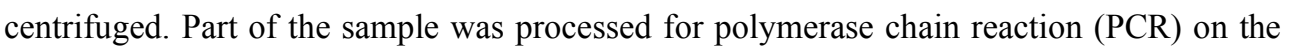

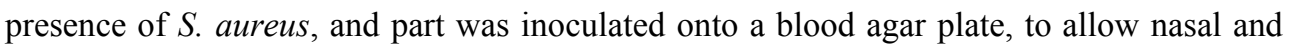

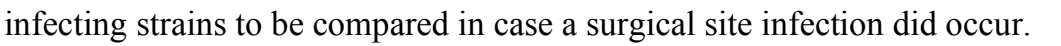

$\square$

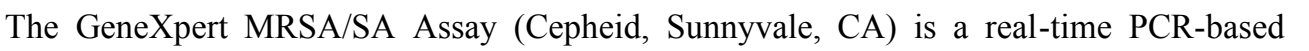

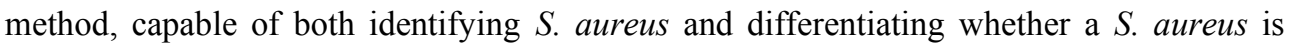

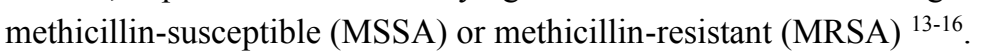
$\square$

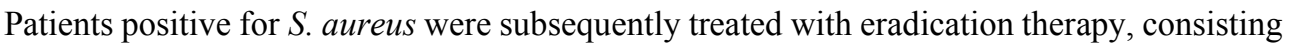

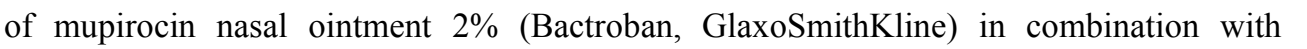

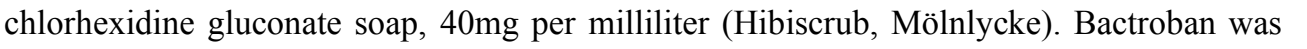

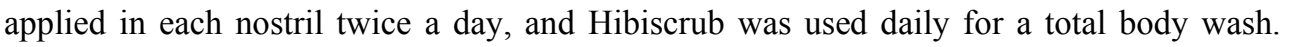

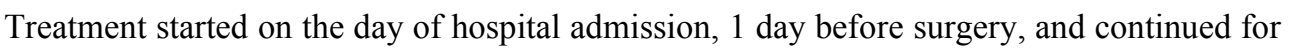

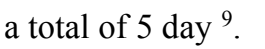

$\square$

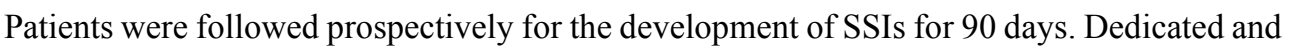

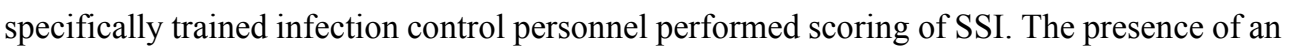

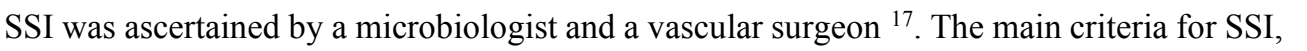

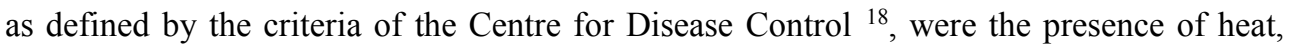




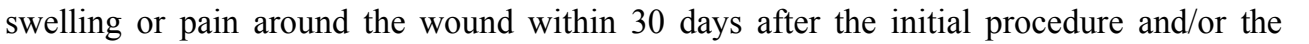

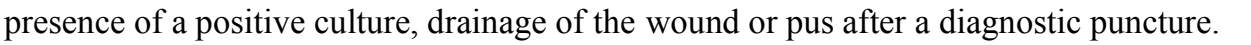

$\square$

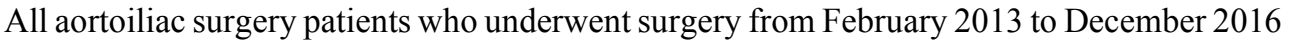

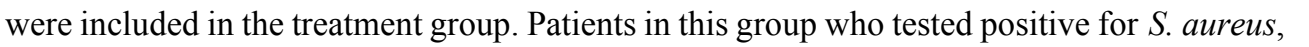

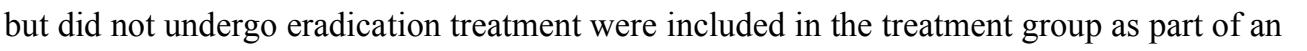

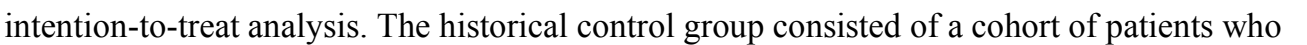

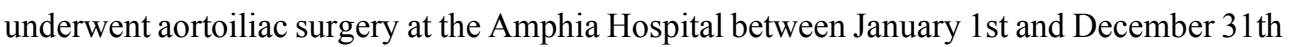

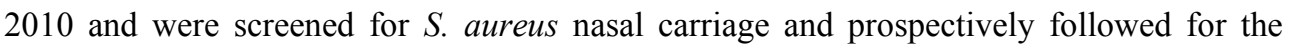

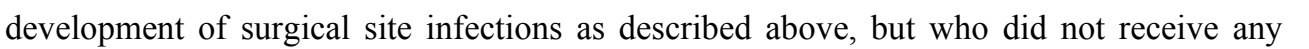

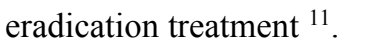

$\square$

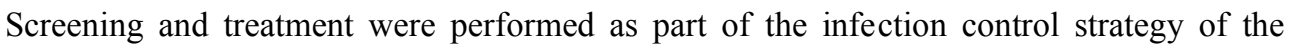

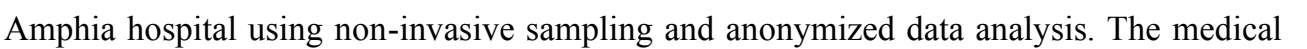



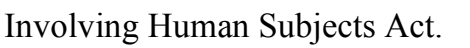

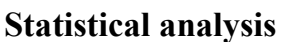

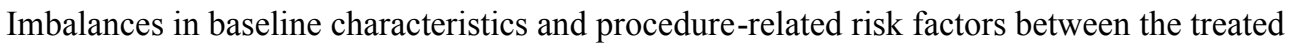

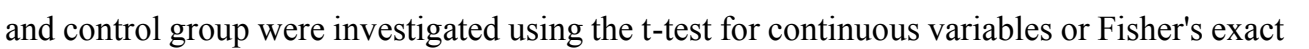

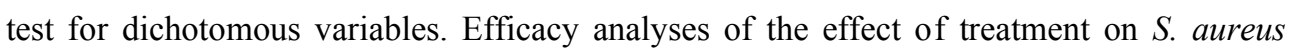

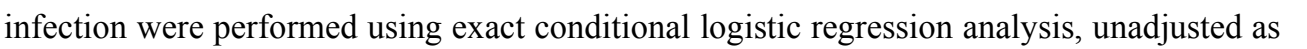

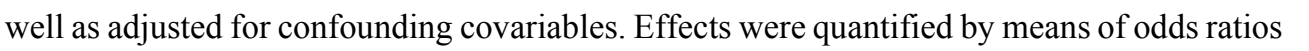

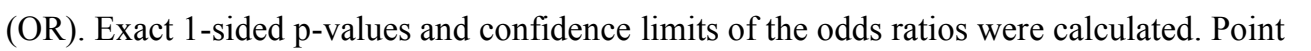

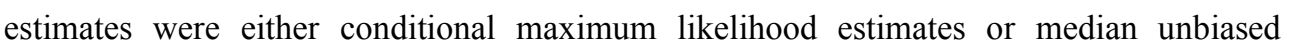

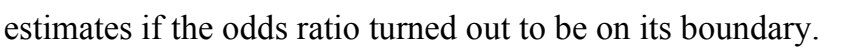

$\square$

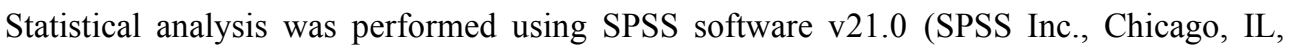

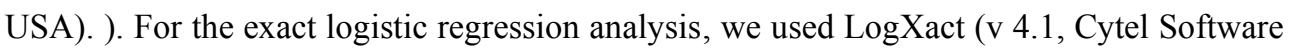

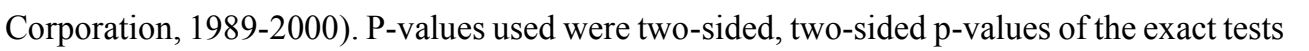

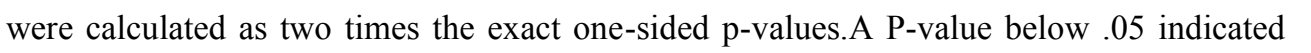

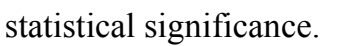

$\square$

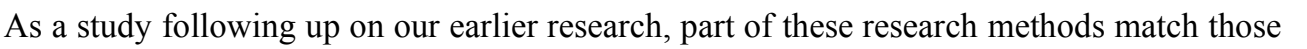

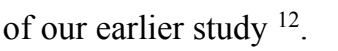




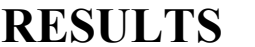

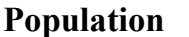

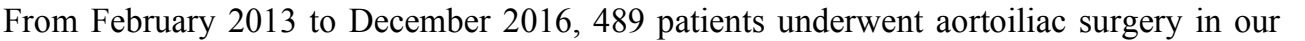

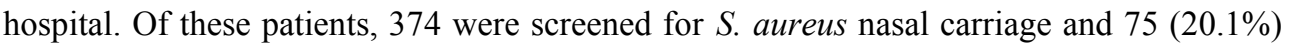

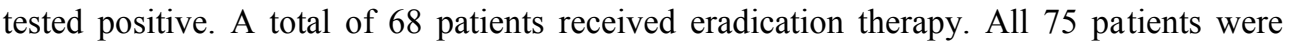

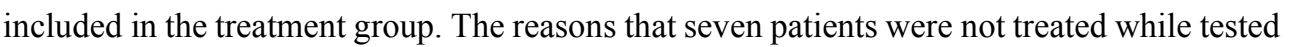

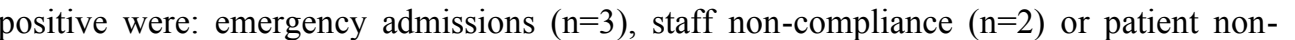

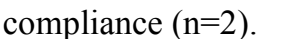

$\square$

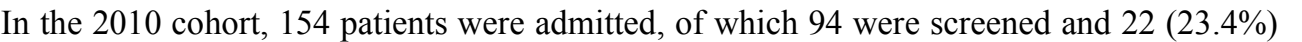

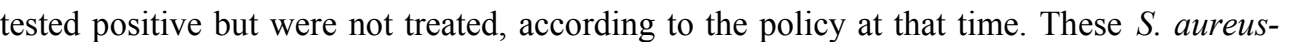

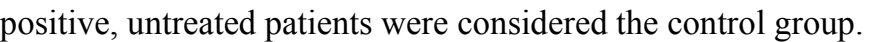

$\square$

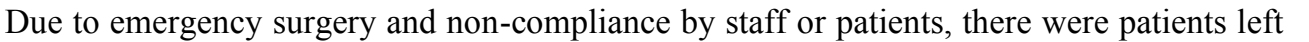

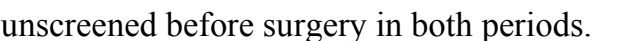

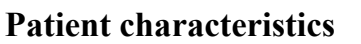

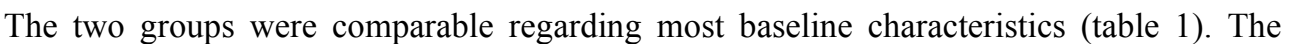

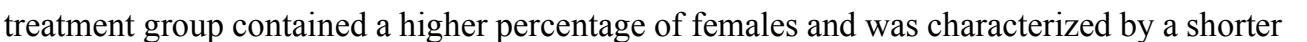

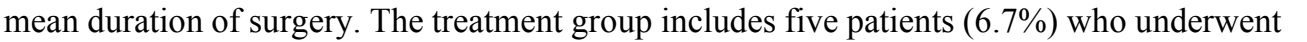

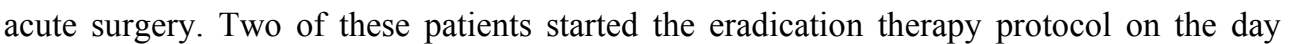

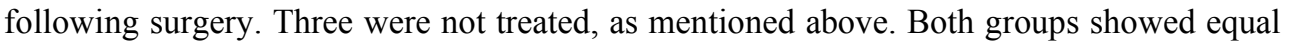

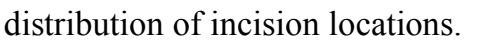

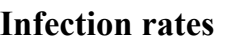

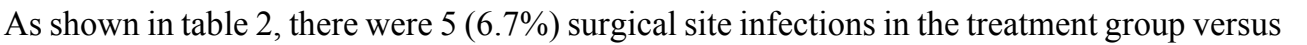

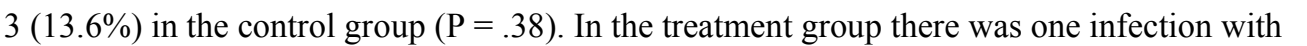

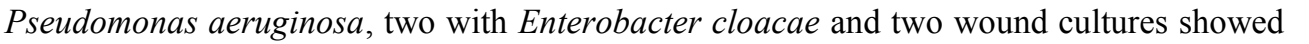

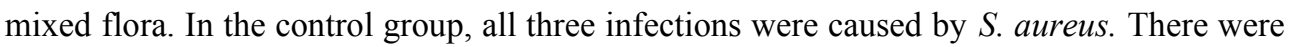

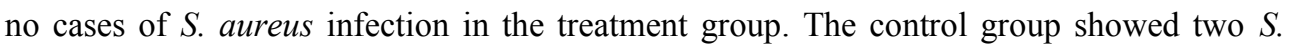

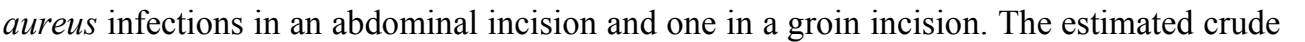

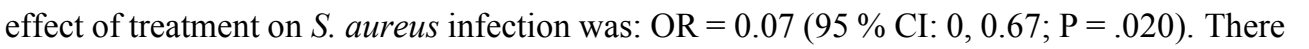

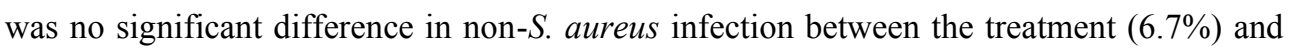

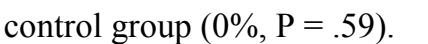




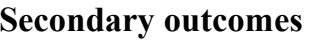

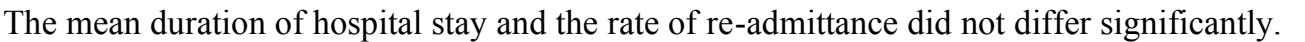

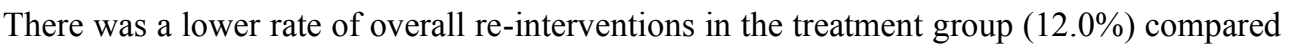

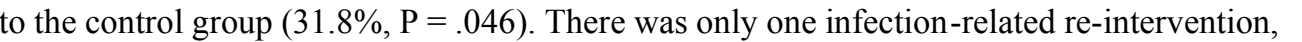

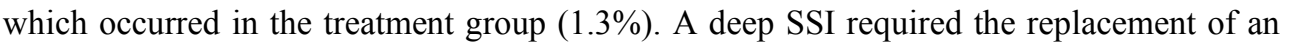
ए

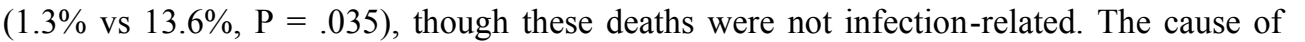

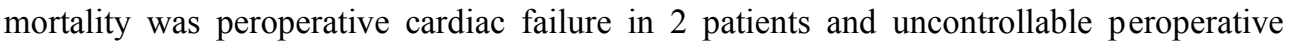

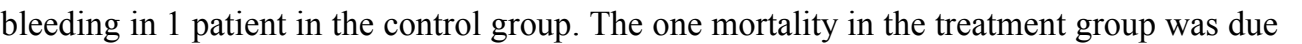

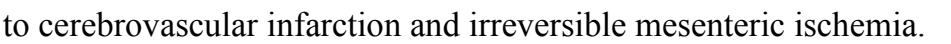

$\square$

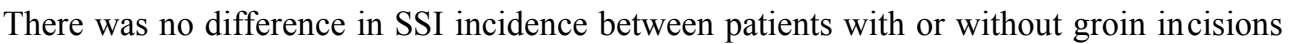

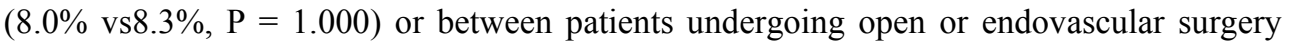

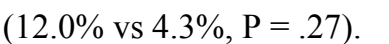

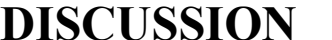

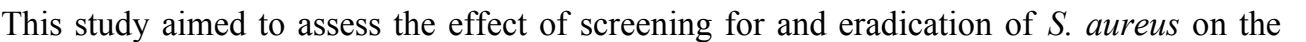

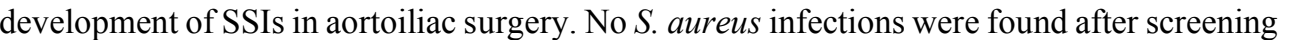

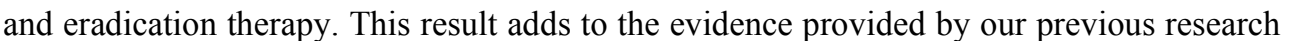

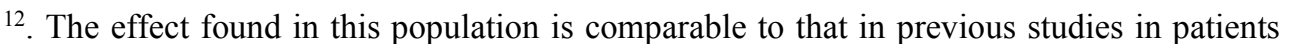

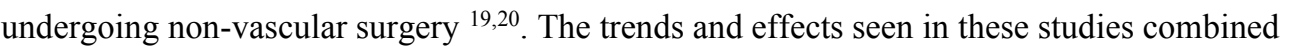

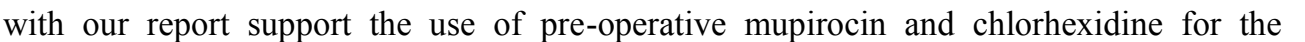
prevention of SSI in aortoiliac surgery. The World Health Organization's Global Guideline $\square$

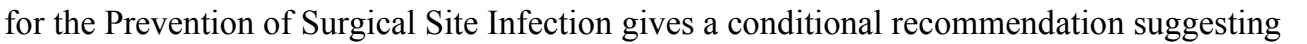
प

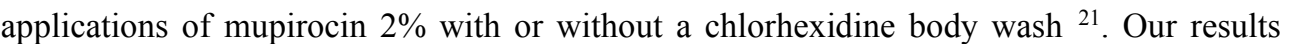

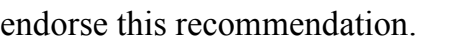


Chapter 3

\begin{tabular}{|c|c|c|c|}
\hline 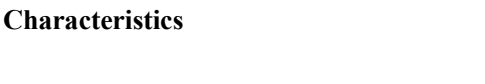 & 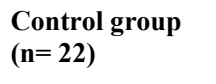 & 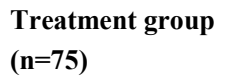 & $\square \square \square \square \square$ \\
\hline 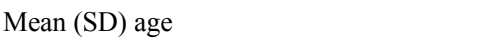 & पणमणणमाण & पणाणाण & पाणाण \\
\hline 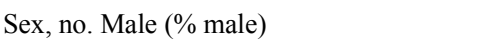 & एवाणाण & एवाणाण & पणाणाप \\
\hline 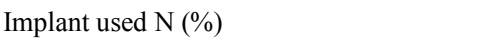 & पाणाणाप & पाणाणाप & पणाणाप \\
\hline 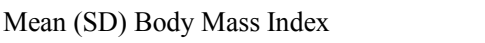 & पाणाणा & பாவாயா & पाणाण \\
\hline ASA Score $\geq 3(\%) \square$ & पाणाणा & पाणाणा & पणाणाए \\
\hline 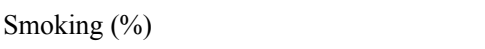 & पाणाणा & पाणाणाण & पणाणाण \\
\hline 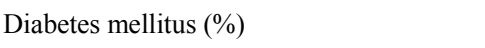 & 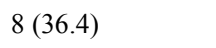 & एवाणाण & पणमाण \\
\hline 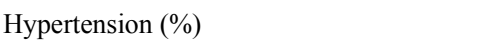 & पाणाणा & एवाणाण & पणाणाप \\
\hline 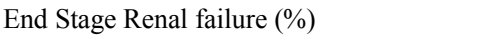 & पाणाणा & पण口णाण & पामाप्य \\
\hline 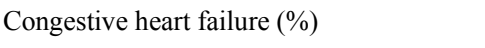 & पणाणाप & पणाणाए & एणाएा \\
\hline 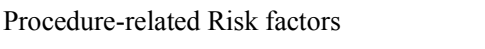 & $\square$ & $\square$ & $\square$ \\
\hline 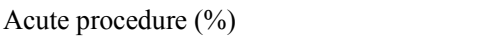 & 미 & 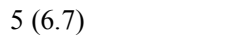 & पामाप्य \\
\hline 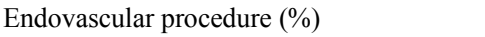 & पाणा山 & पाणाए & एणाएण \\
\hline 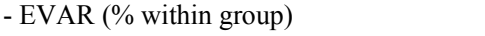 & $\square \square \square \square$ & एवाणा & \\
\hline 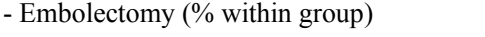 & & 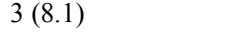 & \\
\hline 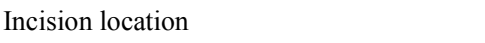 & $\square$ & $\square$ & पणमाप \\
\hline 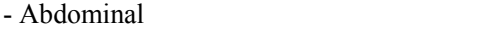 & 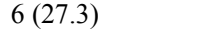 & $\square \mathrm{m} 1 \mathrm{~m}$ & \\
\hline पण口冋口卄 & पा山ा山ा & एाणाणा & \\
\hline 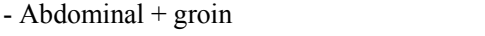 & 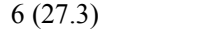 & पाणा山ा & \\
\hline 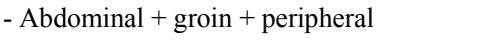 & $\square$ & 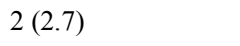 & \\
\hline 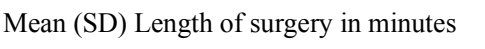 & पाणाणा & एाणाण & पणाणाप \\
\hline 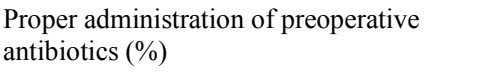 & पाणाणाप & पाणाणाप & पामाणा \\
\hline 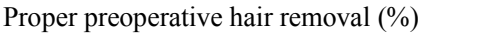 & 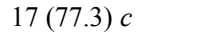 & 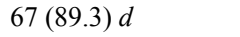 & पामापा \\
\hline 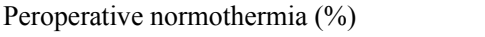 & 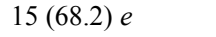 & 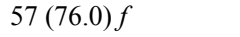 & पणाणाए \\
\hline
\end{tabular}

\section{$\square$ Fisher's Exact Test $\square$}

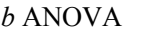

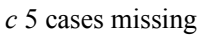

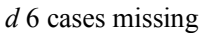

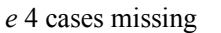

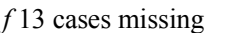




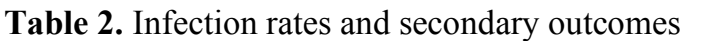

\begin{tabular}{|c|c|c|c|}
\hline$\square$ & 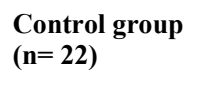 & 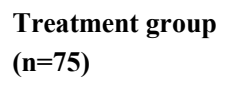 & $\begin{array}{l}\text { पाणाणा } \\
\square\end{array}$ \\
\hline 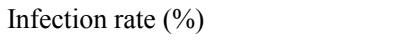 & एवाणाए & 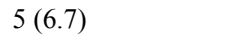 & 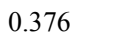 \\
\hline 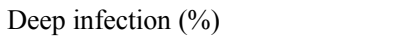 & $\square$ & पण口卄ाण & 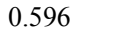 \\
\hline 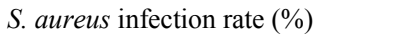 & पाणाणा & $\square$ & पाणाए \\
\hline 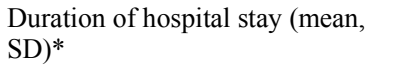 & पणाणाणाप & पणाणमाणाए & 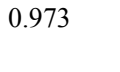 \\
\hline 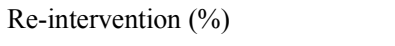 & पाणाणा & पण口卄ाण & पण1ए \\
\hline 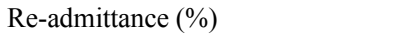 & एणाणाய & पाणा山ा & $\square ण 1 \square$ \\
\hline 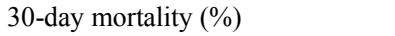 & एण口冋ाए & एणाण & 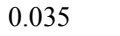 \\
\hline
\end{tabular}

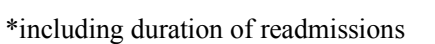

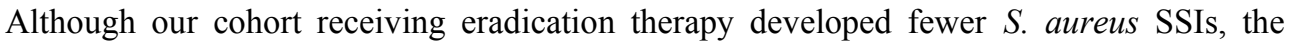

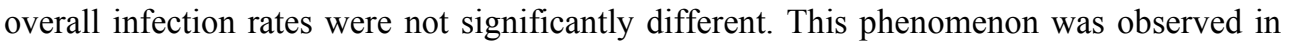

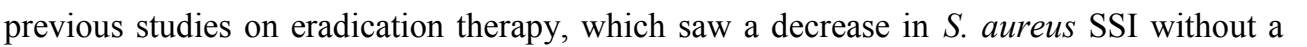

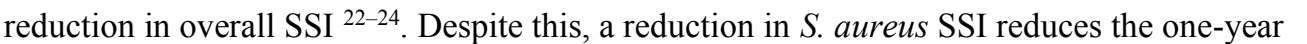

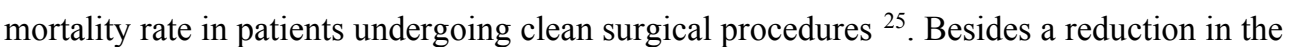

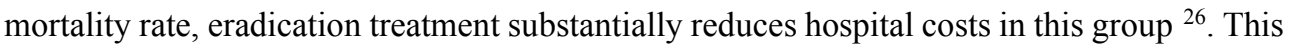

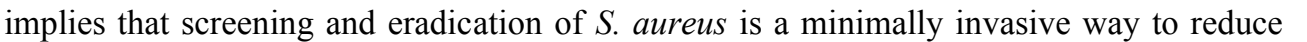

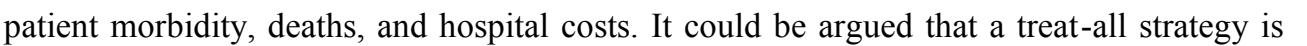

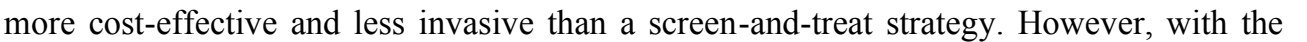

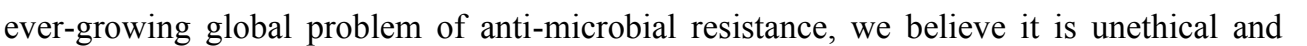

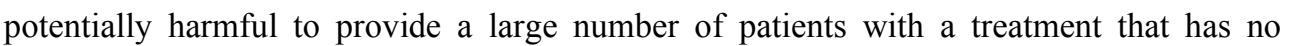

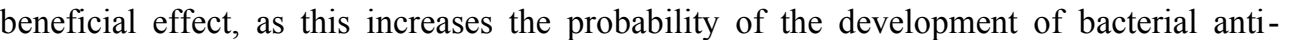

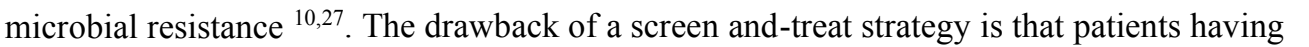
प

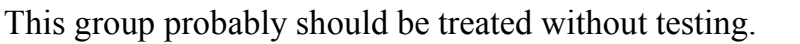




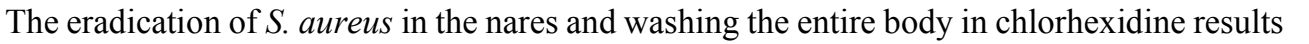
प

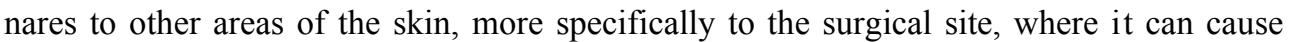
पाणाणाएा

$\square$

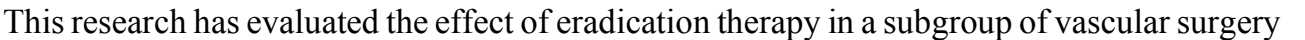

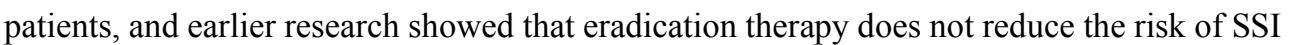
ए

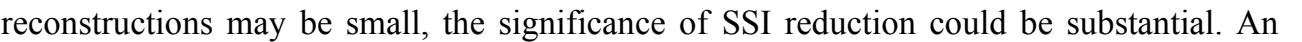

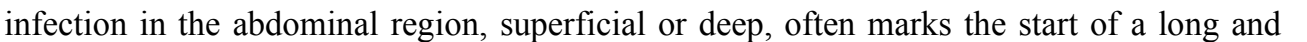

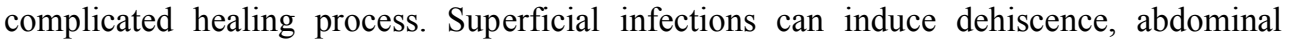

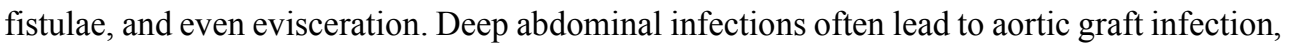

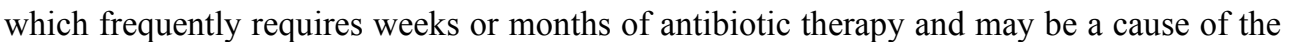

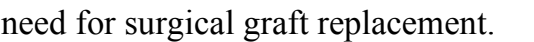

$\square$

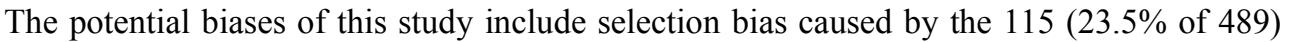

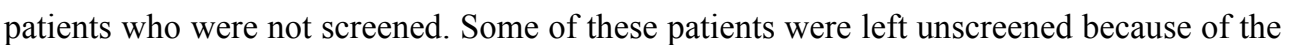

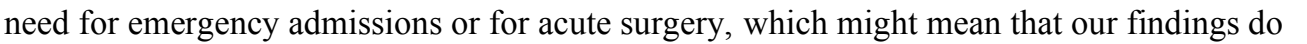

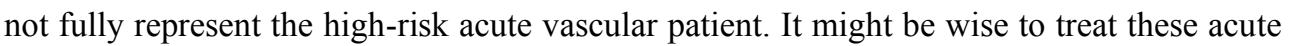

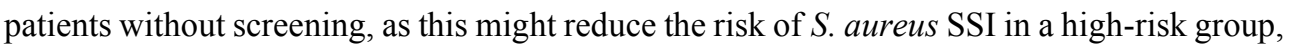

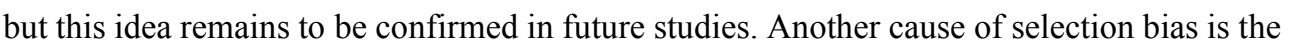

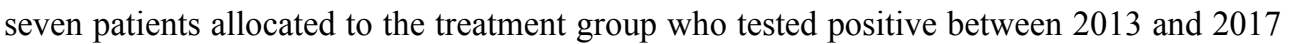

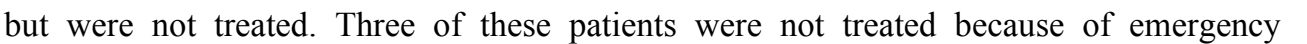
$\square \square \square \| \square \mid$ with immediate surgery; the other four had no apparent reasons treatment was

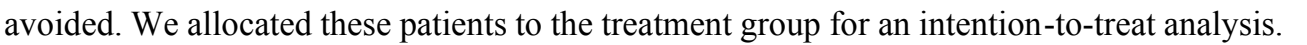

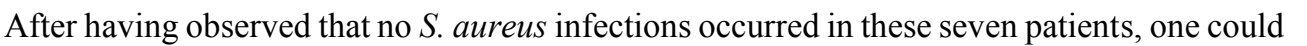

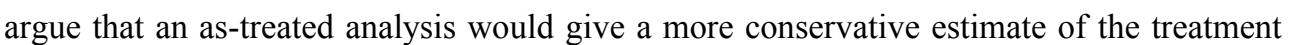

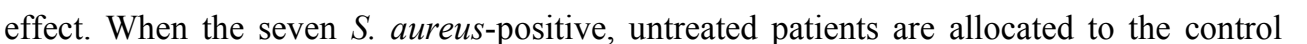

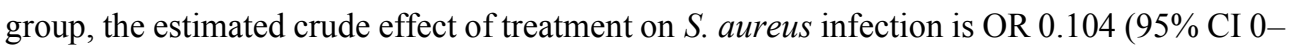

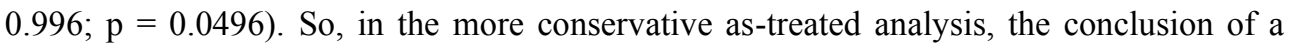

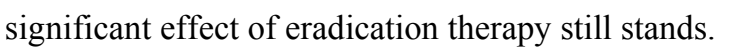

$\square$

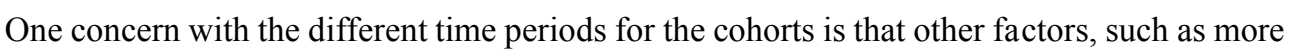

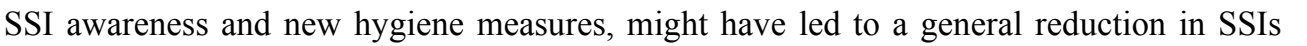

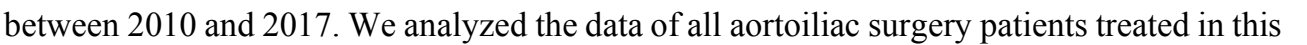

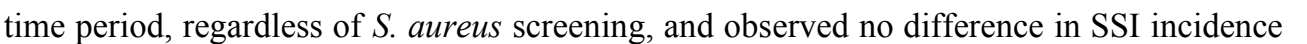
between patients treated in 2010 (nine of $141 ; 6.4 \%$ ) or after 2013 (26 of 488; 5.3\%; p =

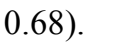

$\square$

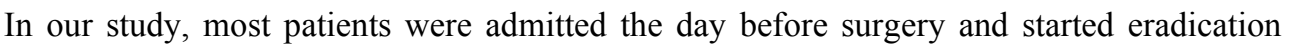

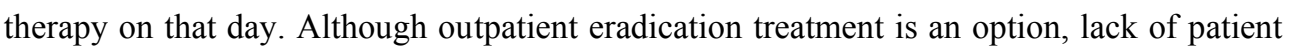




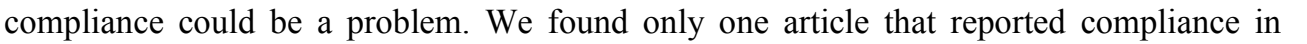

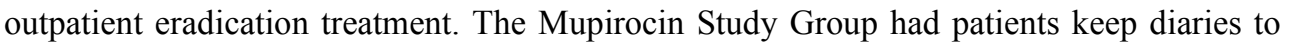

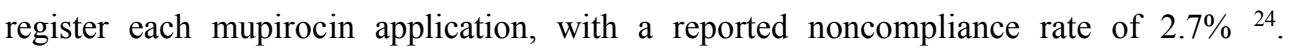

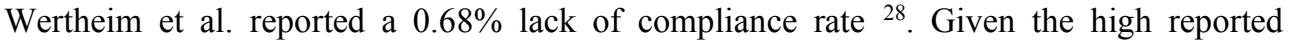

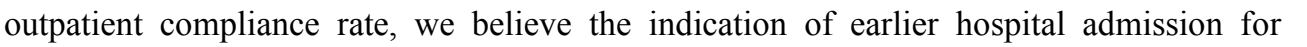

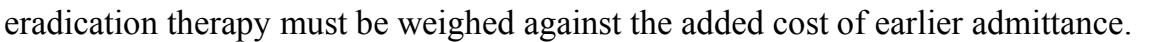

$\square$

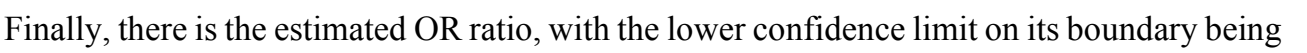

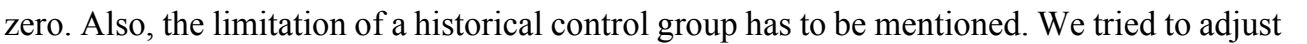

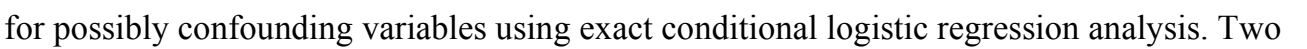

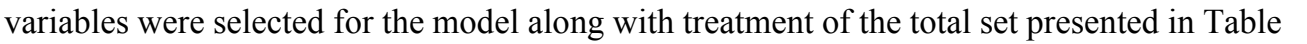

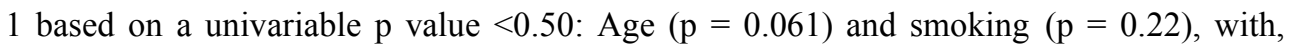

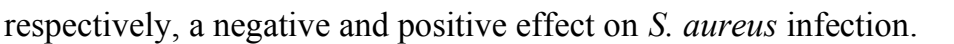

$\square$

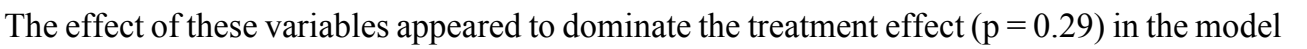

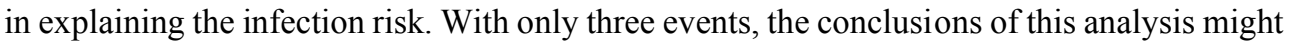

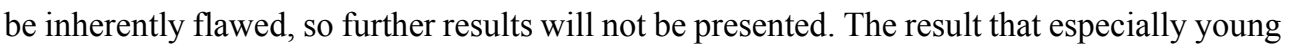

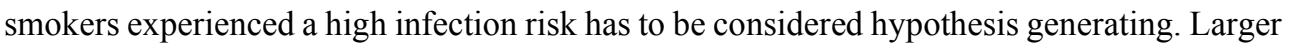

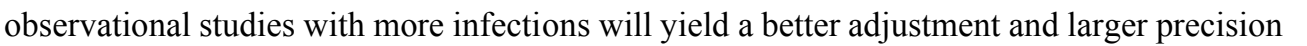

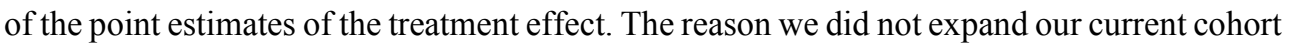

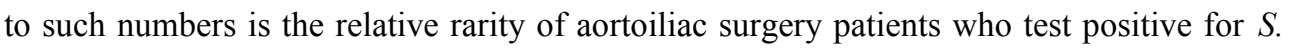

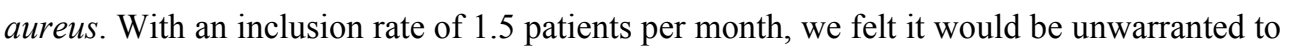

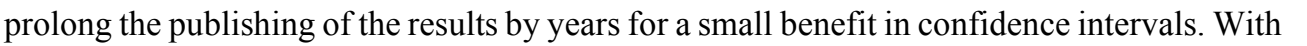

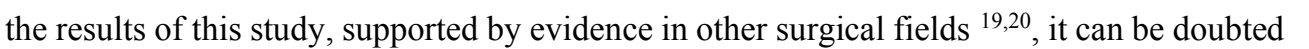

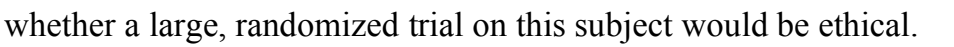

$\square$

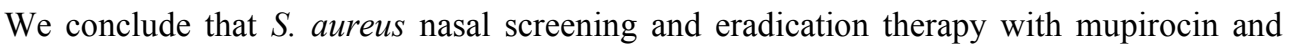

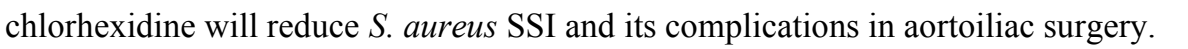




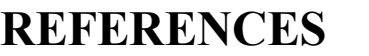

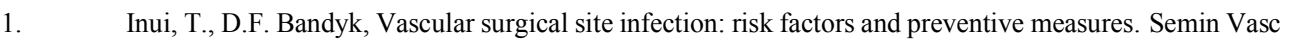

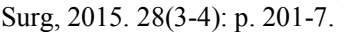

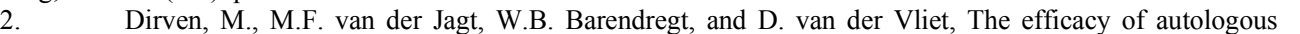

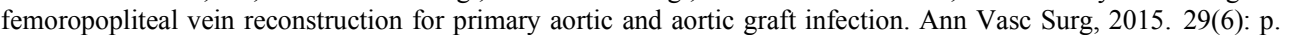
पामाणा

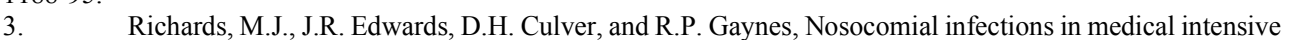

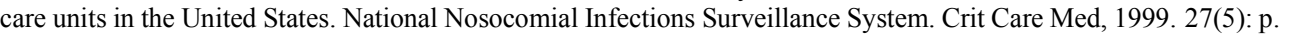
प11णाW

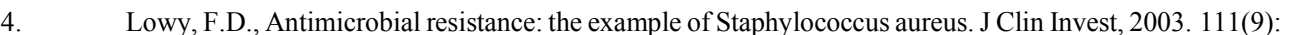
पाणापापाप

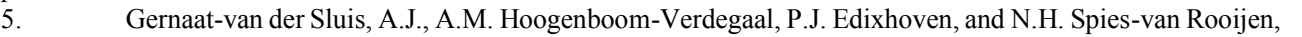

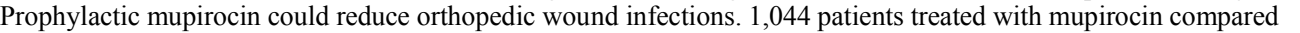

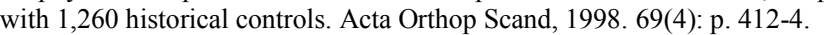

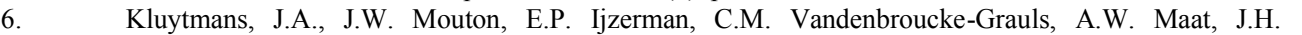

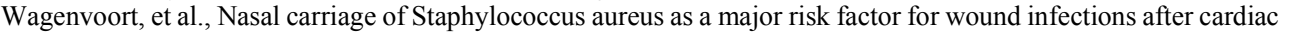

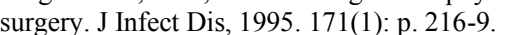

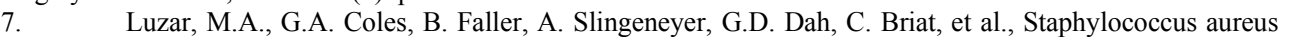
प I पालाणाप

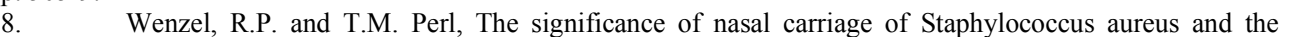

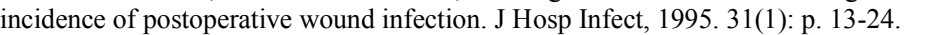

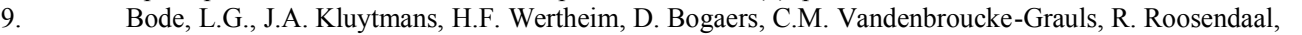

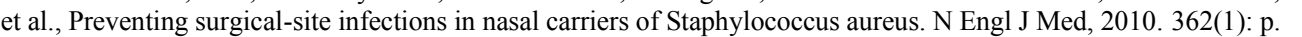
पाIII

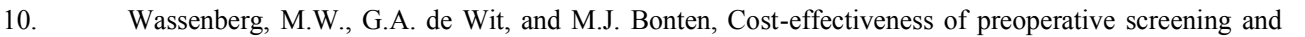

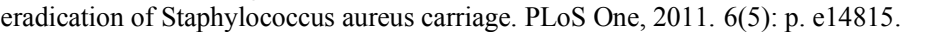

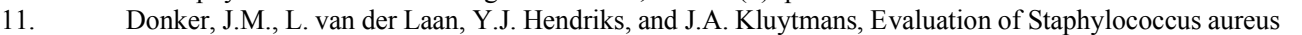

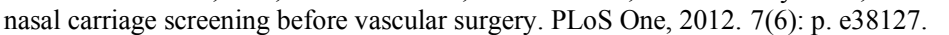

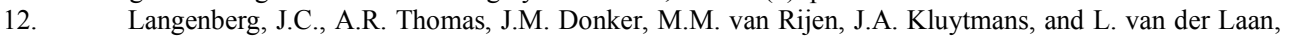

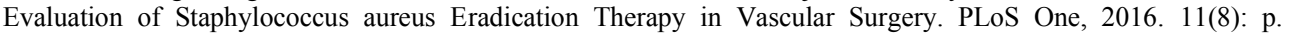

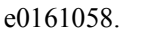

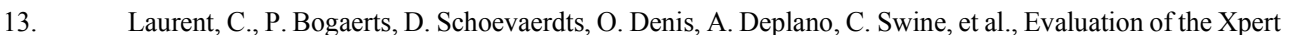

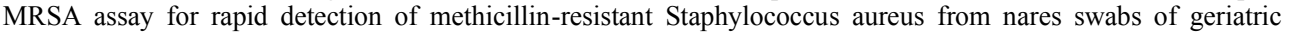

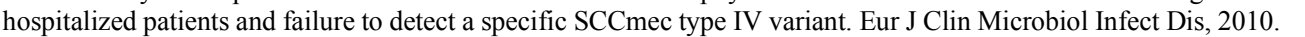
पापापायापाताप

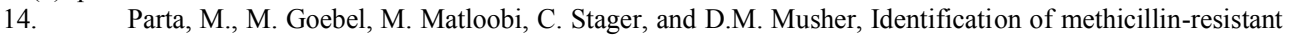

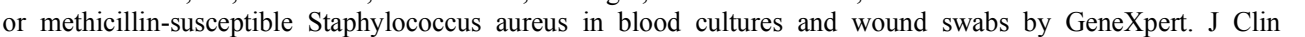

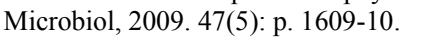

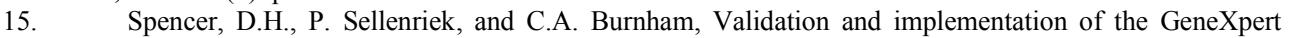

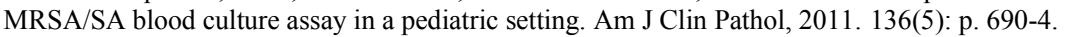

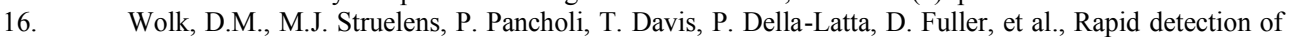

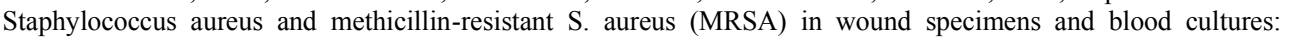

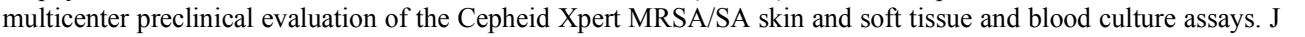

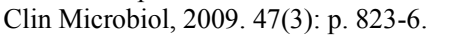

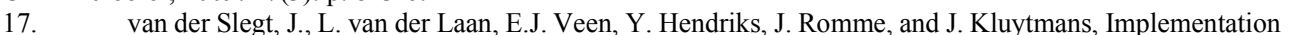

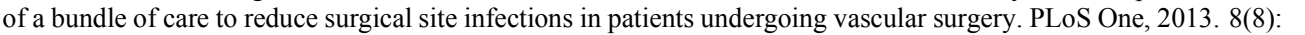
पाIगापा

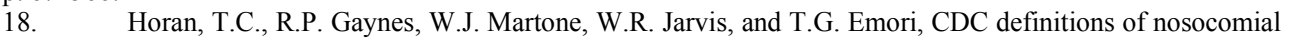

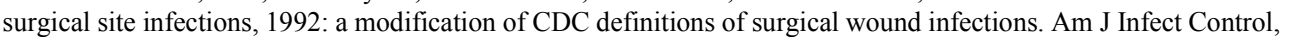

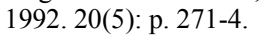

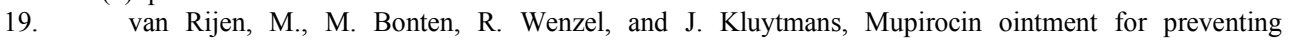

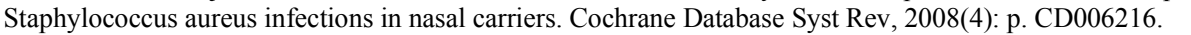

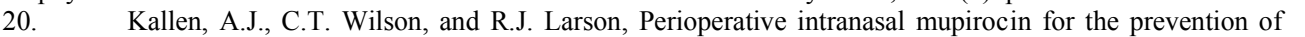

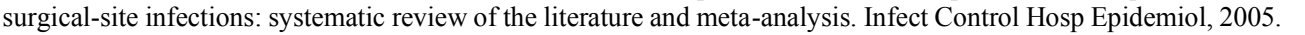

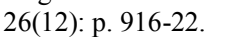

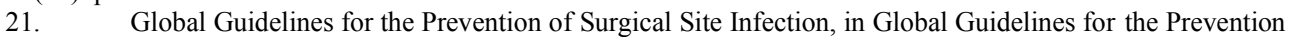

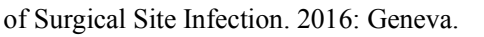


Perioperative nasal eradication therapy prevents Staphylococcus aureus surgical site infections in aortoiliac surgery

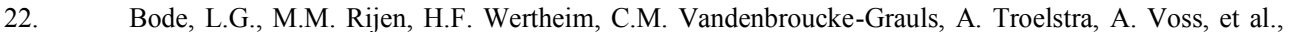

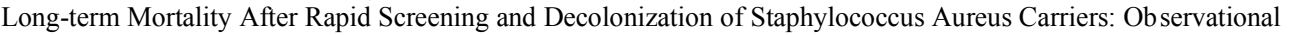

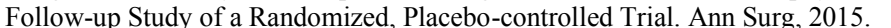

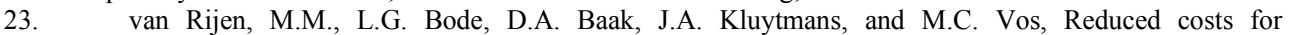

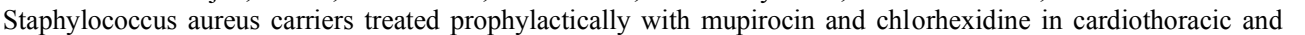

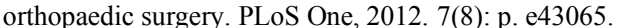

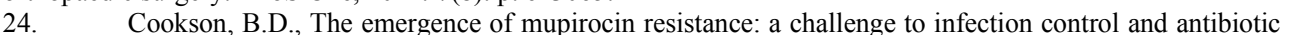

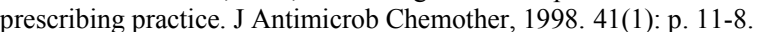




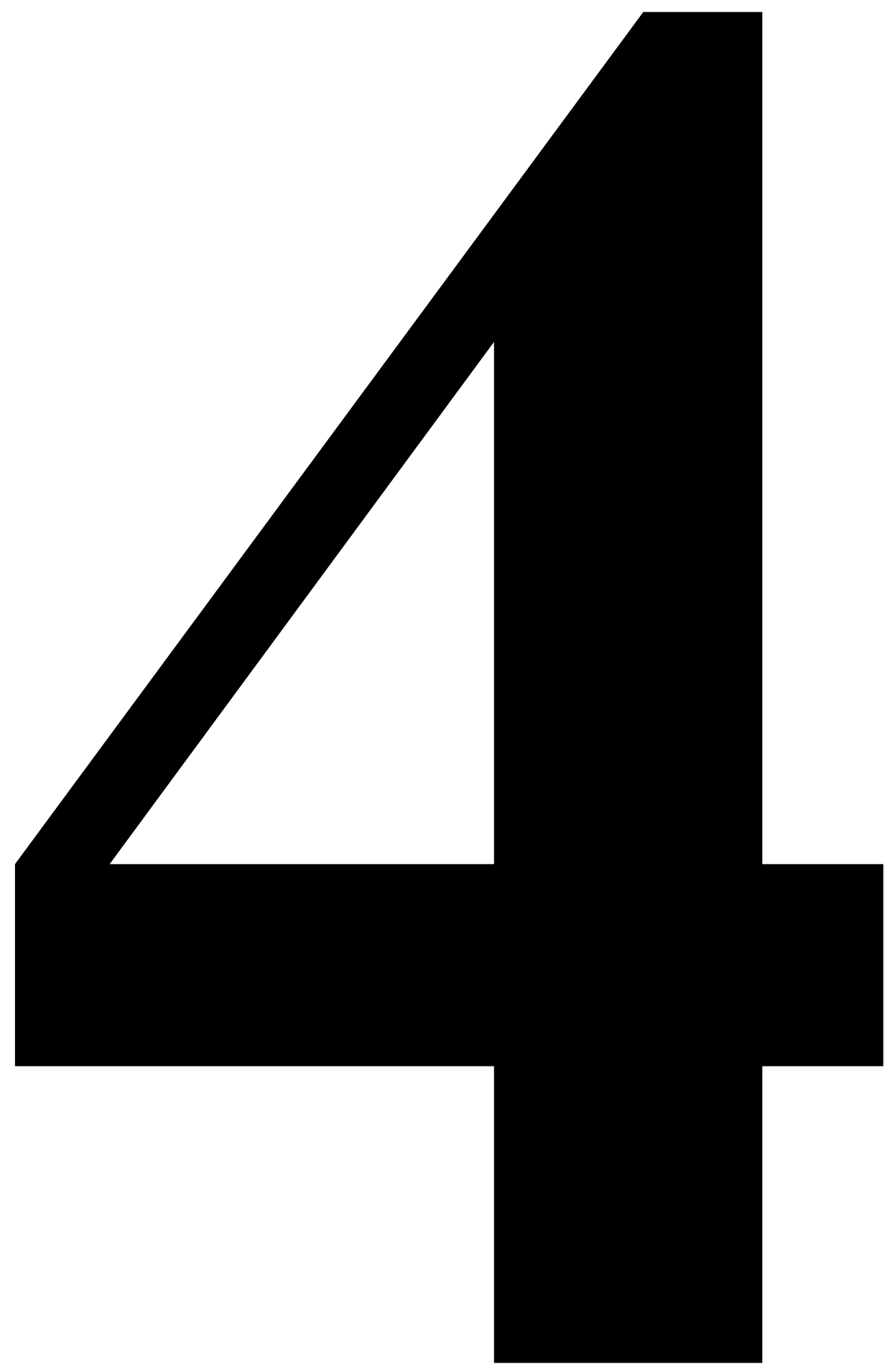




\section{Chapter 4}

\section{Infection risk following common femoral artery endarterectomy versus a hybrid procedure}

Langenberg JCM, Te Slaa A, de Groot HGW, Ho GH, Veen EJ, Buimer MG, van der Laan L. 


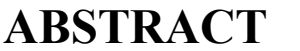

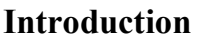

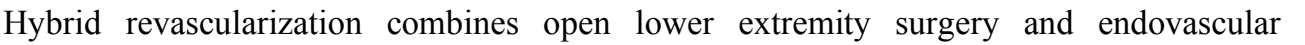

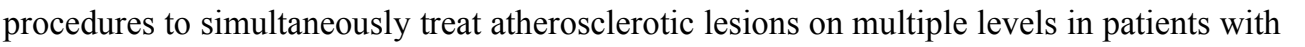

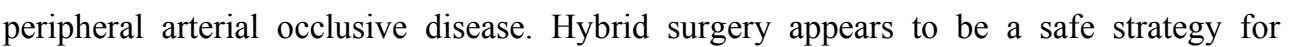

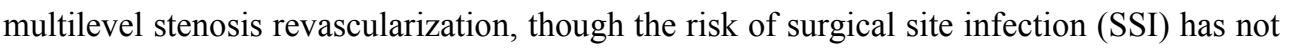

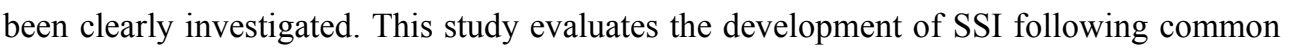

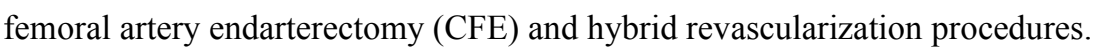

\section{$\square \square \square \square \square \square$}

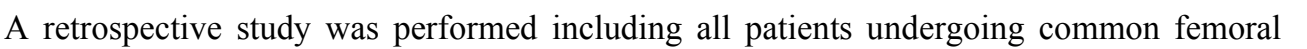

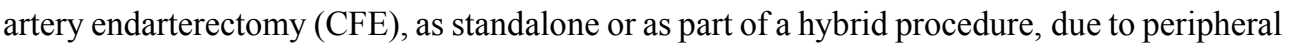

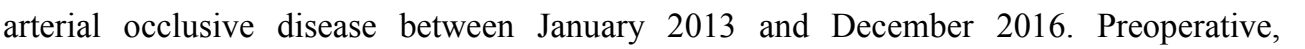

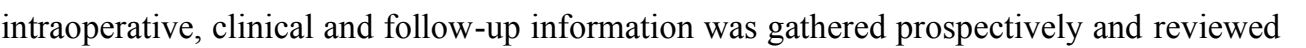

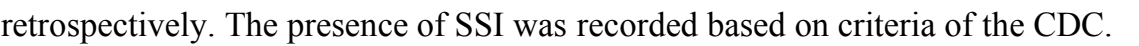

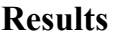

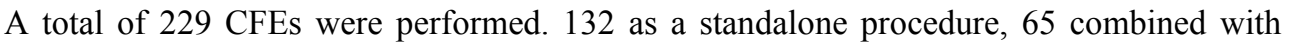

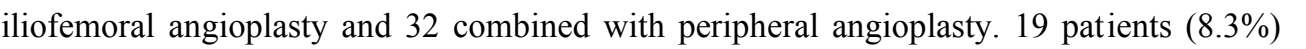

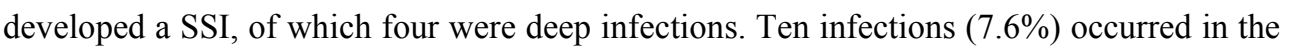

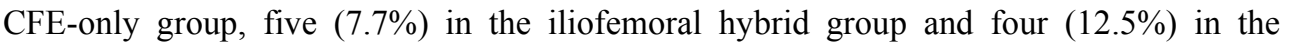

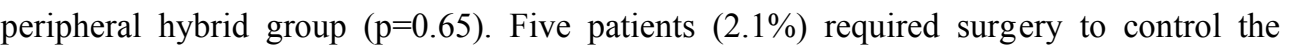
ए

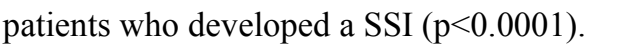

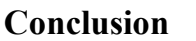

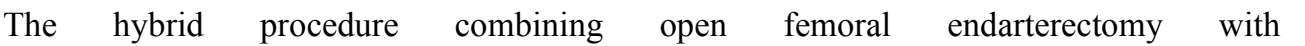
पा

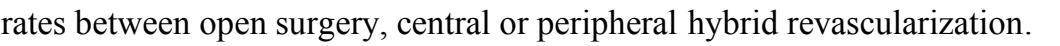




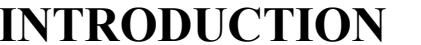

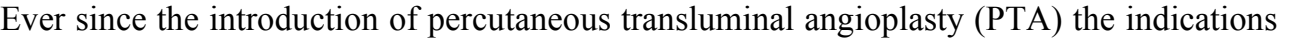

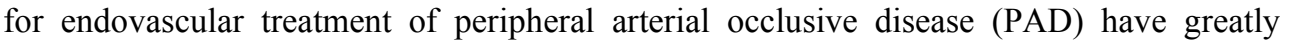

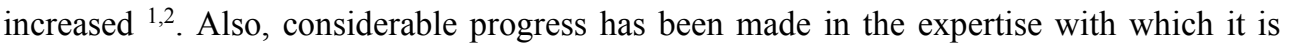

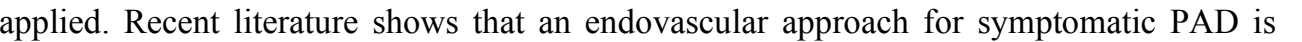

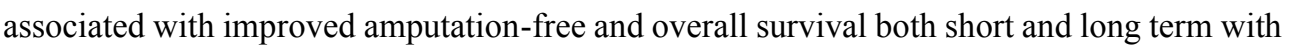

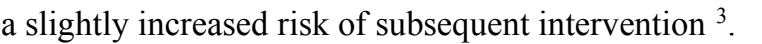

$\square$

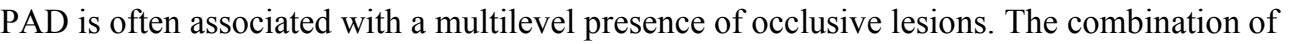
प

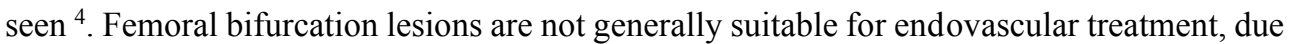

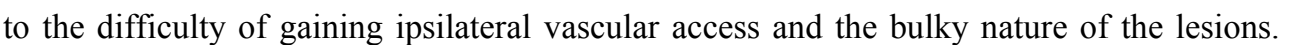

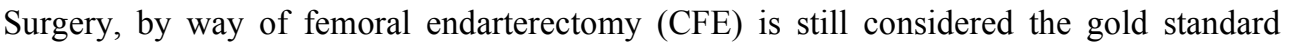

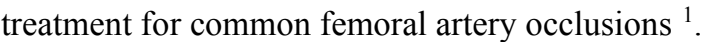

$\square$

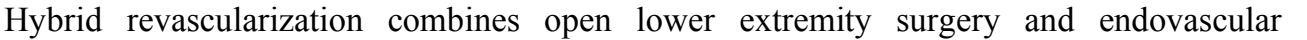

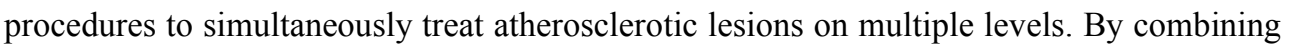

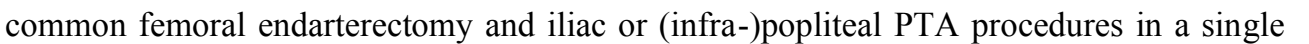

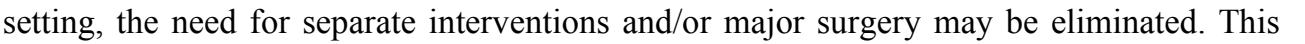

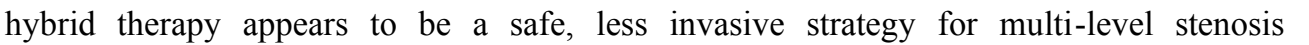

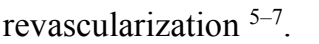

$\square$

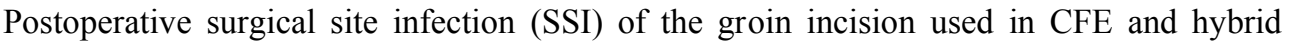

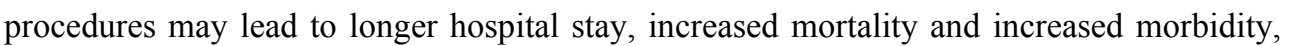

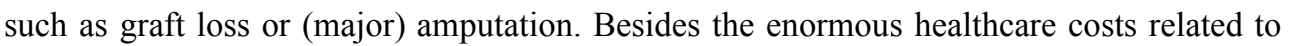

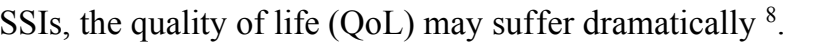

$\square$

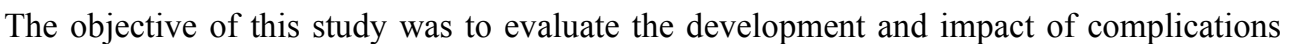

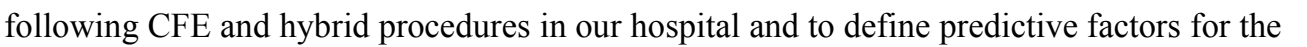

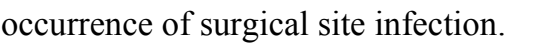

$\square$

$\square \square \square \square \square \square \square \square$

$\square \square ण 10 \square$

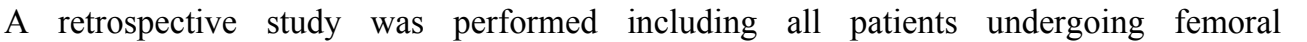

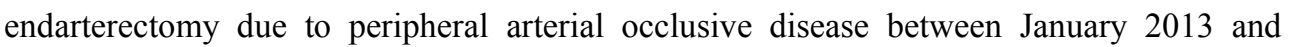

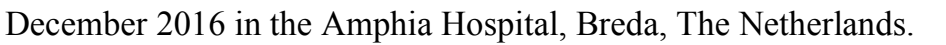




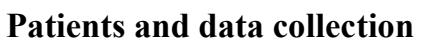

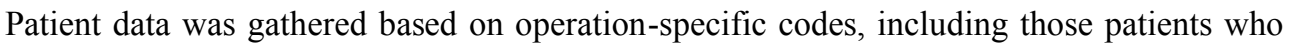

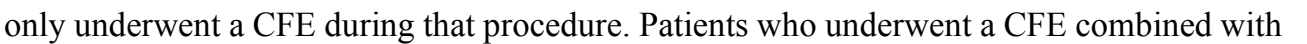

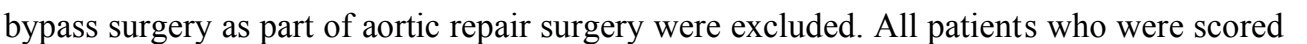

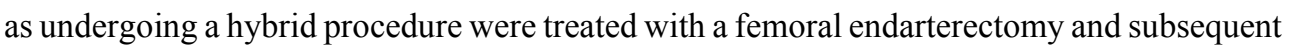

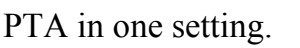

$\square$

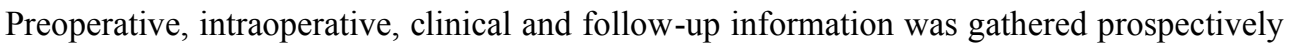

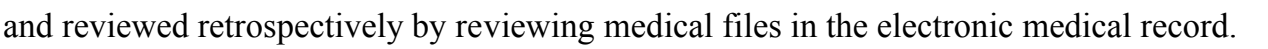
$\square$

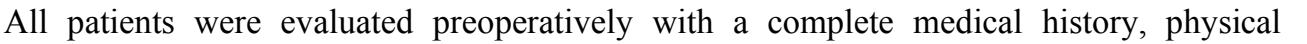

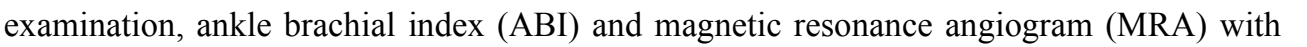

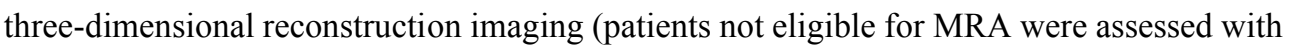

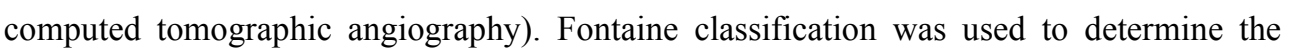

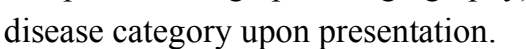

$\square$

Patients were included based on individual limbs; patients undergoing pro $\square \square \square\|\| \square \square \square$

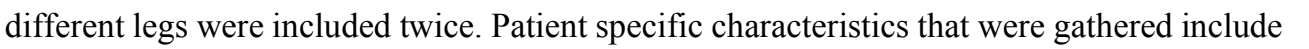

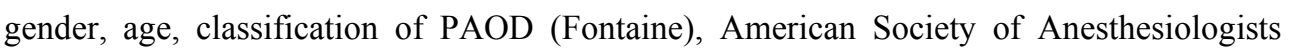

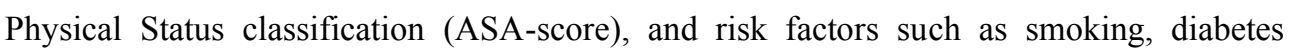

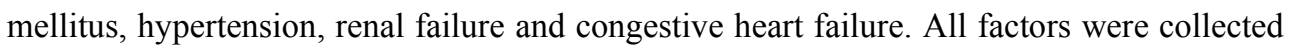

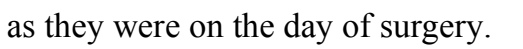

$\square$

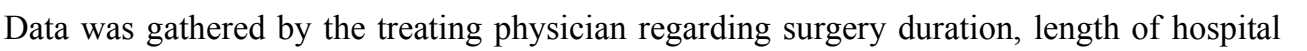

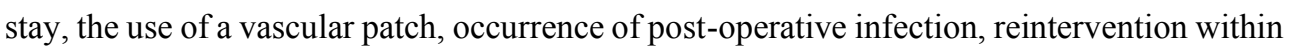

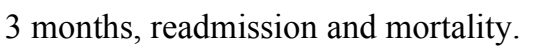

$\square$

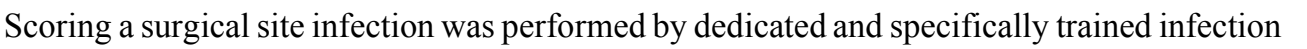

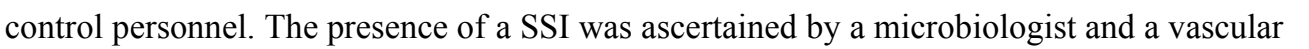

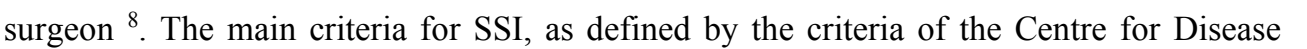

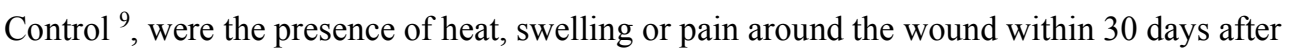

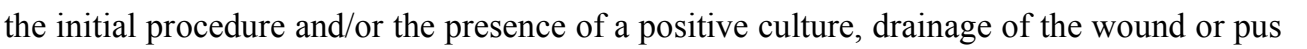

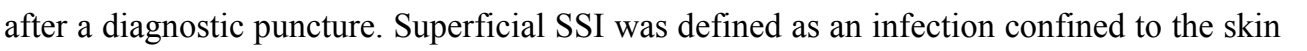

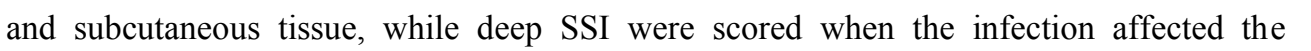

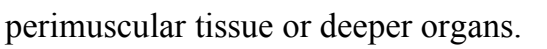

$\square$

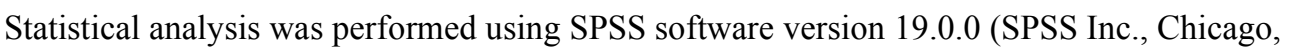

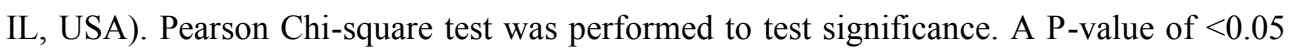

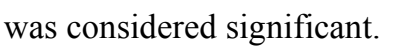

$\square$ 


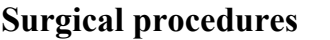

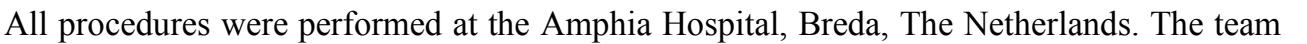

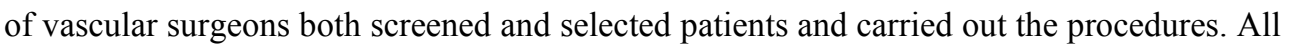

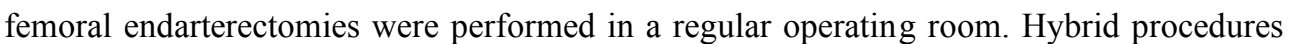

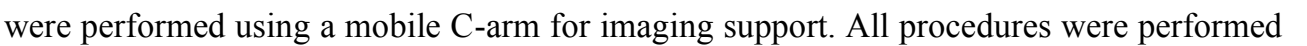

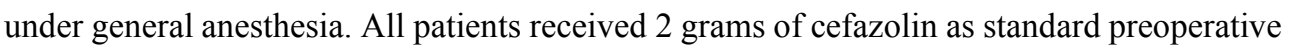

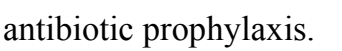

$\square$

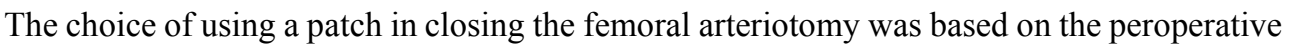

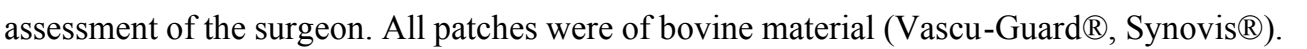

$\square$

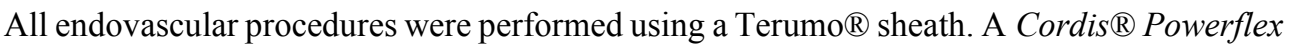

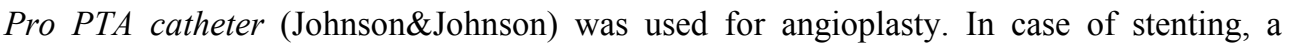

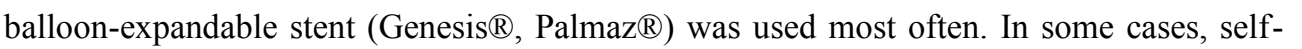

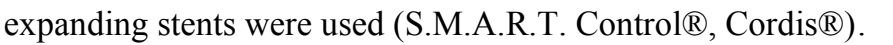

$\square$

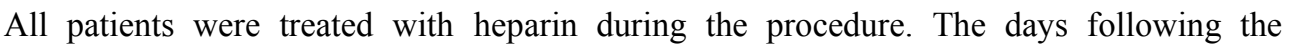

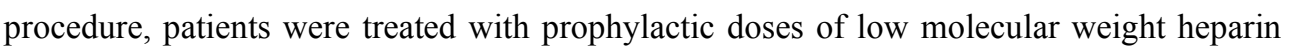

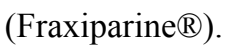

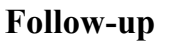

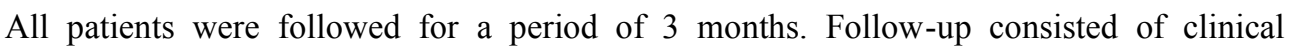

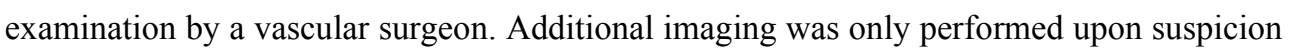

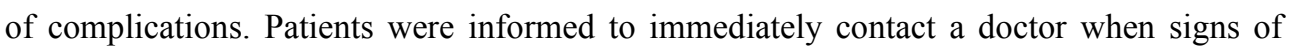

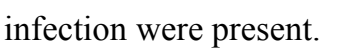

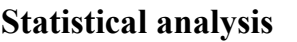

\section{A Pearson $\chi \square \square\|\|\|\square \square\|\|\| ा$ to compare categorical variables; continuous variables were}

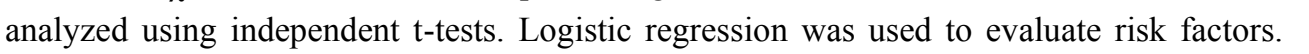

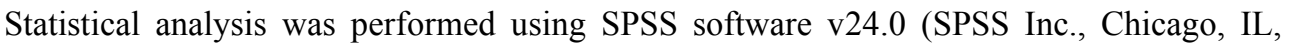

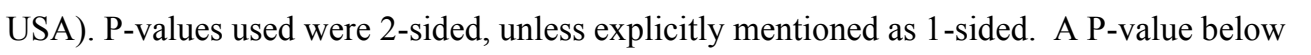

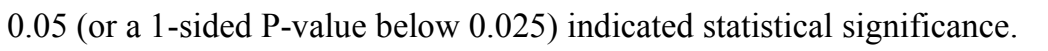

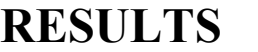

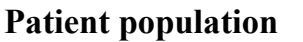

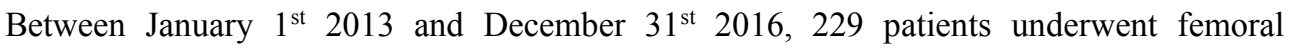

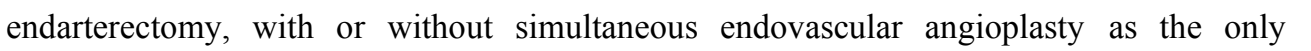




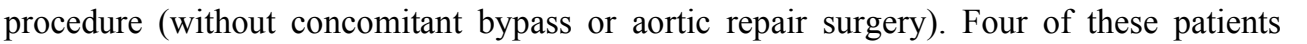

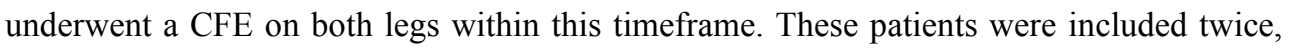

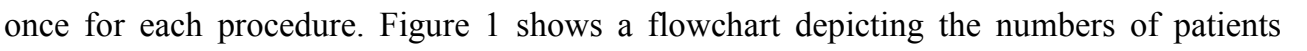

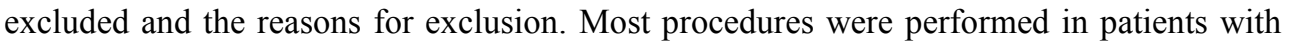

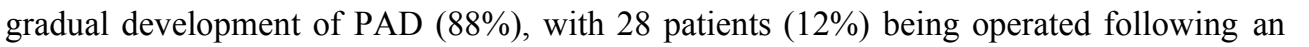

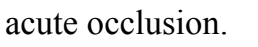

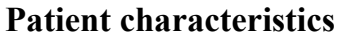

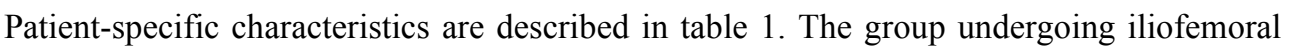

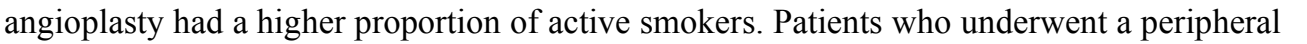

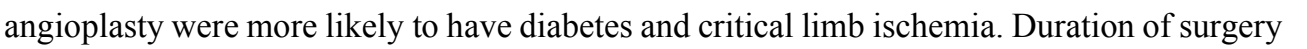

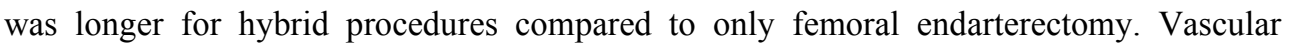

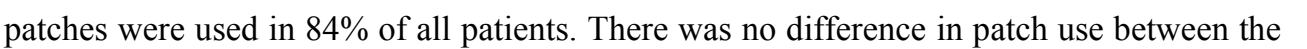

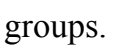

$\square$

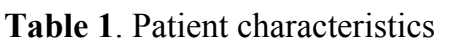

\begin{tabular}{|c|c|c|c|c|}
\hline 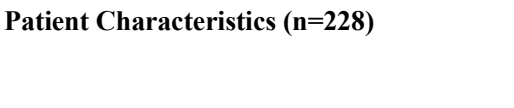 & 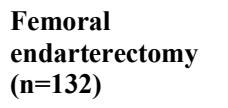 & 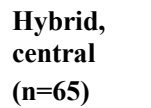 & 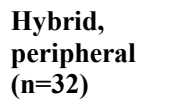 & பயாயா \\
\hline 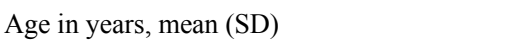 & पामाणाण & पामाणाण & पालाणाण & $\square \square$ \\
\hline 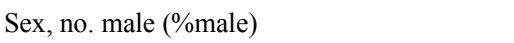 & 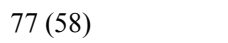 & 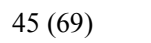 & 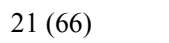 & $\square \square$ \\
\hline 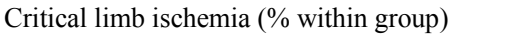 & पण口冋 & एवाण & एवाणा & एण \\
\hline $\mathrm{ASA} \geq 3(\%) \square$ & पण口冋 & पाणाण & पाणाण & एवाए \\
\hline 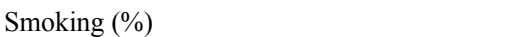 & एवाणा & पाणाणा & एणाणा & पाण \\
\hline 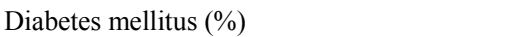 & पाणाण & $\square \mathrm{Im} 110$ & पाणाण & एणा \\
\hline 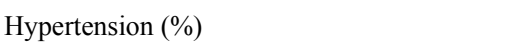 & 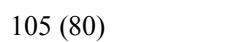 & 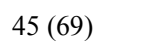 & 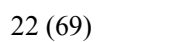 & $\square \square$ \\
\hline 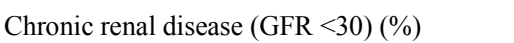 & 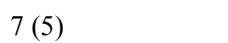 & 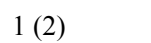 & 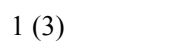 & $\square \square$ \\
\hline 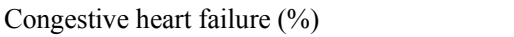 & एवाण & 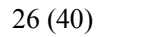 & एवाणा & एण \\
\hline 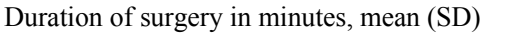 & एाणाण & $\square 1010$ & 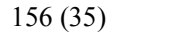 & घणाए \\
\hline 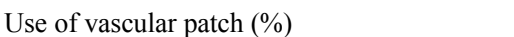 & पाणाणा & पाणाणा & $\square \mathrm{m} 110$ & $\square[11 \square$ \\
\hline
\end{tabular}

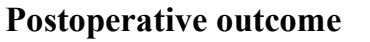

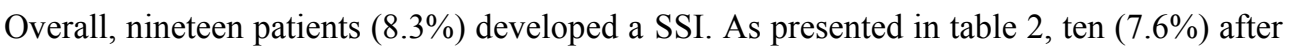

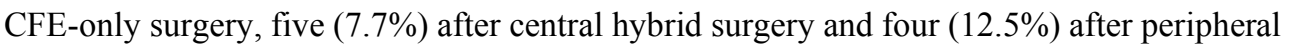

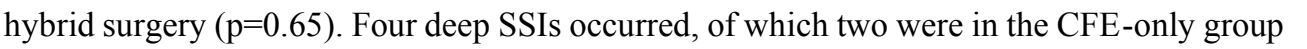

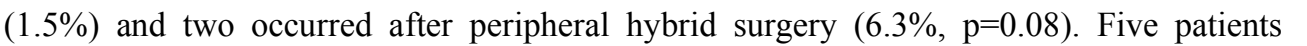

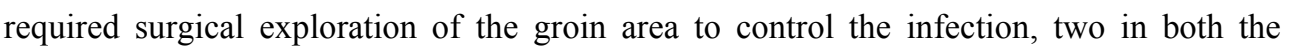




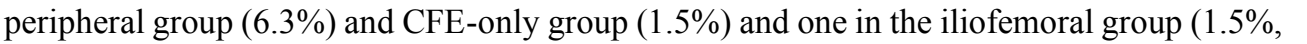

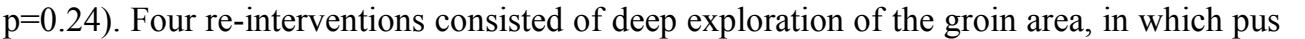

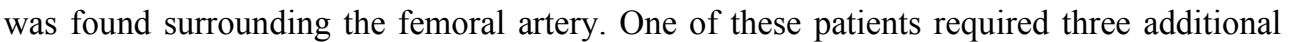

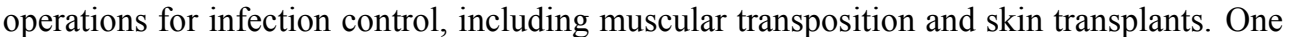

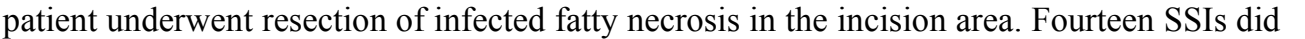

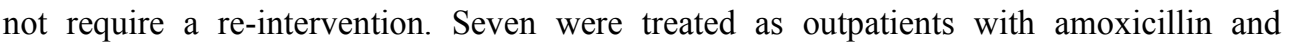

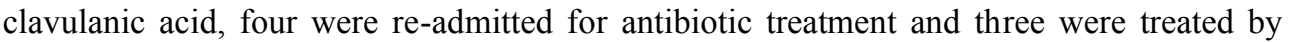

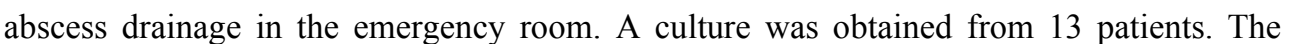

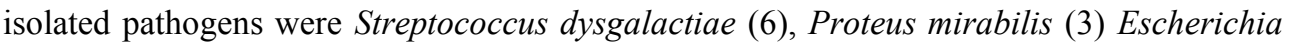

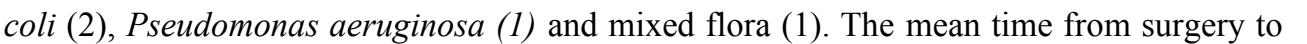

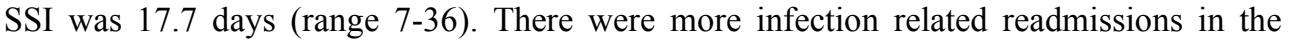

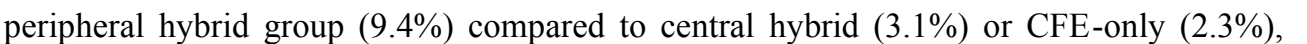

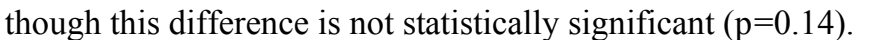

$\square$

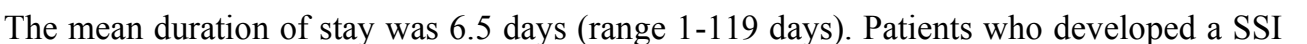

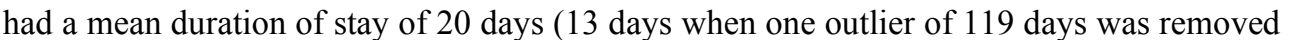

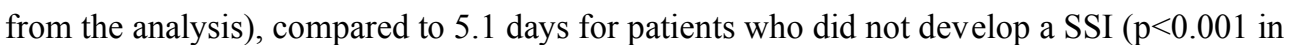

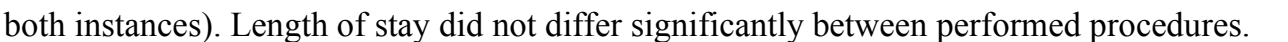
$\square$

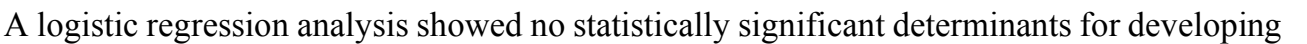

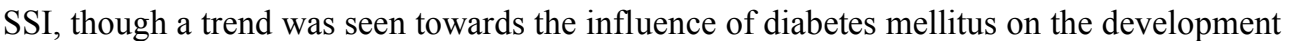

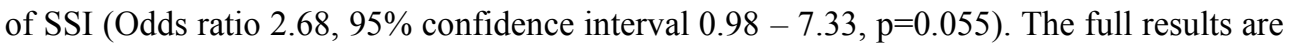

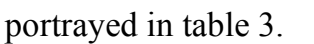

$\square$

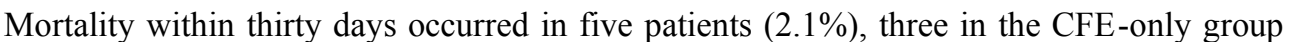

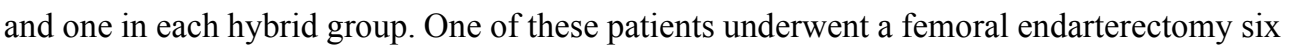

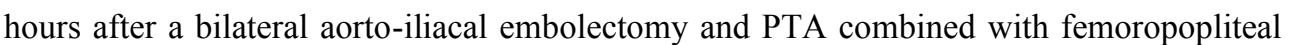

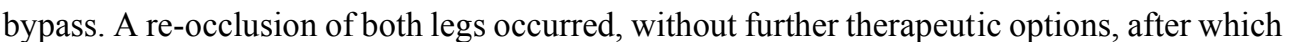

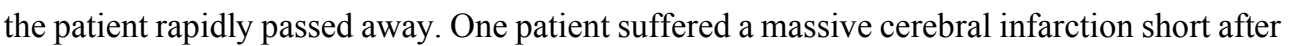

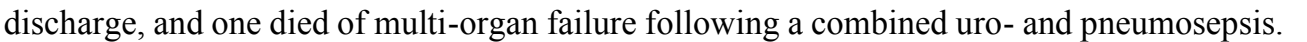

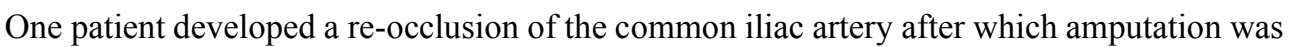

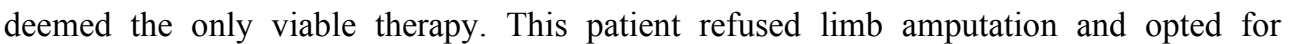

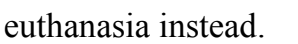




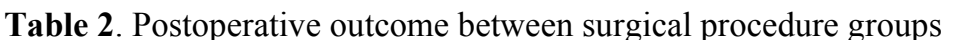

\begin{tabular}{|c|c|c|c|c|}
\hline & 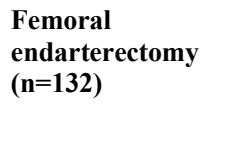 & 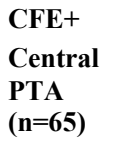 &  & 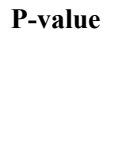 \\
\hline 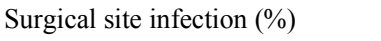 & पाणाणा & पाणाण & एणापाप & $\square \mathrm{पाए}$ \\
\hline 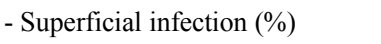 & पाणाण & पाणाण & पणाणा & पाए \\
\hline 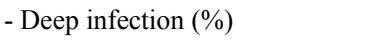 & पाणाणा & $\square$ & पाणाण & \\
\hline 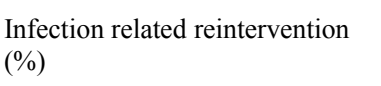 & पाणाणा & पणाणा & पणमाण & पामाप \\
\hline 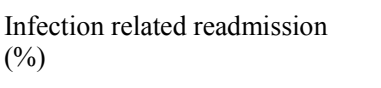 & 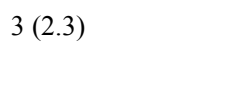 & पणाणाण & पणाणाण & 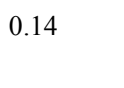 \\
\hline 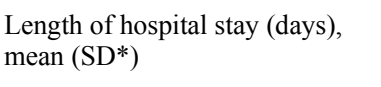 & पणाणाणा & पणाणाण & पण口冋ाण & पाणा \\
\hline 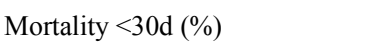 & पणापाण & पणाणा & पणमाण & पाणा \\
\hline
\end{tabular}

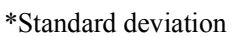

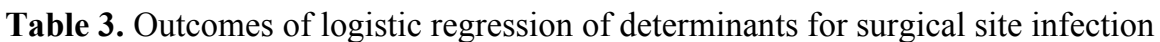

\begin{tabular}{|c|c|c|c|}
\hline पएाणा & 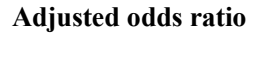 & 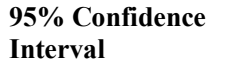 & पणमाप \\
\hline 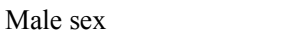 & $\square$ & पणम-णाणम & पाण \\
\hline पमणणम & $\square \square$ & एणम-ாயம & पणा \\
\hline 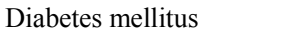 & $\square \square$ & पणनएण & $\square ण$ \\
\hline पणाणाएण & एणाए & एणमाणा & पणाए \\
\hline 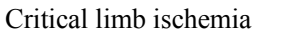 & एणाए & एणनाणम & एणा \\
\hline 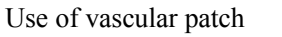 & $\square \square$ & एणनणण口 & एणाए \\
\hline 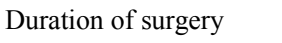 & $\square$ & पणम-णाए & पाण \\
\hline 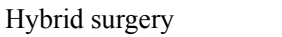 & एणाए & एणनाणम & एणा \\
\hline
\end{tabular}




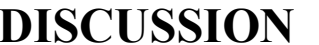

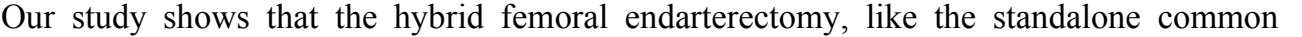

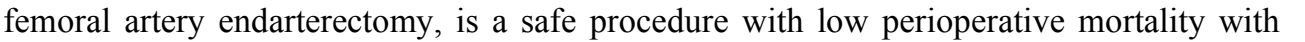

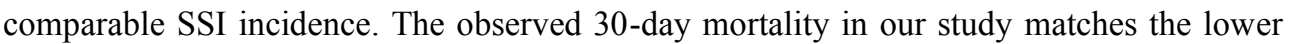

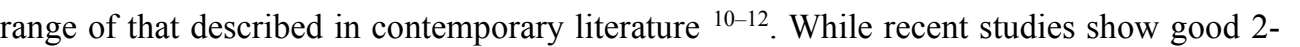

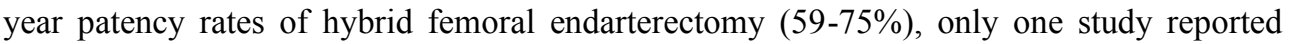

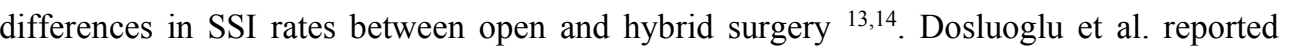

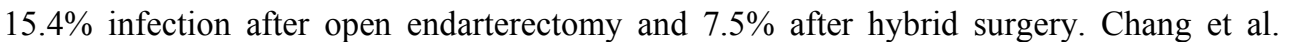

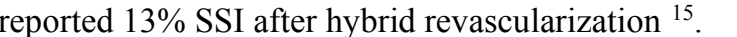

$\square$

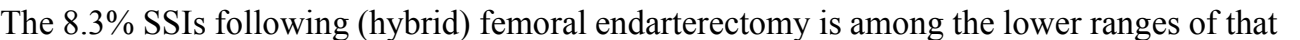

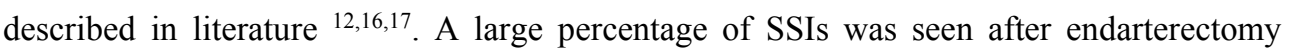

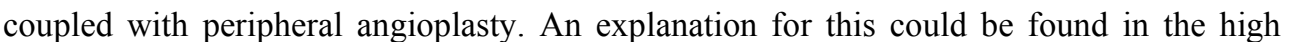

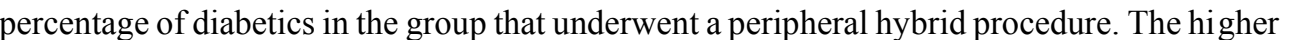
ए ए ए ए।

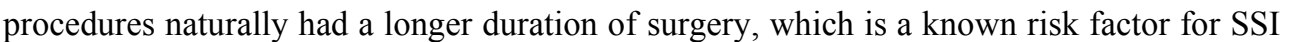

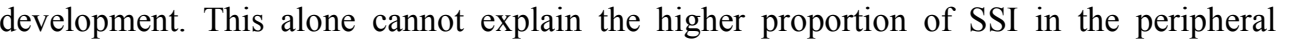
पाm

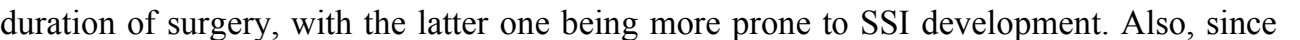

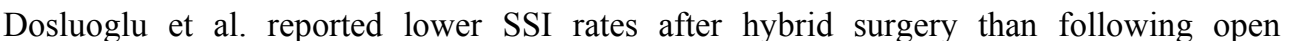

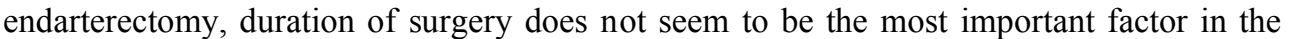

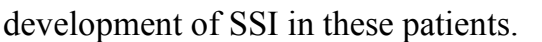

$\square$

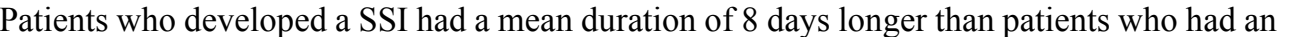

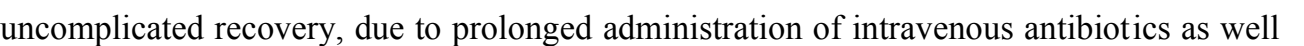

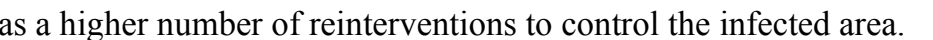

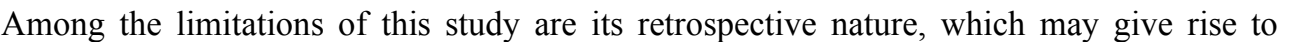
ए

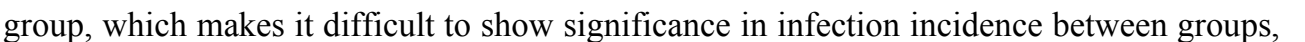

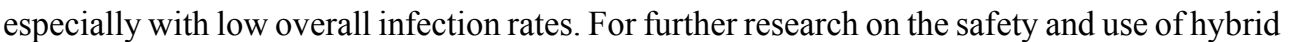

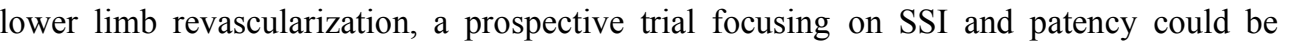
पामाणामाप

$\square$

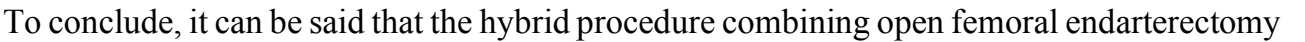

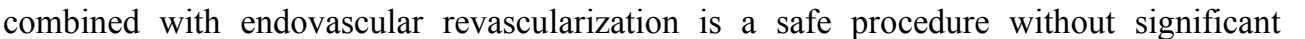

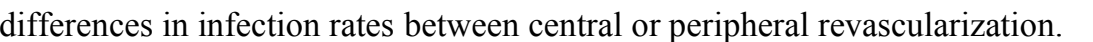




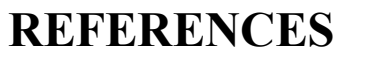

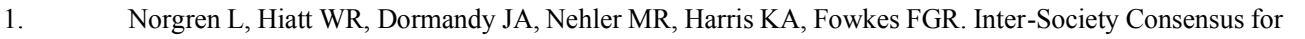

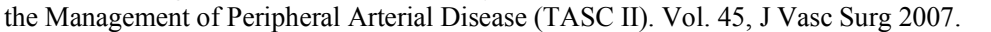

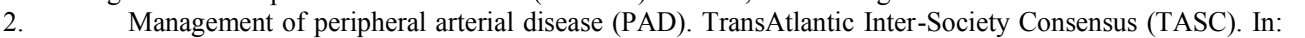

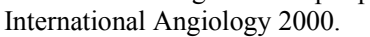

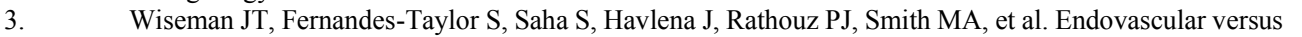

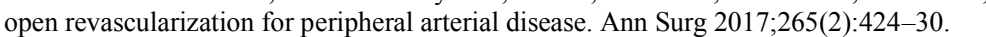

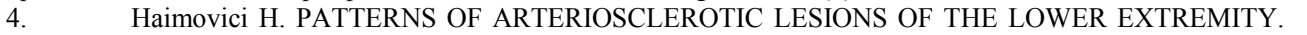

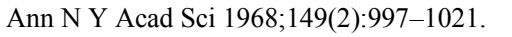

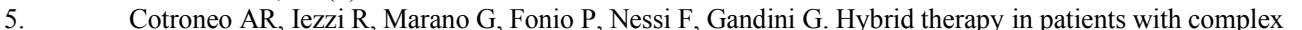

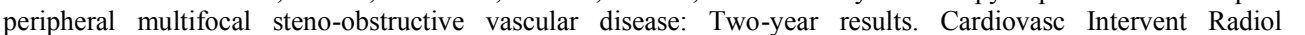
2007;30(3):355-61.

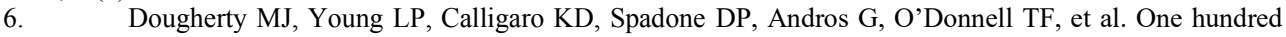

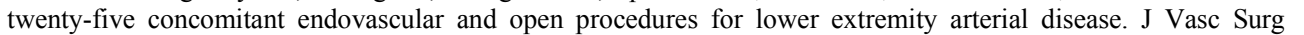
$2003 ; 37(2): 316-\square \Pi \Pi$

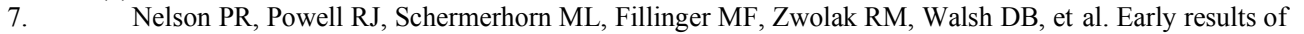
external iliac artery stenting combined with common femoral artery endarterectomy. J Vasc Surg 2002;35(6):1107$\square \square$

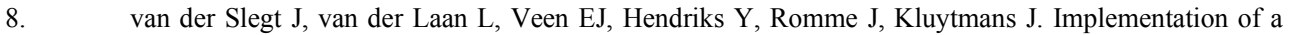

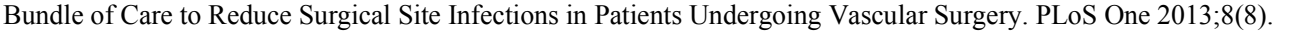
II Horan TC; Andrus, M; Dudeck M. CDC/NHSN Surveillance Definitions for Specific Types of Infections. Am J Infect Control 2008;36:309- $\square \square \square$

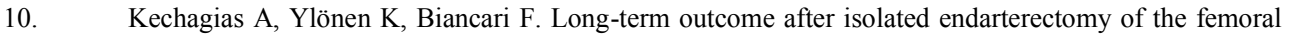
bifurcation. World J Surg 2008;32(1):51- $\square$

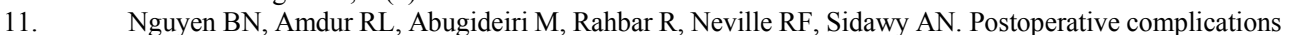

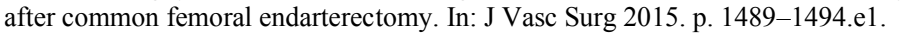

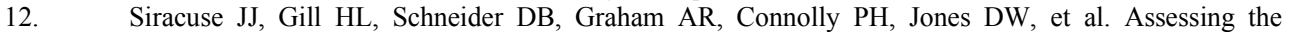

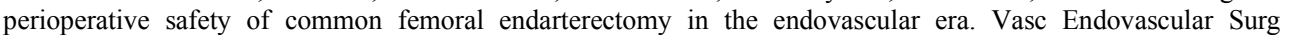
$2014 ; 48(1): 2 \square-\square \square \square$

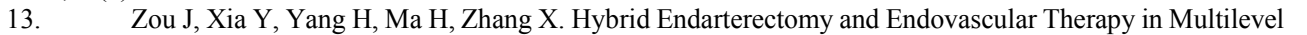
Lower Extremity Arterial Disease Involving the Femoral Artery Bifurcation. Int Surg 2012;(300):56-64. $\square$

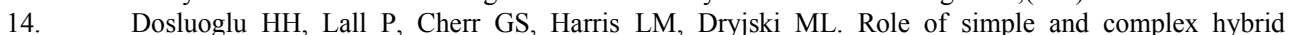
revascularization procedures for symptomatic lower extremity occlusive disease. J Vasc Surg 2010;51(6). $\square$

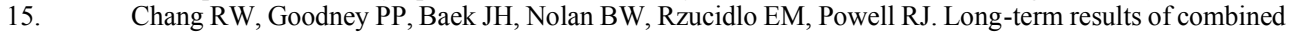
—ommon femoral endarterectomy and iliac stenting/stent grafting for occlusive disease. J Vasc Surg 2008;48(2):362_पIII

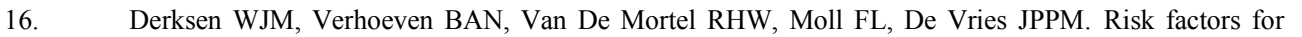

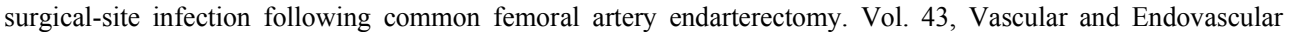
Surgery 2009. p. 69- $\square \square \square$

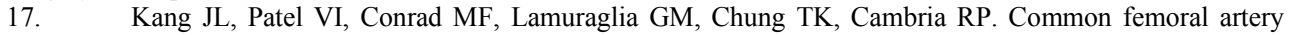

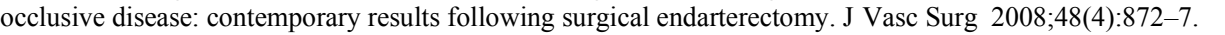

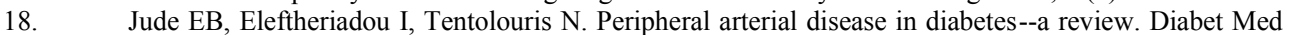
2010;27(1):4- पाए 
Infection risk following common femoral artery endarterectomy versus a hybrid procedure 


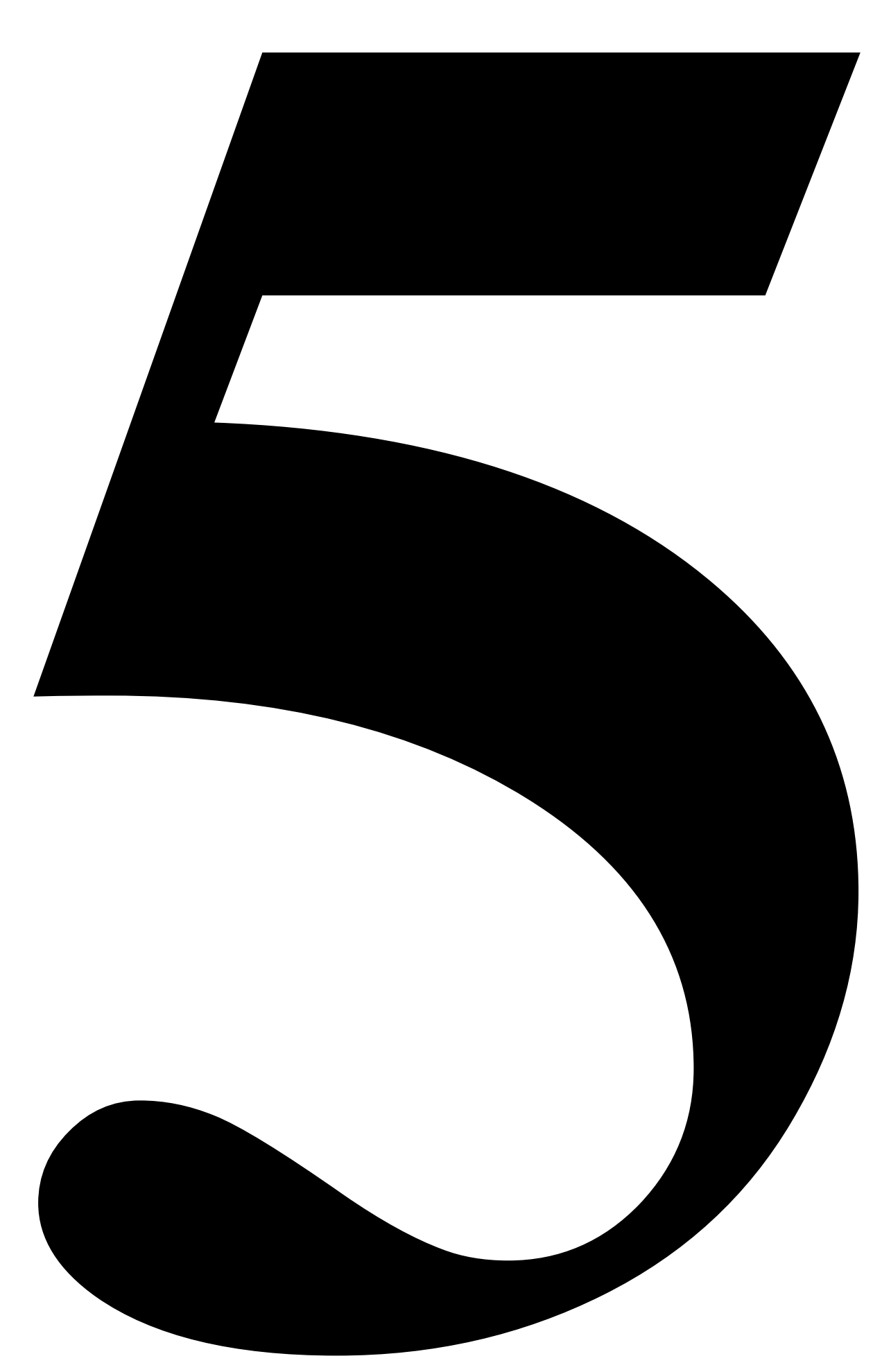




\section{Chapter 5}

\section{Do surgical site infections in open aortoiliac surgery differ between occlusive and aneurysmal arterial disease?}

Langenberg JCM, Roijers J, Kluytmans JAJW, de Groot HGW, Ho GH, Veen EJ, Buimer $M G$, van der Laan L. 


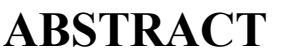

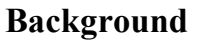

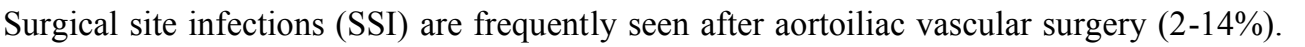

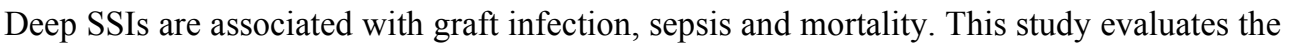

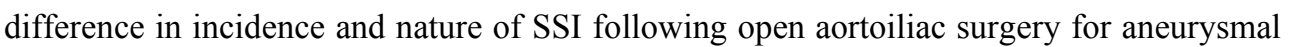

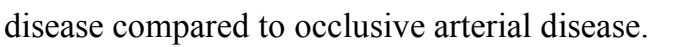

\section{$\square \square \square \square \square \square$}

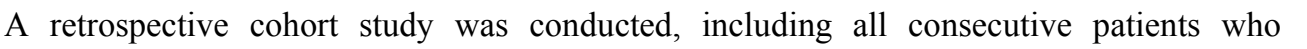

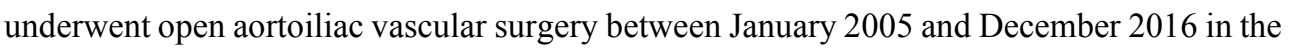

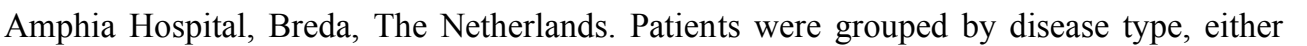

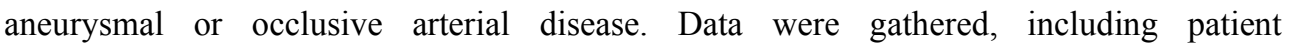

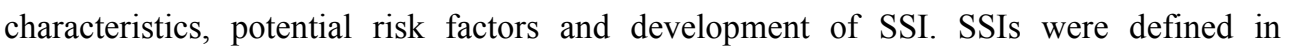

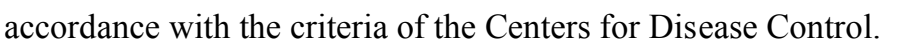

\section{$\square \square \square \square \square \square$}

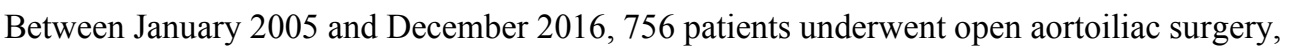

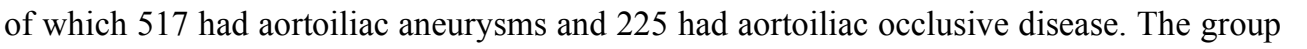

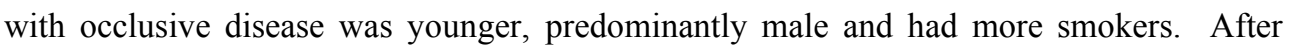

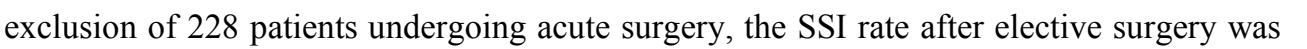

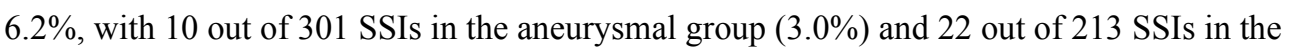

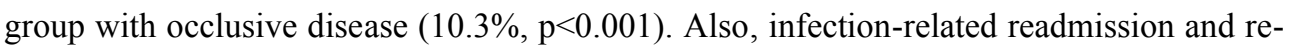
पाm

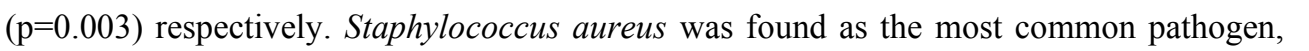

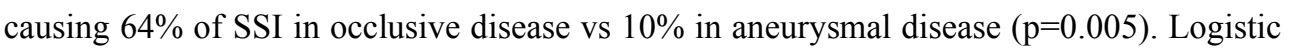

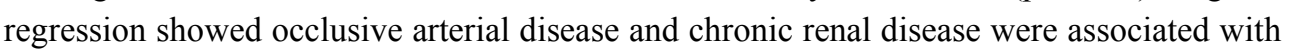
$\square \square \square$

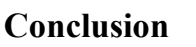

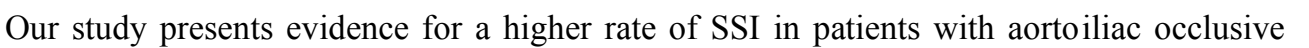

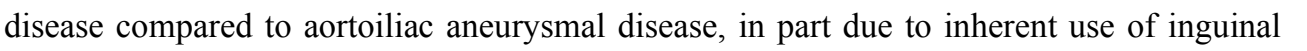

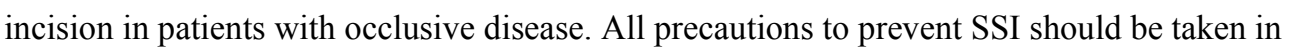

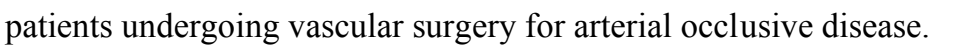




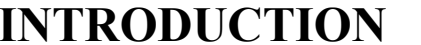

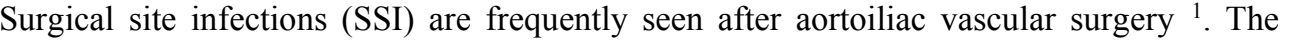

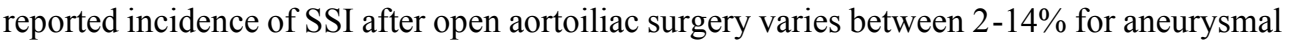

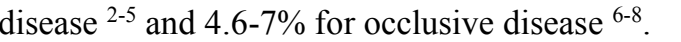

$\square$

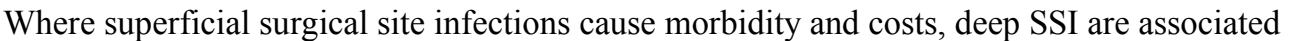

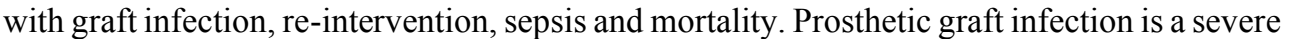

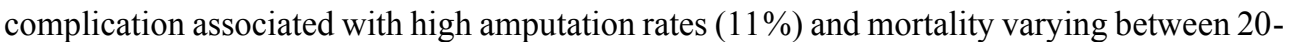

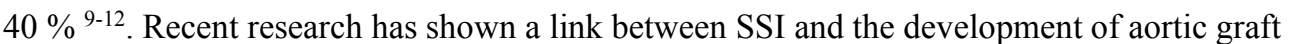

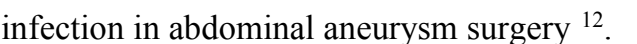

$\square$

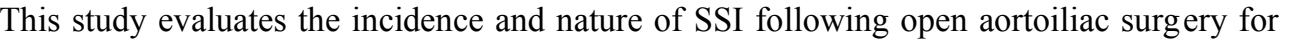

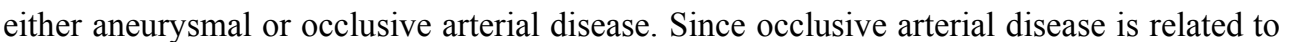

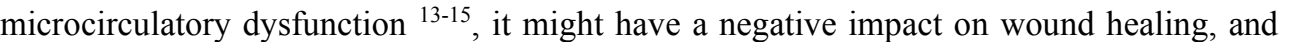

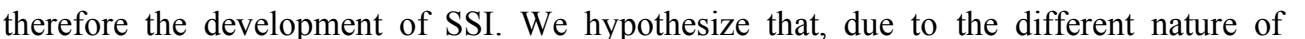

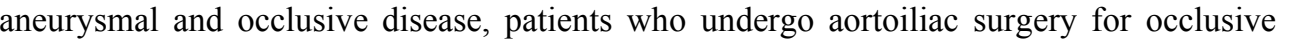

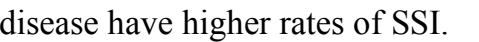

$\square \square \square \square \square \square \square \square$

$\square \square \| \square \square$

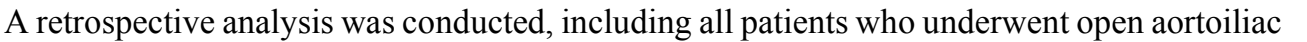

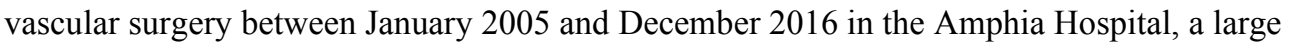

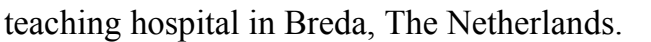

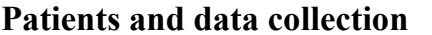

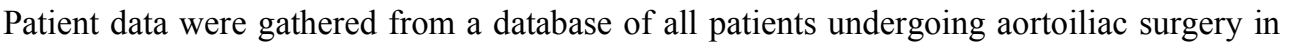

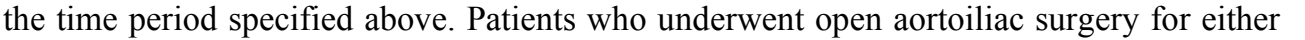

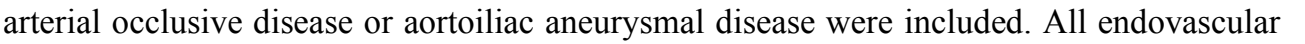

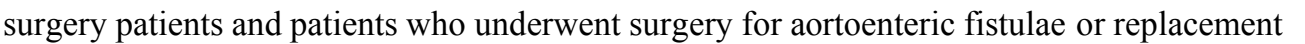

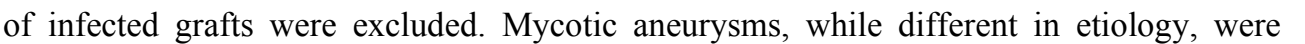

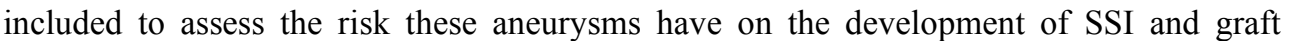
एणाणाणा

$\square$

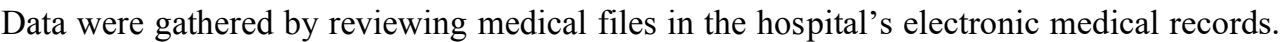

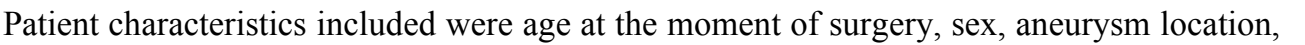

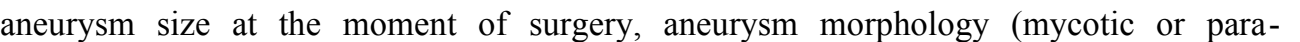

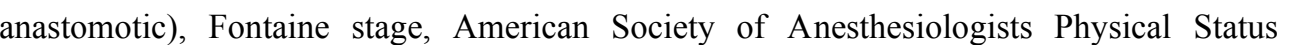




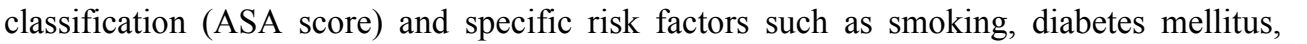

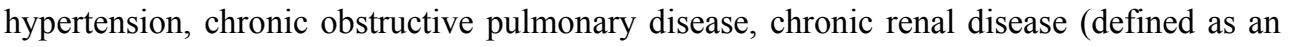

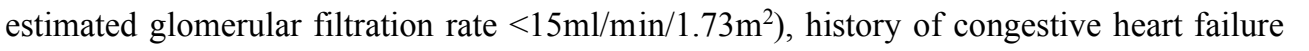

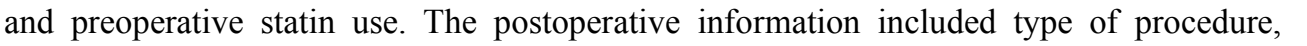

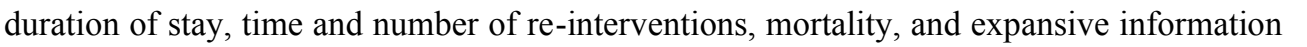

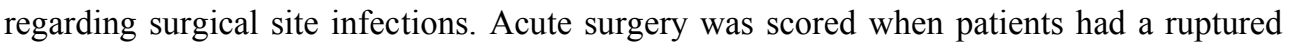

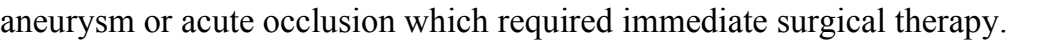

$\square$

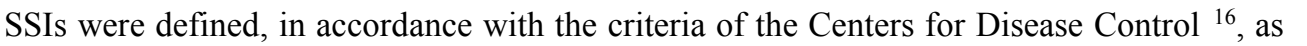

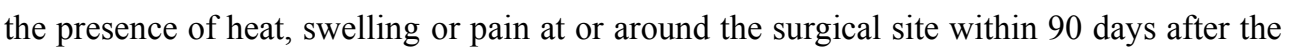

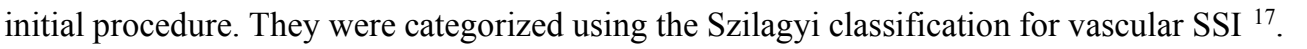

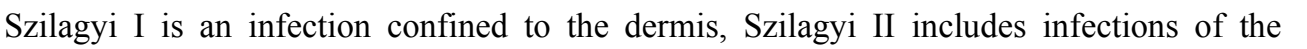

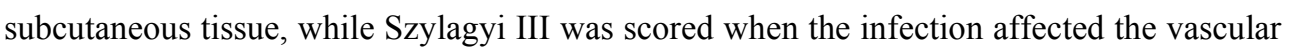

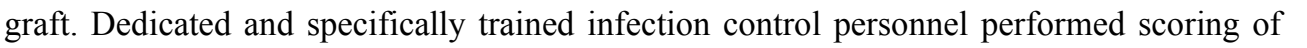

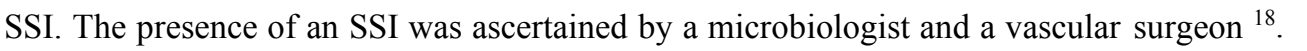
口

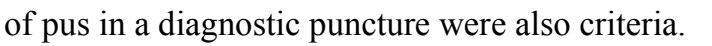

$\square$

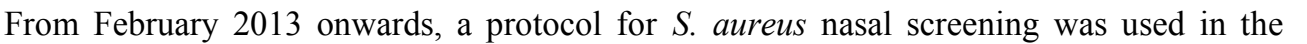

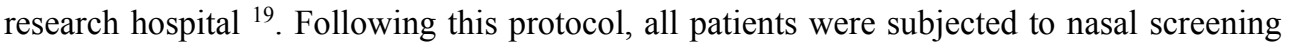

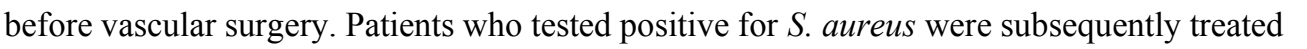

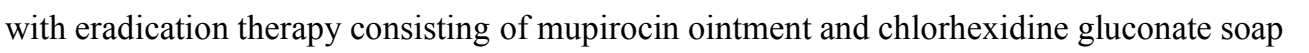

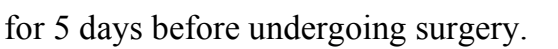

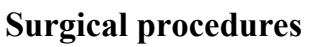

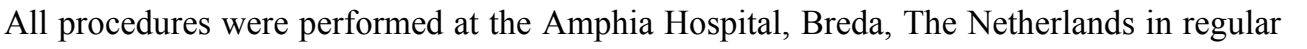

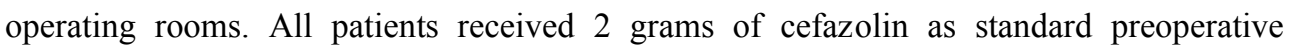

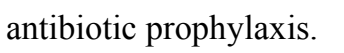

$\square$

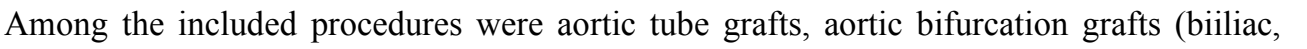

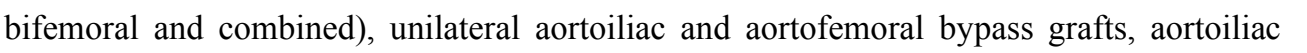

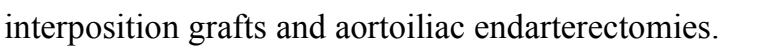

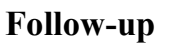

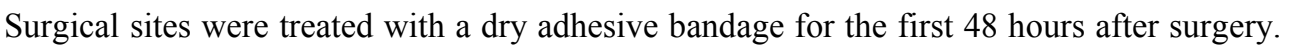

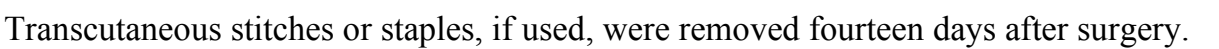

$\square$

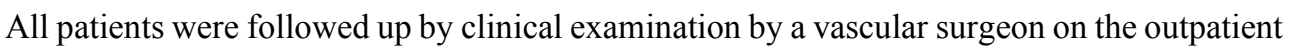

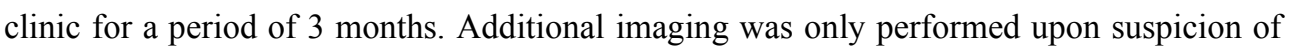




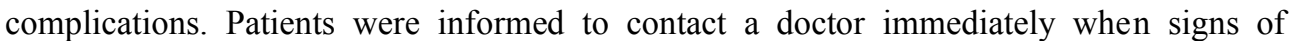
ए

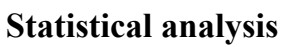

A Pearson $\chi \llbracket$ test was used to compare categorical variables; continuous variables were

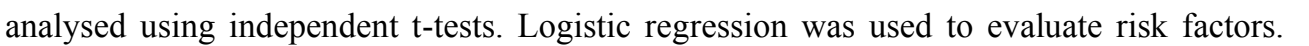

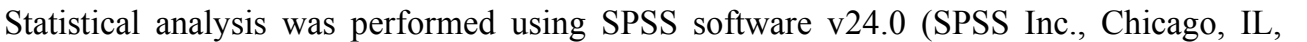

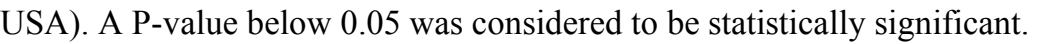

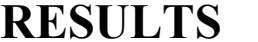

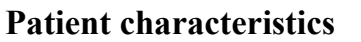

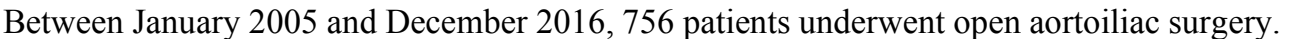

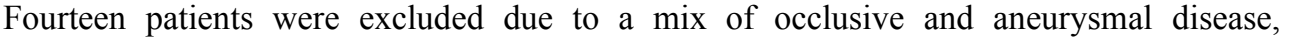

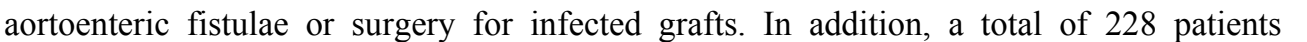

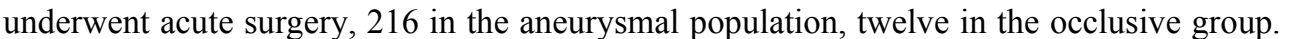

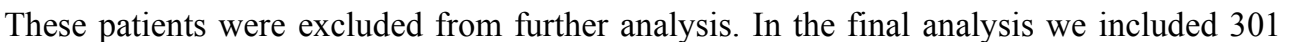

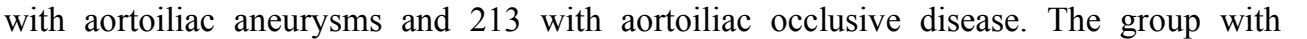

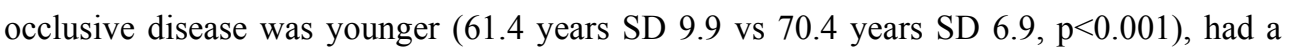

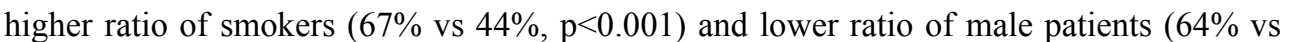

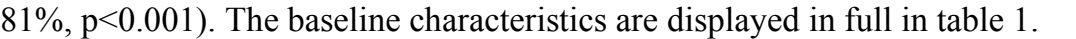

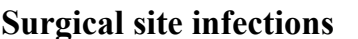

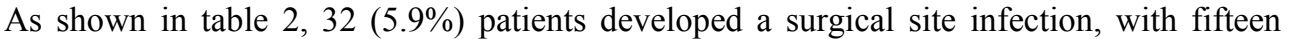

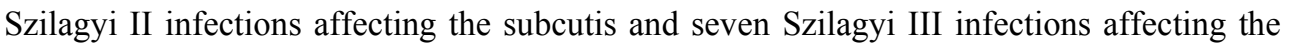

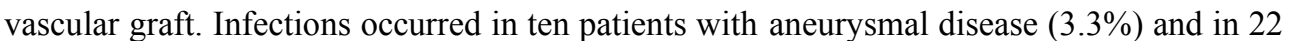

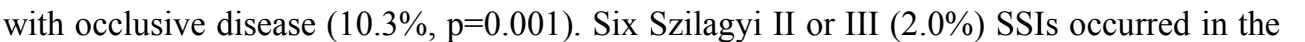

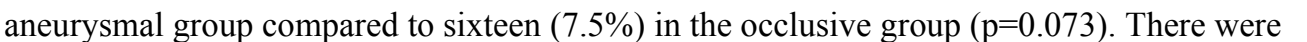

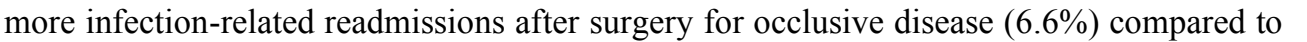

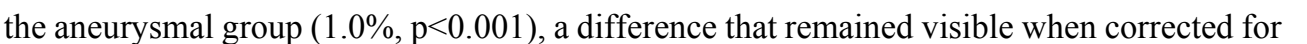

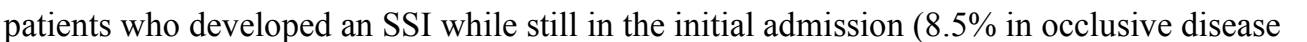

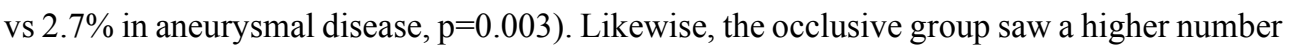

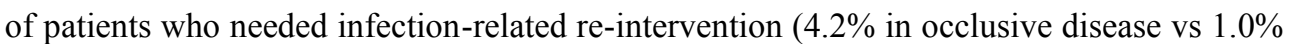

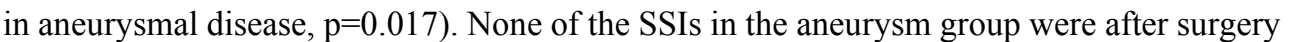

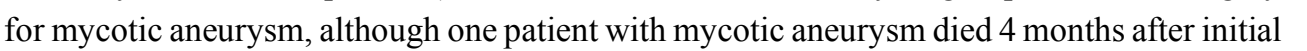

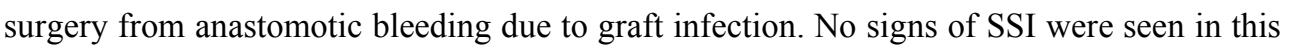

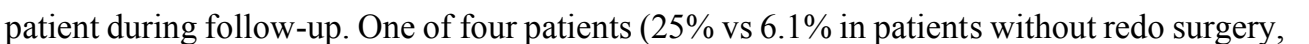


Chapter 5

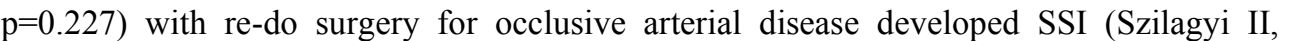

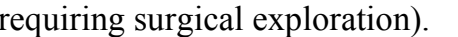

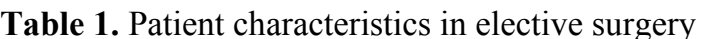

\begin{tabular}{|c|c|c|c|}
\hline 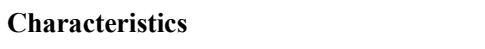 & 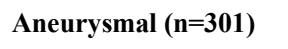 & 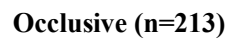 & पणाणमा \\
\hline 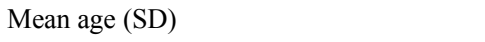 & पाणाणाणा & 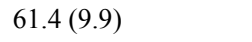 & पाणाए \\
\hline 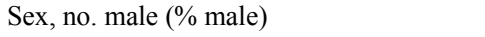 & एवाणाய & एवाणाण & $\square \square \square \square$ \\
\hline ASA Score $\geq 3(\%) \square$ & पाणाणाण & एाणाणाण & पाणाए \\
\hline 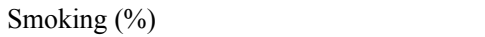 & एणाயण & एणाயण & 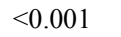 \\
\hline  & पाणाणा & 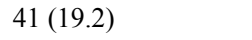 & 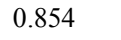 \\
\hline 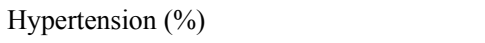 & पाणाणाण & $\square 1\|ण\| \square$ & 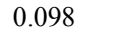 \\
\hline 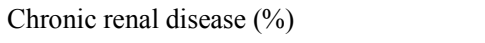 & पाणाणा & पणाणाण & $\square \amalg \square$ \\
\hline 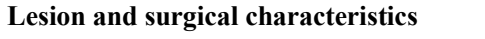 & $\square$ & $\square$ & $\square$ \\
\hline 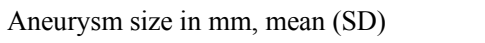 & एणाणाणा & $\square$ & $\square$ \\
\hline 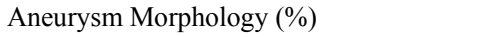 & $\square$ & $\square$ & $\square$ \\
\hline 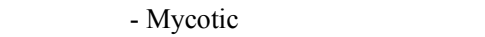 & पाणाणा & & \\
\hline 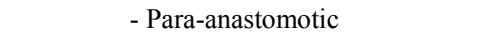 & पणाणाए & & \\
\hline 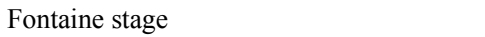 & $\square$ & $\square$ & $\square$ \\
\hline 血直 & $\square$ & पाणाण & \\
\hline 㽞 & & $\square 101010$ & \\
\hline 血 & & 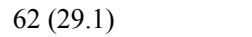 & \\
\hline 血 & & 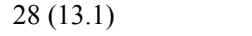 & \\
\hline 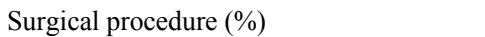 & $\square$ & $\square$ & $\square$ \\
\hline 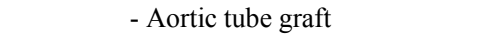 & 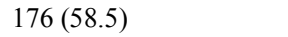 & $\square$ & \\
\hline 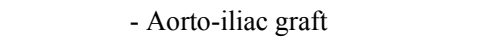 & पाणाणा & पाणाणाण & \\
\hline 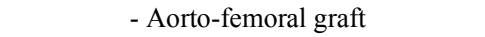 & एाणाण & 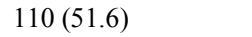 & \\
\hline 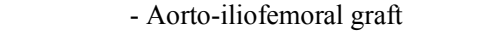 & पाणाण & 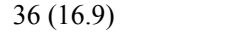 & \\
\hline 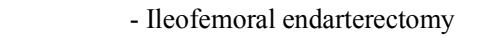 & $\square$ & एवाणाण & \\
\hline 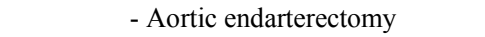 & $\square$ & एणा山ा & \\
\hline 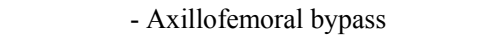 & $\square$ & पाणाणा & \\
\hline 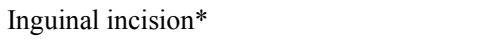 & 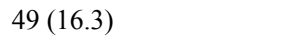 & 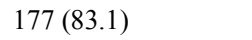 & पाणाए \\
\hline 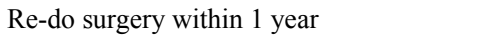 & $\square$ & पण口卄ा & एणाए \\
\hline
\end{tabular}

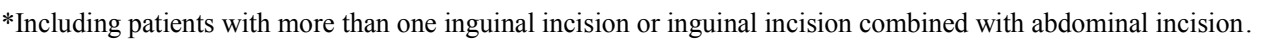


Do surgical site infections in open aortoiliac surgery differ between occlusive and aneurysmal arterial disease?

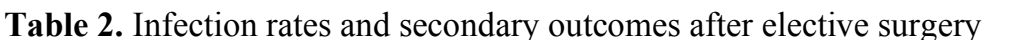

\begin{tabular}{|c|c|c|c|}
\hline$\square$ & 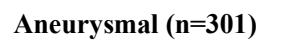 & 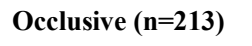 & 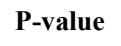 \\
\hline 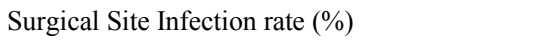 & पापाणा & पाणाणा & पाएण \\
\hline 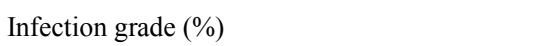 & $\square$ & $\square$ & एणाए \\
\hline 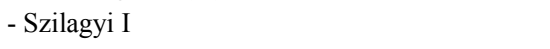 & पणाणा & पण口णाण & \\
\hline (2) & पाणाणा & पाणाणा & \\
\hline 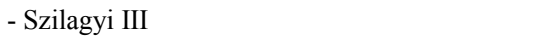 & पणाणा & पणाणाप & \\
\hline 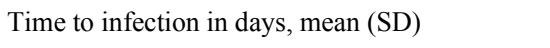 & पापाणाण & पणमाणा & एणाए \\
\hline 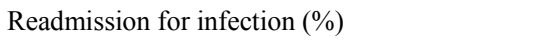 & एणाणाण & पाणाणा & 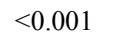 \\
\hline$\square$ Including patients still admitted $\dagger \square$ & पणाणाण & पाणाणाण & एणाए \\
\hline 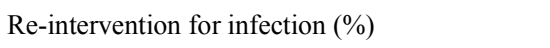 & पणाणा & 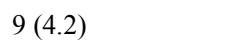 & एणाए \\
\hline 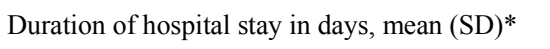 & पाणाणाणा & पणाणाणा & पणाए \\
\hline 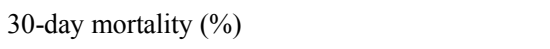 & पाणाणा & पणाणा & पाएाए \\
\hline 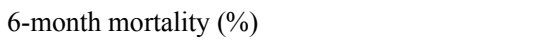 & पाणाण & पाणाणा & पाएण \\
\hline 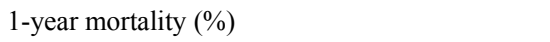 & पाणापा & पाणापा & एणाए \\
\hline
\end{tabular}

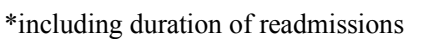

$\dagger$ including patients who developed a SSI during the initial admission $\square$

$\square$

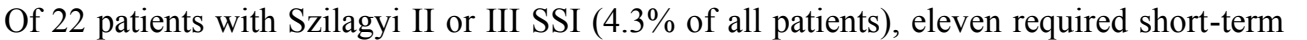

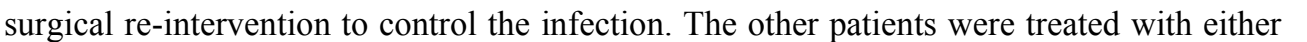

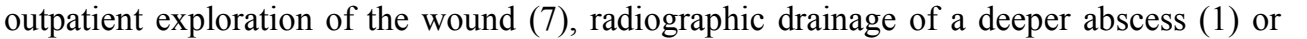

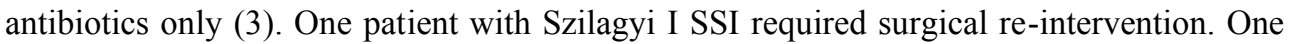

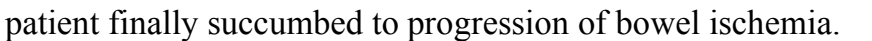

四

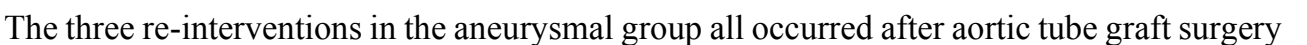

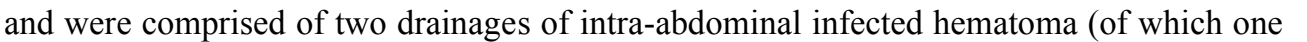
प

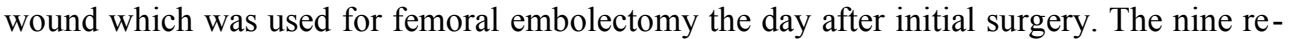

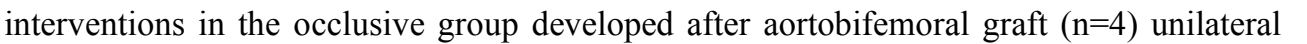

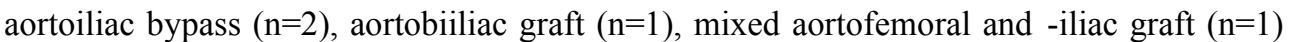

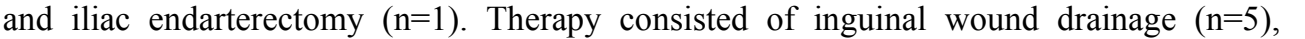
पाम

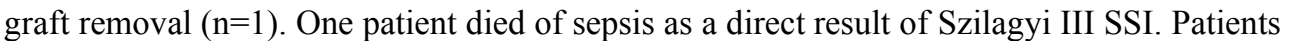

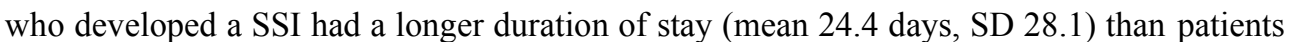
who did not (mean 11.0 days, SD 8.6; $\mathrm{p}<0.001$ ). The mean time from initial surgery to

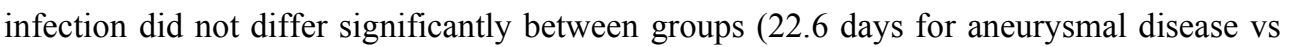

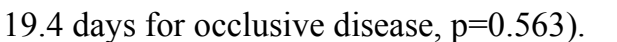

$\square$ 

incision $(10.2 \%$ vs $3.1 \%$; $=0.001) .19$ of these $23(82.6 \%)$ infected inguinal incisions $\square\|\square\| \| \square \square$ tients with occlusive disease ( $\mathrm{p}=0.013$ ). SSIs in inguinal incisions were not

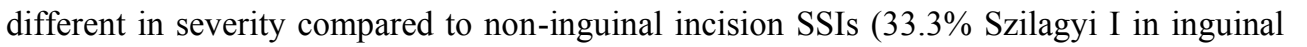
incision vs 30.4\% Szilagyi I in other incisions; p=0.983). There was no significant diff $\square \amalg \square \amalg$ in SSI in patients with higher Fontaine classification (8.9\% in Fontaine 2, 12.9\% in Fontaine $3,10.7 \%$ in Fontaine $4 ; \mathrm{p}=0.70)$.

Table 3 displays the distribution of infectious pathogens in patients with SSI. The majority

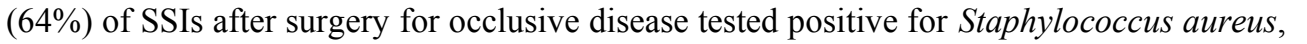
compared to $10 \%$ of the SSIs after aneurysm surgery $(\mathrm{p}=0.005)$. There were no cases of

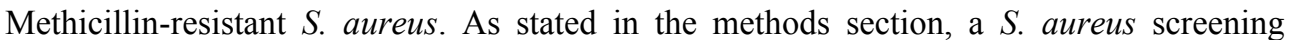

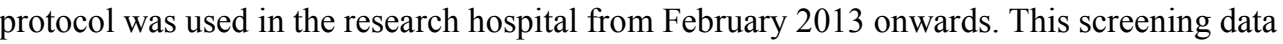
was only available for $66 \%$ of our study population. There was no difference in SSI incidence or Szilagyi type between patients positive or negative for $\square\|\| \square \| \square$ nasal screening $(\mathrm{p}=0.140)$.

$\square \square \square \square m$ Infectious pathogens in patients with surgical site infection $\square$

\begin{tabular}{|c|c|c|c|}
\hline$\square$ & 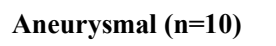 & 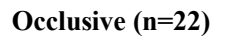 & पणाणाप \\
\hline 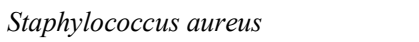 & $1(10) \square$ & $14(63.6) \square$ & $0.005 \square$ \\
\hline 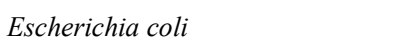 & $2(20) \square$ & $\mathbb{\square}$ & $\square \square \square$ \\
\hline 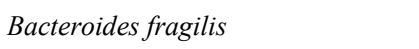 & $1(10) \square$ & $1(4.5) \square$ & $\square \square \square$ \\
\hline 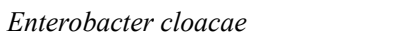 & $\square$ & $3(13.6) \square$ & $\square \square \square$ \\
\hline 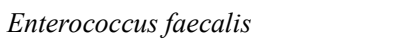 & $1(10) \square$ & 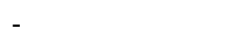 & $\square \square \square$ \\
\hline 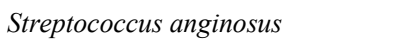 & $2(20) \square$ & 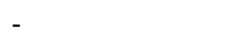 & $\square \square \square$ \\
\hline 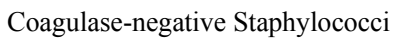 & $\square$ & $2(9.1) \square$ & $\square \square \square$ \\
\hline 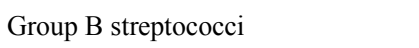 & $\square$ & $1(4.5) \square$ & $\square \square \square$ \\
\hline 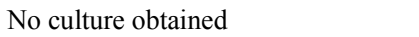 & $3(30) \square$ & $1(4.5) \square$ & 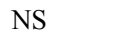 \\
\hline
\end{tabular}

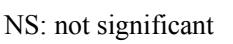

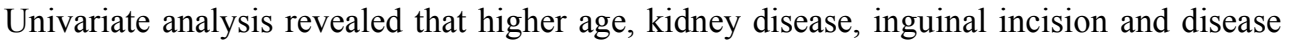
type affected the risk of surgical site infections. A logistic regression model was created to ascertain the effects of age, sex, incision location, disease type (occlusive of aneurysmal) and kidney disease on the likelihood of developing SSI.

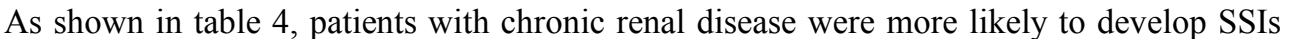

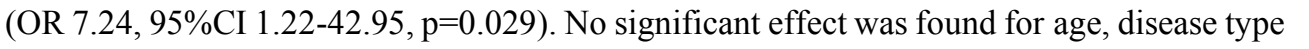
or the use of an inguinal incision in this model. 


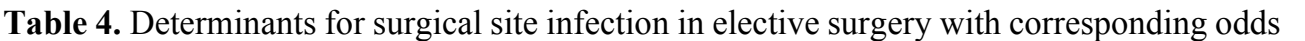

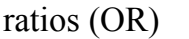

\begin{tabular}{|c|c|c|c|}
\hline पणाயणम & 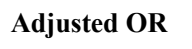 & 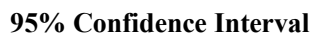 & पणाणम \\
\hline पएा & पाए & पणमाण & पणाए \\
\hline$\square \square \square ण \square$ & पणा & पणाणाए & पणाए \\
\hline 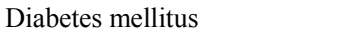 & एणा & पणाणम & पाणा \\
\hline 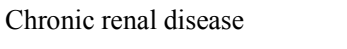 & एण & पणमाण & पणाए \\
\hline 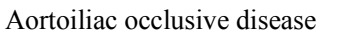 & एण & एणाणा & पणाए \\
\hline 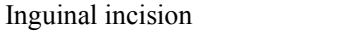 & पाएा & पणाणाए & एवाए \\
\hline
\end{tabular}

\section{पणापणाणाणापाण}

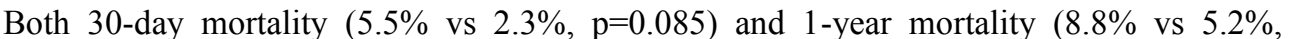

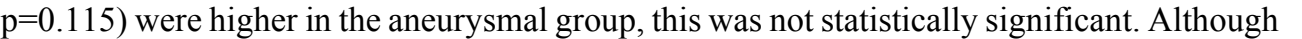

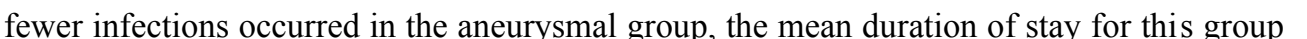
was significantly longer (13.1 days, SD 12.9; vs 10.1 days, SD 7.8; $\mathrm{p}=0.003$ ). $\square$

\section{$\square \square \square \square \square \square \square \square \square$}

\section{$\square \square \square \square \square \|$}

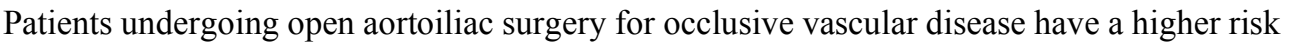

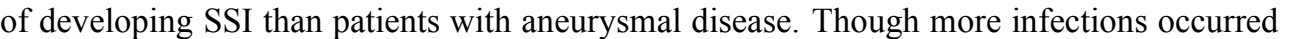

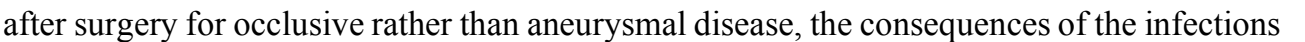

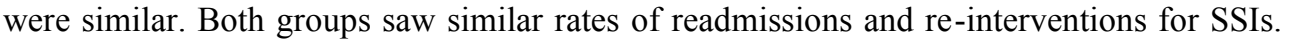

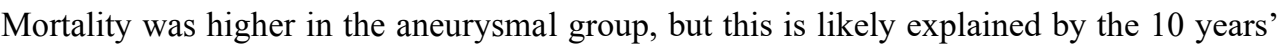

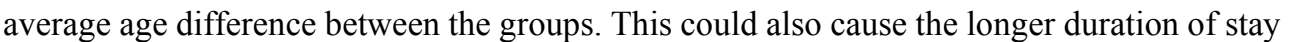

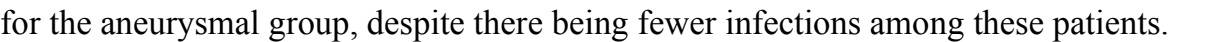
$\square$

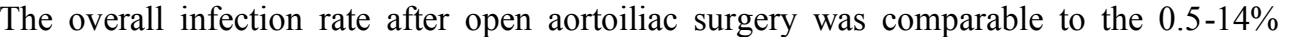

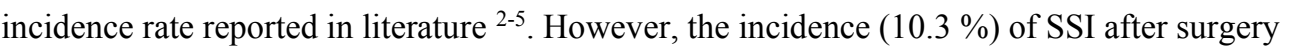
ए

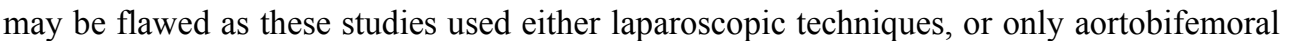

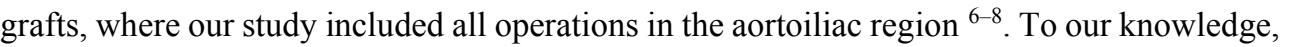
ए

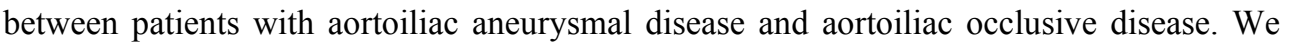

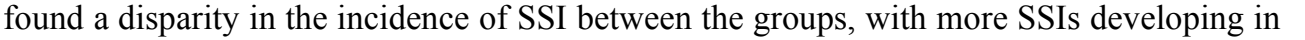

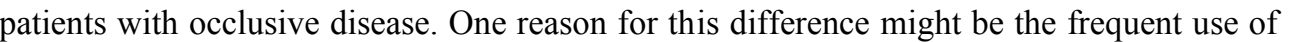




\section{Chapter 5}

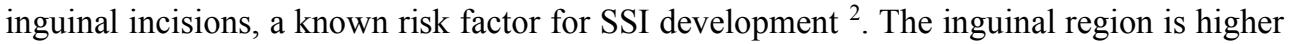

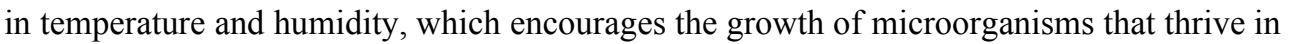

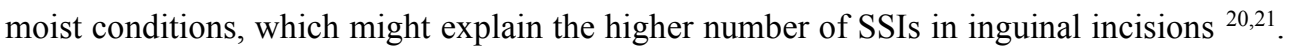

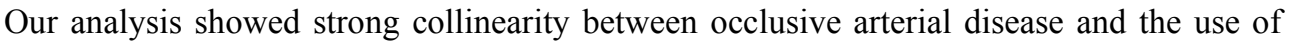

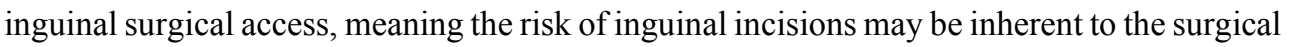
r

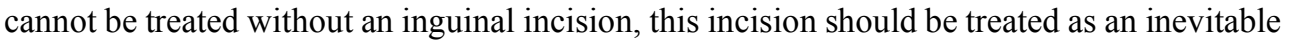

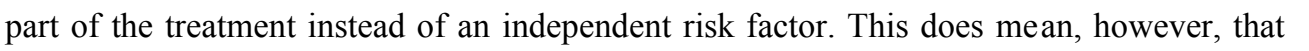

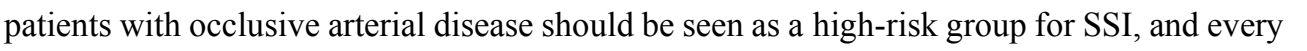

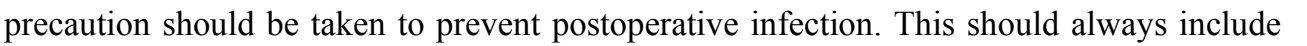

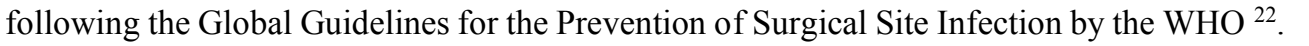

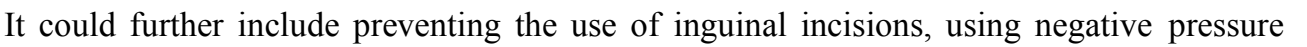

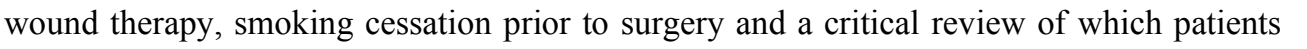

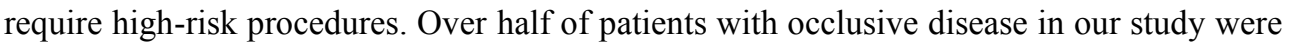

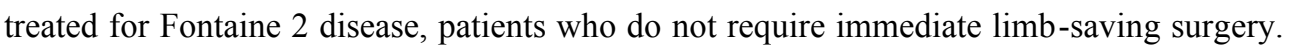

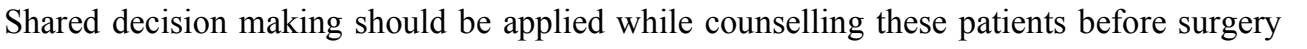

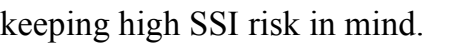

$\square$

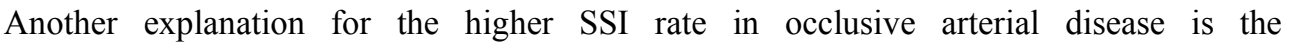

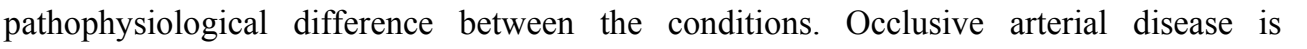

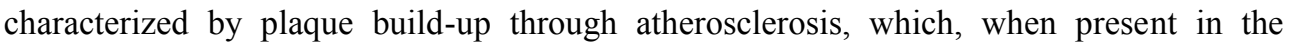

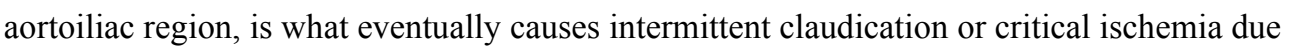

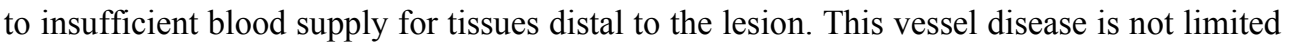
ए

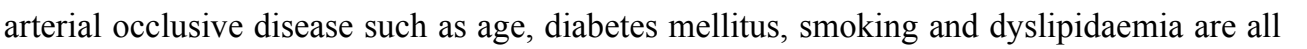

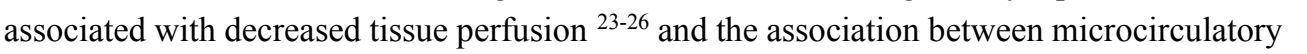

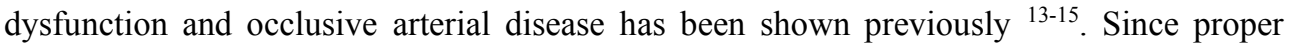

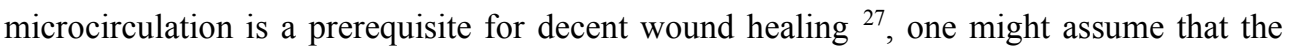

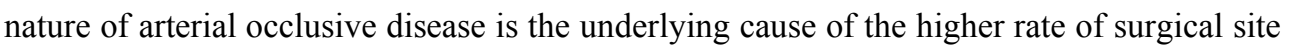
एणमाणाणाய

$\square$

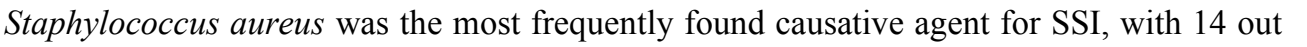

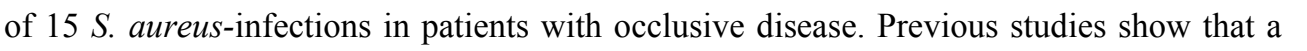

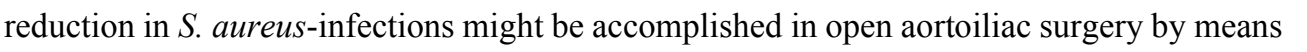

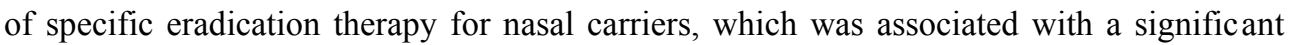

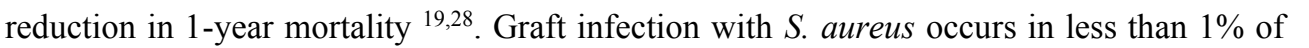

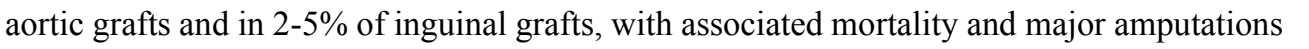

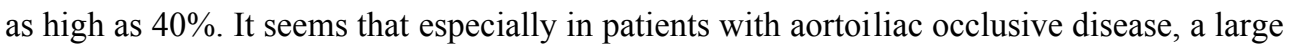

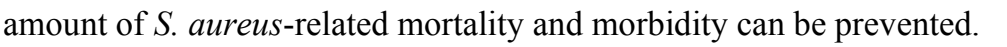




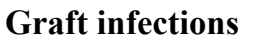

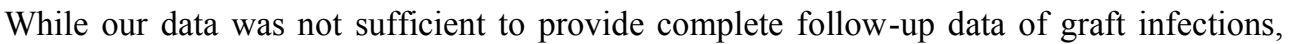

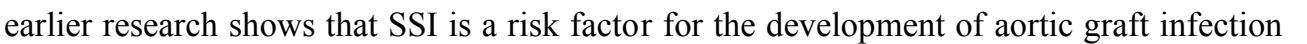

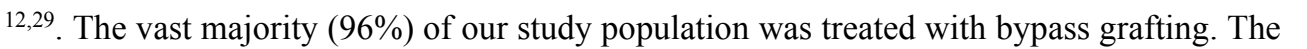
प

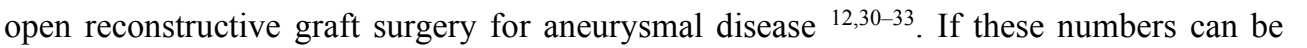

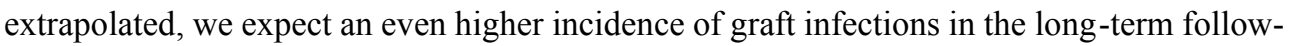

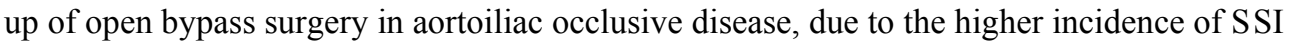

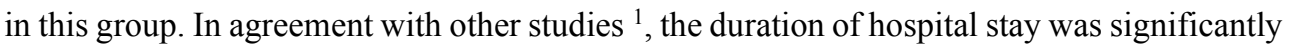

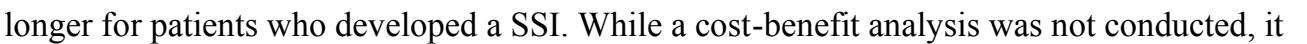

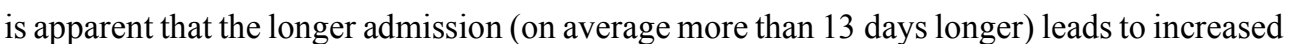

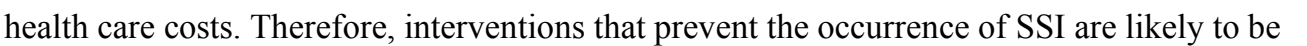

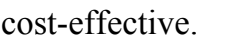

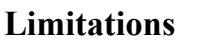

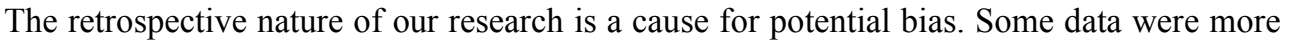

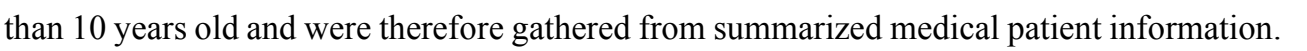

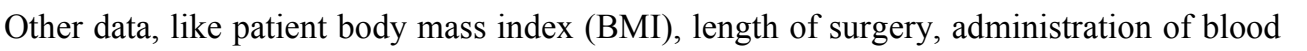

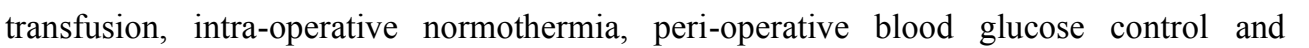

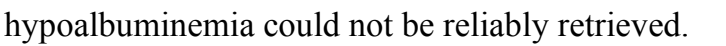

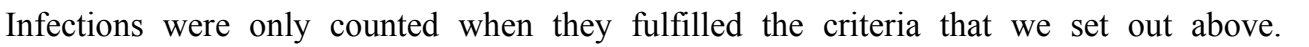

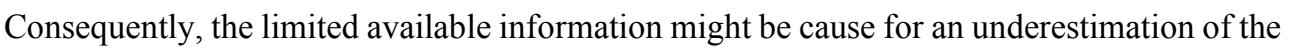
पाm

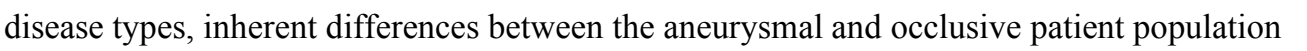

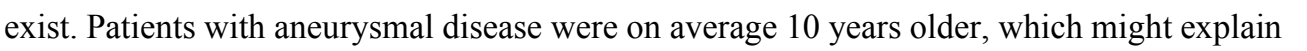

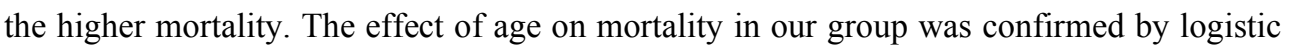

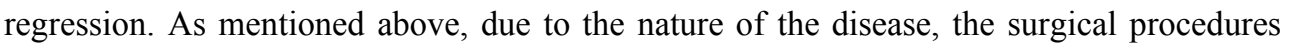

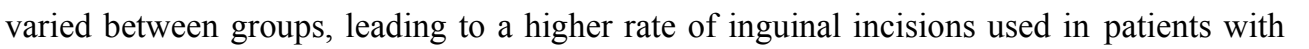

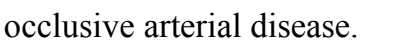

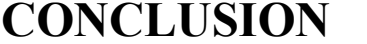

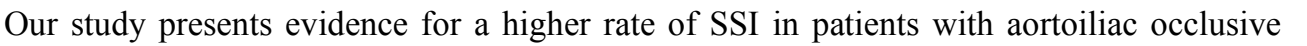

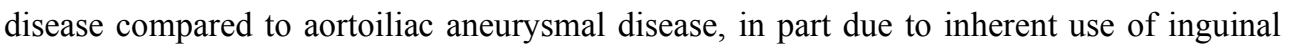

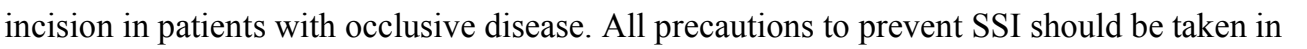

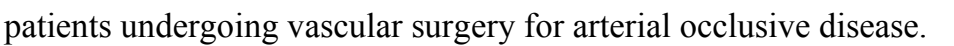




\section{प्रण $\square \square \square \square \square \square$}

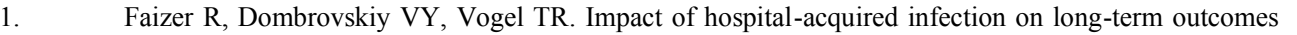

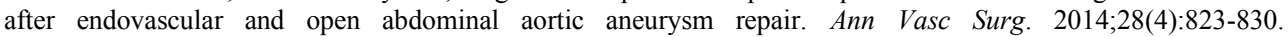
doi:10.1016/j.avsg.2013.06.028 $\square$

पIII Inui T, Bandyk DF. Vascular surgical site infection: Risk factors and preventive measures. $\square \square \square \square \square \square \square$

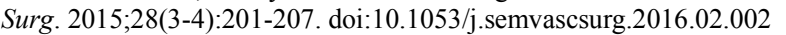

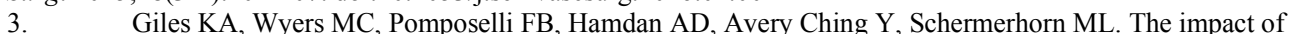

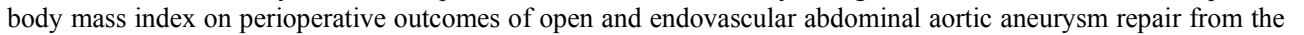

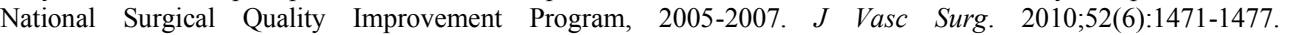
doi:10.1016/j.jvs.2010.07.013 $\square$

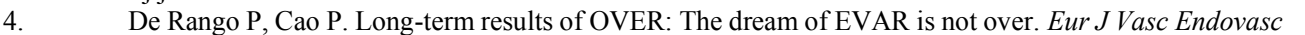
पIII. 2013;45(4):313 314. doi:10.1016/j.ejvs.2013.01.013

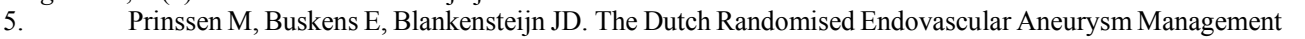

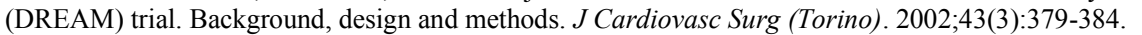

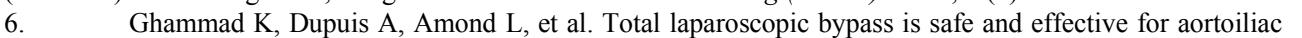

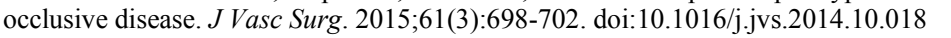

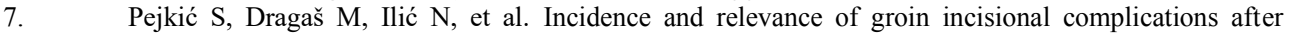

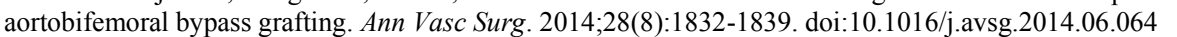

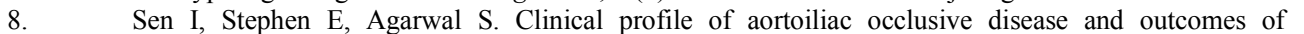

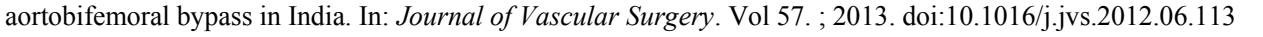

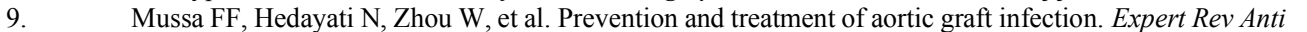
पापापाप. 2007;5(2):305 315. doi:10.1586/14787210.5.2.305 $\square$

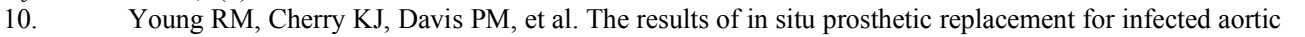

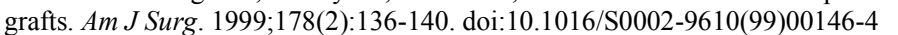

पाII Dirven M, Van Der Jagt MF, Barendregt WB, Van Der Vliet D. The efficacy of autologous

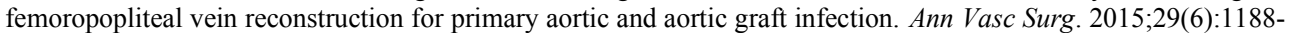
1195. doi:10.1016/j.avsg.2015.03.043 $\square$

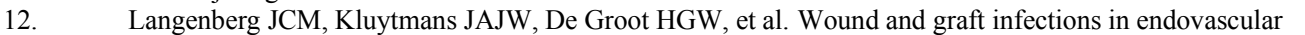

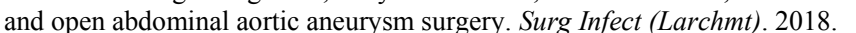

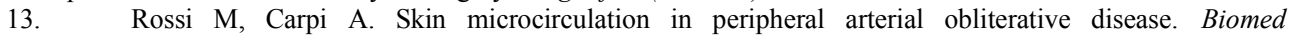

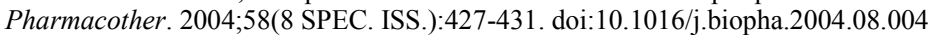

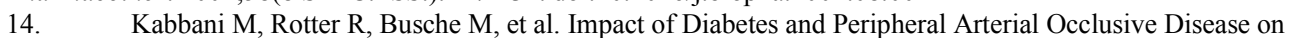

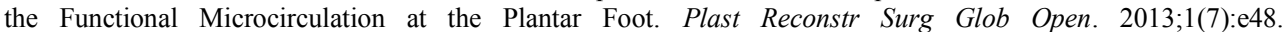
doi:10.1097/GOX.0b013e3182a4b9cb $\square$

पIII Abularrage CJ, Sidawy AN, Aidinian G, Singh N, Weiswasser JM, Arora S. Evaluation of the

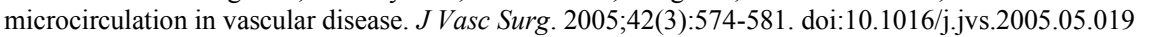

16. $\square$ Horan TC; Andrus, M; Dudeck M. CDC/NHSN Surveillance Definitions for Specific Types of

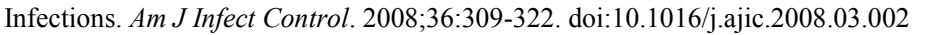

पIII Szilagyi DE, Smith RF, Elliott JP, Vrandecic MP. Infection in Arterial Reconstruction with Synthetic

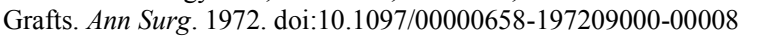

18. $\square \quad \square \square \square \square \square \square$ J, van der Laan L, Veen EJ, Hendriks Y, Romme J, Kluytmans J. Implementation of a

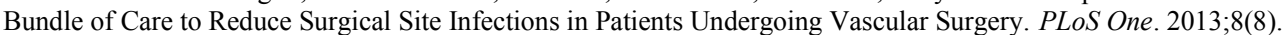
doi:10.1371/journal.pone.0071566

19. $\square \quad$ Langenberg JCM, Thomas AR, Donker JMW, van Rijen MML, Kluytmans JAJW, van der Laan L.

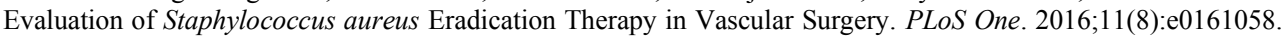
doi:10.1371/journal.pone.0161058 $\square$

$\square$ Roth RR, James WD. Microbial Ecology of the Skin. $\quad \square \square \square \square \square \square \square \square \square \square ा \Pi$. 2003. doi:10.1146/annurev.mi.42.100188.002301 $\square$

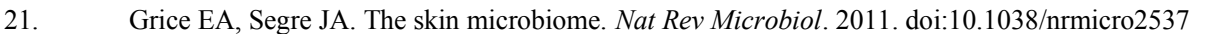

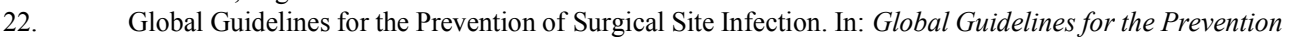

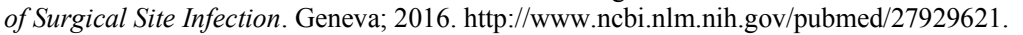

23. $\square \quad$ Wang L, Jerosch Herold M, Jacobs DR, Shahar E, Folsom AR. Coronary risk factors and myocardial

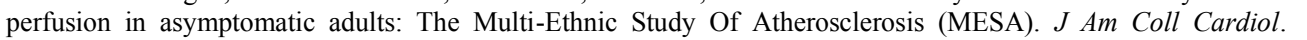
2006;47(3):565 572. doi:10.1016/j.jacc.2005.09.036

IIII Ijzerman RG, Serne EH, van Weissenbruch MM, de Jongh RT, Stehouwer CD a. Cigarette smoking is

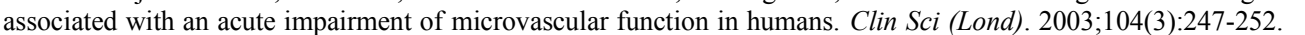
doi:10.1042/CS20020318 $\square$ 


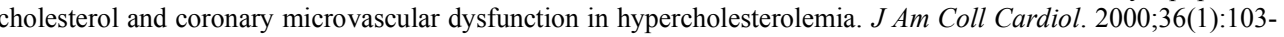

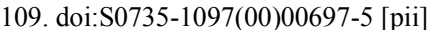

26.

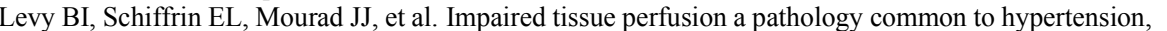

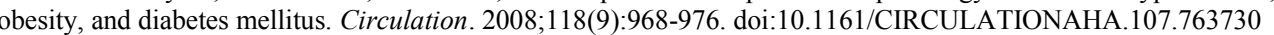
27. Gottrup F. Oxygen in Wound Healing and Infection. $\square \square \square \square \square \square \square \square . ~ 2004 ; 28(3): 312315$.

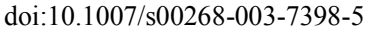

$\square \mathrm{B}$ Bode LGM, Rijen MML van, Wertheim HFL, et al. $\square \square \square \| \Pi \square \square \square$ tality After Rapid Screening and Decolonization of Staphylococcus Aureus Carriers. $\quad \square \square \quad \square \square$ 2016;263(3):511515. doi:10.1097/SLA.0000000000001060

29.

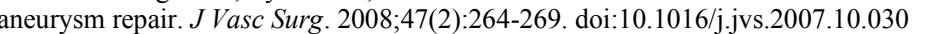

30. $\square$ Chiu KWH, Davies RSM, Nightingale PG, Bradbury AW, Adam DJ. Review of Direct Anatomical Open

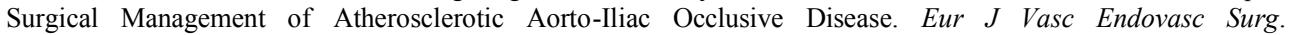
2010;39(4):460 471. doi:10.1016/j.ejvs.2009.12.014

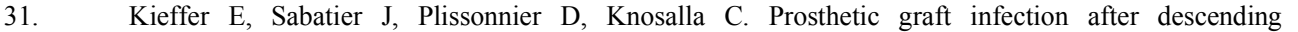
thoracic/thoracoabdominal aortic aneurysmectomy: Management with in situ arterial allografts $\square \square \square \square \| \square \square \square \square \square$ 2001;33(4):671 678. doi:10.1067/mva.2001.112314

32. $\square$ Swain TW, Calligaro KD, Dougherty MD. Management of Infected Aortic Prosthetic Grafts.

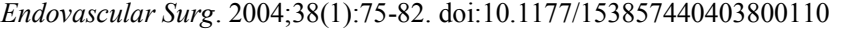

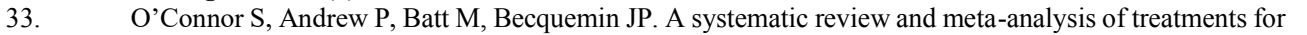

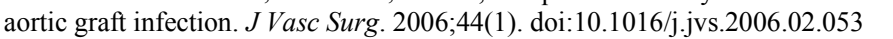




$$
6
$$




\section{Chapter 6}

\section{Surgical Site and Graft Infections in Endovascular and Open Abdominal Aortic Aneurysm Surgery}

Langenberg JCM, Kluytmans JAJW, de Groot HGW, Ho GH, Veen EJ, Buimer $M G$, van der Laan $L$. 


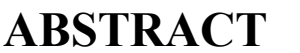

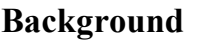

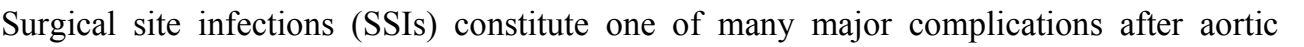

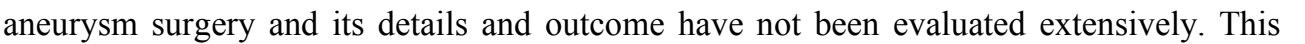

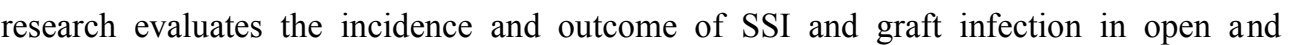

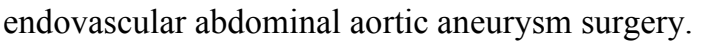

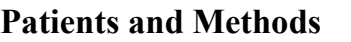

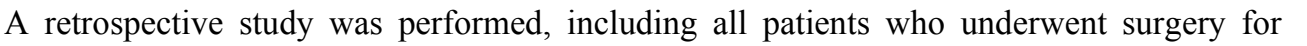

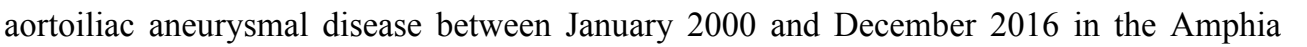

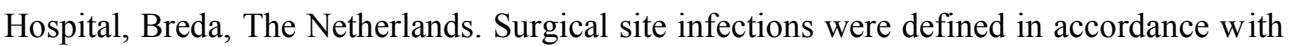

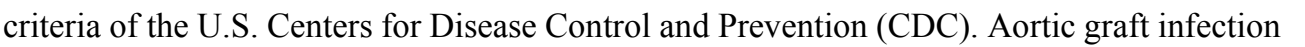

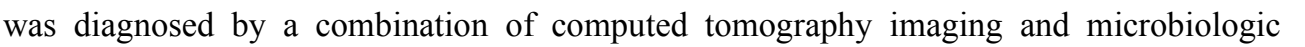
पा\|ा\|ा山ा

\section{$\square \square\|\square\| \square$}

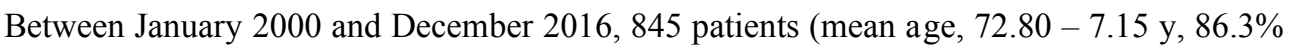

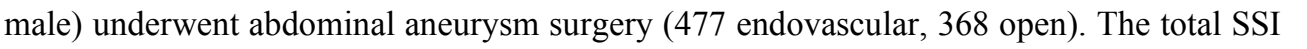

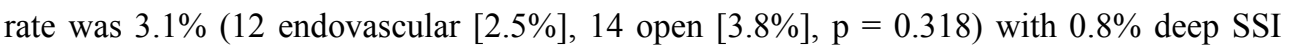

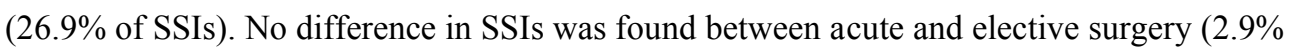

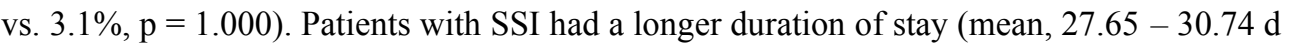

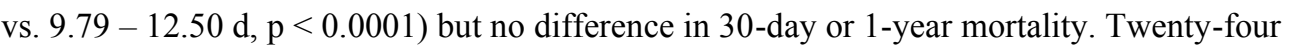

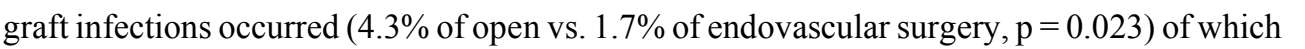

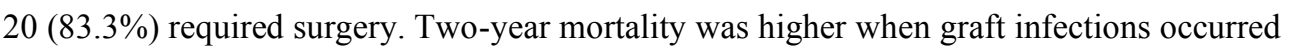
ए।

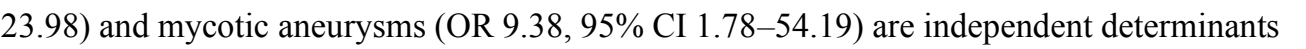

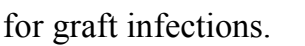

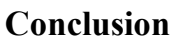

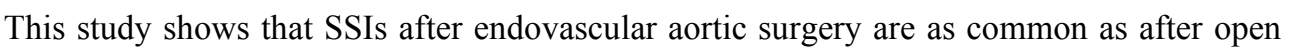

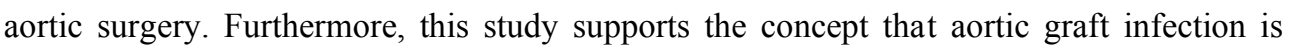

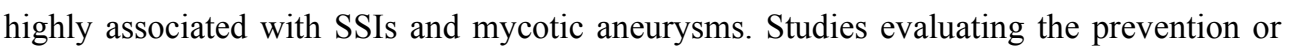

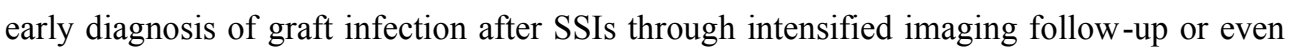

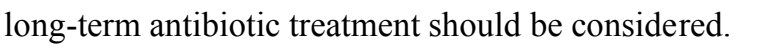
$\square$ 


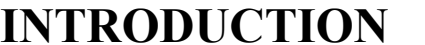

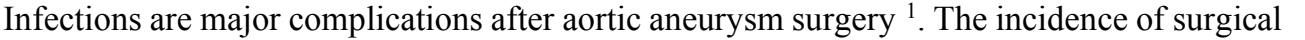

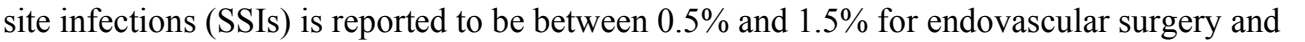

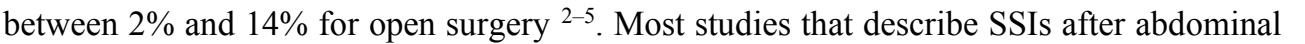

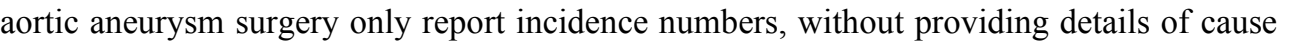

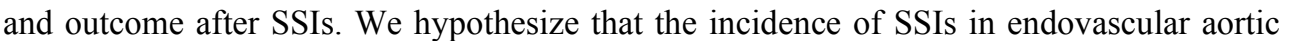

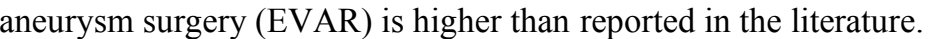

$\square$

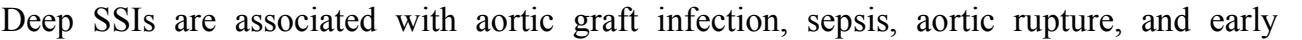

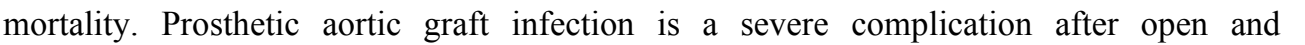

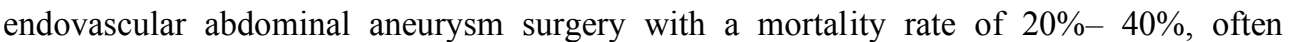

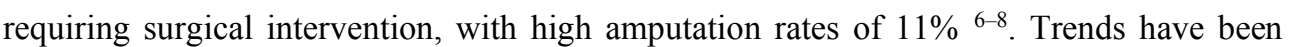

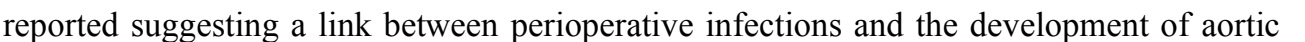

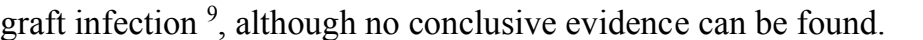

$\square$

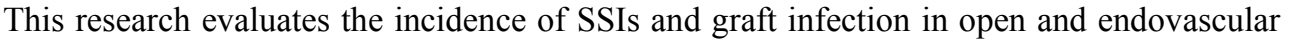
पाD

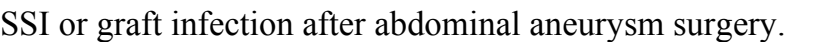

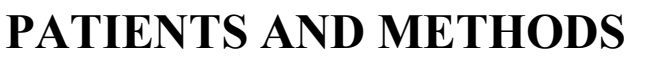

$\square \square \| ण \square$

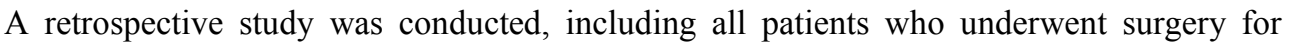

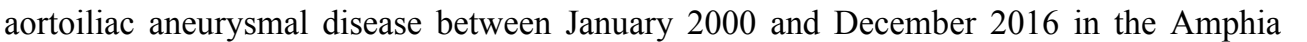

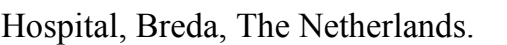

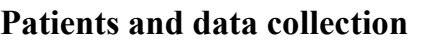

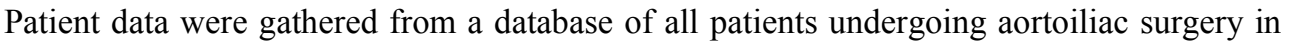

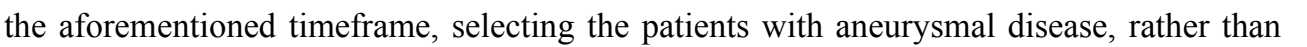

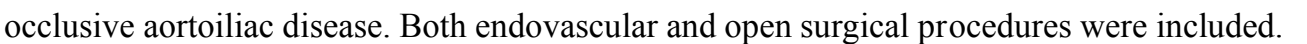

\section{Data were gathered retrospectively by reviewing medical files in the hospital's electronic}

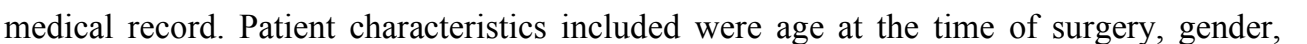

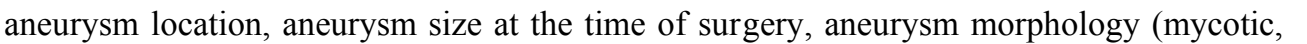

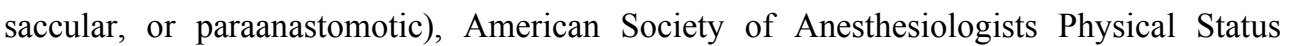

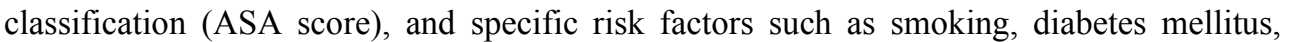

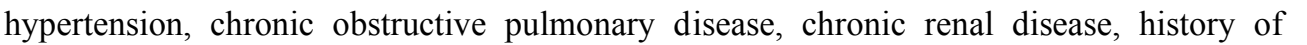

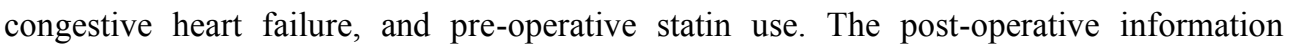
ए। 


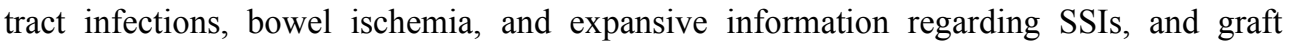

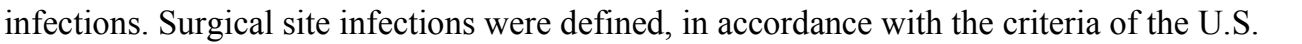
$\square$

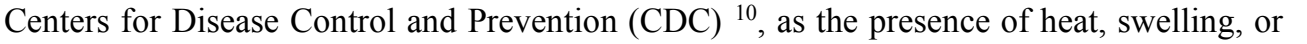

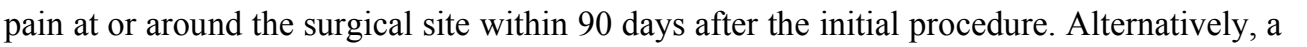

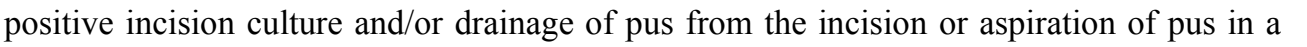

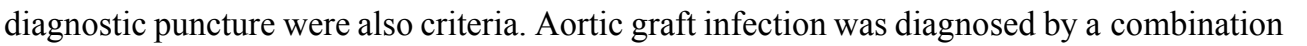

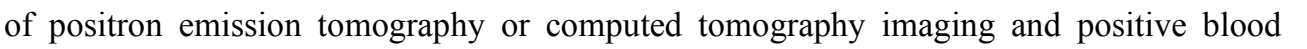

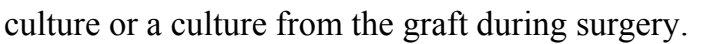

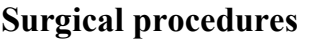

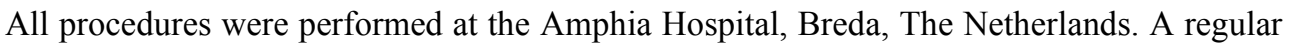

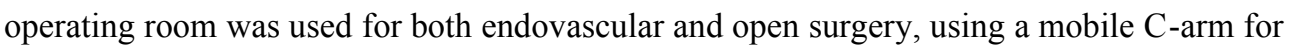

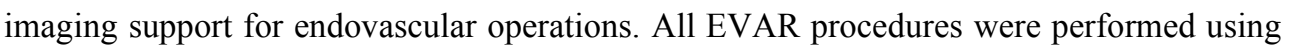

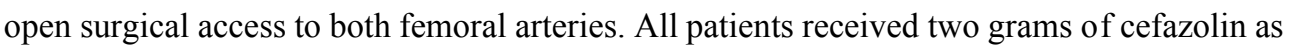

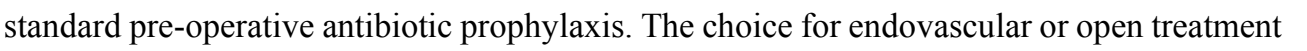

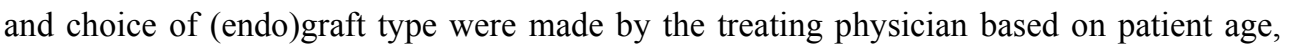

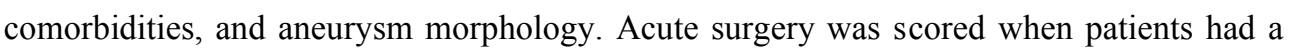

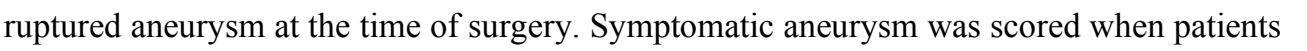

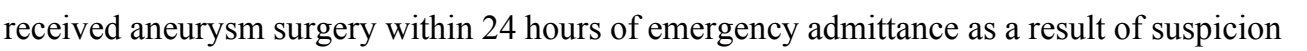

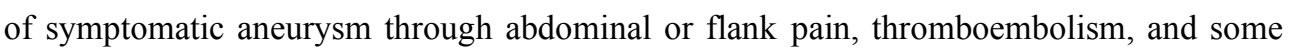

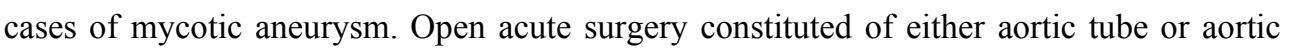

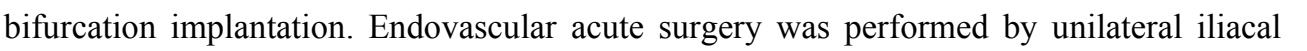

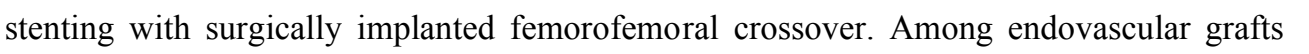

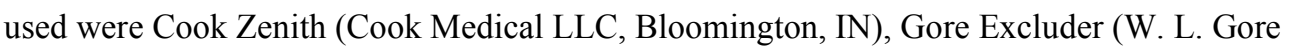

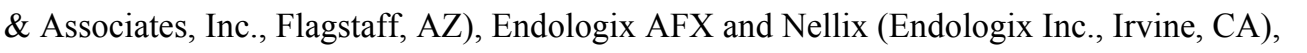

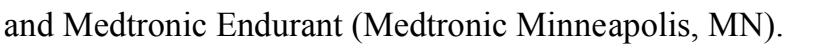

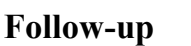

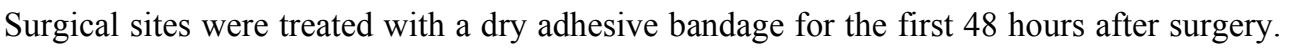

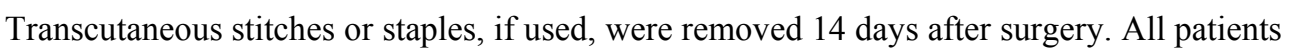

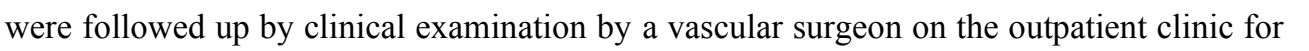

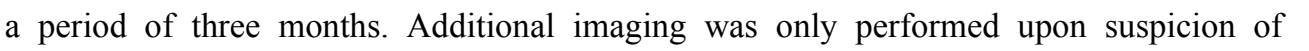

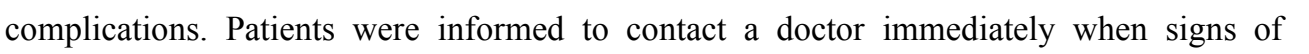

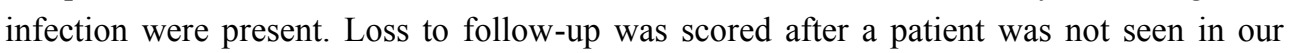

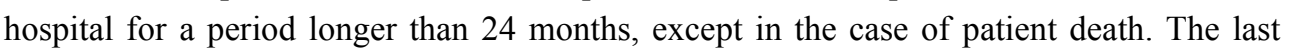
patient visit was extracted from our hospital's electronic patient records. $\square$ 


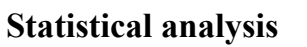

$\square \square \square \square \square\|\| \square \square \square$ test was used to compare categorical variables; continuous variables were

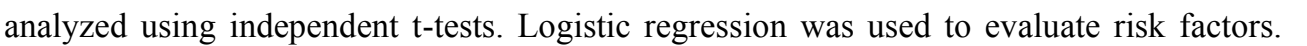

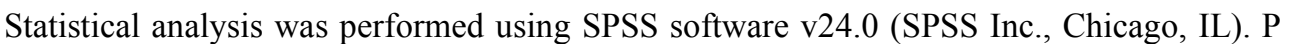

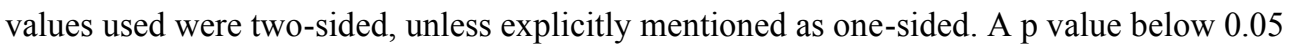

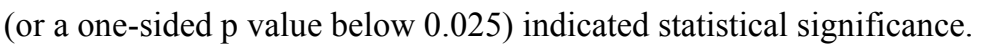

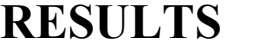

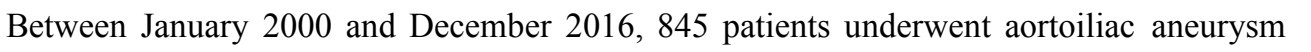

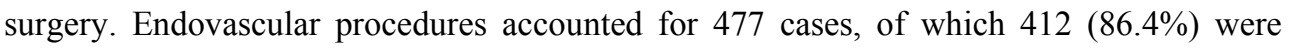

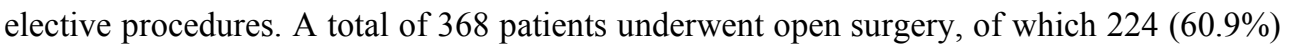

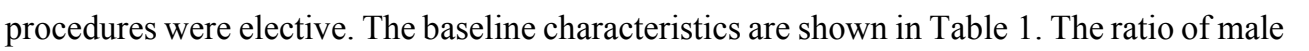

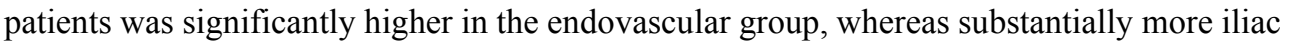

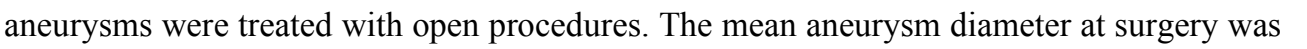

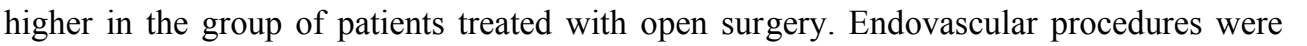

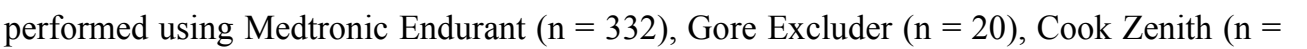

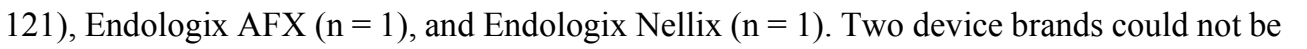

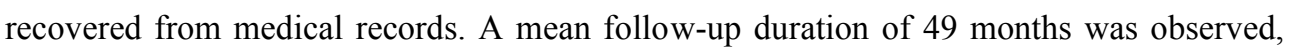

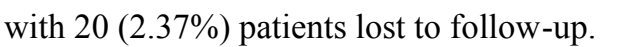

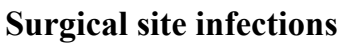

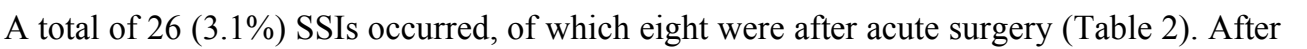

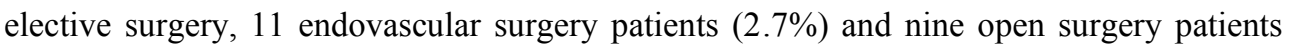

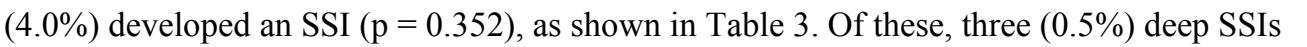

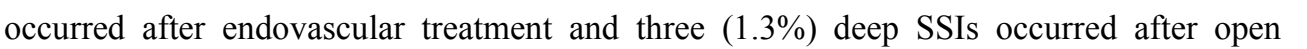
पाम

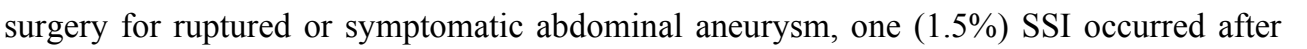

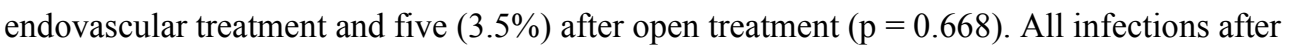

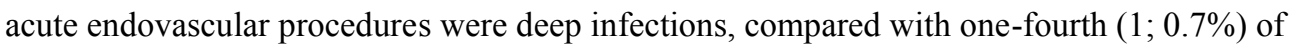

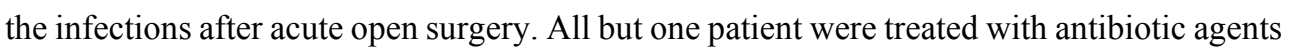

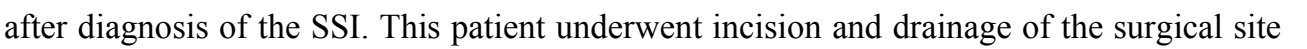

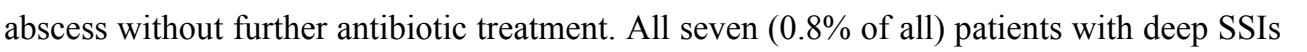

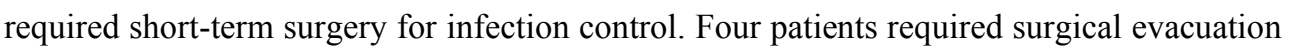

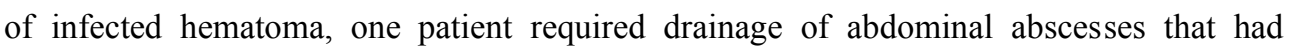

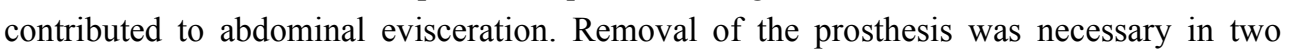

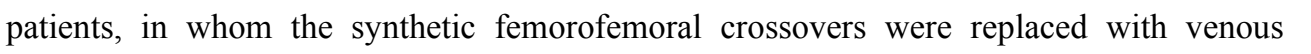

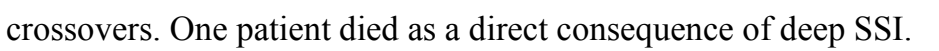

$\square$ 


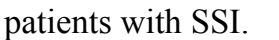

\begin{tabular}{|c|c|c|c|}
\hline 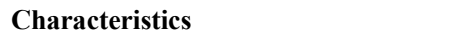 & 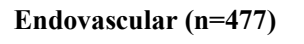 & 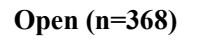 & 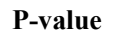 \\
\hline Mean (SD) age $\square$ & $73.82(7.06) \square$ & $71.47(7.06) \square$ & $<0.0001 \square$ \\
\hline Sex, no. male (\% male) $\square$ & $423(88.7) \square$ & $306(83.2) \square$ & $\square \square \square$ \\
\hline ASA Score $\geq 3(\%) \square$ & $286(61.5) \square$ & $222(64.7) \square$ & $\square \square \square$ \\
\hline Smoking $(\%) \square$ & $153(32.1) \square$ & $157(42.9) \square$ & $\square \square \prod$ \\
\hline Diabetes mellitus (\%) $\square$ & $\square(17.0) \square$ & $59(16.0) \square$ & $\square \square \square$ \\
\hline Hypertension (\%) $\square$ & $269(56.8) \square$ & $212(59.6) \square$ & $\square \square \square$ \\
\hline Chronic renal disease (\%) $\square$ & $19(4.1) \square$ & $21(5.8) \square$ & $\square \square \square$ \\
\hline Cardiac history (\%) $\square$ & $218(45.9) \square$ & $139(39.3) \square$ & 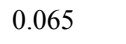 \\
\hline Ruptured aneurysm (\%) $\square$ & $45(9.4) \square$ & $125(34.0) \square$ & $<0.0001 \square$ \\
\hline 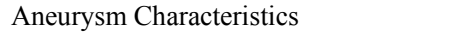 & $\square$ & $\square$ & $\square$ \\
\hline Mean (SD) aneurysm diameter in $\mathrm{mm} \square$ & $62.99(11.98) \square$ & $70.31(17.31) \square$ & $<0.0001 \square$ \\
\hline Mycotic (\%) $\square$ & $3(0.6) \square$ & $9(2.5) \square$ & $\square \square \square$ \\
\hline Anastomotic (\%) $\square$ & $6(1.3) \square$ & $3(0.8) \square$ & $\square \square \square \square$ \\
\hline Saccular (\%) $\square$ & $6(1.3) \square$ & $1(0.3) \square$ & $\square \square \square$ \\
\hline Iliac aneurysm (\%) $\square$ & $34(7.1) \square$ & $55(14.9) \square$ & $<0.0001 \square$ \\
\hline
\end{tabular}

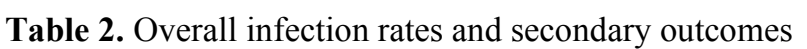

\begin{tabular}{|c|c|c|c|}
\hline$\square$ & 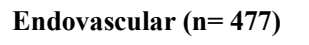 & 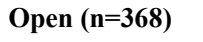 & पामापा \\
\hline Surgical Site Infection rate (\%) $\square$ & $12(2.5) \square$ & $14(3.8) \square$ & $\square \square \square \square$ \\
\hline$\square$ Superficial infection (\%) $\square$ & $9(1.9) \square$ & $10(2.7) \square$ & $\square \square \square$ \\
\hline$\square$ Deep infection (\%) $\square$ & $3(0.6) \square$ & $4(1.1) \square$ & \\
\hline Readmission for infection (\%) $\square$ & $9(1.9) \square$ & $5(1.4) \square$ & $\square \square \square \square$ \\
\hline$\square \square$ intervention for infection (\%) $\square$ & $4(0.8) \square$ & $4(1.1) \square$ & $\square \square \square \square$ \\
\hline Duration of hospital stay (mean, SD)* $\square$ & $6.55(7.56) \square$ & $15.26(17.83) \square$ & $<0.0001 \square$ \\
\hline$\square$ day mortality (\%) & $15(3.1) \square$ & $47(12.8) \square$ & $<0.0001 \square$ \\
\hline$\square \square \square \square$ mortality (\%) $\square$ & $31(6.5) \square$ & $65(17.7) \square$ & $<0.0001 \square$ \\
\hline 1 year mortality $(\%) \square$ & $40(8.4) \square$ & $69(18.8) \square$ & $<0.0001 \square$ \\
\hline
\end{tabular}

*including duration of readmissions $\square$ 


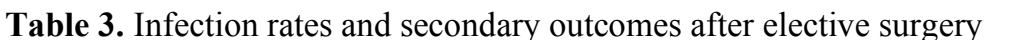

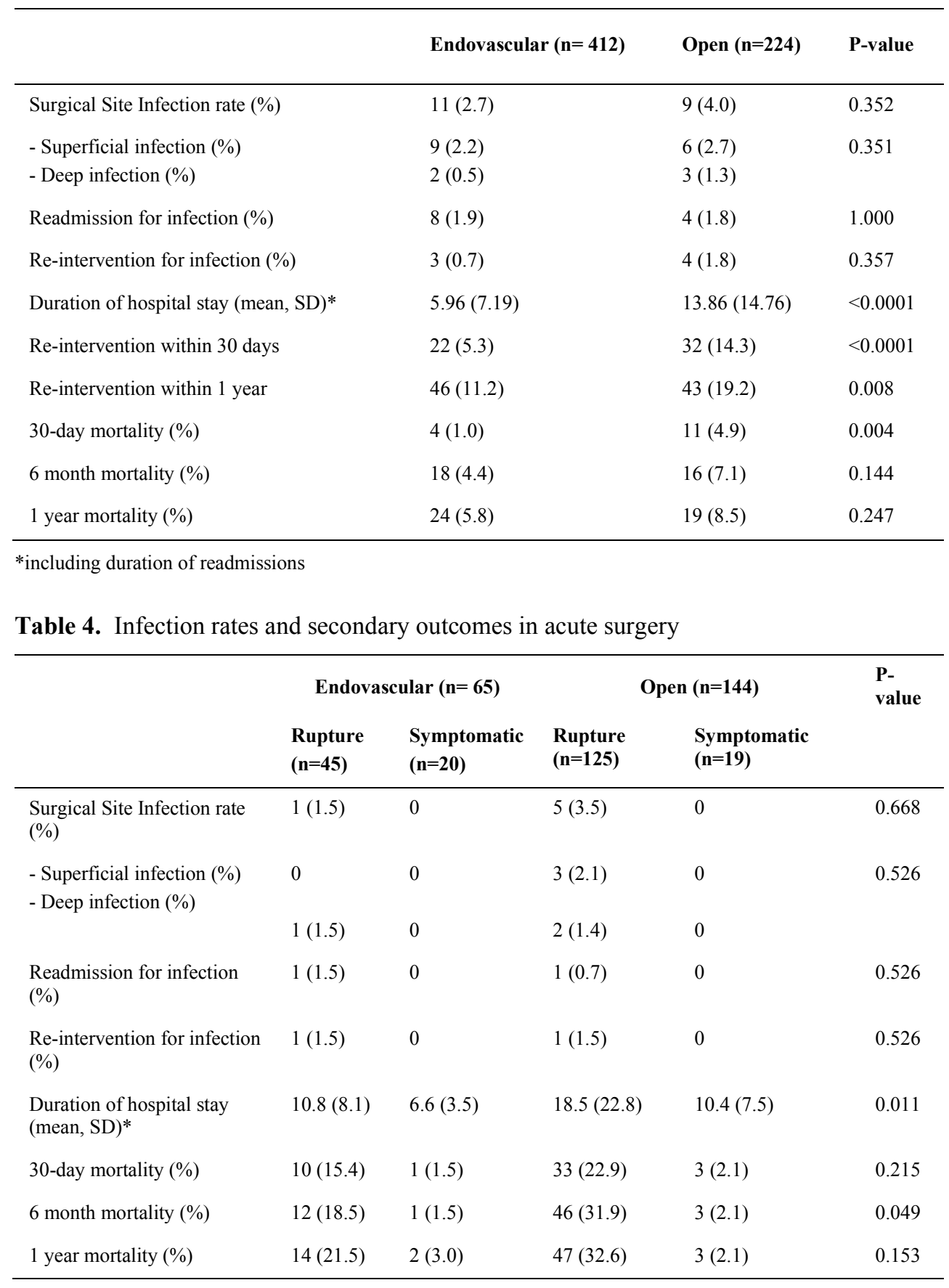

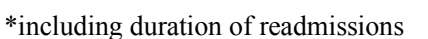




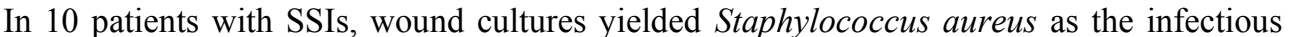

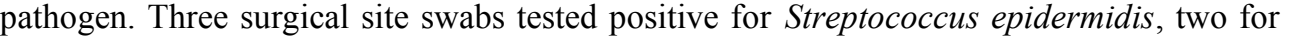

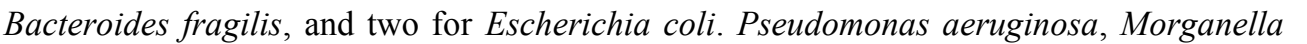

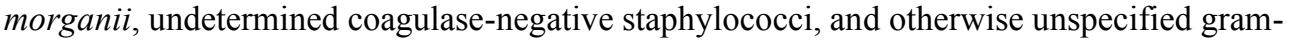

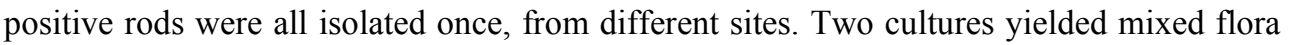

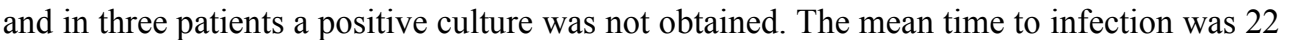

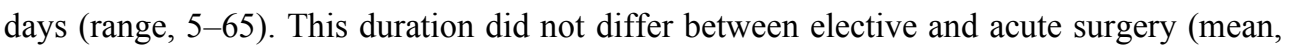

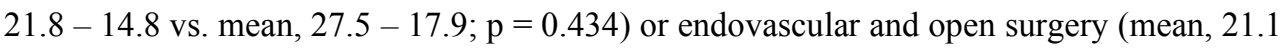

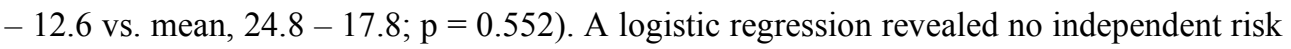

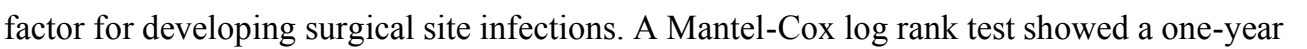

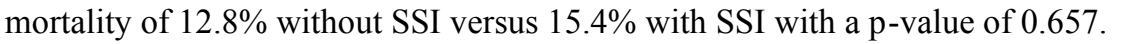
$\square$

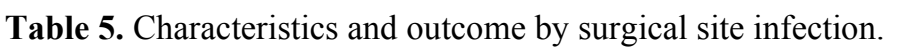

\begin{tabular}{|c|c|c|c|}
\hline$\square$ & 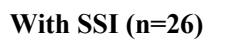 & 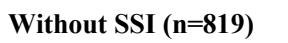 & 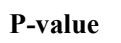 \\
\hline Mean duration of hospital stay (SD) $\square$ & $27.65(30.74) \square$ & 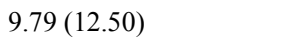 & 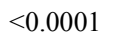 \\
\hline$\square \square$ intervention $<30$ days $(\%) \square$ & $9(34.6) \square$ & पाणाणाप & एणा \\
\hline 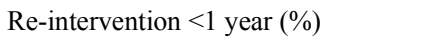 & $11(42.3) \square$ & $135(16.5) \square$ & पणाए \\
\hline 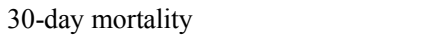 & $1(3.8) \square$ & पाणापा & पणाए \\
\hline 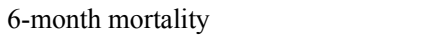 & 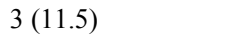 & $93(11.4) \square$ & एणा \\
\hline 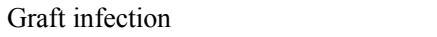 & एणाणाण & पण口卄ाण & $\square ण \square$ \\
\hline
\end{tabular}

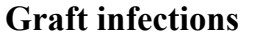

A total of 24 (2.8\%) graft infections occurred, 16 open reconstructive grafts (4.3\% of all open grafts) and eight endografts $(1.7 \%$ of endovascular grafts, $\mathrm{p}=0.023)$. All cases were

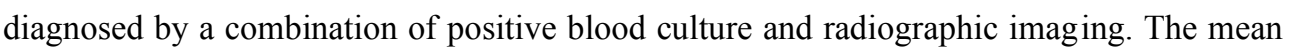
time to graft infection was 392 days (-696; range, 12-3,289) with a median of 118 days. Surgery was required in $20(83.3 \%)$ patients with graft infection, although five of them died

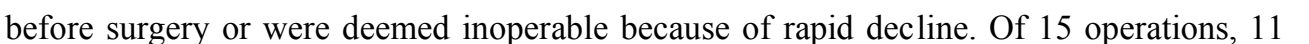

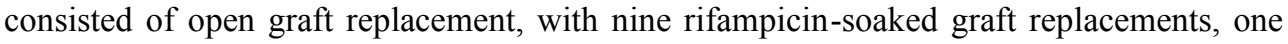

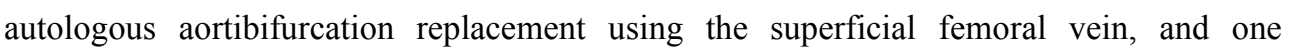

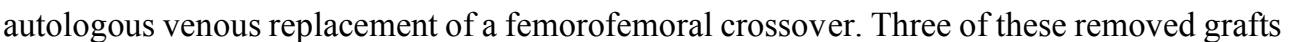
were endografts after EVAR, constituting $0.6 \%$ of all endovascular treatments, compared with eight $(2.2 \%)$ graft removals after open surgery $(\mathrm{p}=0.066)$. The remaining four

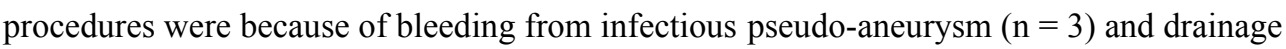
of abdominal abscesses and evisceration treatment $(n=1)$. Patients with graft infections were treated with antibiotic agents for an average of 325 days, ranging from 0 to 2,447 days. When

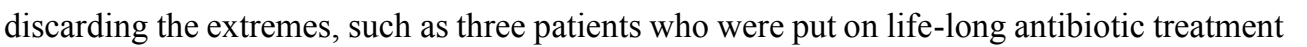
and three patients who died within a week of being diagnosed with graft infection, patients 


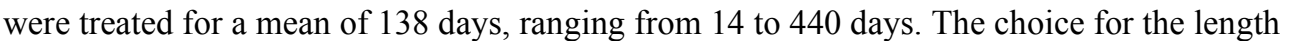

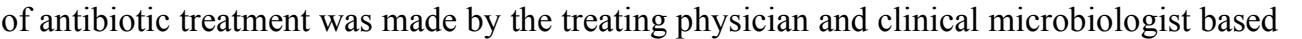
on the patient's symptoms, infectious pathogen, radiographic imaging, and laboratory tests.

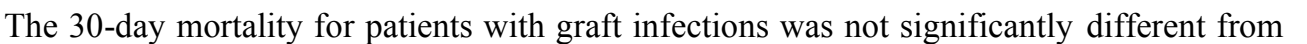

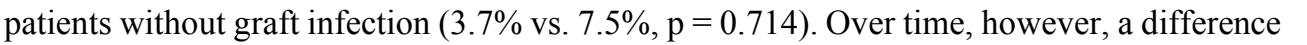
प

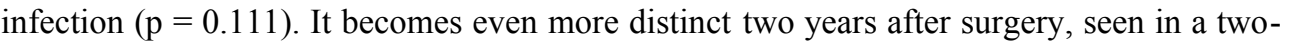

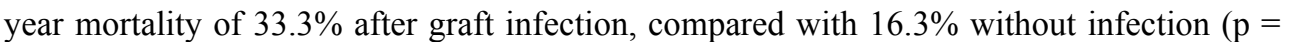

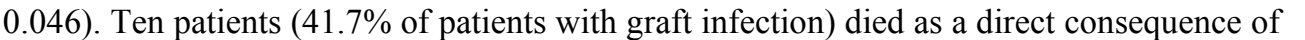

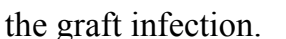

四

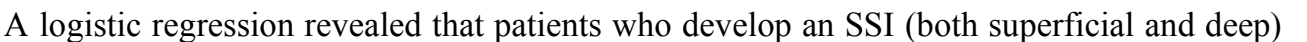

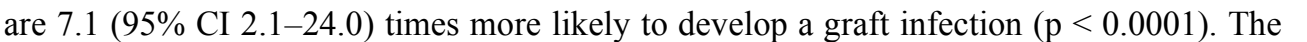

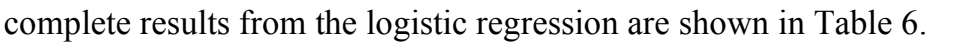

$\square$

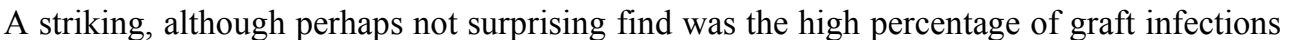

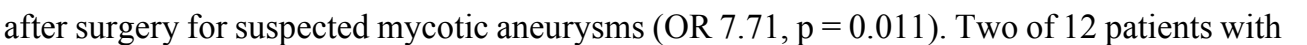

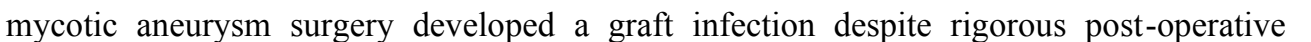

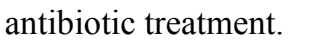

$\square$

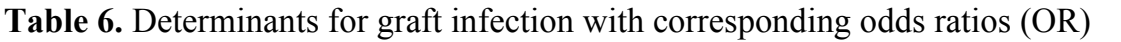

\begin{tabular}{|c|c|c|}
\hline पणाயण & 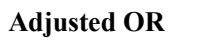 & 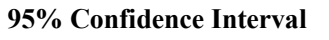 \\
\hline 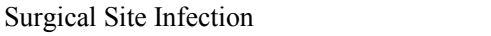 & एणाए & 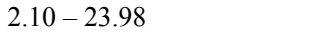 \\
\hline 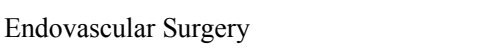 & पण口 & मणनயण \\
\hline 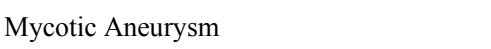 & पाए & पणमणाாए \\
\hline 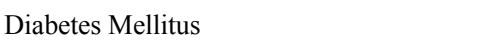 & पणा & पणामणमा \\
\hline पमणणा & पणा & पणमाणम \\
\hline பாயாயாாாயாட & $\square \square \square$ & पणमाणாए \\
\hline 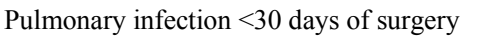 & एणा & पणामणाण \\
\hline
\end{tabular}

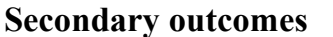

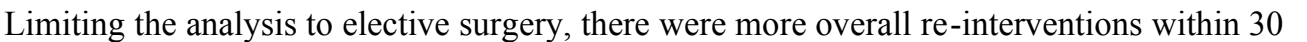

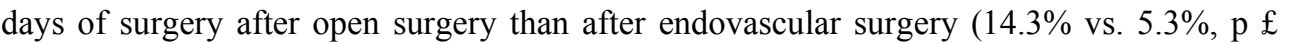

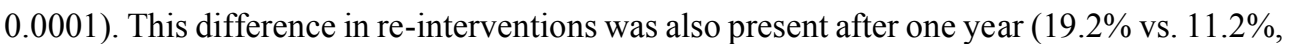

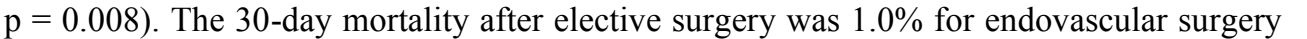

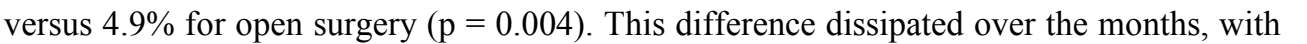

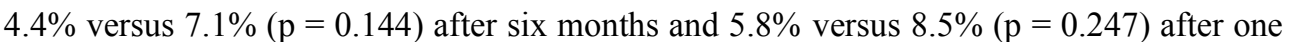

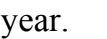




\section{Chapter 6}

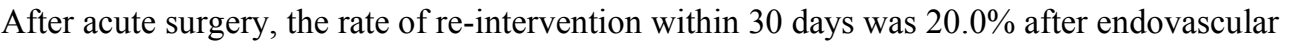

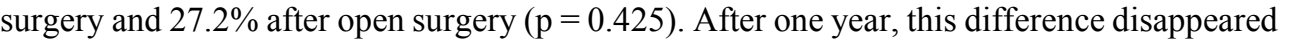

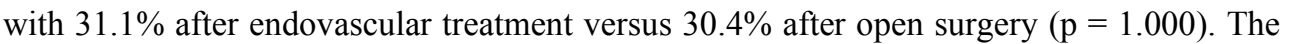

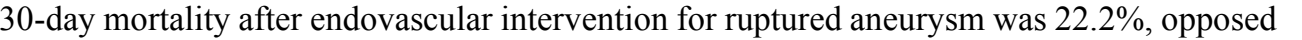

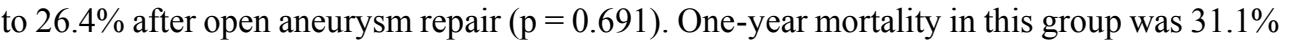

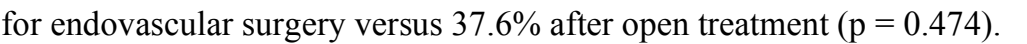

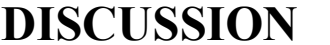

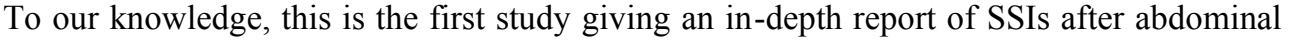

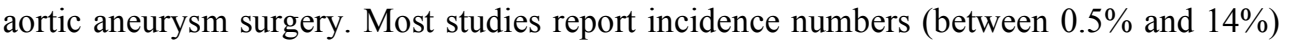

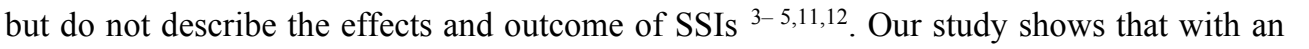

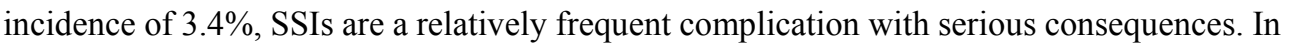

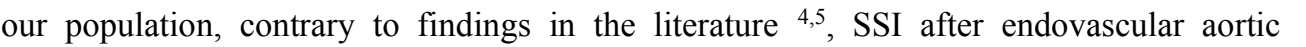

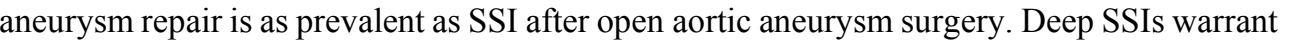

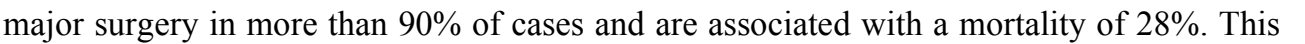

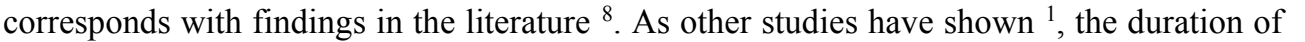

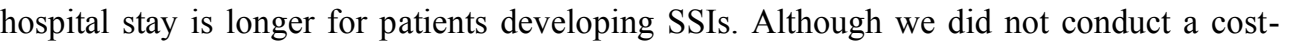

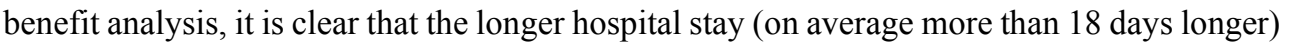

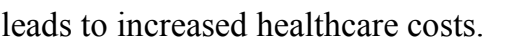

$\square$

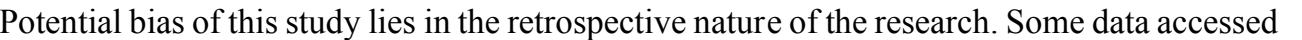

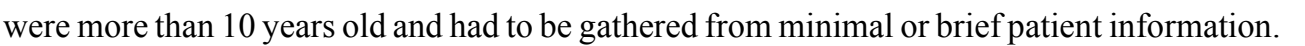

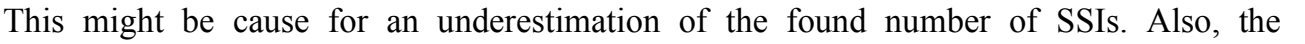

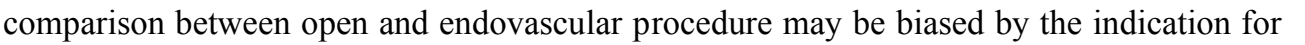

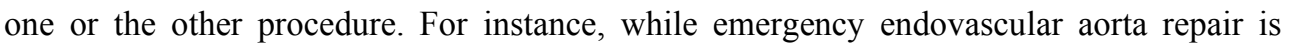

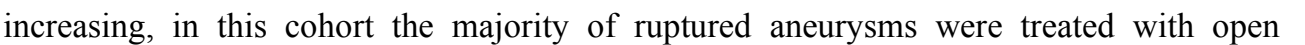

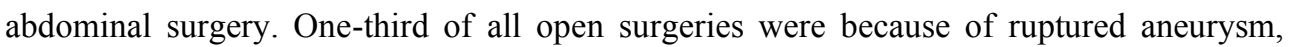

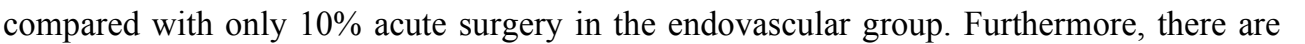

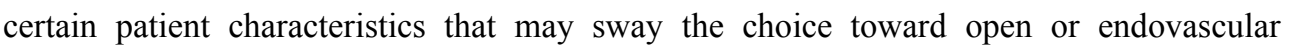

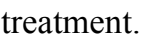

$\square$

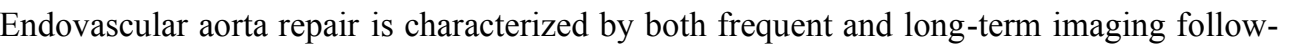

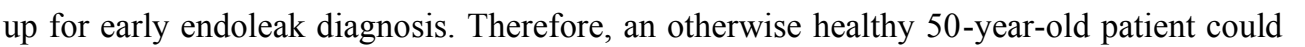

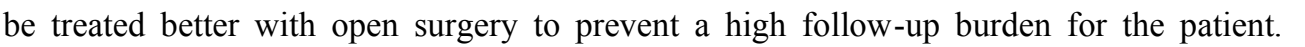

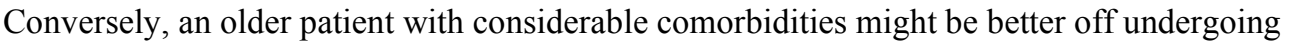

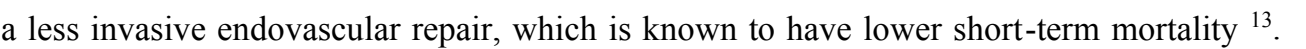

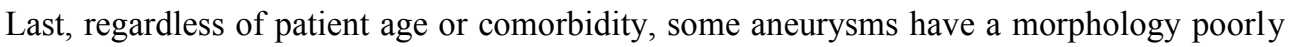

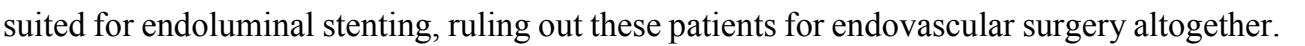

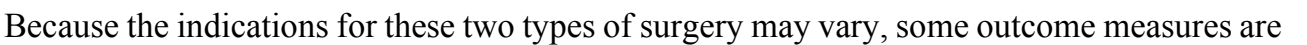




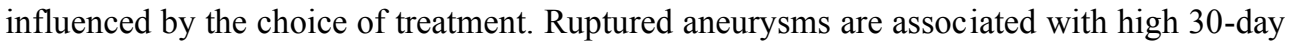

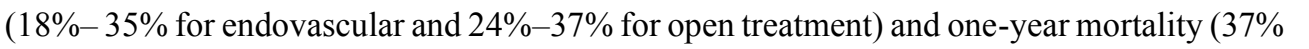

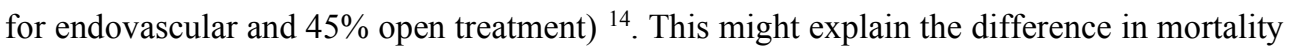

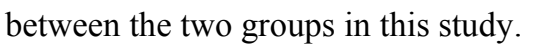

$\square$

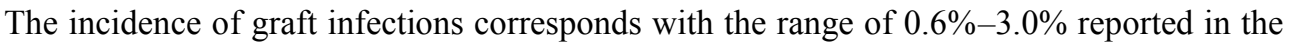

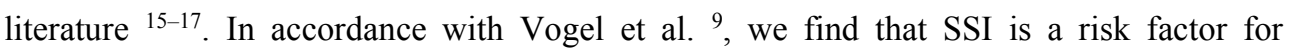

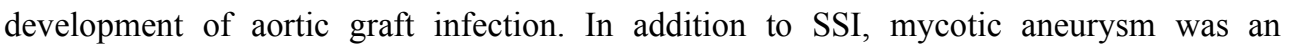

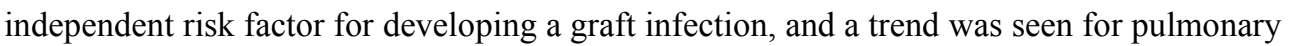

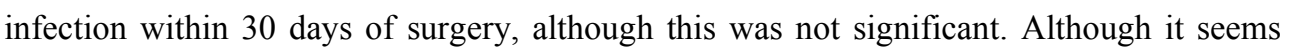

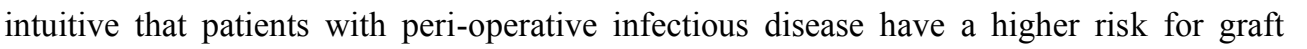

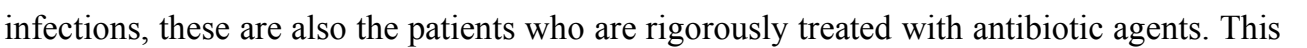

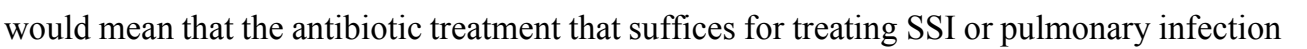

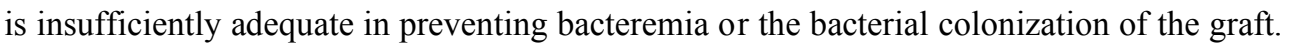

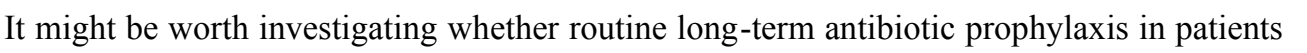

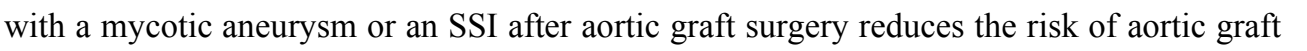

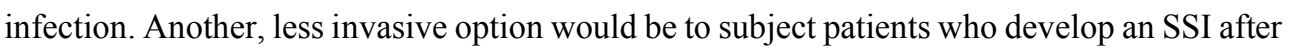

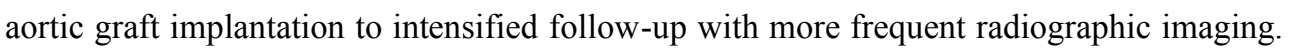

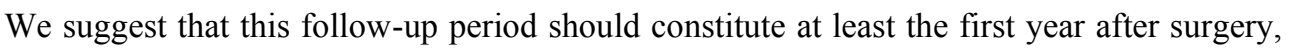

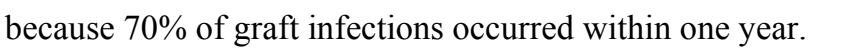

$\square$

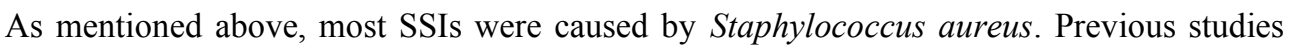

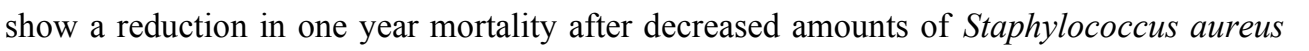

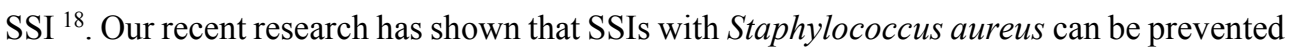

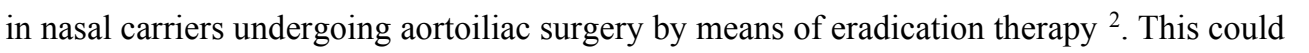

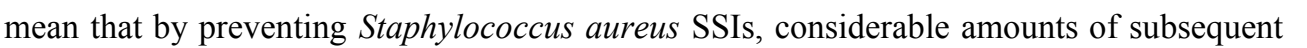

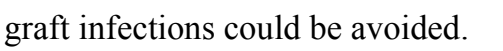

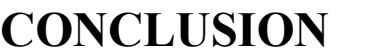

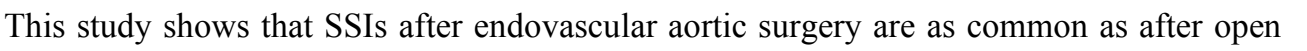

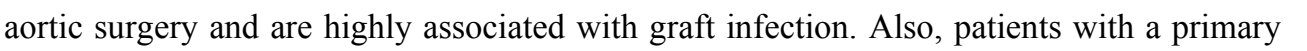

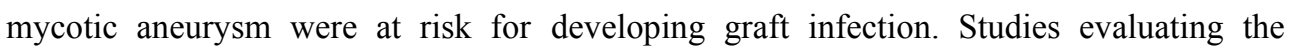

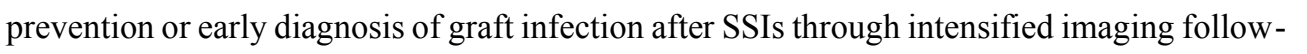

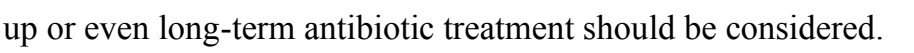

$\square$

$\square$ 


\section{Chapter 6}

\section{प्रण $\square \square \square \square \square \square$}

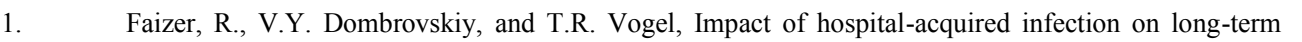

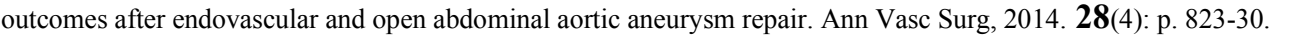

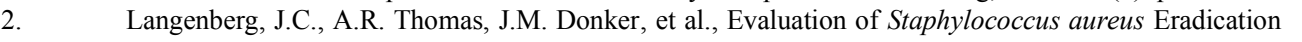

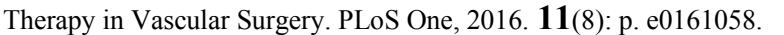

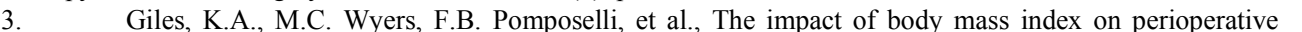

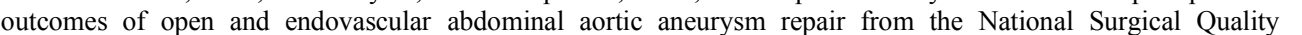

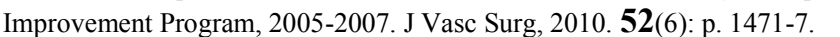

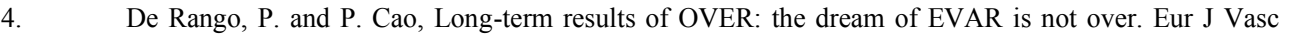

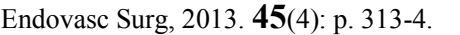

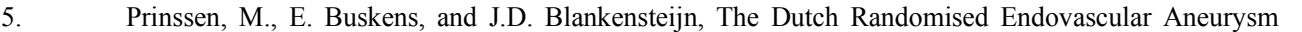

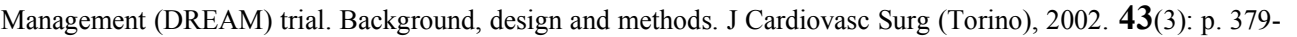
पाII

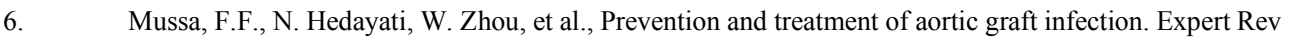

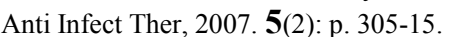

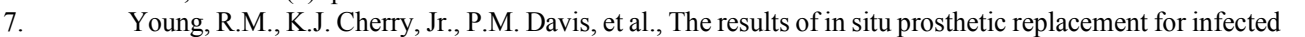

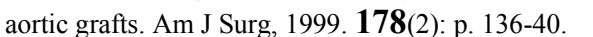

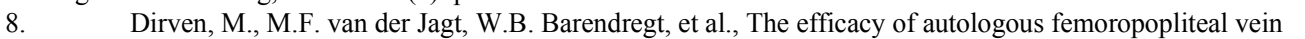

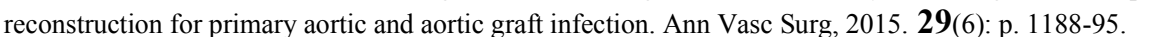

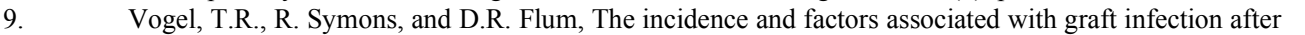

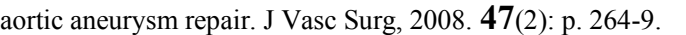

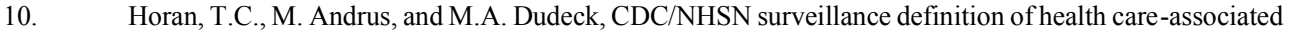

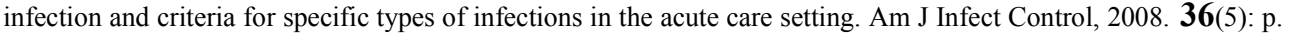
पाणाण

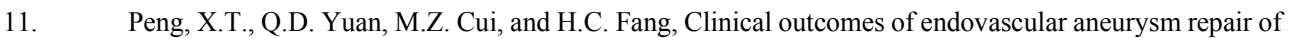

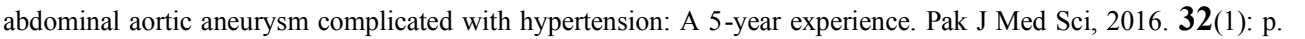
पाणाए

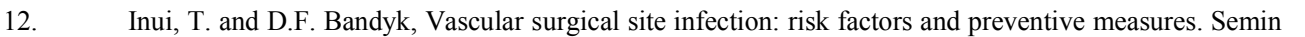

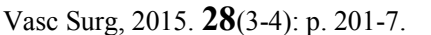

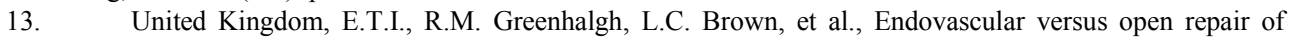

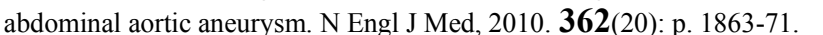

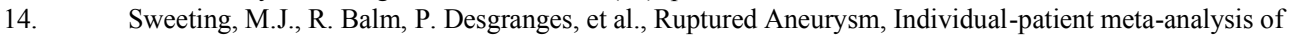

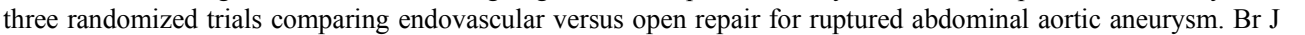

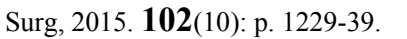

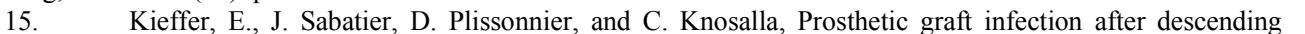
प एव पामाणाणाणाप

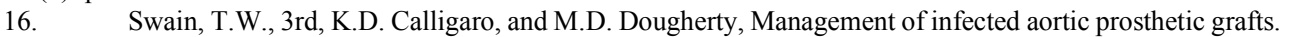

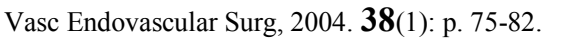

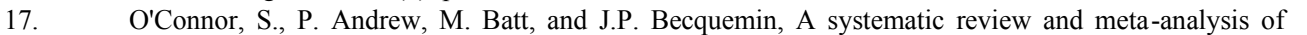

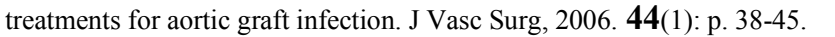

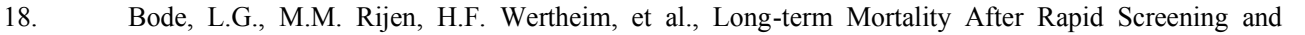

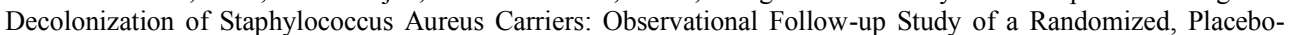

controlled Trial. Ann Surg, 2016 Mar;263(3):511 سயm

$\square$ 


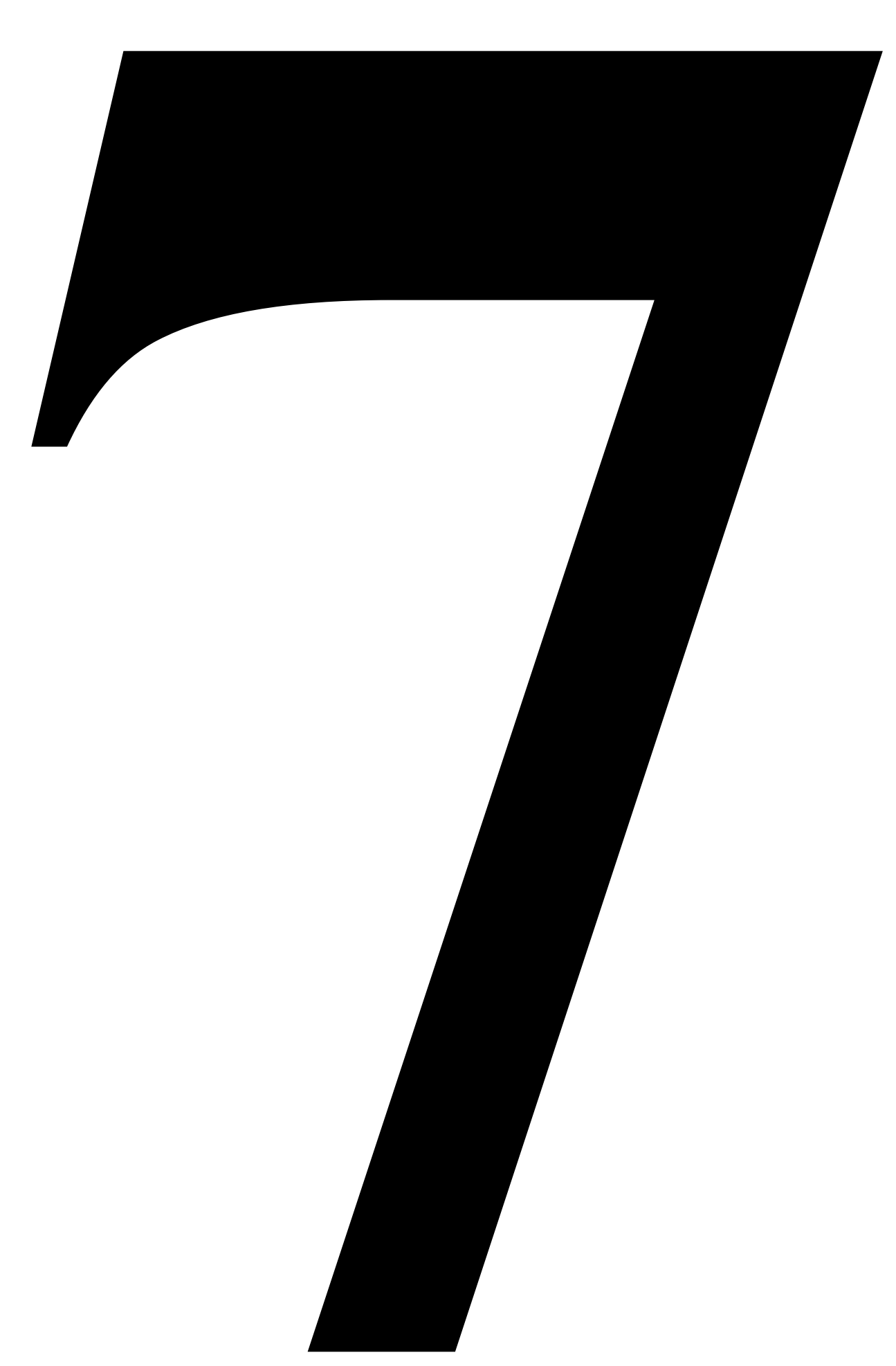




\section{Chapter 7}

Summary, general discussion and future aspects 


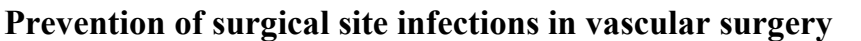

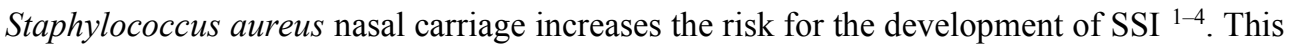

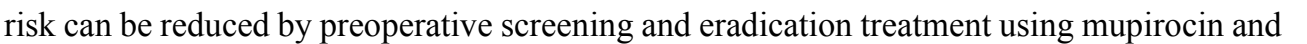

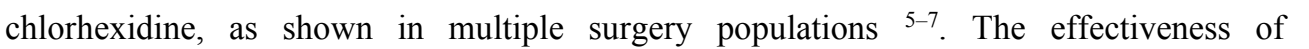

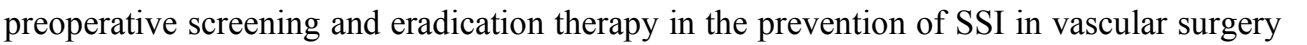

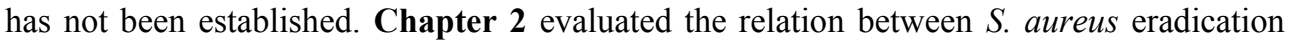
ए

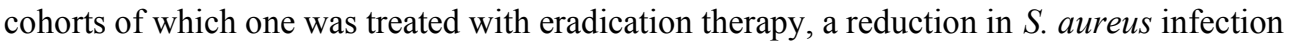

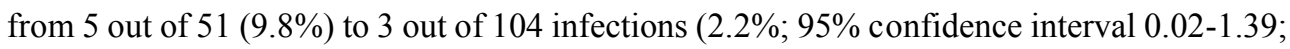

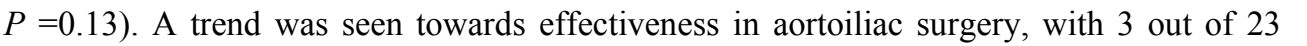

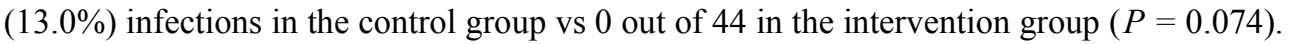

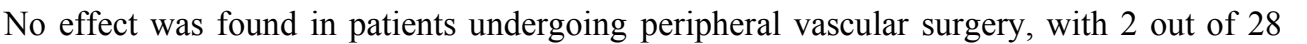

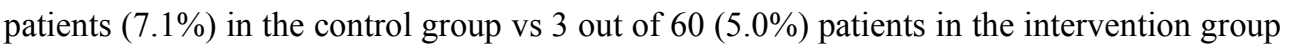

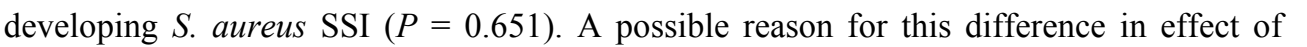

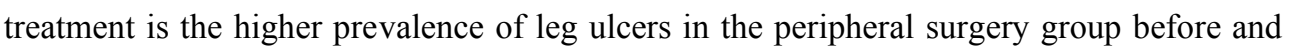

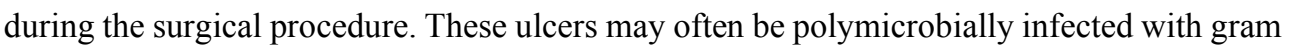

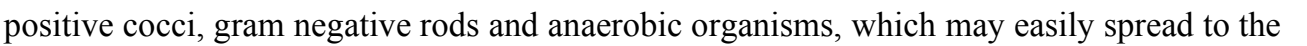

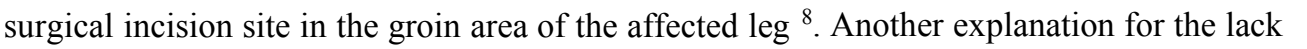

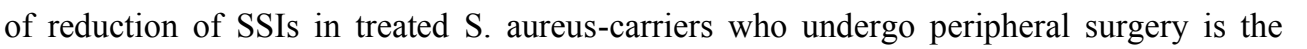

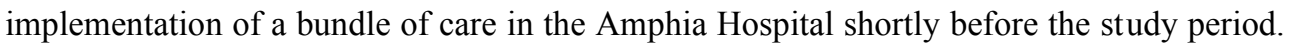

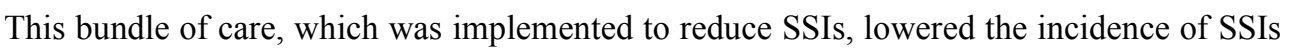
in patients who underwent vascular surgery by $44 \%$ in two years' time (from $14.9 \%$ to $8.4 \%$ )

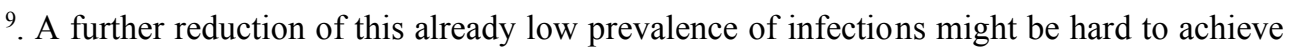

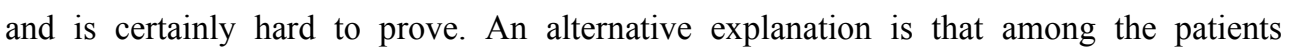

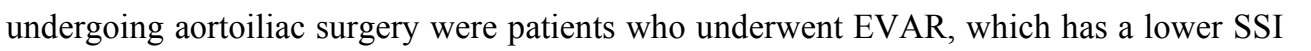

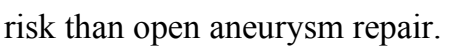

$\square$

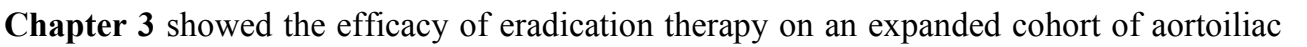

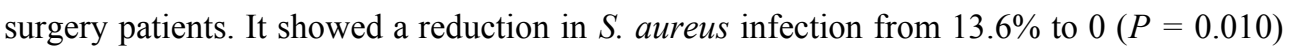

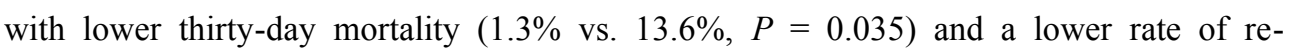

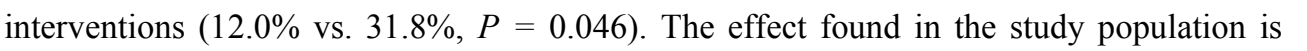

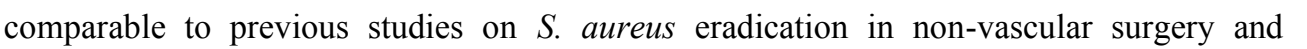

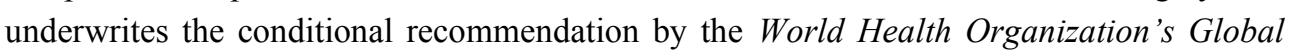

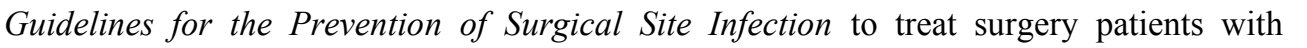

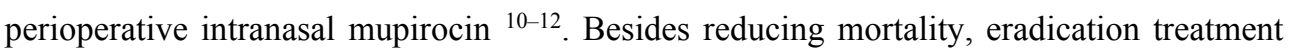
has also shown to reduce hospital costs substantially. On average, €1911 per patient was

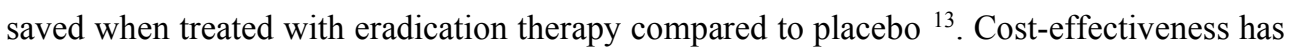

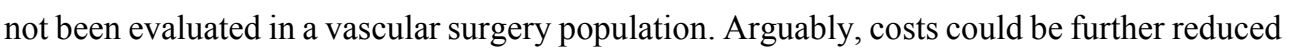

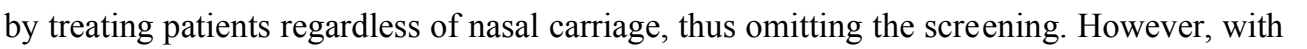

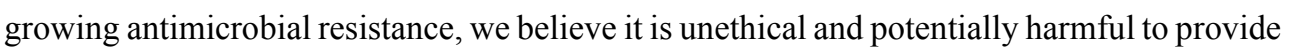




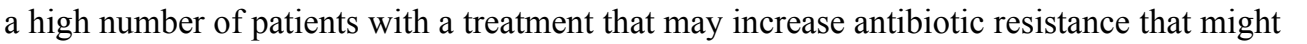

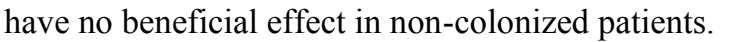

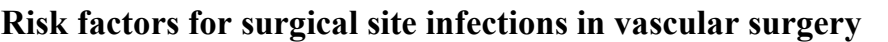

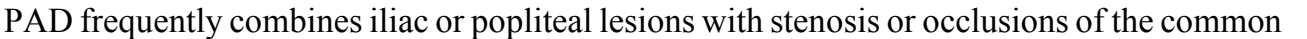

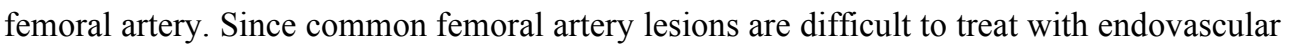

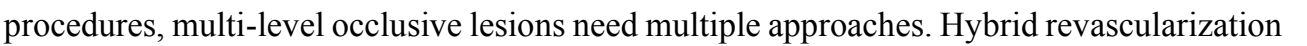

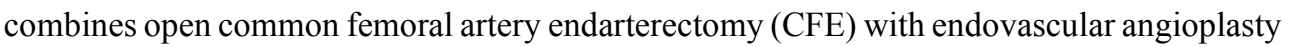

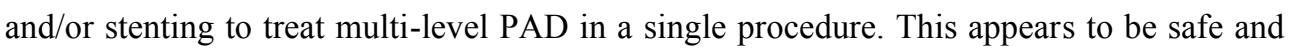

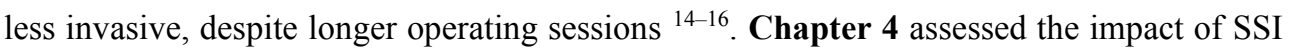

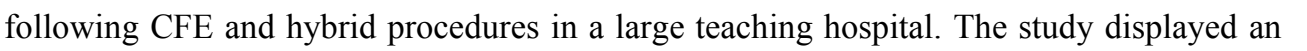

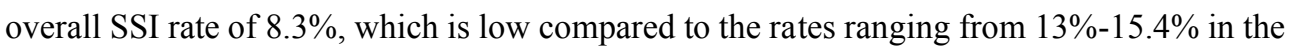

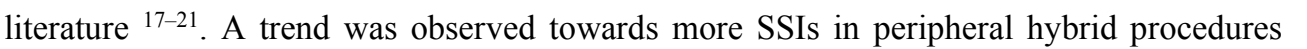

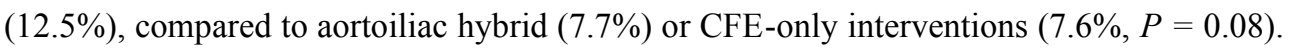

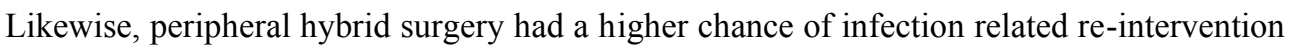



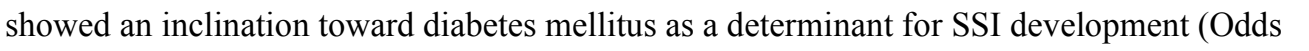

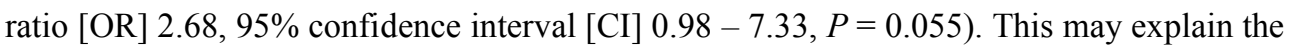

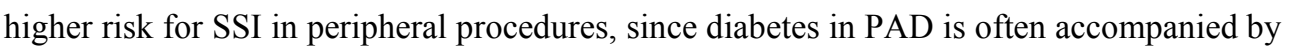

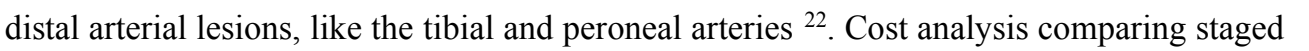

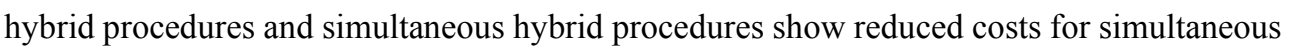

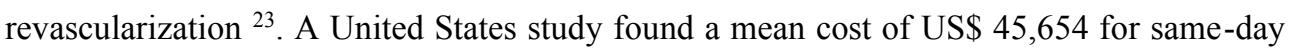

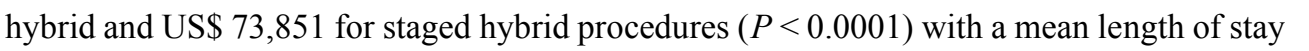

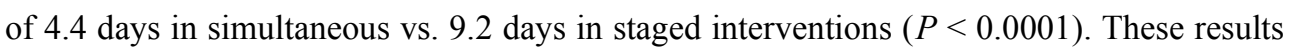

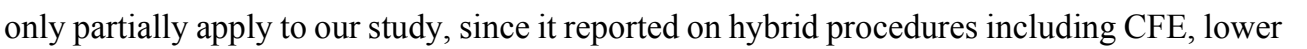

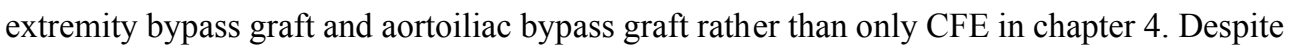

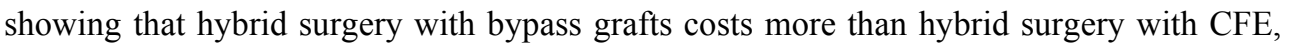

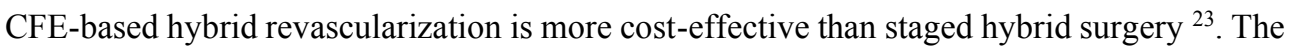

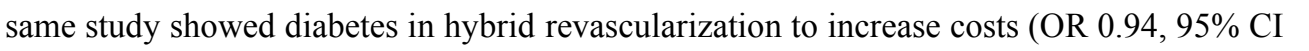

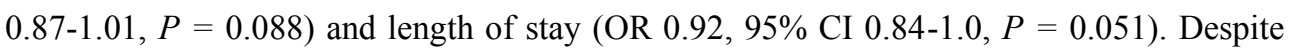

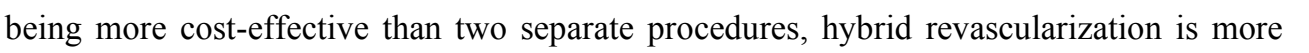

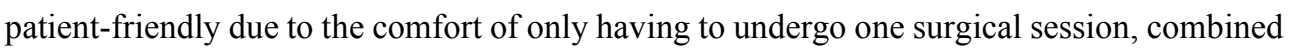

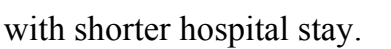

$\square$

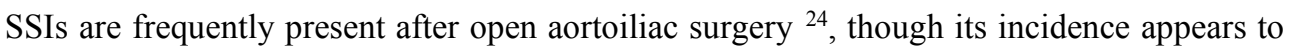

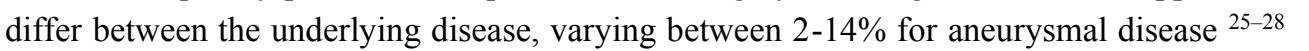

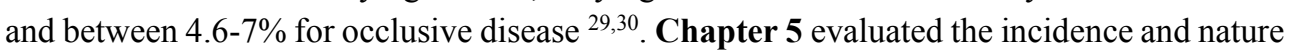

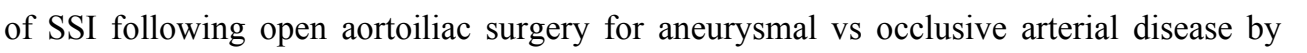

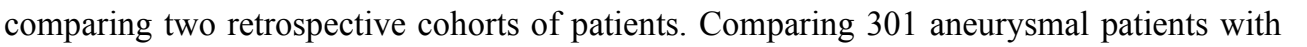

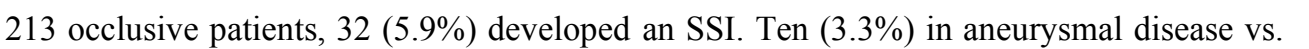




\section{Chapter 7}

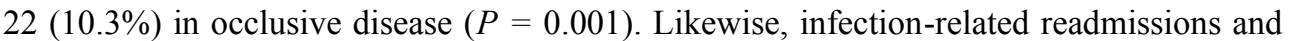

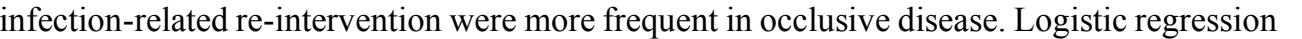

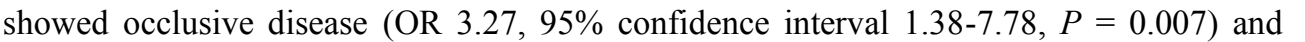

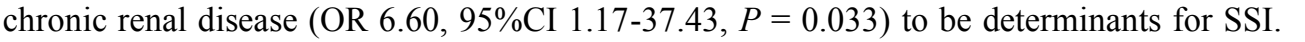

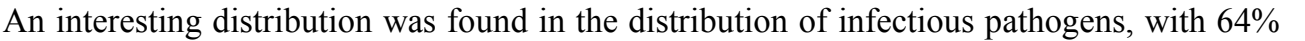

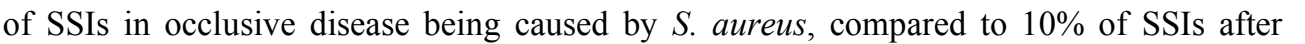

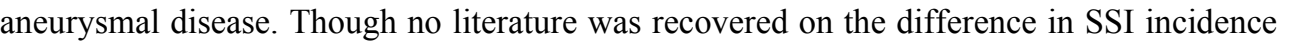

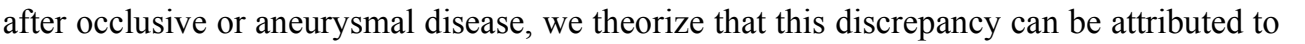

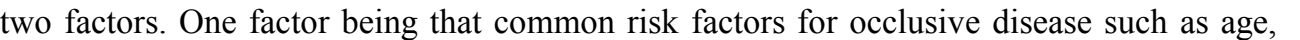

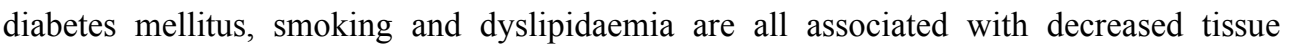

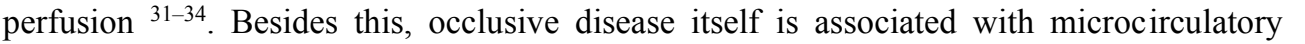

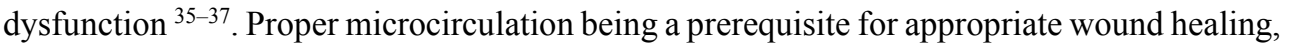

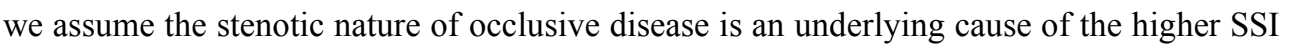

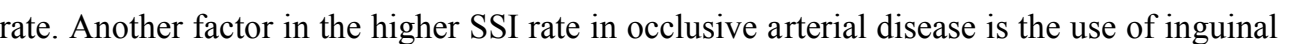

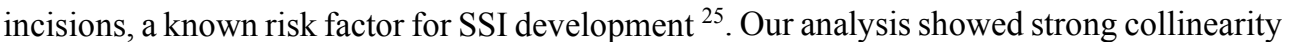

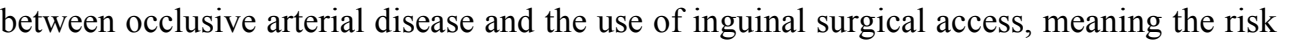

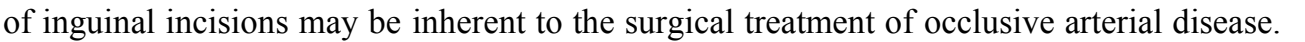

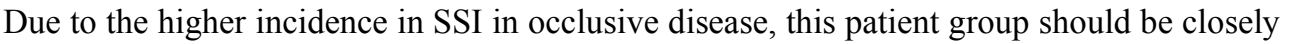

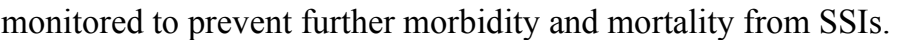

$\square$

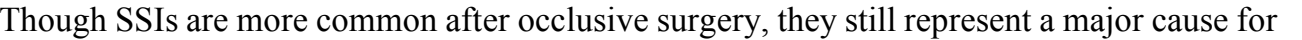

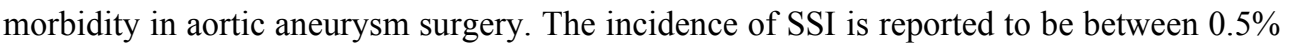

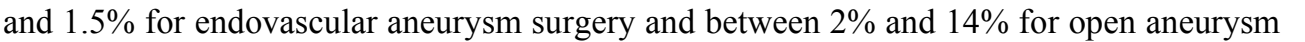

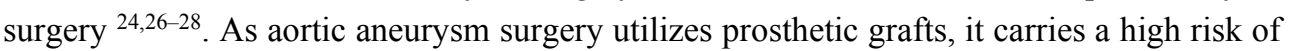

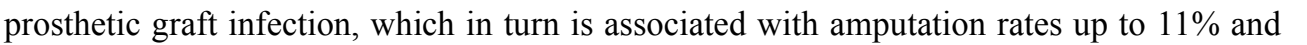

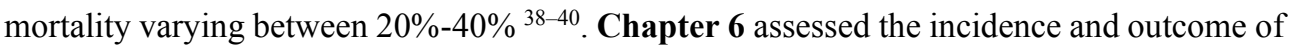

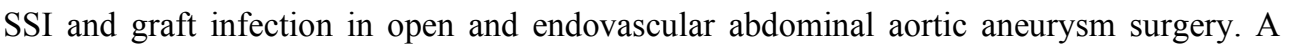

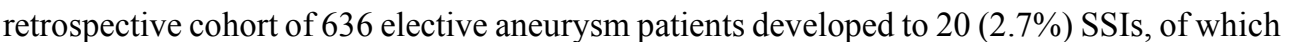

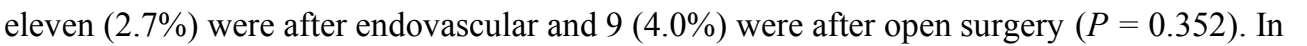

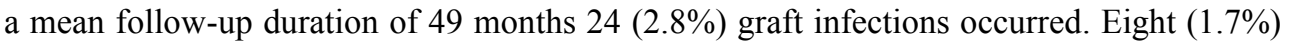

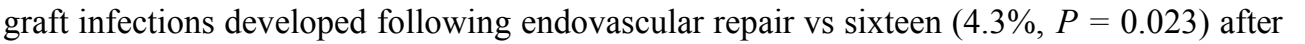

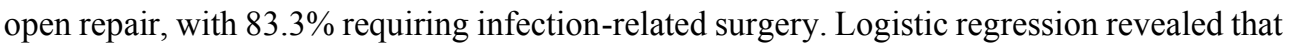

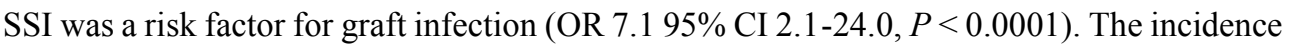

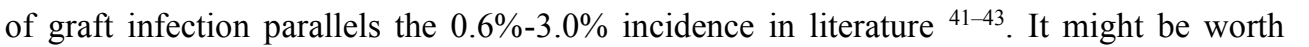

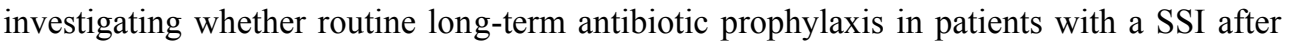

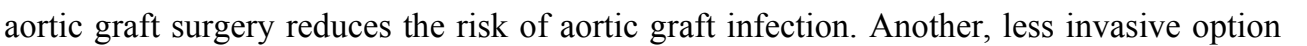

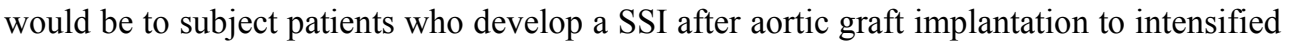
ए एव

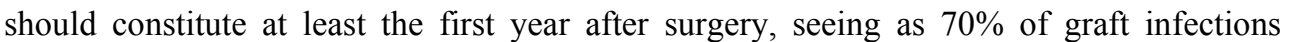

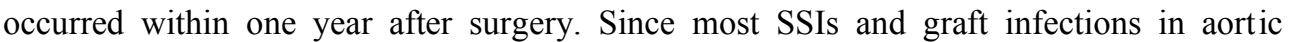




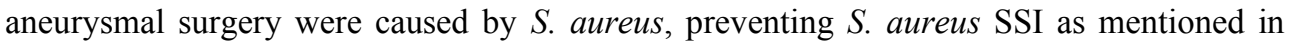

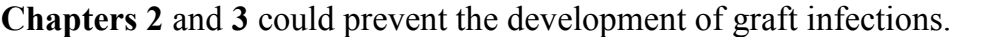

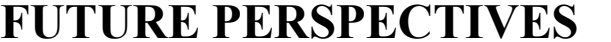

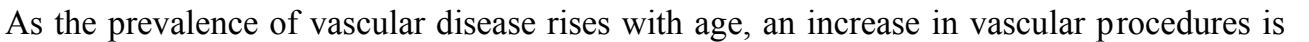

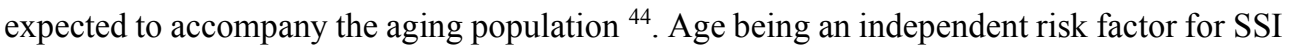

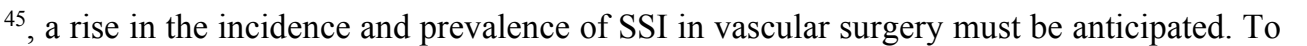

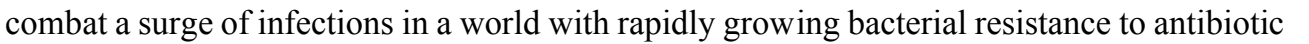

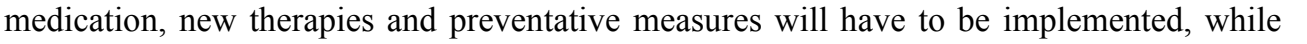

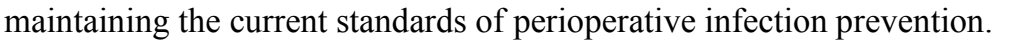

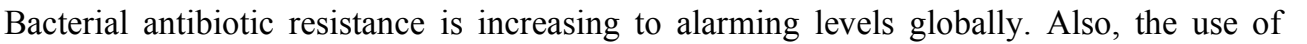

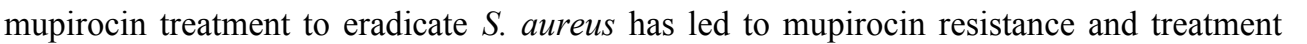

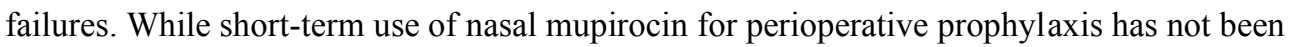

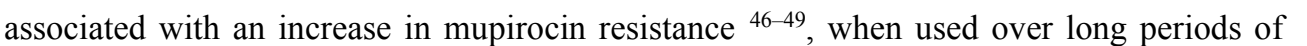

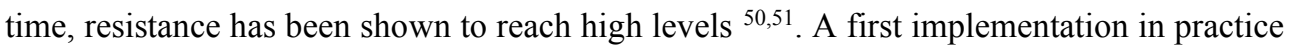

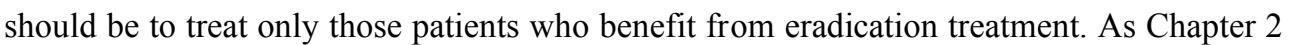

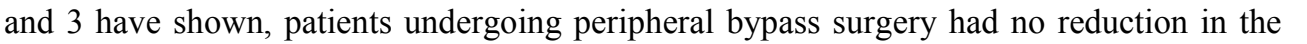

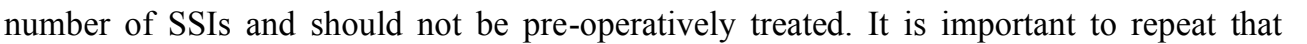

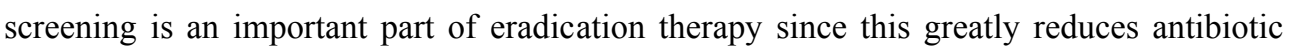

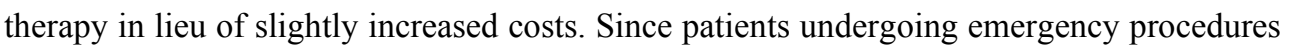

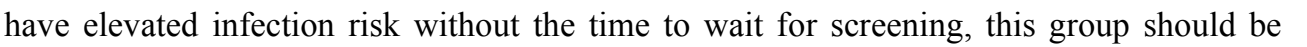

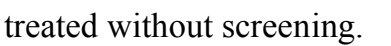

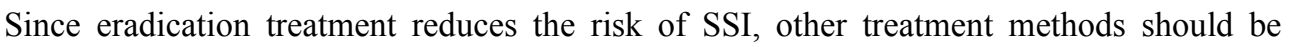

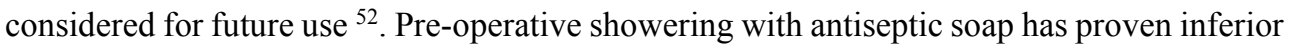

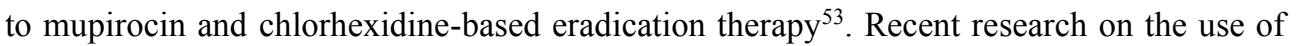



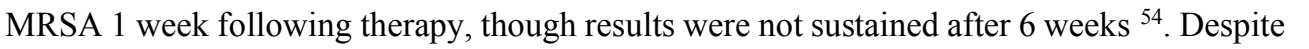

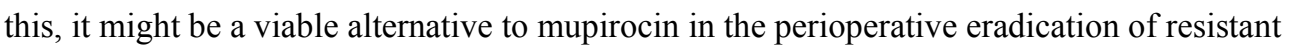

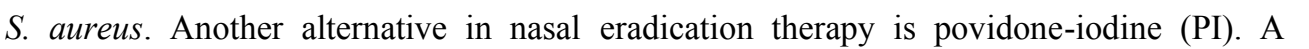

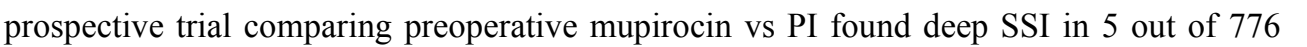

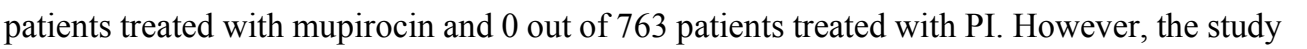

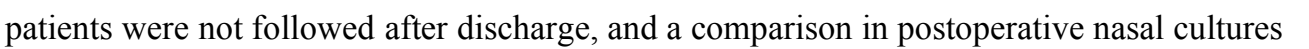

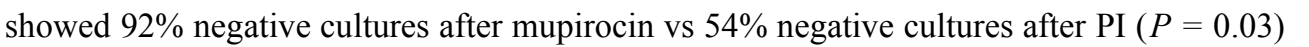

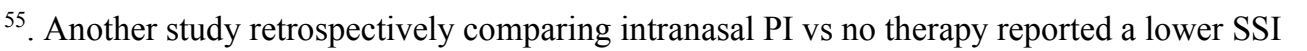

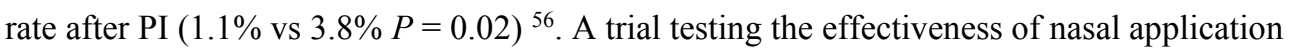

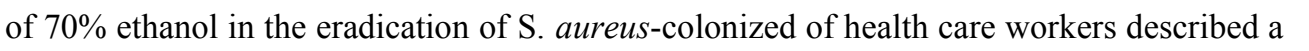

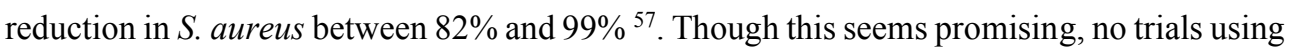

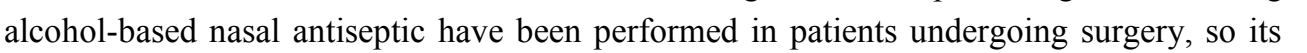

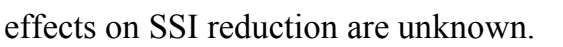




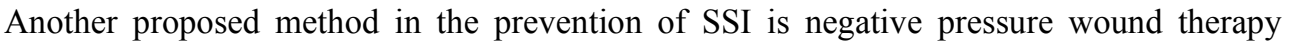

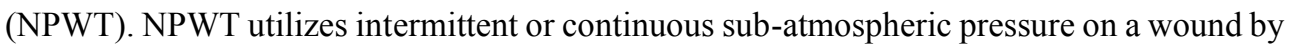

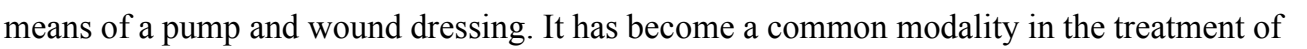

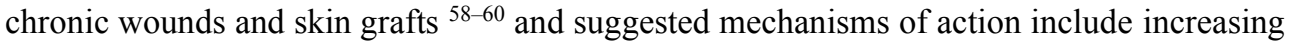

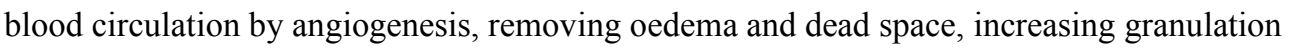

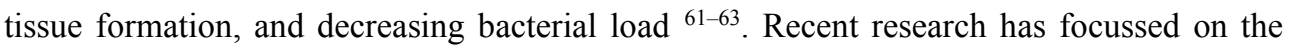

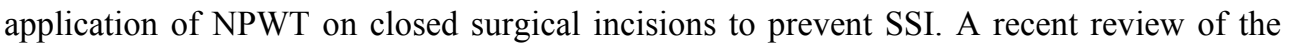

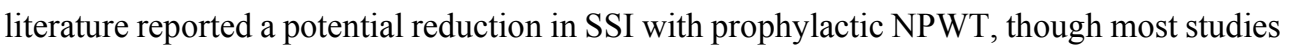

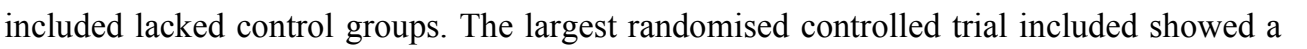

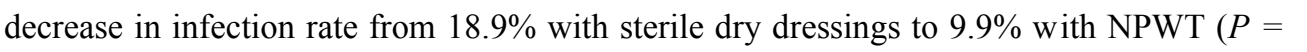

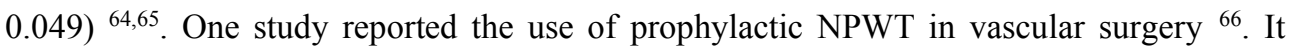

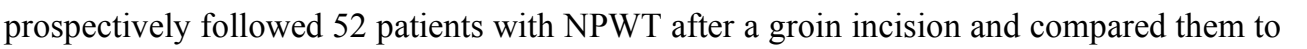

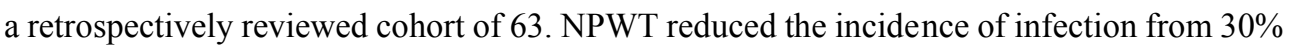

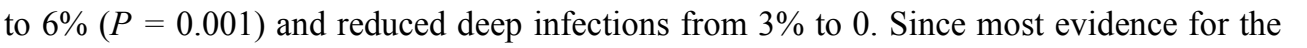

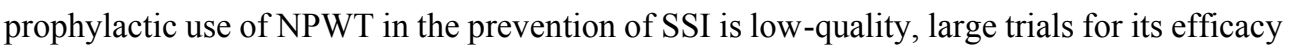

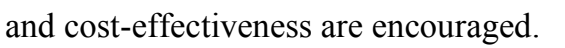

\section{$\square \square \square \square \square \square \square \square \square \square$}

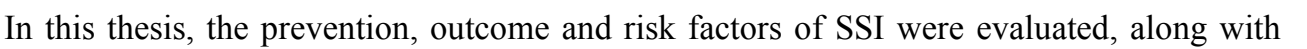

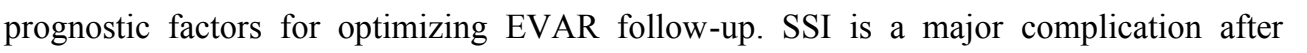

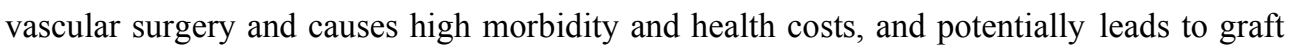

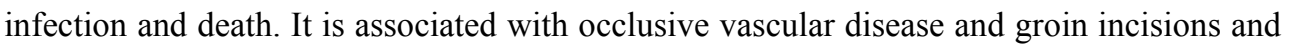

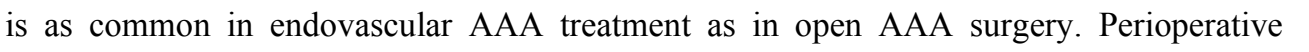

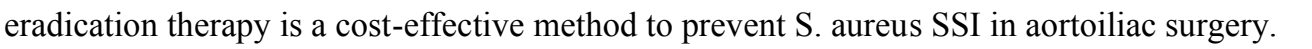
$\square$ 


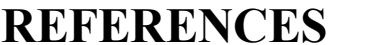

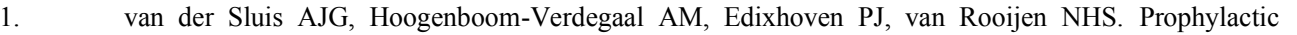

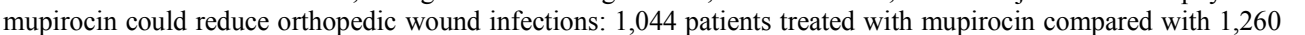

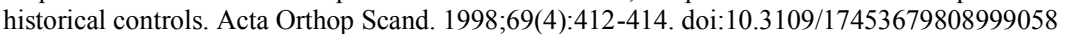

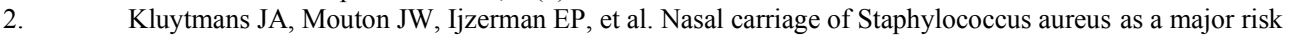

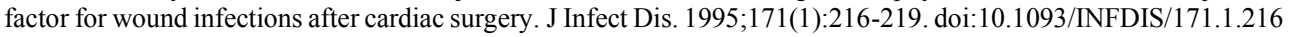

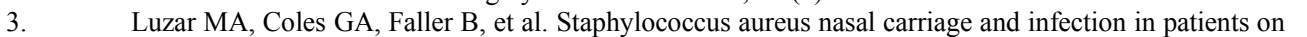

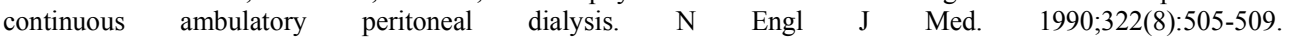

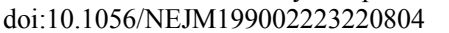

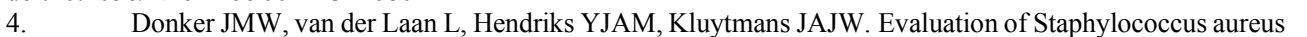
nasal carriage screening before vascular surgery. PLoS One. 2012;7(6):e38127. doi:10.1371/journal.pone.0038127 $\square$

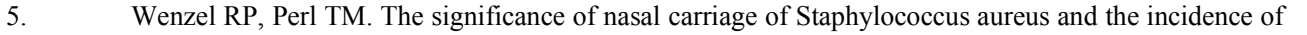

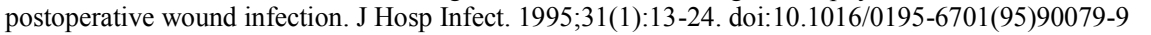

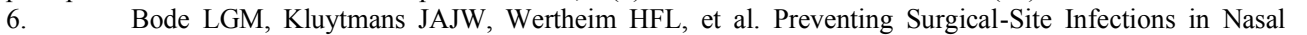

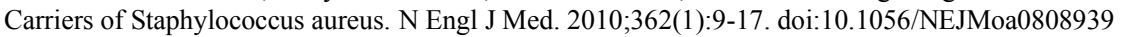

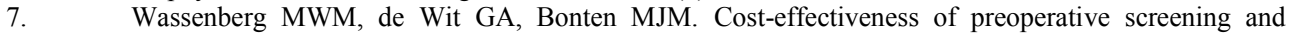
eradication of staphylococcus aureus carriage. PLoS One. 2011;6(5). doi:10.1371/journal.pone.0014815 $\square$

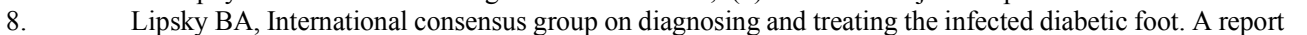

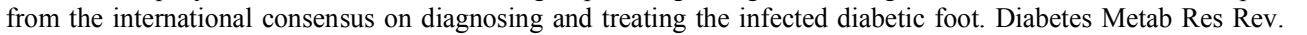

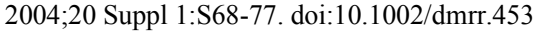

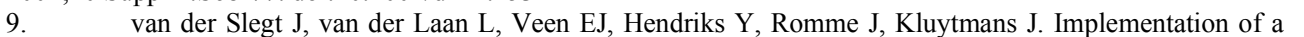

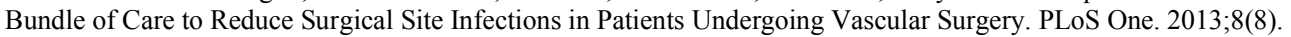

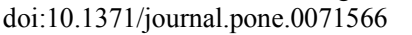

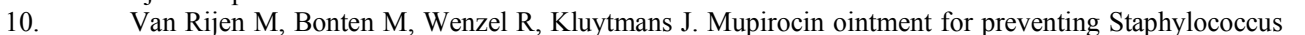

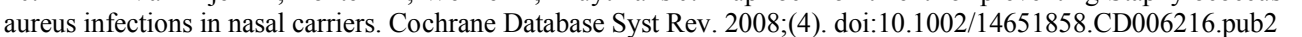

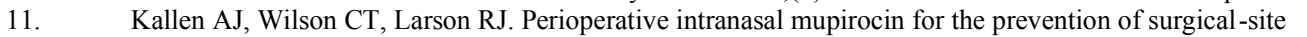

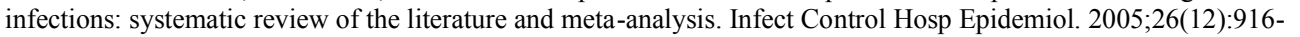

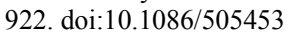

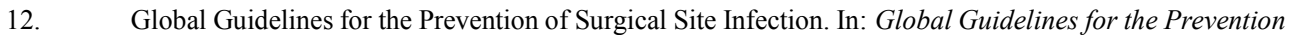

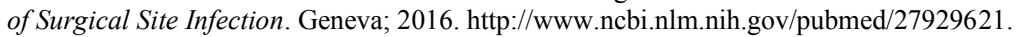

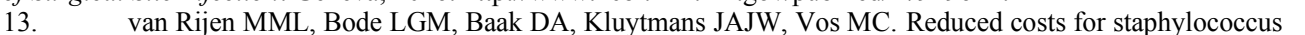

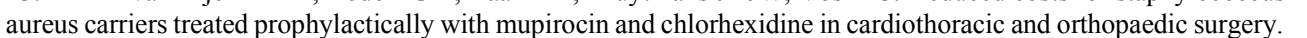

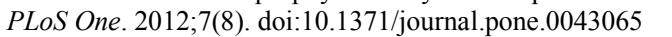

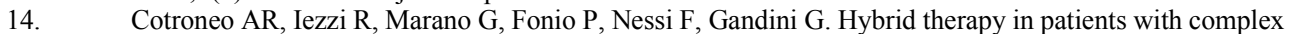

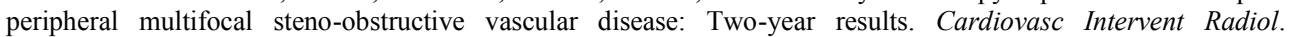

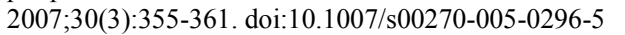

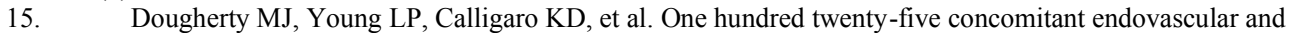

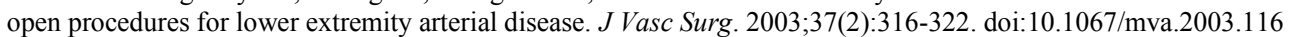

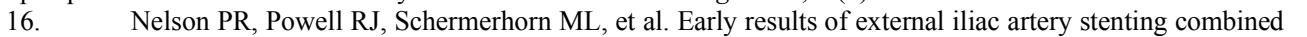

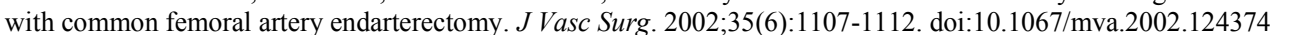

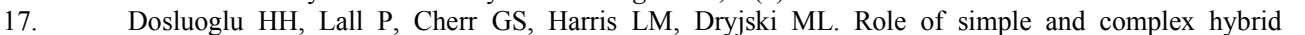

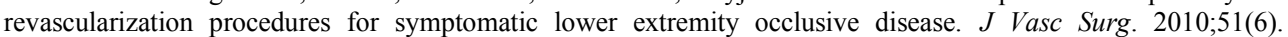

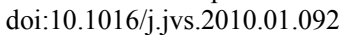

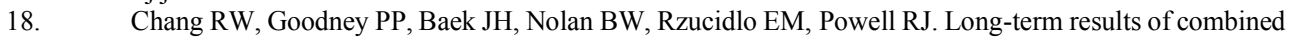

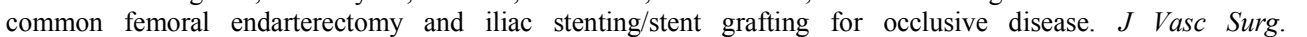

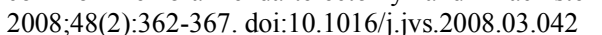

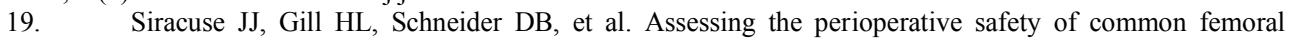

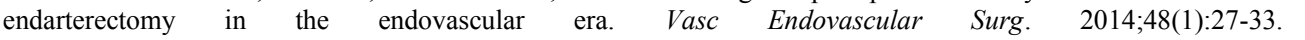

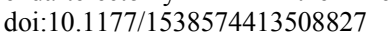

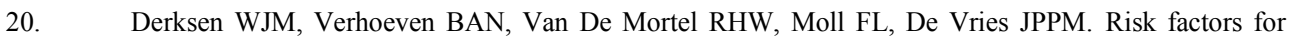

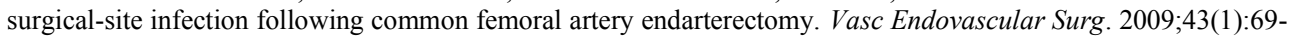

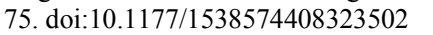

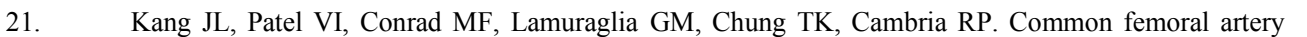

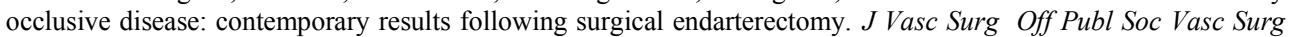

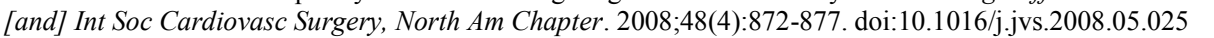

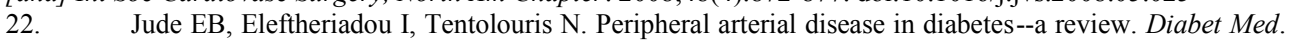

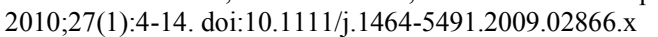




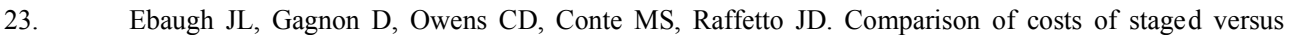

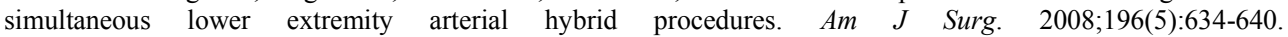
doi:10.1016/j.amjsurg.2008.08.003 $\square$

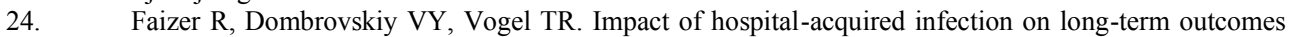

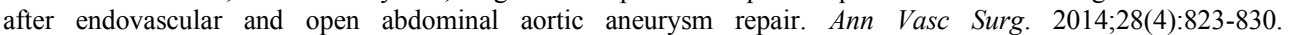
doi:10.1016/j.avsg.2013.06.028 $\square$

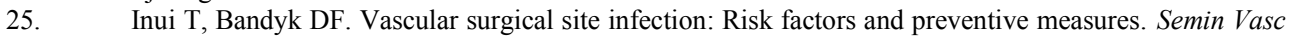
पIII. 2015;28(3 4):201 207. doi:10.1053/j.semvascsurg.2016.02.002

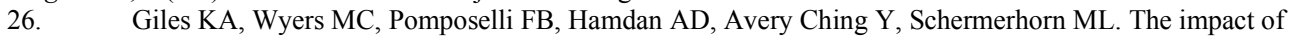

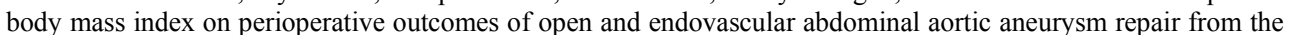

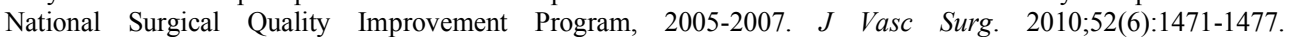
doi:10.1016/j.jvs.2010.07.013

पाW पIII. 2013;45(4):313 314. doi:10.1016/j.ejvs.2013.01.013

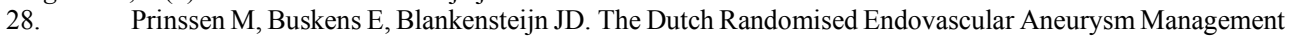
(DREAM) trial. Background, design and methods. $\square\left(\begin{array}{ll}0 \\ \text { (D) }\end{array}\right.$

29. Pejkić S, Dragaš M, Ilić N, et al. Incidence and relevance $\square$ एवा

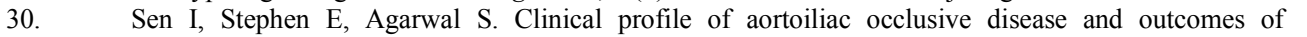

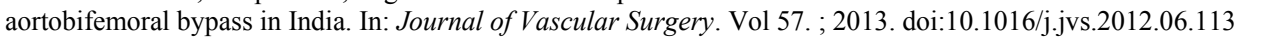

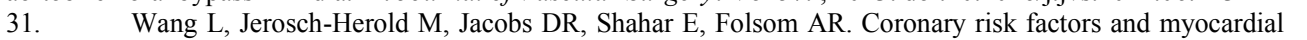

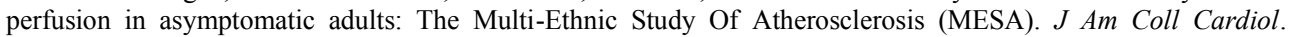
2006;47(3):565 572. doi:10.1016/j.jacc.2005.09.036

पIII) Ijzerman RG, Serne EH, van Weissenbruch MM, de Jongh RT, Stehouwer

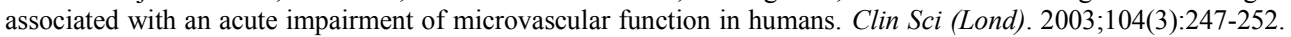
doi:10.1042/CS20020318 $\square$

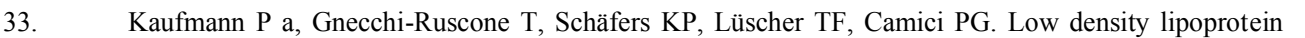

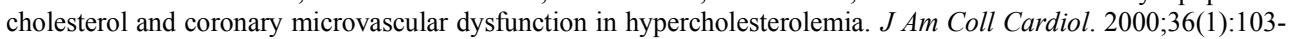
109. doi:S0735 $1097(00) 006975$ [pii] $\square$

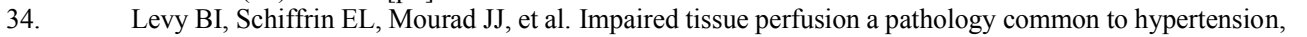

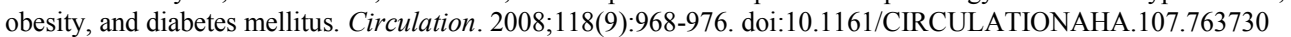

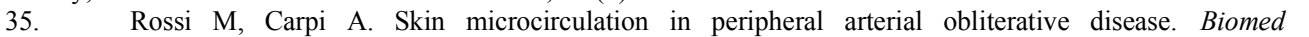

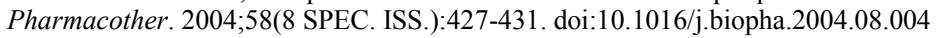

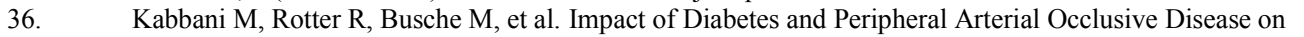

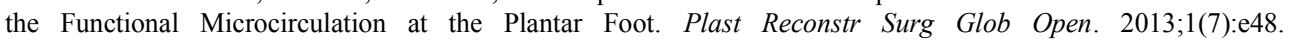
doi:10.1097/GOX.0b013e3182a4b9cb $\square$

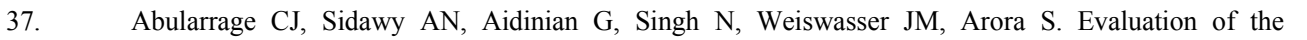

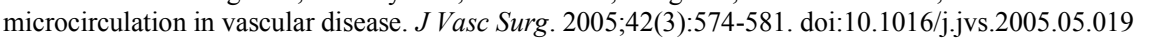

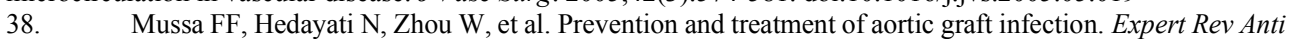

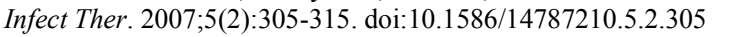

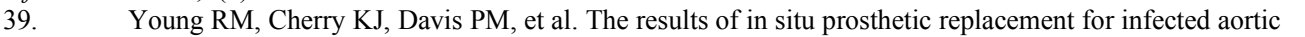

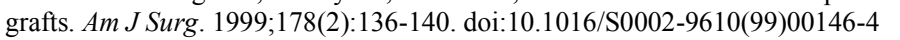

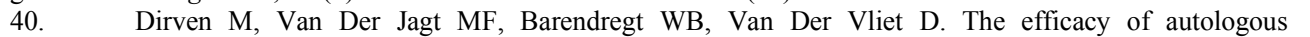

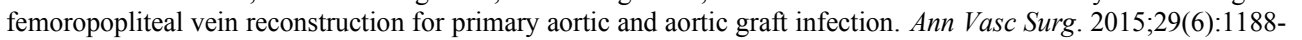
1195. doi:10.1016/j.avsg.2015.03.043

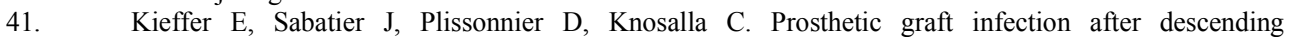
thoracic/thoracoabdominal aortic aneurysmectomy: Management with in situ arterial allografts. $\square \square \square\|\square\|\|\| \square$ 2001;33(4):671 678. doi:10.1067/mva.2001.112314

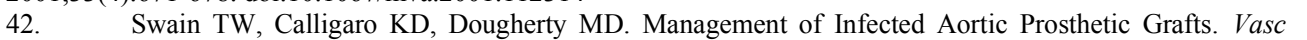

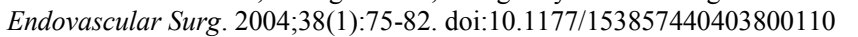

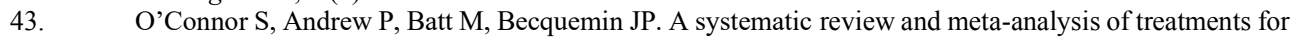

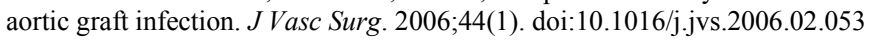

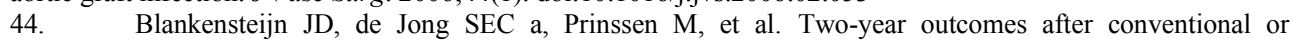

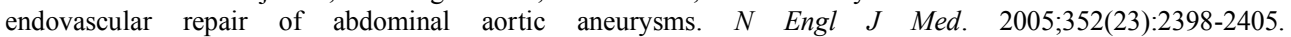
doi:10.1056/NEJMoa051255 $\square$

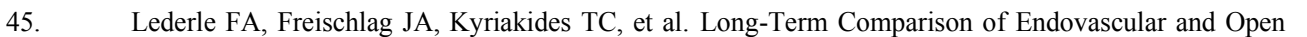

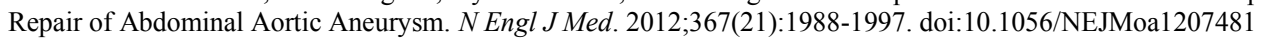

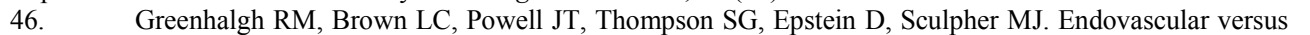

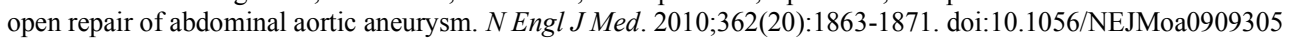




\section{$\square 10$}

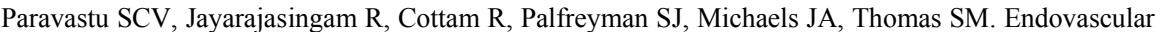

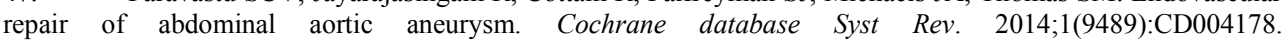
doi:10.1002/14651858.CD004178.pub2 $\square$

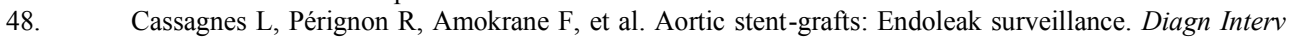

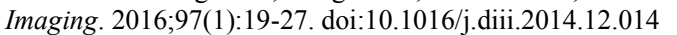

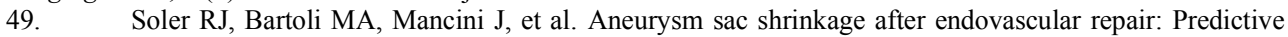

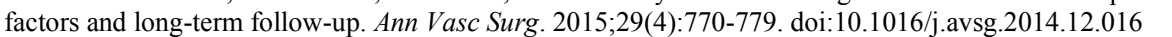

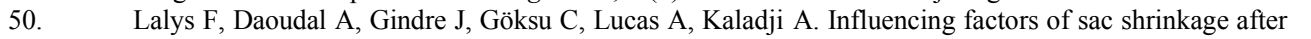

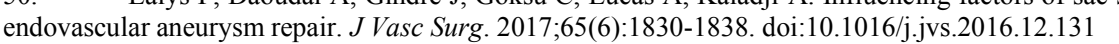

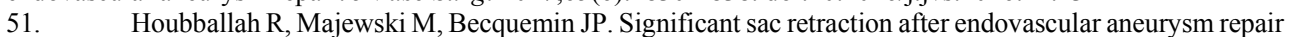

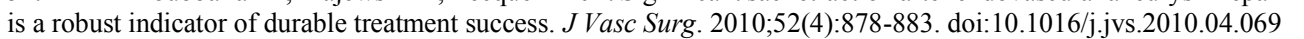
52. $\square$ Bastos Gonçalves F, Baderkhan H, Verhagen HJM, et al. Early sac shrinkage predicts a low risk of late

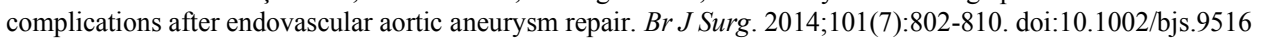

53. $\square \quad$ Kooiman J, Pasha SM, Zondag W, et al. $\square \square$ Manalysis: Serum creatinine changes following contrast

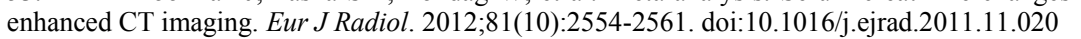

54. $\square \quad$ Walsh SR, Tang TY, Boyle JR. Renal consequences of endovascular abdominal aortic aneurysm repair.

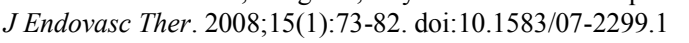

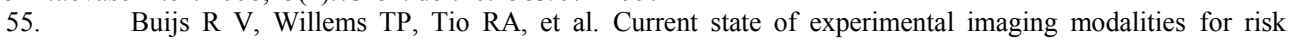

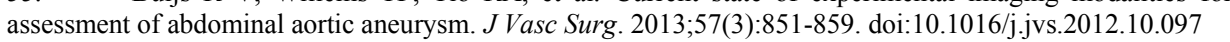

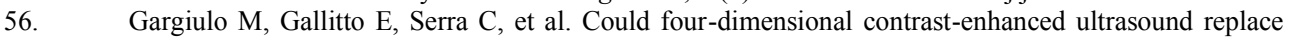

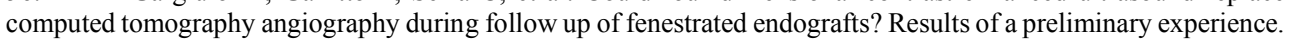

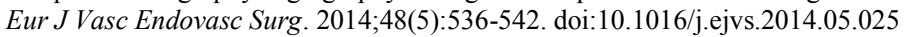

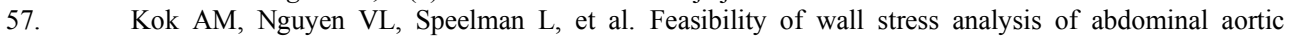

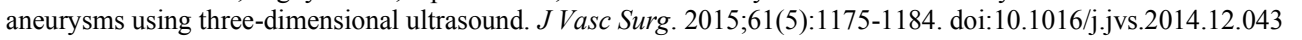

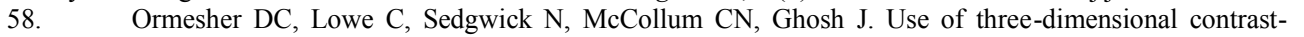

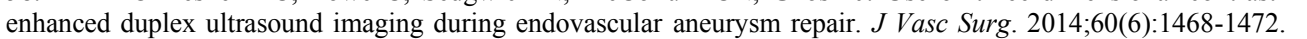
doi:10.1016/j.jvs.2014.08.095 $\square$

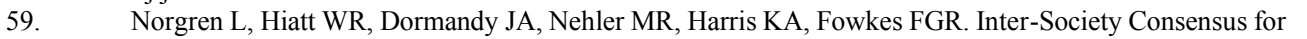
the Management of Peripheral Arterial Disease (TASC II). $\quad \square \square \square \square \square \square \square \square \square 7 ; 45(1 \quad$ SUPPL.). doi:10.1016/j.jvs.2006.12.037 $\square$

60. $\square$ Mangram AJ, Horan TC, Pearson ML, Silver LC, Jarvis WR. Guideline for Prevention of Surgical Site

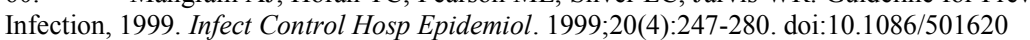

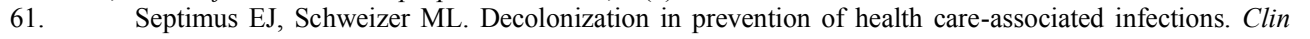

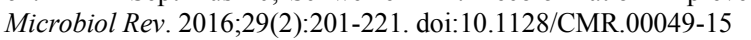

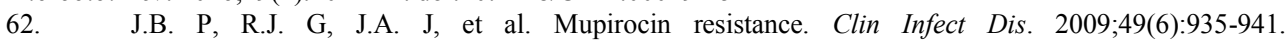
doi: $10.1086 / 605495 \square$

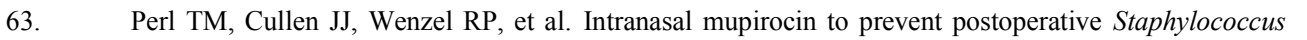

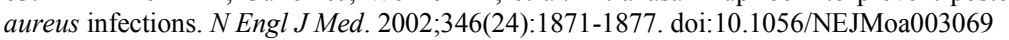

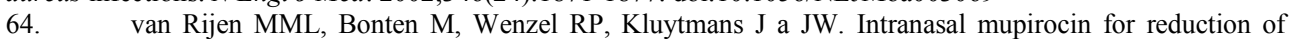

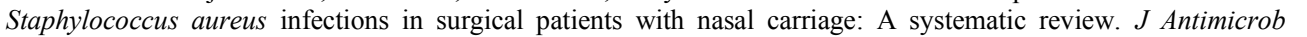
$\square \square \square \square \square ा .2008 ; 61(2): 254$ 261. doi:10.1093/jac/dkm480 $\square$

65. $\square \quad$ Vasquez JE, Walker ES, Franzus BW, Overbay BK, Reagan DR, Sarubbi FA. The epidemiology of

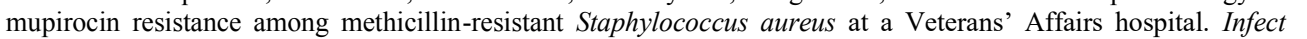

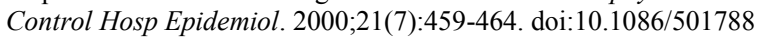

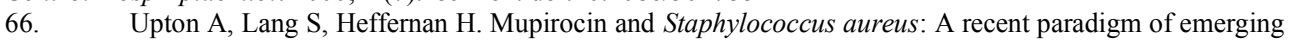

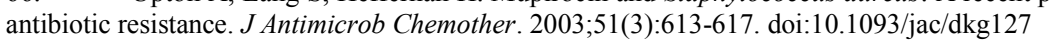

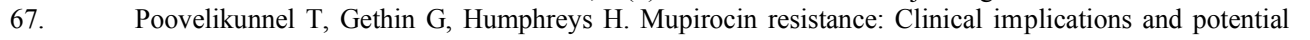

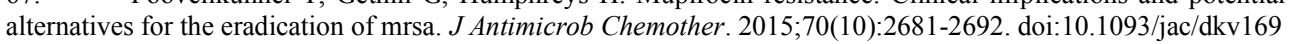

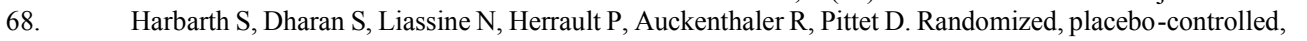

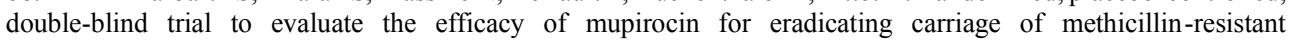

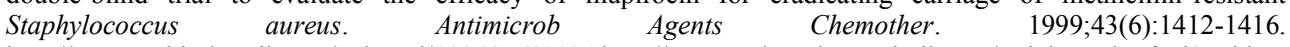

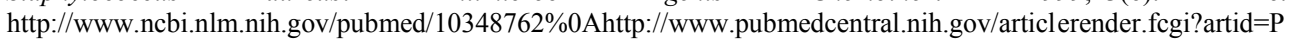
MC89288.

69. $\square \quad$ Phillips M, Rosenberg A, Shopsin B, et al. Preventing Surgical Site Infections: A Randomized, Open $\square$

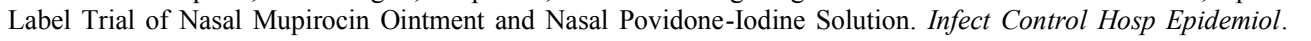
2014;35(7):826 832. doi:10.1086/676872 $\square$

पII Bebko SP, Green DM, Awad SS. Effect of a preoperative decontamination protocol on surgical site

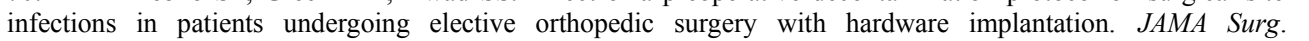
2015;150(5):390 395. doi:10.1001/jamasurg.2014.3480 


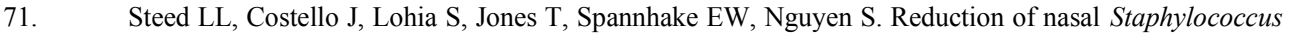

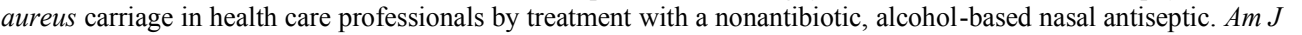

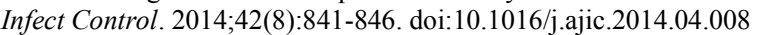

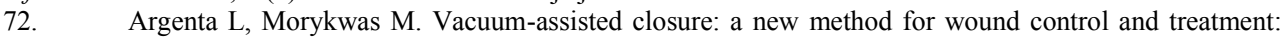

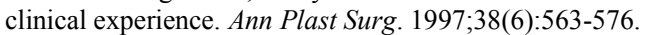

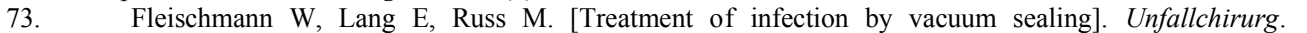
1997;100(4):301 304. http://www.ncbi.nlm.nih.gov/pubmed/9229781.

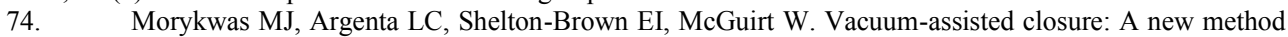

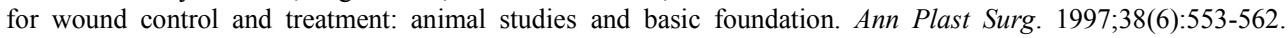

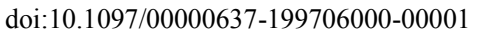

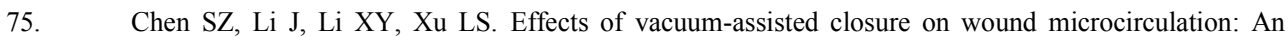

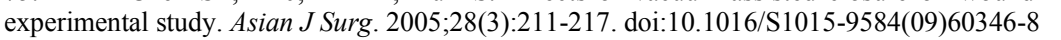

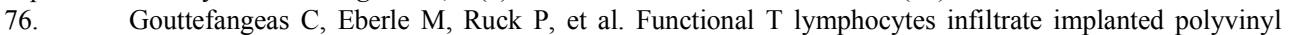

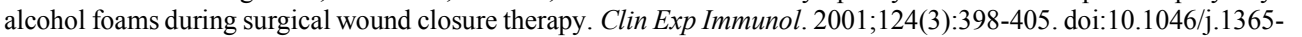
2249.2001.01547.x $\square$

पाW Malmsjö M, Gustafsson L, Lindstedt S,

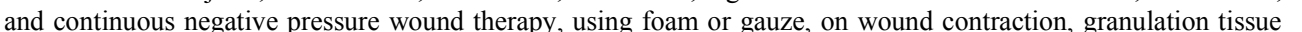

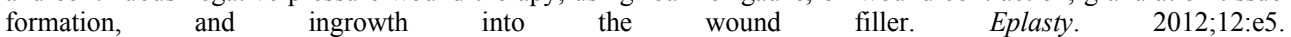
http://www.pubmedcentral.nih.gov/articlerender.fcgi?artid=3266212\&tool=pmcentrez\&rendertype=abstract. $\square$

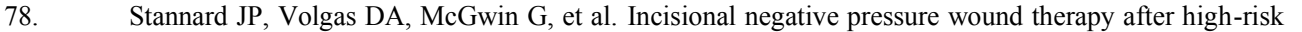

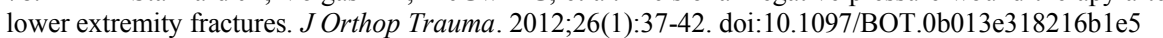

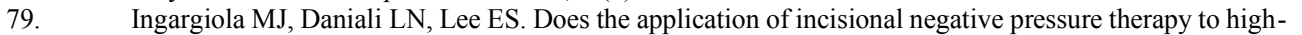
risk wounds prevent surgical site complications? A systematic review. $\square \square \square \square[1.2013 ; 13:$ e49. $\square$

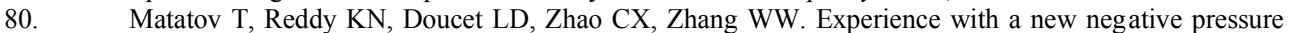

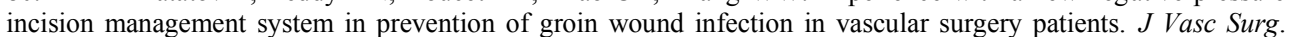
2013;57(3):791 795. doi:10.1016/j.jvs.2012.09.037 $\square$

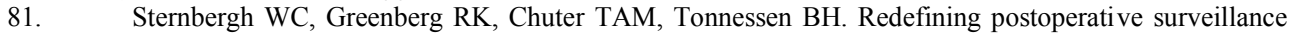

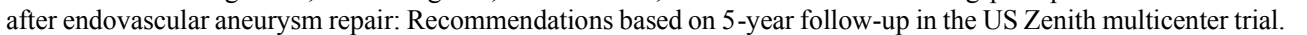

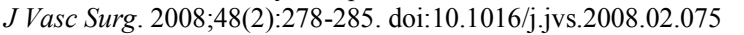




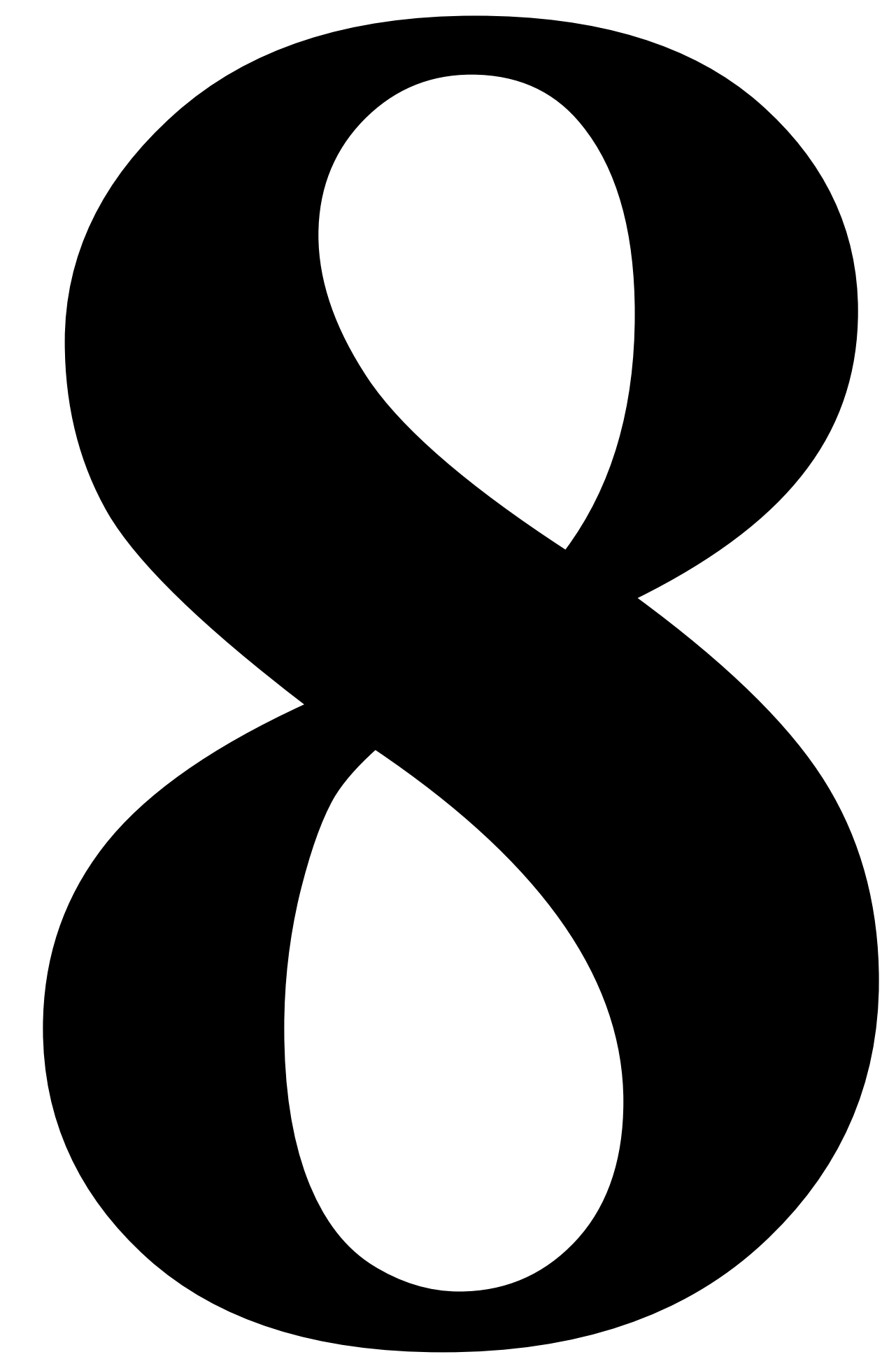




\section{Chapter 8}

Impact Paragraph 


\section{Chapter 8}

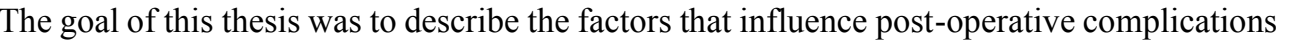

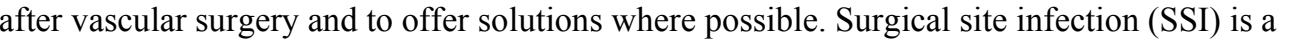

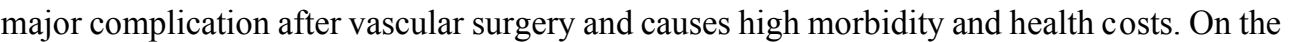

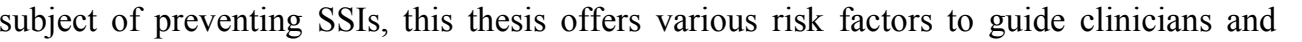

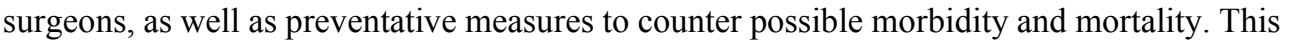

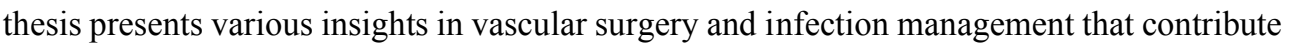

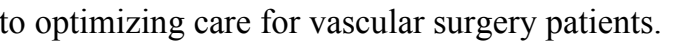

$\square$

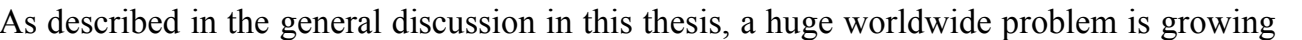

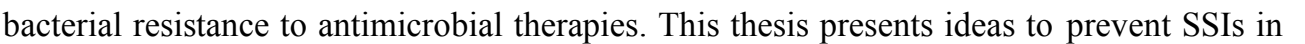

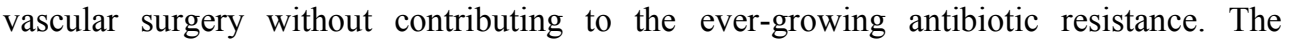

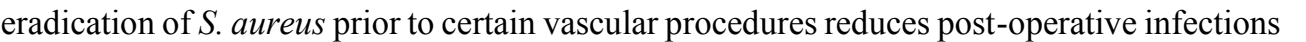

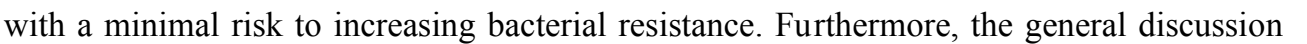

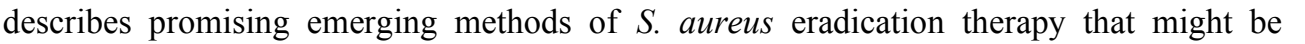

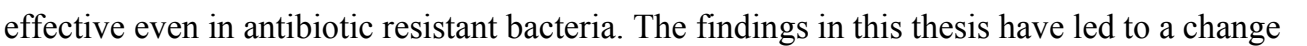

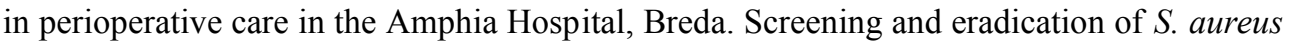

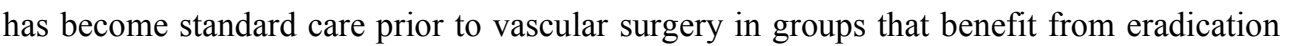
ए ए।

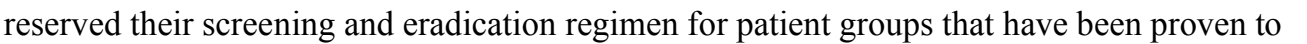

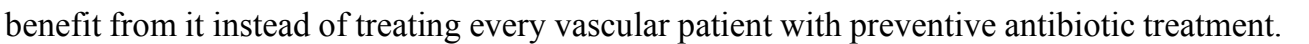
晸

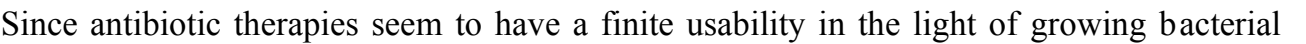

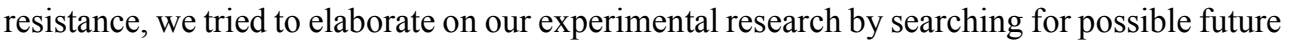

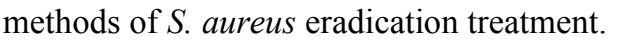

$\square$

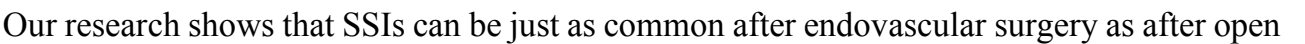

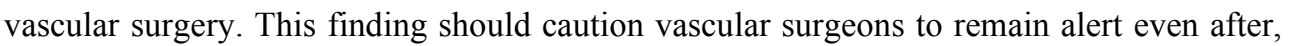

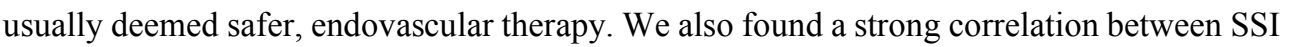

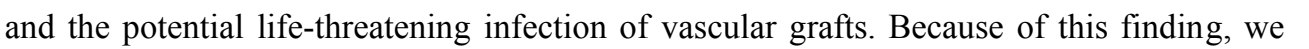

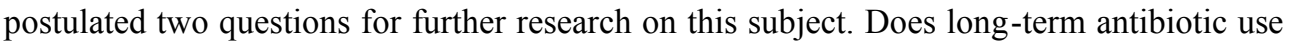

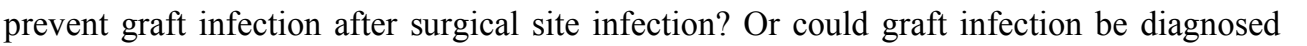

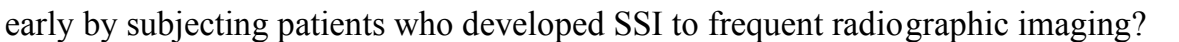

$\square$

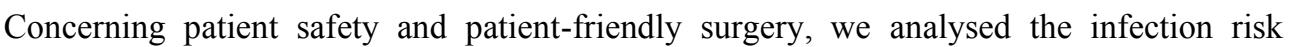

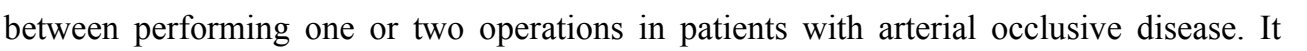

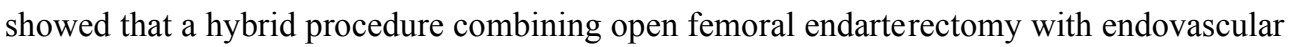

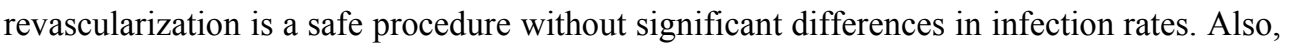

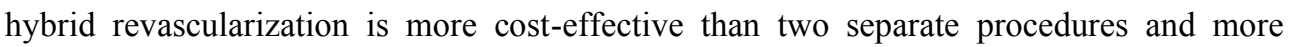

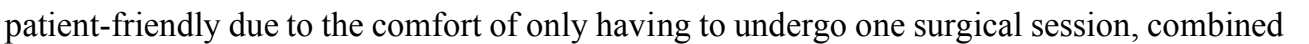

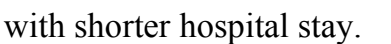

$\square$ 


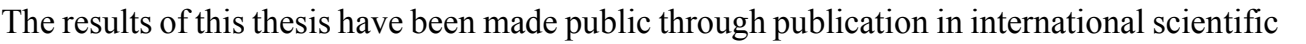
पा

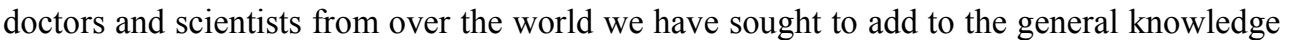

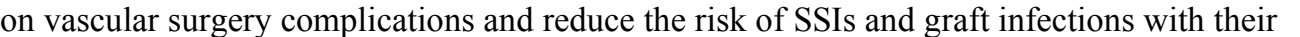

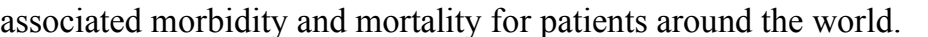




$$
9
$$




\section{Chapter 9}

Acknowledgements List of publications Curriculum Vitae 


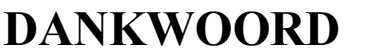

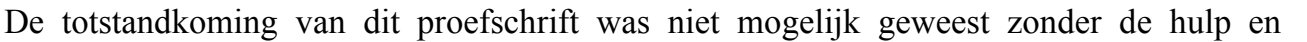

ondersteuning van enthousiaste collega's, vrienden en familie. Graag wil ik iedereen die $\square \square$

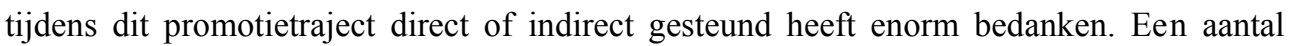

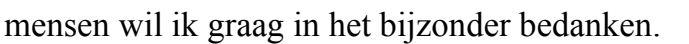
$\square$

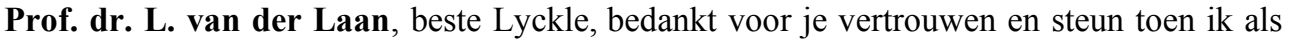
एव

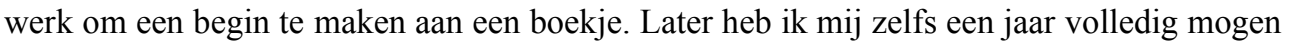

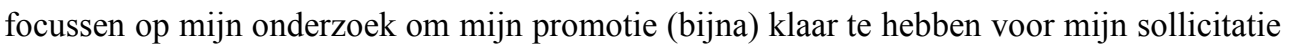

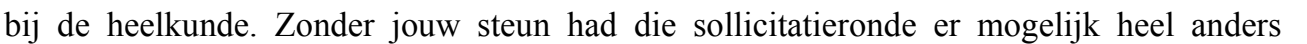

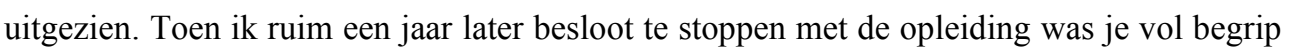

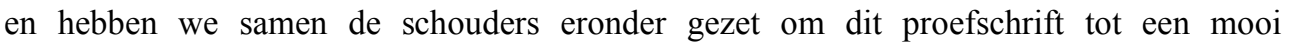

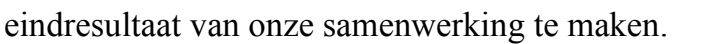

$\square$

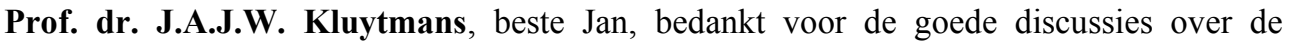

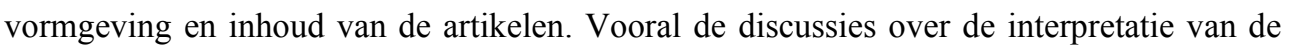

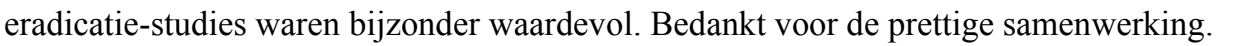

$\square$

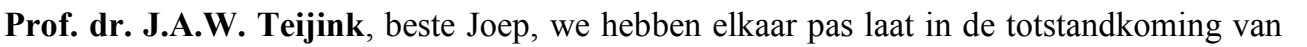

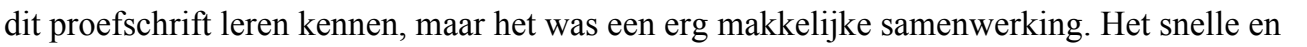

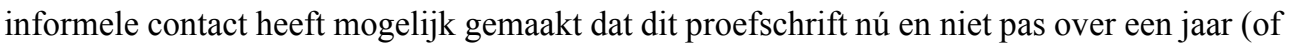

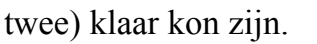

$\square$

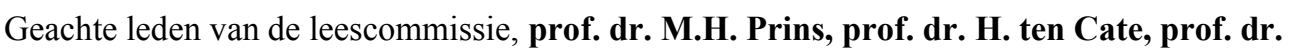

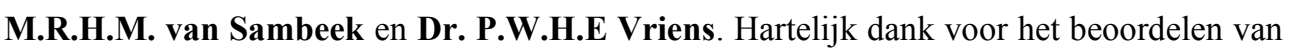

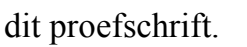

$\square$

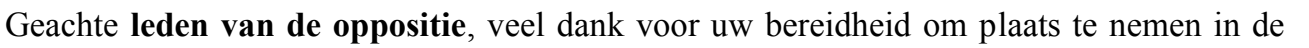

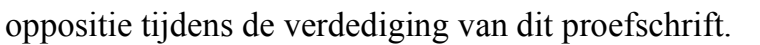

$\square$

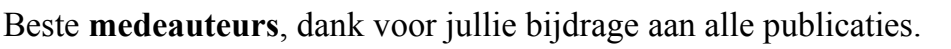

$\square$

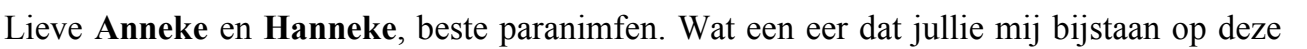

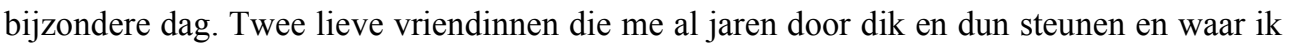

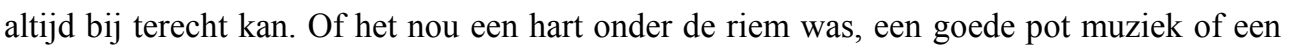

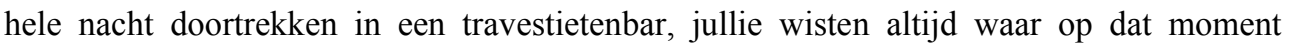

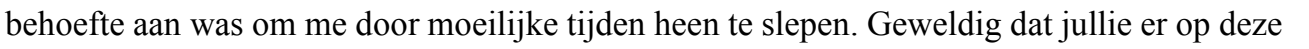

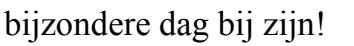

$\square$ 


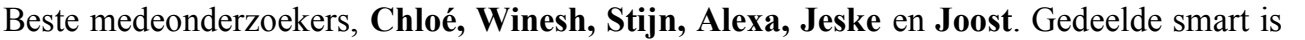

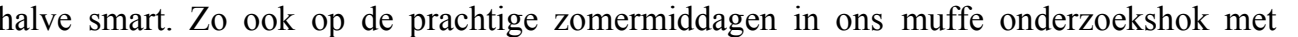

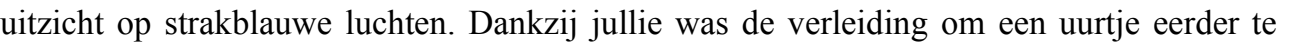

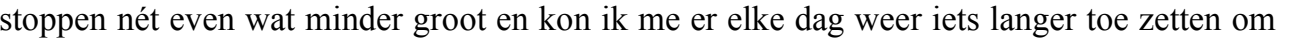

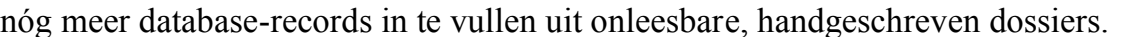

$\square$

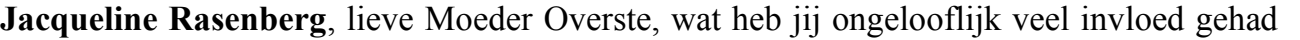

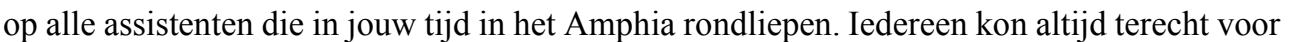

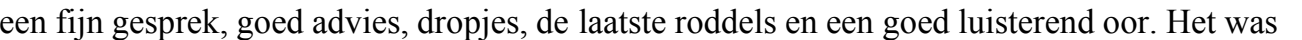

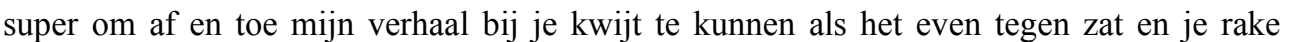

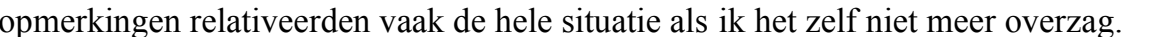

$\square$

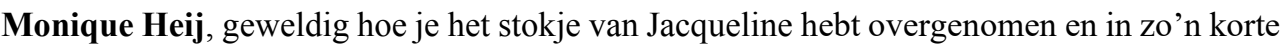

\section{tijd alles volledig overzag en aanstuurde. Dankzij jouw hulp heb ik 'de baas' regelmatig toch}

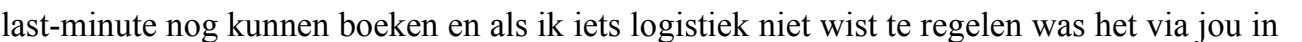

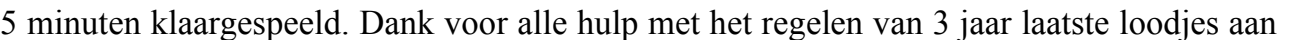

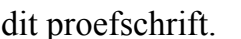

$\square$

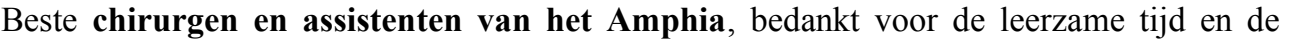

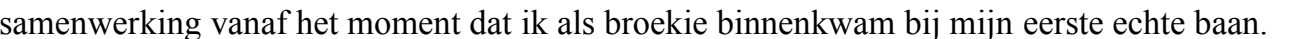
$\square$

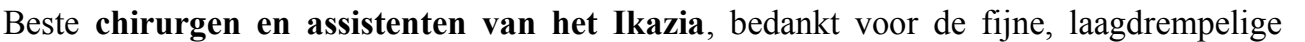

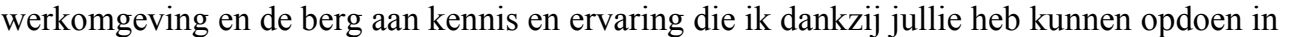

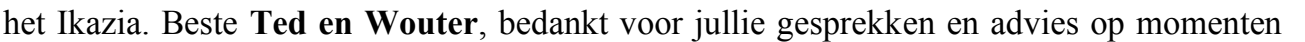

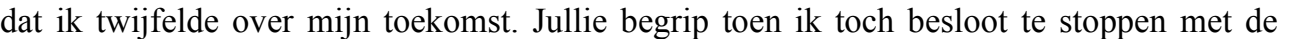

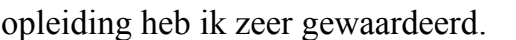

$\square$

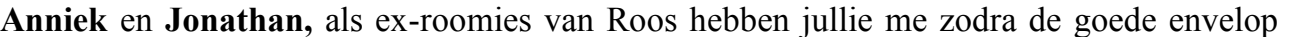

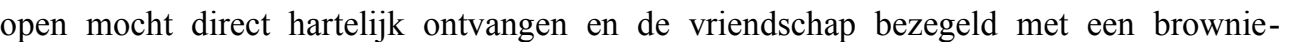

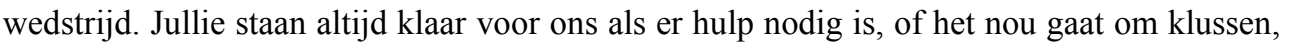

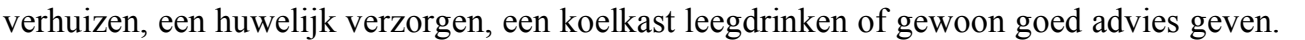

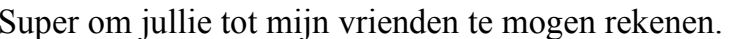

$\square$

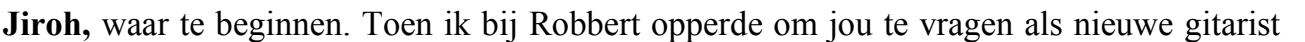

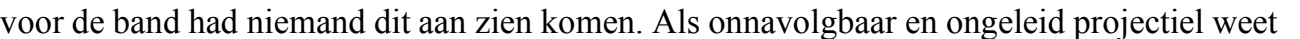

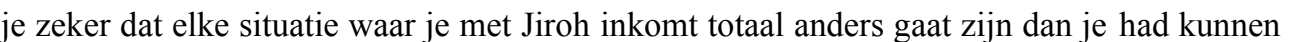

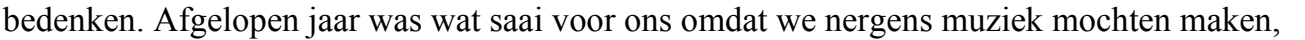

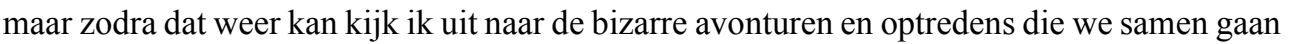

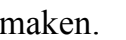

$\square$ 


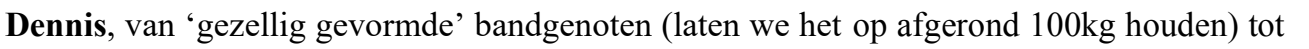
प

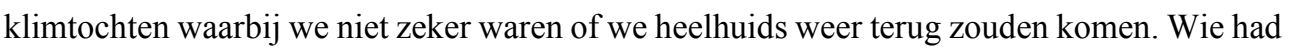

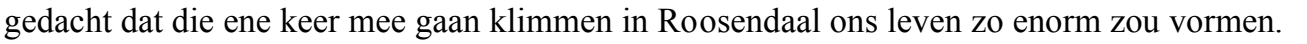

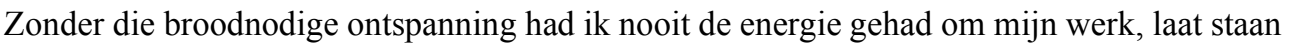

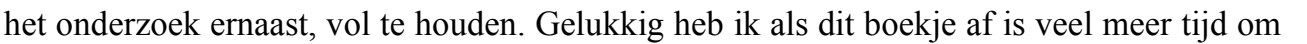

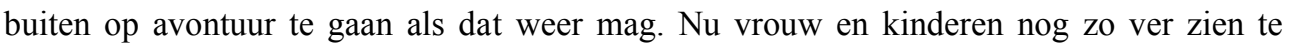
krijgen... $\square$

$\square$

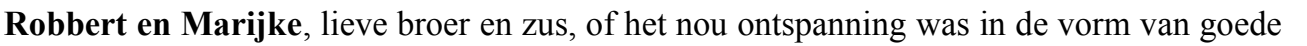

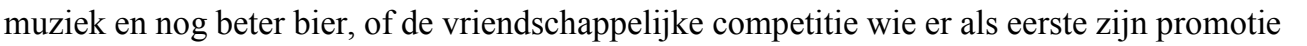

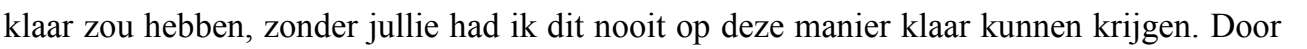

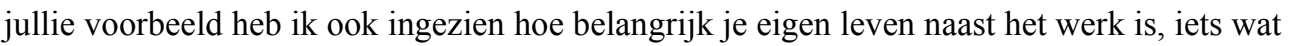

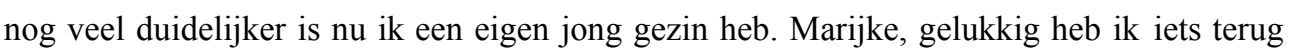

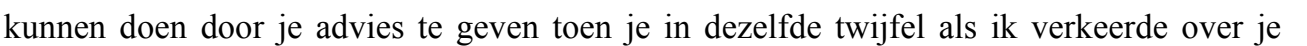

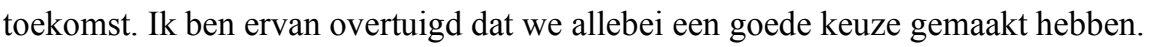

$\square$

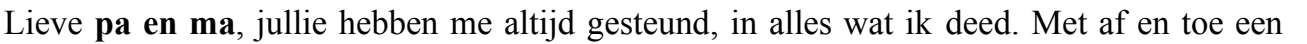

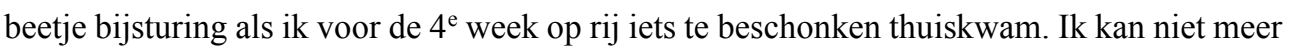

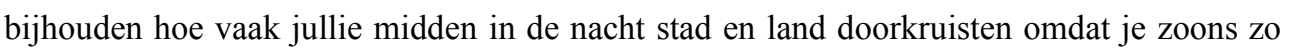

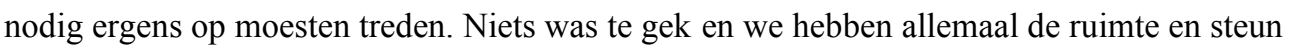

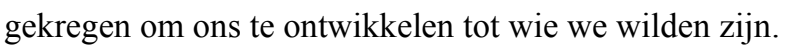

De goedbedoelde vraag: 'Hoe staat het nu met je proefschrift?' als ik bij jullie een weekendje

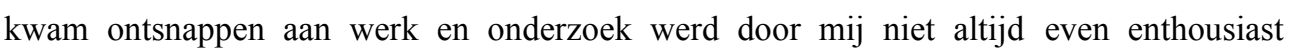

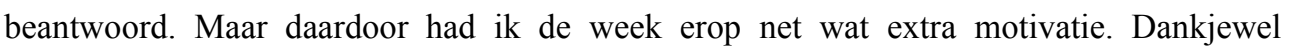

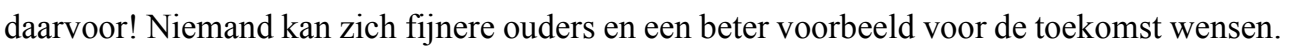

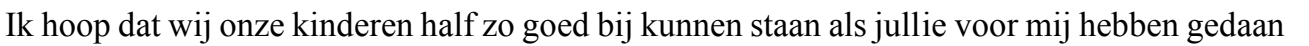

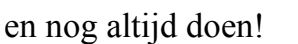

$\square$

$\square \square$, ongelooflijk wat zo'n klein beest met je kan doen als mens. Het huis was een stuk

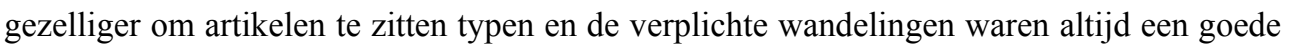

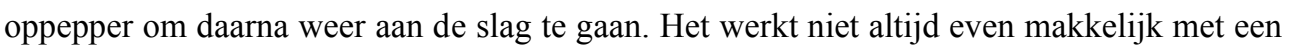

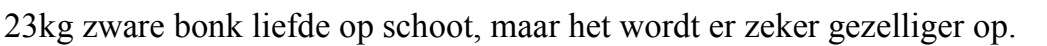

$\square$

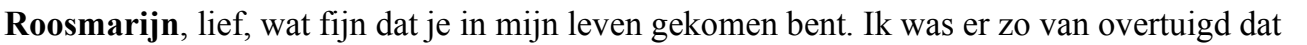

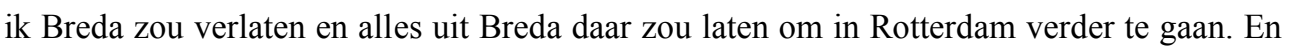

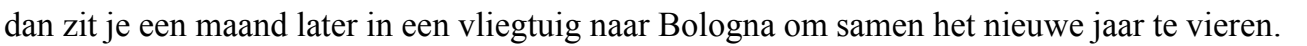

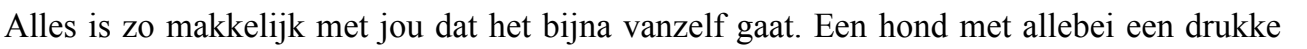

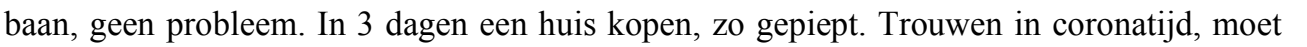

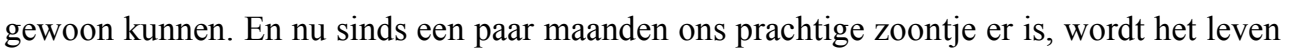

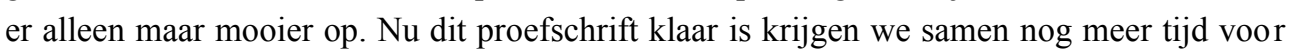




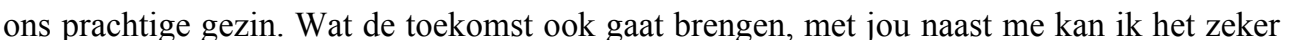

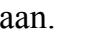




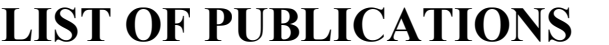

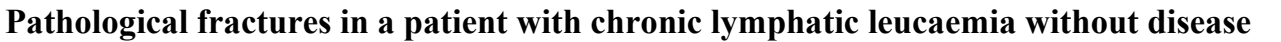

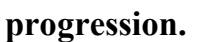

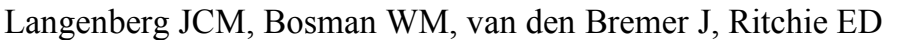

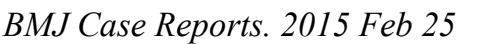

$\square$

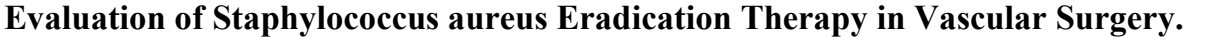

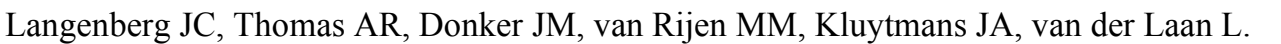
$\square \square \square$ One. 2016 Aug 16;11(8) $\square$

$\square$

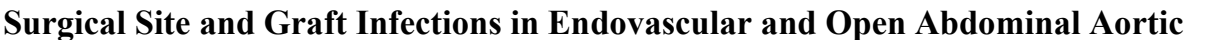

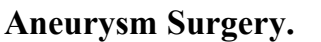

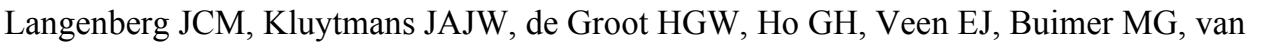
पाणापाणा

Surgical Infections. 2018 May/Jun;19(4) $\square$

$\square$

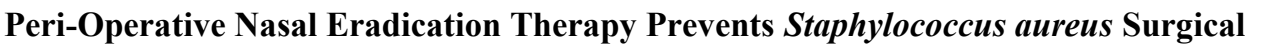

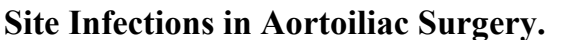

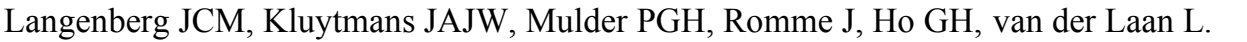

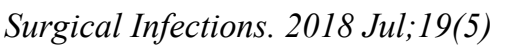

$\square$

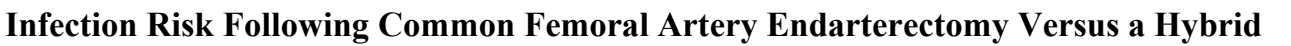

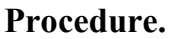

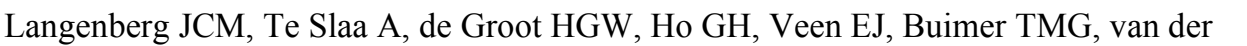

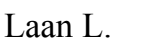

Annals of Vascular Surgery. 2018 Nov;53:148 $\square 53 . \square$

$\square$

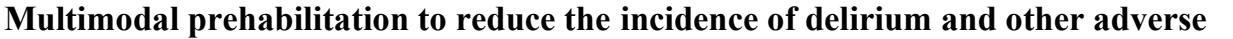

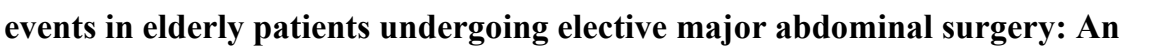

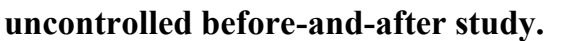

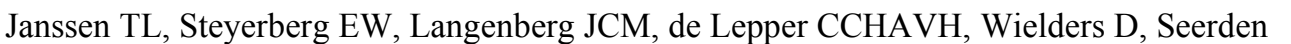

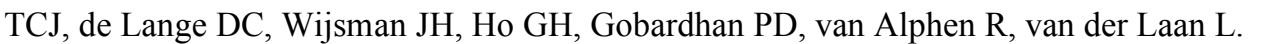
PLoS One. 2019 Jun 13;14(6) $\square$

$\square$

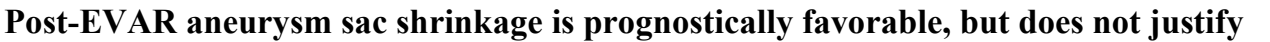

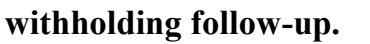

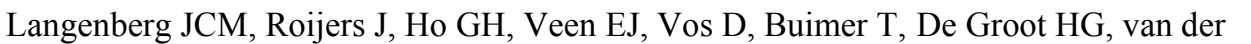

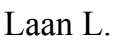

Journal of Cardiovas $\square|\square| \| \amalg \mid$ ery. 2020 Jun;61(3) $\square$

$\square$ 


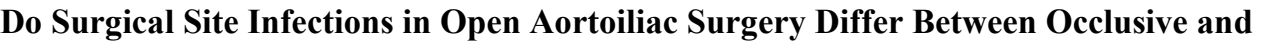

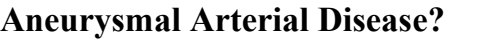

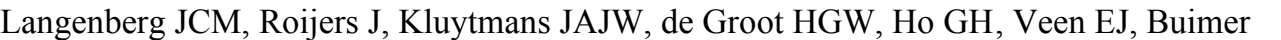

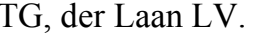

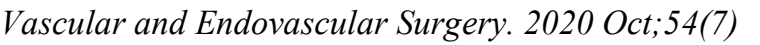




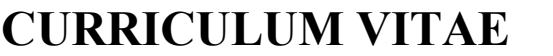

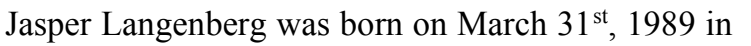

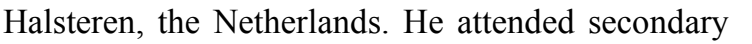

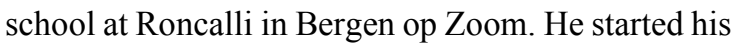

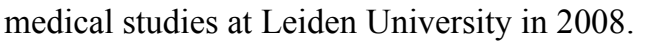
$\square$

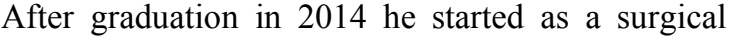

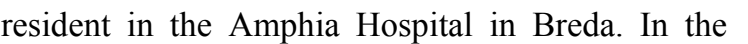

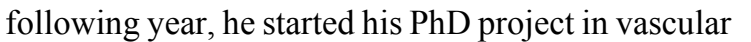

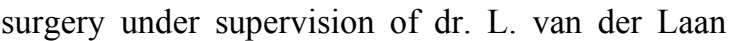

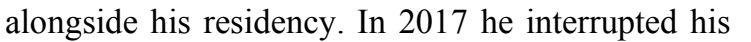

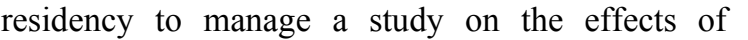

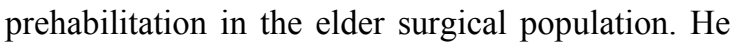

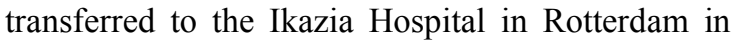

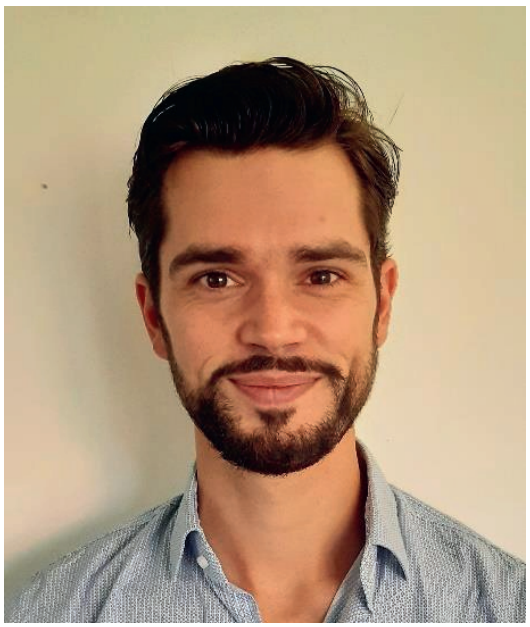

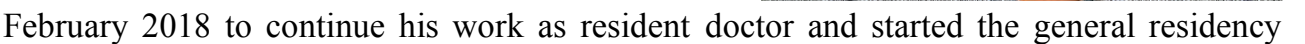

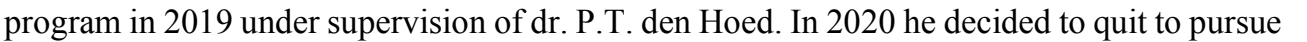

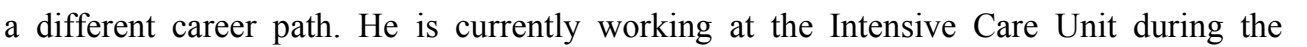

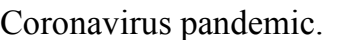

$\square$

ए ए $\square$

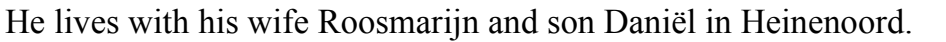

